\title{
General Fate Model for Microconstituents in an Activated Sludge System
}

\author{
Bahman Banihashemi
}

Thesis submitted to the

Faculty of Graduate and Postdoctoral Studies

in partial fulfilment of the requirements

for the Doctorate in Philosophy degree in Environmental Engineering

\author{
Ottawa-Carleton Institute for Environmental Engineering \\ Department of Civil Engineering \\ Faculty of Engineering \\ University of Ottawa
}

(C) Bahman Banihashemi, Ottawa, Canada 2014 


\section{Abstract}

Mathematical models elaborated for removal of microconstituents (MCs) in activated sludge (AS) system have not incorporated developments in International Water Association (IWA) models. In this thesis, sorption and biodegradation kinetic models that can be applied to describe transformation of $\mathrm{MCs}$ in an $\mathrm{AS}$ process were evaluated (volatilization and photodegradation were considered negligible).

Bisphenol-A (BPA), 17 $\alpha$-ethinylestradiol (EE2), and triclosan (TCS) have been selected as target compounds in this thesis. Sorption batch tests were conducted to retrieve kinetic and equilibrium data. Nine lab-scale continuous flow porous-pot bioreactors operating at various solids retention times (SRTs) and hydraulic retention times (HRTs) were studied for biodegradation of MCs. The effects of SRT, HRT and the biomass concentration on sorption and removal of MCs were also investigated and the results of each phase were incorporated into MCs fate models. Freundlich and linear sorption isotherms and pseudo-second-order kinetic models with different kinetic rates were found to best fit the sorption and desorption results. The result of biodegradation study in the presence of $20 \mu \mathrm{g} / \mathrm{L}$ of MCs demonstrated 90-98, 63-91 and 97-98\% mean removal rates of BPA, EE2 and TCS, respectively, in systems operating at SRT of 5-15 d 
and HRT of 4-10 h. Calculation of mass fluxes of selected MCs in the dissolved and particulate phases showed that biotransformation was the principal removal mechanism of targeted MCs.

The fate models for the degradation mechanism of selected MCs were evaluated by applying various mathematical models. The pseudo-second-order model was found to best fit the results when active MCs degraders $\left(\mathrm{X}_{\mathrm{C}}\right)$ were used in the model. It was found that biodegradation studies should incorporate $\mathrm{X}_{\mathrm{C}}$ and not mixed liquor suspended solids concentration in their kinetic formulations. Therefore, the result of this study could be seen in the context, where the active MCs degraders are proposed to reduce the variability of biodegradation kinetic rates in AS systems operating at different operational conditions. Finally nitrification inhibitors, allylthiourea (ATU) were added to reactors and it was found that although nitrification process affects the fate of MCs in AS system, heterotrophs were most likely responsible for the biotransformation of the targeted MCs. 
This thesis is dedicated to my beloved wife Sara for her dedicated support and encouragement;

and also to my dear parents Hossein and Fereshteh for instilling the importance of hard work and higher education 


\section{Acknowledgements}

It is an honor for me to thank those who made this thesis possible and words fail to appreciate them in a way that it should be.

First and foremost, I would like to give my sincere gratitude to Dr. Ronald Droste for his extraordinary supervision, guidance, and contribution which have helped me form and strengthen this thesis and the work presented herein. I would like to acknowledge all my friends and colleagues in the department of civil engineering at the University of Ottawa for their supports specially Drs. Kennedy and Delatolla for their consultations.

Above all I would like to convey particular thanks to my family for their unwavering encouragement and inseparable supports. Special thanks to my wife, Sara, who always supported me in every moment in my life; she is my most important motivation to start such a long journey.

I also acknowledge funding support from the Natural Sciences and Engineering Research Council of Canada. 


\section{Publications}

Banihashemi B, Droste RL. Evaluation of Biodegradation Kinetics Models for Microconstituents Under Typical Sewage Treatment Conditions. Water Environment Federation 2011: 5049-5061.

Banihashemi B, Droste RL. Trace level determination of bisphenol-A in wastewater and sewage sludge by high-performance liquid chromatography and UV detection. Water Quality Research Journal of Canada 2013; 48: 133-144.

Banihashemi B, Droste RL. Sorption-desorption and biosorption of bisphenol A, triclosan, and 17alpha-ethinylestradiol to sewage sludge. Sci Total Environ 2014; 487: 813-21.

Banihashemi B, Droste RL. Fate of Bisphenol A, Triclosan, and 17 $\alpha$-ethinylestradiol In Simulated Activated Sludge Bioreactors, 2014. Submitted to Journal of Environmental Technology \& Innovation.

Banihashemi B, Droste RL. The Role of Nitrification and Heterotrophic Biomass on Biodegradation of MCs in Activated Sludge System, 2014. In preparation.

Banihashemi B, Droste RL. General Fate Model for Microconstituents under Typical Sewage Treatment Conditions, 2014. Submitted to Water Research Journal. 


\section{Table of Contents}

Abstract................................................................................................................................ ii

Acknowledgements ................................................................................................ v

Publications ........................................................................................................... vi

Table of Contents .................................................................................................................... vii

List of Tables ................................................................................................................... xi

List of Figures................................................................................................................. xiv

Abbreviations .............................................................................................................................. xvii

Nomenclature …................................................................................................................. $\mathbf{x x}$

Chapter 1: Introduction ............................................................................................................ 1

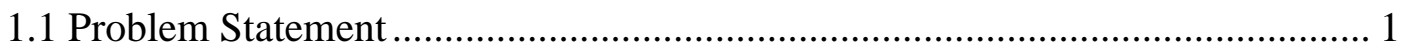

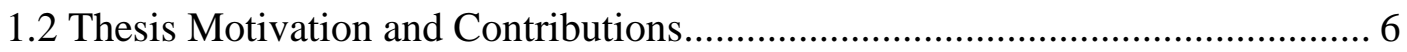

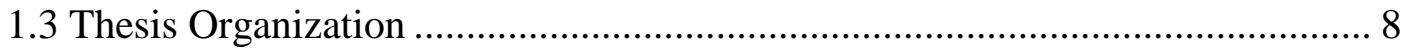

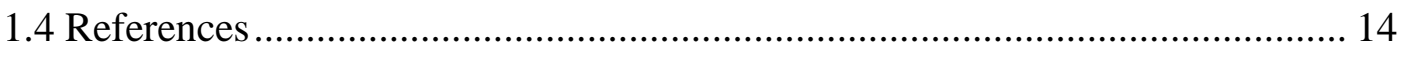

Chapter 2: Technical Background ....................................................................................... 16

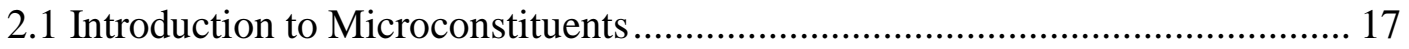

2.2 Occurrence and Transformation of MCs in the Environment ........................... 21

2.3 Choosing Target MCs ................................................................................... 24

2.3.1 Presence in Canadian environment ........................................................... 25

2.3.2 Chemical-physical properties.................................................................. 27

2.3.3 Health and environment concern ........................................................... 30 
2.3.4 Characterization of selected MCs ............................................................... 33

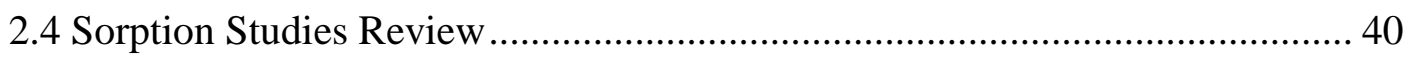

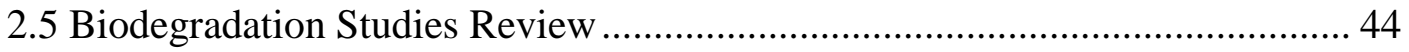

2.6 Biodegradation Kinetics Models for MCs in AS Systems................................. 52

2.6.1 Microconstituents fate model development ................................................ 59

2.6.2 Biodegradation models used in commercial modeling software ............... 62

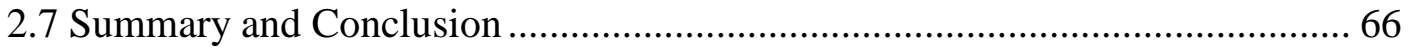

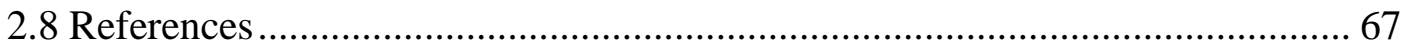

Chapter 3: Analytical Methods............................................................................................ 84

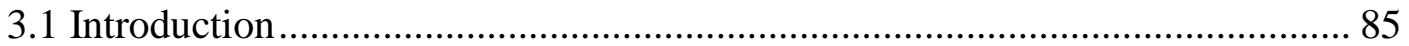

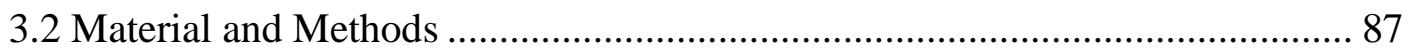

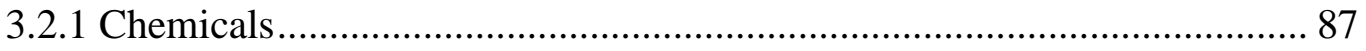

3.2.2 Extraction of liquid samples ................................................................... 88

3.2.3 Extraction of solid samples ................................................................. 90

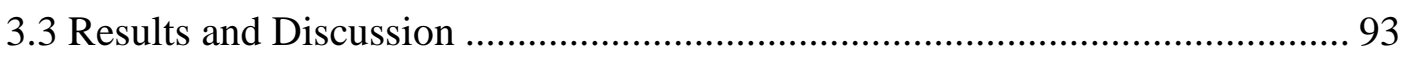

3.3.1 Optimization of solid phase extraction .................................................... 93

3.3.2 Results of method comparison for extraction of BPA in sludge samples.. 99

3.3.3 Validation of the method ......................................................................... 101

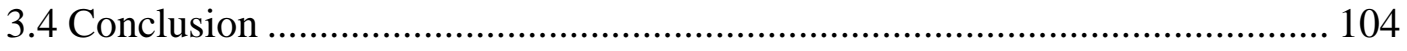

3.5 Modification of Analytical Method for TCS and EE2.................................. 105

3.6 Conventional Chemical Analysis..................................................................... 107

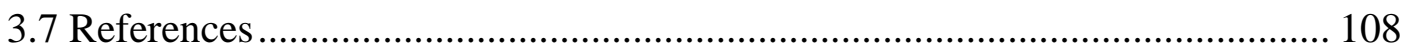

Chapter 4: Sorption-desorption and biosorption of MCs to AS............................ 113

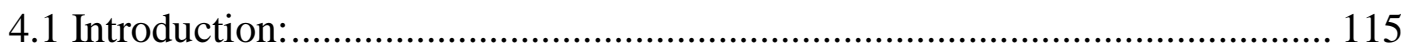

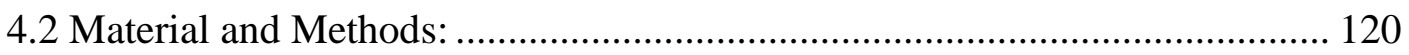

4.2.1 Chemical and reagents ....................................................................... 120

4.2.2 Activated sludge, synthetic wastewater and inactivation treatment ........ 121 
4.2.3 Sorption experiments with activated and inactivated sludge 124

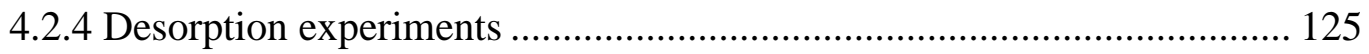

4.2.5 Sample preparation and analytical methods ....................................... 126

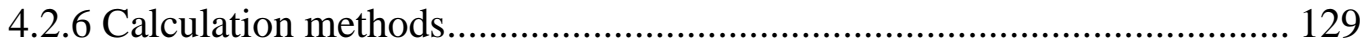

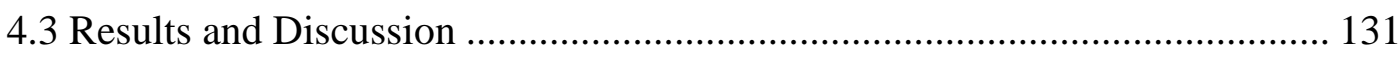

4.3.1 Sorption equilibrium to inactive AS ............................................. 131

4.3.2 Physicochemical sorption versus biosorption to inactive and active AS. 131

4.3.3 Sorption and desorption kinetics of MCs onto inactive AS................... 136

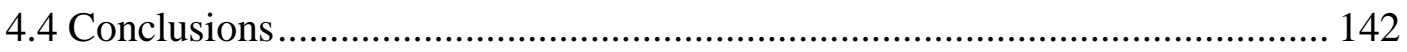

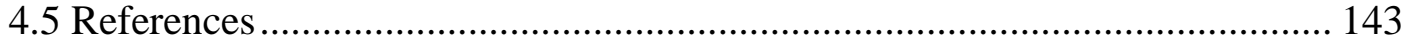

Chapter 5: Fate of MCs In Simulated AS Bioreactors ............................................ 150

5.1 Introduction:

5.2 Material and Methods: ............................................................................. 160

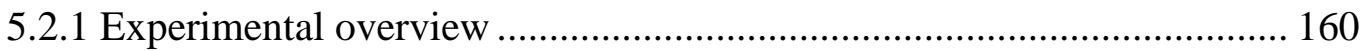

5.2.2 Activated sludge, synthetic wastewater and Porous-Pot Bioreactor........ 161

5.2.3 Batch sorption experiments ........................................................ 167

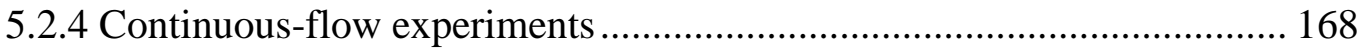

5.2.5 Chemical and analytical method .................................................... 170

5.2.6 Calculation methods.................................................................... 172

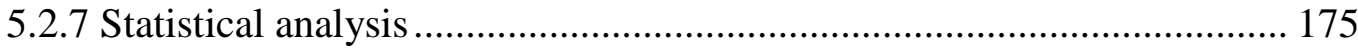

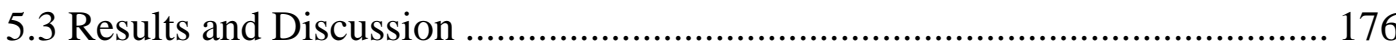

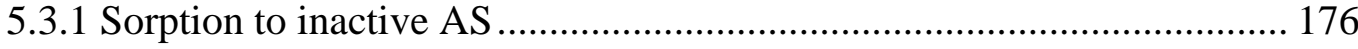

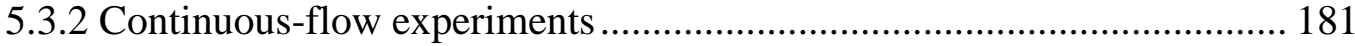

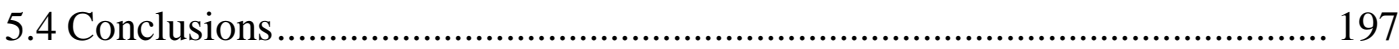

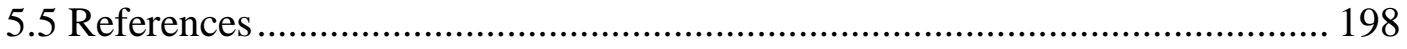

Chapter 6: General Fate Model for MCs under Typical Sewage Treatment

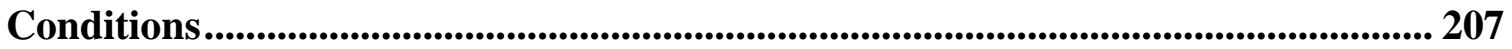




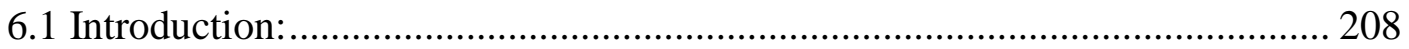

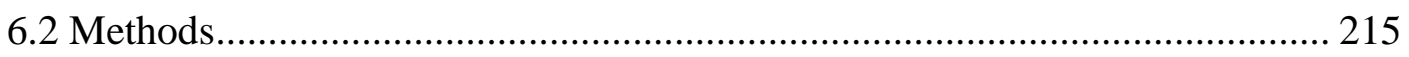

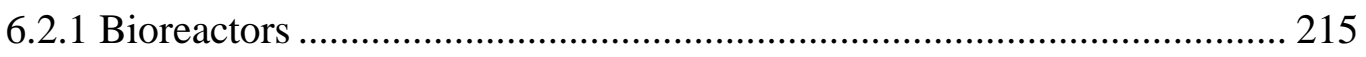

6.2.2 Biodegradation Experiments.............................................................. 216

6.2.3 Estimation of Active Heterotrophic Biomass ......................................... 217

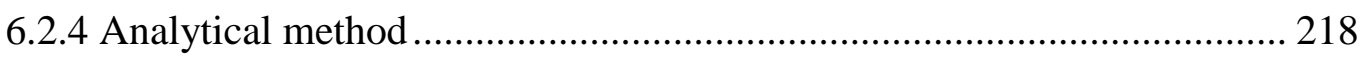

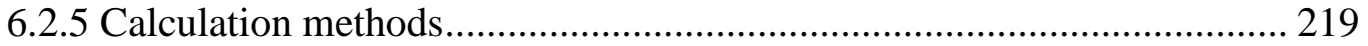

6.2.6 Model parameter estimation and model validation.................................. 221

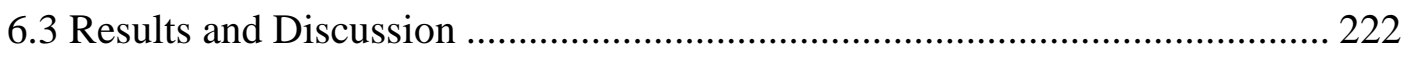

6.3.1 MCs biodegradation results ................................................................. 222

6.3.2 Parameter estimation results .............................................................. 226

6.3.3 Evaluation of biodegradation kinetic models ....................................... 230

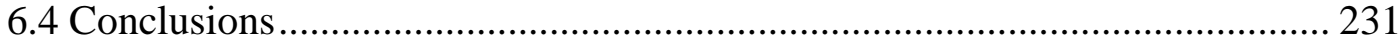

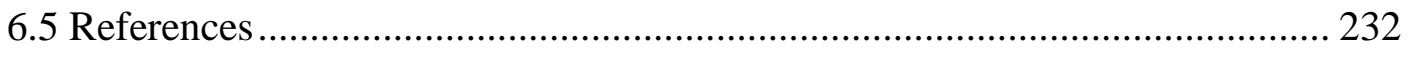

Chapter 7: Discussions and Conclusions ........................................................................ 239

Appendices.................................................................................................................................. 242

Appendix A: Extraction systems used for selected MCs..................................... 243

Appendix B: Reactors performance in phases A and B ...................................... 247 


\section{List of Tables}

Table 2-1 Physico-chemical characteristics and biodegradability of selected MCs... 39

Table 2-2 Model of the AS Process for Carbon Removal ....................................... 52

Table 2-3 Zero-, first- and pseudo first-order models for biological degradation of

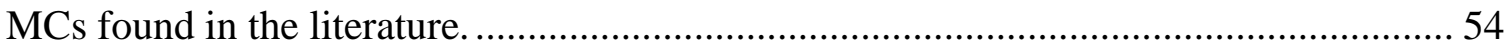

Table 2-4 Growth kinetic models of biomass with substrate inhibition ..................... 55

Table 2-5 Possible Rate Formulations for biological degradation of MCs ............... 56

Table 2-6 Petersen matrix for specific MC degrading biomass model (Lindblom et al., 2009) 57

Table 3-1 SPE and analytical condition for liquid chromatography-ultraviolet analysis of BPA 99

Table 3-2 Spiked concentration of BPA in sludge samples, mean recovery, and relative standard deviation $(\mathrm{RSD})$ 100

Table 3-3 Precision and mean recovery data of the extraction and analytical procedure to detect BPA in solid and liquid samples 104

Table 3-4 Result of one-way ANOVA and Tukey analysis for BPA recoveries from three porous pot reactors (Multiple Comparisons) 104 
Table 3-5 SPE and analytical condition for liquid chromatography-ultraviolet analysis of BPA 107

Table 4-1 Physico-chemical characteristics of selected MCs 121

Table 4-2 Composition of the synthetic wastewater. 123

Table 4-3 SPE and analytical condition for liquid chromatography-ultraviolet analysis of BPA 128

Table 4-4 Summery of sorption kinetic coefficients evaluated by different kinetic models 139

Table 4-5 Calculation of partition coefficient $\left(\mathrm{K}_{\mathrm{d}}\right)$ as a function of octanol-water partition coefficient $\left(\mathrm{K}_{\mathrm{ow}}\right)$ based on semi-empirical equations. 140

Table 4-6 Summery of desorption kinetic coefficients evaluated by different kinetic models 141

Table 5-1 Physico-chemical characteristics of selected MCs 158

Table 5-2 Composition of the synthetic wastewater. 166

Table 5-3: Experimental operational conditions 168

Table 5-4 Linear and Freundlich isotherm constants for the adsorption of MCs onto sludge. 179

Table 5-5 Summery of sorption kinetic coefficients evaluated by different kinetic models 180

Table 5-6 Comparison of biological performance of experimental runs 184 
Table 5-7 Mean total removal efficiency (\%) of selected MCs in simulated AS operating at different HRTs and SRTs ( $\mathrm{n}=$ number of determination)

Table 5-8 Effects of HRT and SRT on total removal rate of MCs using Two-way ANOVA.

Table 5-9 The effect of nitrification inhibition on total removal rate of MCs using two-way ANOVA (the inhibition factor was presented as 01 and 00 for presence and absence of ATU) 196

Table 6-1 Zero-, first- and pseudo first-order models for biological degradation of

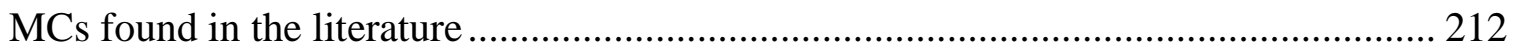

Table 6-2 Possible rate formulations for biological degradation of MCs................ 213

Table 6-3 Physico-chemical characteristics of selected MCs ............................... 215

Table 6-4 Experimental operational conditions .............................................. 216

Table 6-5 Comparison of biological performance of experimental runs .................. 223

Table 6-6 Mass balances (\%) of the target MCs in continuous-flow AS systems.... 224

Table 6-7 Estimation of biodegradation kinetics for each model and the sum of chi

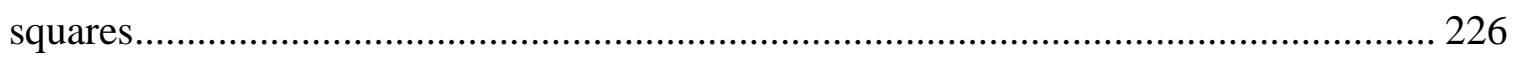

Table 6-8 Estimation of active MCs degraders $\left(\mathrm{X}_{\mathrm{C}}\right)$ and comparison with active

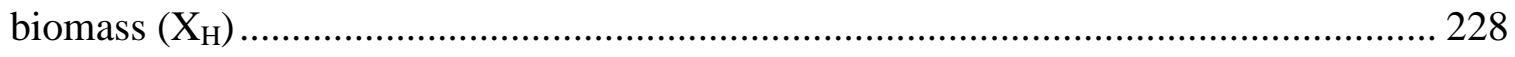

Table 6-9 Evaluation of biodegradation kinetics models based on linear least squares method 230 


\section{List of Figures}

Figure 1-1. Different types of MCs............................................................... 2

Figure 1-2. Structure of this thesis and summary of chapters..................................... 13

Figure 2-1. Chemical structures of selected MCs .................................................... 39

Figure 2-2. Proposed state model variables applied to ASM1 model after Lidblom

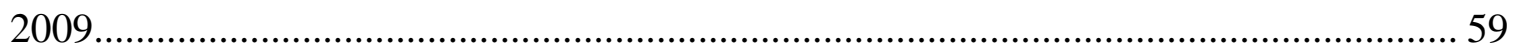

Figure 3-1. Effect of sample $\mathrm{pH}$ on recovery of BPA from wastewater effluent sample 94

Figure 3-2. Effect of sample volume on recovery of BPA in SPE sample loading step 95

Figure 3-3. Effect of volume of $\mathrm{MeOH}$ in solvent solution on recovery of BPA in

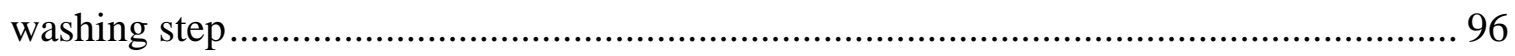

Figure 3-4. Effect of solvent selection on recovery of BPA in SPE elution step ....... 96

Figure 3-5. Effect of solvent ratio on recovery of BPA in HPLC-UV system ........... 97

Figure 3-6. Effect of injection volume on recovery of BPA in HPLC-UV system .... 98

Figure 3-7. Schismatic diagram of analytical procedure for analysis of BPA in liquid and solid phases 101

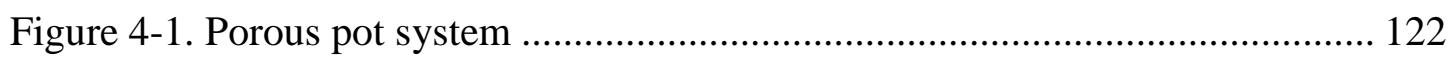


Figure 4-2. Concentration change of MCs in liquid and solid phases of inactive AS, sorption 132

Figure 4-3. Concentration change of MCs in liquid and solid phases of active AS, biosorption 134

Figure 4-4. Concentration change of MCs in liquid phase of inactive AS, spiked at 10 $\mu \mathrm{g} / \mathrm{L}$, desorption study 137

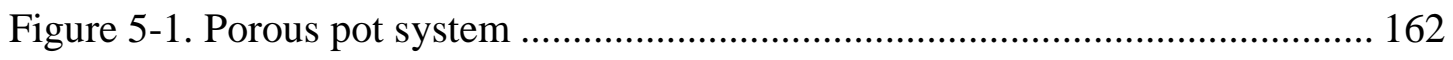

Figure 5-2. Porous pot aeration vessel details ....................................................... 163

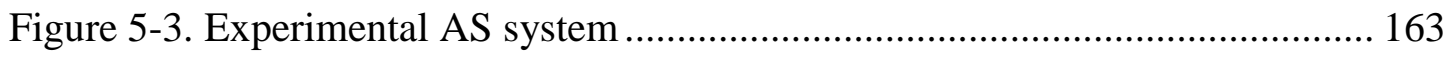

Figure 5-4. Schematic of the simulated AS system ................................................... 164

Figure 5-5. Concentration change of MCs in liquid and solid phases of inactive AS, sorption 177

Figure 5-6. Concentration change of effluent COD in the presence of the selected MCs. 182

Figure 5-7. Recovery percentage of spiked MCs in the control reactor 185

Figure 5-8. Mass balances (\%) of the target MCs in continuous-flow AS systems operating at HRT of $6 \mathrm{~h}$. Standard deviations are presented in parenthesis 188

Figure 5-9. Mass balances (\%) of the MCs in continuous-flow AS systems operating at $\mathrm{HRT}=10 \mathrm{~h}$ 188

Figure 5-10. Mass balances (\%) of the MCs in continuous-flow AS systems operating at $\mathrm{HRT}=4 \mathrm{~h}$ 189 
Figure 5-11. Total removal of selected MCs with and without ATU inhibitor in continuous-flow AS systems operating at different SRTs .......................................... 195

Figure 6-1. Effect of operational conditions on biomass degradation performance

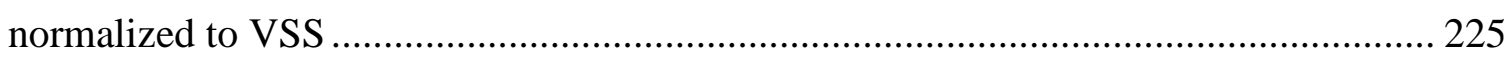




\section{Abbreviations}

$\begin{array}{ll}\text { ACN } & \text { acetonitrile } \\ \text { ANOVA } & \text { one-way analysis of variance } \\ \text { AOB } & \text { ammonia oxidizing bacteria } \\ \text { AS } & \text { activated sludge } \\ \text { ASE } & \text { accelerated solvent extraction } \\ \text { ASMs } & \text { activated sludge models } \\ \text { ATU } & \text { allylthiourea, nitrification inhibitor } \\ \text { BFRs } & \text { brominated flame-retardants } \\ \text { BOD } & \text { biochemical oxygen demand } \\ \text { BPA } & \text { bisphenol A } \\ \text { C:N:P } & \text { carbon/nitrogen/phosphorus } \\ \text { CAS } & \text { conventional activated sludge } \\ \text { CECs } & \text { compounds of emerging concern } \\ \text { CEPA } & \text { Canadian Environmental Protection Act } \\ \text { CM } & \text { complete mixed } \\ \text { COD } & \text { chemical oxygen demand } \\ \text { DCF } & \text { diclofenac } \\ \text { DCM } & \text { dissolved/colloidal matter } \\ \text { DEHP } & \text { bis(2-ethylhexyl) phthalate } \\ \text { DNA } & \text { deoxyribonucleic acid } \\ \text { DO } & \text { dissolved oxygen } \\ \text { E1 } & \text { estrone } \\ \text { E2 } & \text { 17ß-estradiol } \\ \text { E3 } & \text { estriol } \\ \text { EDCs } & \text { endocrine disrupting compounds } \\ & \end{array}$




\begin{tabular}{|c|c|}
\hline EE2 & $17 \alpha$-ethynilestradiol \\
\hline EFSA & European food safety authority \\
\hline FISH & fluorescent in situ hybridization \\
\hline GC & gas chromatography \\
\hline GEM & gemfibrozil \\
\hline HBCDs & hexabromocyclododecanes \\
\hline HHCP & galaxolide \\
\hline HPH & high-pressure homogenizer \\
\hline HPLC & high-performance liquid chromatography \\
\hline HRT & hydraulic retention time \\
\hline HRT & hydraulic retention time \\
\hline IBP & ibuprofen \\
\hline IWA & international water association \\
\hline LC & liquid chromatography \\
\hline LOD & limit of detection \\
\hline LOQ & limits of quantification \\
\hline MAE & microwave assistant extraction \\
\hline MBR & membrane bioreactor \\
\hline MCs & microconstituents \\
\hline $\mathrm{MeOH}$ & methanol \\
\hline MLSS & mixed liquor suspended solid \\
\hline MLVSS & mixed liquor volatile suspended solids \\
\hline MS & mass spectrometric \\
\hline MW & molecular weight \\
\hline NP & nonylphenol \\
\hline NPEO & nonylphenol ethoxylates \\
\hline $\mathrm{OP}$ & 4-tert-octylphenol \\
\hline PBDEs & polybrominated diphenyl ethers \\
\hline PBT & persistent, bioaccumulative and toxic \\
\hline PF & plug flow \\
\hline PhACs & pharmaceutically active compounds \\
\hline
\end{tabular}




$\begin{array}{ll}\text { PPCPs } & \text { pharmaceuticals and personal care products } \\ \text { PVC } & \text { polyvinyl chloride } \\ \text { ROPEC } & \text { Robert O. Pickard Environmental Centre } \\ \text { RSD } & \text { relative standard deviation } \\ \text { sCOD } & \text { soluble COD } \\ \text { SFE S } & \text { upercritical fluid extraction } \\ \text { SPE } & \text { solid phase extraction } \\ \text { SRTs } & \text { sludge retention times } \\ \text { SS } & \text { suspended solids } \\ \text { STPs } & \text { sewage treatment plants } \\ \text { TBBP-A } & \text { tetrabromobisphenol-A } \\ \text { TCS } & \text { triclosan } \\ \text { TKN } & \text { total Kjeldahl nitrogen } \\ \text { TOC } & \text { total organic carbon } \\ \text { TOrCs } & \text { trace organic compounds } \\ \text { TP } & \text { total phosphorous } \\ \text { TSS } & \text { total SS } \\ \text { TSS } & \text { total suspended solids } \\ \text { TWAS } & \text { thickened activated sludge } \\ \text { USE } & \text { ultrasonication extraction } \\ \text { USEPA } & \text { United States Environmental Protection Agency } \\ \text { UV } & \text { ultraviolet } \\ \text { VSS } & \text { volatile suspended solids } \\ \text { WEF } & \text { Water Environment Federation } \\ \text { WWTPs } & \text { wastewater treatment plants } \\ & \end{array}$




\section{Nomenclature}

\begin{tabular}{|c|c|}
\hline$\mu$ & maximum growth rate $\left(\mathrm{d}^{-1}\right)$ \\
\hline$\mu_{\mathrm{Cm}}$ & maximum growth rate of $\mathrm{MC}$ degrading biomass $\left(\mathrm{d}^{-1}\right)$ \\
\hline$\mu_{\mathrm{Hm}}$ & maximum growth rate of heterotrophic biomass $\left(\mathrm{d}^{-1}\right)$ \\
\hline $\mathrm{b}$ & endogenous decay rate constant $\left(\mathrm{d}^{-1}\right)$ \\
\hline$b_{c}$ & decay rate of specific microorganisms degrading the $\mathrm{MC}\left(\mathrm{d}^{-1}\right)$ \\
\hline$b_{\mathrm{H}}$ & endogenous decay (lysis) coefficient of heterotrophic bacteria $\left(\mathrm{h}^{-1}\right)$ \\
\hline $\mathrm{C}$ & conc. of dissolved $\mathrm{MC}$ in the effluent or inside reactor $\left(\mathrm{mg} \mathrm{L}^{-1}\right)$ \\
\hline $\mathrm{C}_{\mathrm{ps}}^{\prime}$ & conc. of MCs sorbed to non-active solids at equilibrium state $\left(\mathrm{mg} \mathrm{L}^{-1}\right)$ \\
\hline $\mathrm{C}_{0}$ & conc. of dissolved $\mathrm{MC}$ in the influent $\left(\mathrm{mg} \mathrm{L}^{-1}\right)$ \\
\hline $\mathrm{C}_{0}$ & initial concentrations of BPA in sludge sample $\left(\mathrm{ng} \mathrm{g}^{-1}\right)$ \\
\hline $\mathrm{C}_{\mathrm{e}}$ & equilibrium soluble concentrations of MCs $\left(\mu \mathrm{g} \mathrm{L}^{-1}\right)$ \\
\hline $\mathrm{C}_{\mathrm{m}}$ & measured concentrations of BPA in spiked sample $\left(\mu \mathrm{g} \mathrm{L}^{-1}\right)$ \\
\hline $\mathrm{C}_{\mathrm{ps}}$ & concentrations of MCs sorbed to biomass at equilibrium $\left(\mathrm{mg} \mathrm{L}^{-1}\right)$ \\
\hline $\mathrm{C}_{\mathrm{s}}$ & concentrations of BPA spiked into sample $\left(\mu \mathrm{g} \mathrm{L}^{-1}\right)$ \\
\hline$f_{a v}$ & fraction of active heterotrophic biomass \\
\hline$f_{H}$ & endogenous residue fraction \\
\hline$f_{X I}$ & fraction of nbd particulate COD released in biomass decay \\
\hline $\mathrm{H}$ & Henry coefficient $\left(\mathrm{atm} \mathrm{m}^{3} \mathrm{~mol}^{-1}\right)$ \\
\hline $\mathrm{K}$ & first order rate constant $\left(\mathrm{L} \mathrm{d}^{-1}\right)$ \\
\hline $\mathrm{K}_{1}$ & equilibrium sorption rate constant for pseudo-first-order $\left(\mathrm{L} \mathrm{h}^{-1}\right)$ \\
\hline $\mathrm{K}_{2}$ & equilibrium sorption rate constant for pseudo-second-order $\left(\mathrm{L} \mathrm{h}^{-1}\right)$ \\
\hline $\mathrm{K}_{3}$ & equilibrium rate constant of the intra-particle transport $\left(\mu \mathrm{g} \mathrm{g}^{-1} \mathrm{~h}^{-1}\right)$ \\
\hline $\mathrm{K}_{\mathrm{C}}$ & half-velocity coefficient for MC degrading biomass ( $\mathrm{mg} \mathrm{L}^{-1}$ ) \\
\hline $\mathrm{K}_{\mathrm{d}}$ & sludge-water distribution coefficient \\
\hline
\end{tabular}




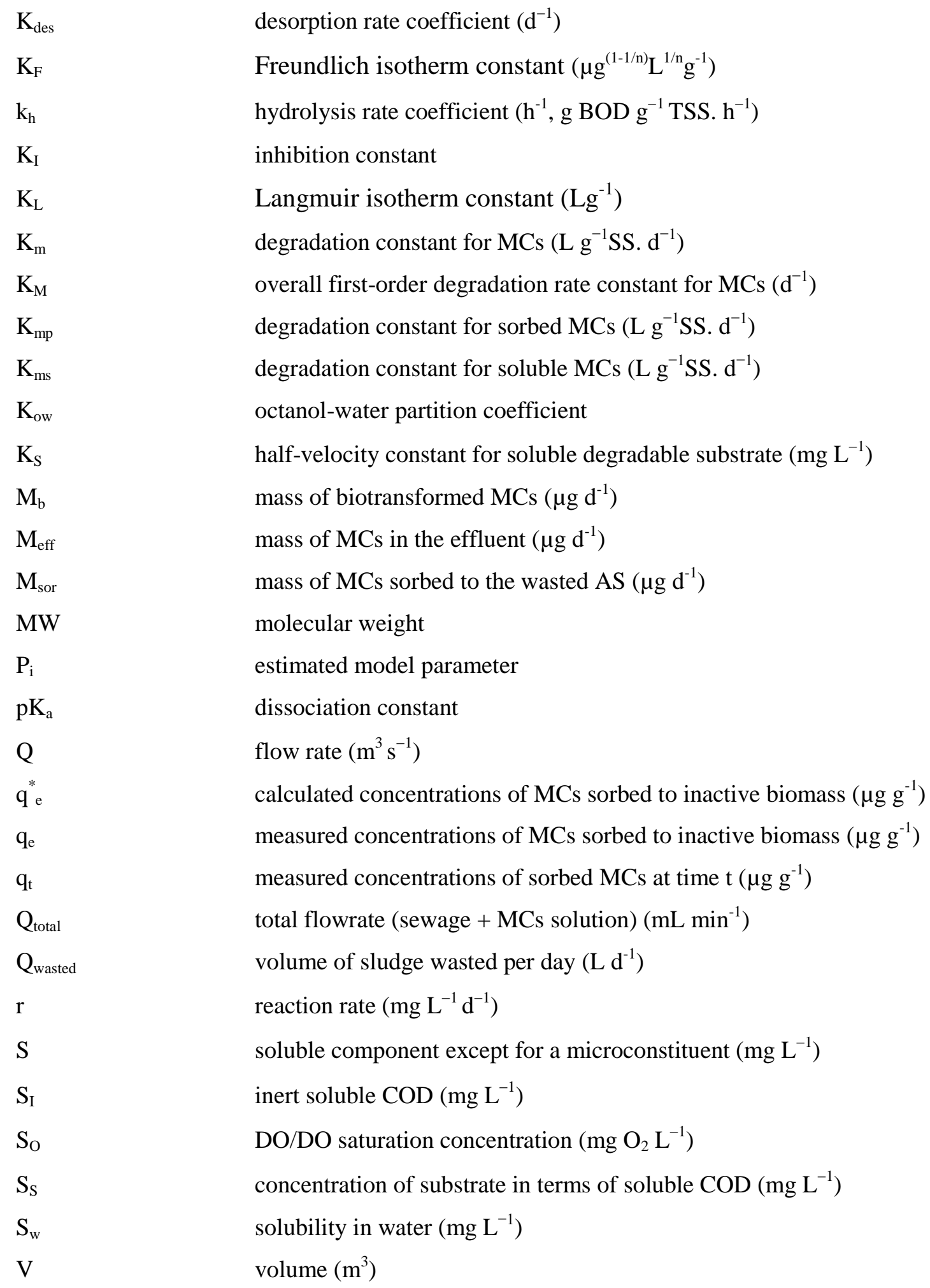




$\begin{array}{ll}\mathrm{X}_{\mathrm{C}} & \text { active biomass that degrade the microconstituent }\left(\mathrm{mg} \mathrm{L}^{-1}\right) \\ \mathrm{X}_{\mathrm{H}} & \text { concentration of active heterotrophic biomass }\left(\mathrm{mg} \mathrm{L}^{-1}\right) \\ \mathrm{X}_{\mathrm{I}} & \text { concentration of substrate in terms inert COD }\left(\mathrm{mg} \mathrm{L}^{-1}\right) \\ \mathrm{X}_{\mathrm{S}} & \text { concentration of substrate in terms of particulate COD }\left(\mathrm{mg} \mathrm{L}^{-1}\right) \\ \mathrm{X}_{\mathrm{T}} & \text { total concentration of solids }\left(\mathrm{mg} \mathrm{L}^{-1}\right) \\ \mathrm{X}_{\mathrm{v}} & \text { volatile SS concentration }\left(\mathrm{mg} \mathrm{L}^{-1}\right) \\ \mathrm{X}_{\mathrm{ve}} & \text { VSS concentration in the effluent }\left(\mathrm{mg} \mathrm{L}^{-1}\right) \\ \mathrm{Y}_{\mathrm{C}} & \text { yield factor of the active mass degrading the } \mathrm{MC}\left(\mathrm{g} \mathrm{g}^{-1}\right) \\ \mathrm{Y}_{\mathrm{H}} & \text { yield factor of the active heterotrophic biomass }\left(\mathrm{g} \mathrm{g}^{-1}\right) \\ \sigma & \text { standard deviation } \\ \chi^{2} & \text { chi-squared } \\ \theta_{\mathrm{d}} & \text { hydraulic retention time }(\mathrm{h}) \\ \theta_{\mathrm{X}} & \text { solids retention time }(\mathrm{d})\end{array}$


P a g e $\mid \mathbf{1}$

\section{Chapter 1: Introduction}

\subsection{Problem Statement}

The occurrence and the fate of toxic, biopersistent microconstituents (MCs) in water sources and their removal in wastewater treatment plants (WWTPs) as major point sources are a growing concern since some of these substances remain at detectable levels in WWTP effluents. MCs were defined by the Water Environment Federation (WEF) as "natural and human-made substances, including elements and inorganic and organic chemicals, detected within water and the environment for which a prudent course of action is suggested for the continued assessment of the potential impact on human health and the environment."

MCs can be classified as natural and synthetic compounds. Natural sources include hormones excreted by humans and animals, substances found in metals, inorganic ions, plants or fungi, and by-products of natural combustion processes. Synthetic MCs include certain biocides (pesticides, herbicides, and fungicides) and their degradation products, pharmaceuticals and personal care products (PPCPs), combustion by-products from burning fossil fuels and incineration of industrial and municipal waste, industrial chemicals and by-products in their production as well as their environmental degradation 


\section{P a g e $\mid \mathbf{2}$}

products. Although pesticides and other toxins have long been recognized as persistent, bioaccumulative, and toxic (PBT) agents, only in the past couple of decades through work in which the Canadian National Water Research Institute (e.g., see NWRI Publications, 1997) was seminal, has there been recognition of environmental ramifications of MCs that are indeed in low concentrations at the source, e.g., agents in pharmaceuticals and PPCPs. Therefore to categorize all those compounds, such as endocrine disrupting compounds (EDCs), pesticides, PPCPs, and pharmaceutically active compounds (PhACs) that might have negative impacts on humans and environment, broader category of chemicals and compounds often referred to in the literature as "emerging contaminants", "Compounds of Emerging Concern (CECs)", "Emerging pollutants", "Trace Organic Compounds (TOrCs)", "Micropollutants" or “"MCs'. Figure 1-1, shows the different types of MCs which can be found in the literature.

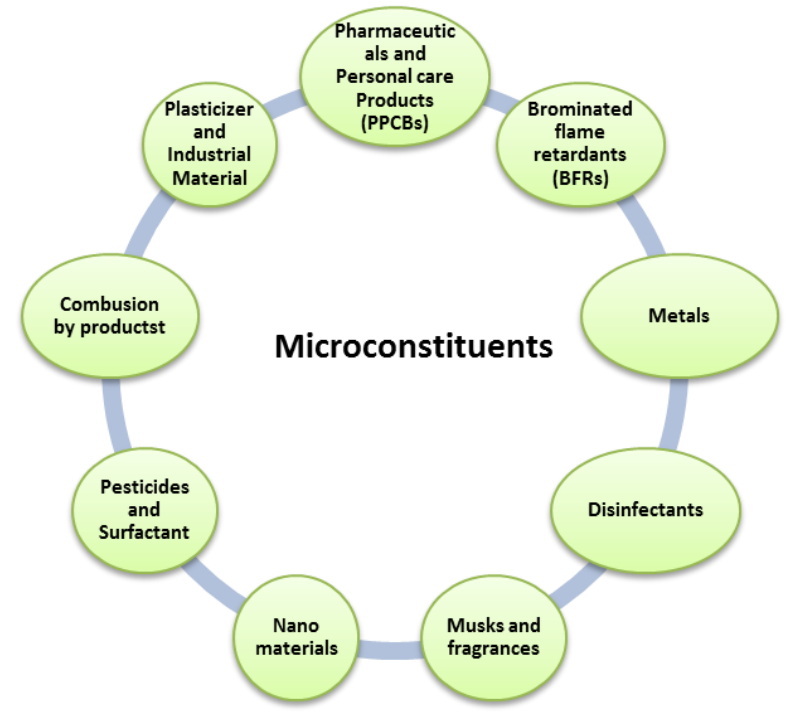

Figure 1-1. Different types of MCs 


\section{P a g e $\mid \mathbf{3}$}

MCs can be discharged into wastewaters by the general population due to the use of products containing them. Some degradation or transformation of these compounds take place at WWTPs and then final dilution of the WWTP effluent by receiving waters occurs. Some of the MCs are volatile and escape to the atmosphere; others are adsorbed or absorbed by solids or biosolids and finally migrate to landfills along with sludge produced in WWTPs. Effluents from municipal WWTPs have been implicated as a major source to surface waters. WWTPs receive MCs from sources including plastics, plant material, cleaning products, pesticides, household chemicals and consumer products, natural and synthetic hormones excreted by humans, and PPCPs washed from the body or flushed to the sanitary sewer. WWTPs might also treat industrial or hospital effluents and stormwater runoff that contain MCs. Although wastewater treatment processes remove some MCs to some extent, resistant chemicals may remain at detectable levels in WWTP effluents. Through the effluent discharge to surface water or groundwater, MCs may be diluted or degraded by physical or biological processes, but some persist in the environment or might be detected due to constant loading. Several studies have shown possible toxicity to non-target organisms due to combined and synergistic effects of MCs

at environmentally relevant concentrations (Pomati et al., 2008; Quinn et al., 2009). Furthermore, since several aquatic species are exposed to MCs for their entire life cycle, chronic toxicity of MCs is a great concern. 


\section{P a g e $\mid \mathbf{4}$}

Because of this growing interest, scientists have studied the environmental fate and toxicology properties of MCs (Melcer and Klecka, 2011; Radjenovic et al., 2009; Samaras et al., 2013) and although no legal limits have been established yet, regulatory authorities around the world have conducted monitoring programs and risk assessments of different MCs for future guidelines of concentration limits of MCs in water bodies or in discharged WWTPs effluent (Roig, 2010).

Conventional wastewater treatment systems, such as activated sludge (AS) are not designed to remove MCs at very low concentration. In addition, advanced treatment methods, such as membrane bioreactor (Lee et al., 2008), advanced oxidation (Plahuta et al., 2014), ozonation or use of granulated activated carbon (Margot et al., 2013), are being explored. However; these treatment options are often expensive to install and operate and might only be feasible for larger WWTPs. Therefore, information on how various MCs are removed from current facilities need to be studied and opportunities to optimize and enhance their treatment need to be explored which requires understanding of the effect of operational conditions, environmental parameters and compound specific properties on the fate of MCs in treatment processes.

The environment in a WWTP biotreatment process, which is the most common form of wastewater treatment, is significantly different from the natural environment. The environment in a biotreatment reactor is rich in organics with a high concentration of suspended solids (SS) which includes a significant concentration of acclimated 


\section{$\mathrm{P}$ a g e $\mid \mathbf{5}$}

microorganisms. Some MCs can be utilized as primary substrates but others are utilized as secondary substrates in conjunction with a primary substrate, i.e., co-metabolism. In biotreatment, the possibility of co-metabolism exists which is a significant route for "real treatment", i.e., the rendering of a harmful substance as a completely harmless entity.

The partitioning of MCs between solid and liquid phases is significant due to the large concentration of biomass and associated solids. Furthermore, stripping of volatile compounds is enhanced due to the intense aeration required in AS processes and the favourable environment for stripping in other processes such as a trickling filter. Accumulation of MCs on solids wasted from a biotreatment operation or losses of them through volatilization are not real treatments but nonetheless they are significant phenomena that affect the fate of MCs in biotreatment or throughout a WWTP.

The number of phenomena and factors affecting the fate of MCs is large, demanding a robust experimental protocol to elucidate all phenomena. Models are still in a state of development and different conceptualizations and data acquisition commensurate with the model, coupled with natural variation, have led to a considerable variability and inconsistency in reported information. The mathematical models developed for design and operation of biological wastewater treatment such as those from the International Water Association (IWA) were only developed to describe removal of chemical oxygen demand (COD), nitrogen and phosphorus and not concerned with specific chemical compounds. Consequently commercial modeling software for MCs removal in secondary 


$$
\text { P a g e | } 6
$$

WWTPs such as SimpleTreat, ASTreat, STP, and TOXCHEM+ have been developed, but the models used in these packages for various MCs with different physico-chemical properties and biodegradability have not incorporated developments in IWA models which present numerous possibilities that have not been evaluated.

Although the presence of MCs during wastewater treatment has been studied by a plethora of reports, significant differences on their concentration levels and removal rates as well as contradictory results on their fate have been reported (Deblonde et al., 2011; Stasinakis et al., 2010). Most studies do not report sufficient information to evaluate the possible fate models for MCs removal and incorporates all those findings from other researchers; furthermore, assumptions are often not experimentally verified. Consequently only limited normalization is possible to relate models or rate coefficients. On the other hand, it should be mentioned that the majority of environmental surveys previously undertaken have mainly been focused on dissolved concentrations of these compounds in wastewater at environmentally relevant concentrations (Feng et al., 2010; Radjenovic et al., 2009; Seyhi et al., 2011). Only in the last few years researchers started to study the MCs concentration in the solid phase at very low concentrations (Nie et al., 2009; Stasinakis et al., 2010; Stevens-Garmon et al., 2011; Zhao et al., 2008).

\subsection{Thesis Motivation and Contributions}

This research provides the new fundamental understanding of the kinetic models for removal of MCs in AS system. Beyond studying the biodegradation and sorption kinetics, 


\section{P a g e $\mid 7$}

the role of sludge retention time (SRT) and hydraulic retention time (HRT) in removal of MCs is investigated and the role of nitrification and nitrifiers versus heterotrophs is studied.

It is important to understand the concept of "removal" when discussing the fate of MCs in WWTP biotreatment process. Studies have shown that for many MCs, transformation by-products (conjugated or metabolized form of parent compound) exist and may even exceed the concentration and/or toxicity of the parent form (Dann and Hontela, 2011; Kang et al., 2006; Prasse et al., 2012). Nevertheless, the first kinetic step in any biotreatment systems is the transformation of parent compounds into non-parent forms that must be quantified as a first measure to understand the fate of MCs in WWTPs. Therefore, the term "removal" in this thesis generally refers to all the losses of MCs parent compounds from aqueous or solid phases. Therefore, possible by-products of MCs and their toxicity level have not been studied in this research. There are two major facets of the research which are undertaken in experimentation: (1) evaluate both solid and liquid phase biodegradation kinetics and (2) determine the simplest model that encompasses all important phenomena. The impacts of active mass and particulate debris in mixed liquor are delineated. The overall long-term objectives of the study are to improve biodegradation kinetics models for MCs. The specific objectives of the proposed research are as follows. 


\section{P a g e $\mid \mathbf{8}$}

1. Review existing kinetic models for MC removal in biotreatment processes in WWTPs and determine the most general model(s) for adsorption and particularly for biodegradation to be allied with the data collected in this study that unifies data for different groups of compounds or specific compounds.

2. Conduct batch sorption studies to develop the best fit adsorption isotherms that are based on total SS (TSS) and volatile SS (VSS). Both sorption and desorption kinetics are determined.

3. Conduct bench-scale continuous-flow AS studies to gather data and evaluate the removal of various MCs under different operating conditions in both the liquid and solid phases. Nitrification inhibitor is added to reactors to study the role of nitrification and nitrifiers versus heterotrophic biomass during biotransformation of MCs.

4. Develop biodegradation models for individual MCs based on the laboratory data acquired in this study and data from the literature. Advantages and disadvantages of different models are outlined. The most practical model that can be applied in the field, cognizant of data acquisition limitations at most WWTPs, in addition to the most theoretically correct model is described.

\subsection{Thesis Organization}

The first chapter in this study (Chapter 1) consists of the background information on the significance of this research as well as the objectives of this study. 


\section{P a g e $\mid \mathbf{9}$}

Chapter 2 presents the literature review explaining the different removal pathways of MCs in typical sewage treatment and the different operational conditions and factors which influence the removal efficiency of these compounds. Besides, three specific compounds, namely 17a-ethinylestradiol (EE2), bisphenol-A (BPA), and triclosan (TCS) that represent the broad range of MCs in environment are identified and a broad description of selected MCs is provided, detailing their most relevant physico-chemical properties which influence their fate and behaviour along sewage treatment. The chapter finishes with the literature review for the kinetic models that can be used to describe transformation of MCs (volatilization and photodegradation were considered negligible) in an AS process.

Chapter 3 describes the experimental methods employed to carry out the experimental work and presents a description of the laboratory reactors to simulate AS system, and methodologies used. In this chapter, the analytical methods for determination of conventional parameters (e.g. organic matter, nitrogen, temperature, solids content, $\mathrm{pH}$ and dissolved oxygen) are detailed. Furthermore, a simple and economical method for the extraction and determination of selected MCs, using high-performance liquid chromatography (HPLC) coupled with ultraviolent (UV) detection at environmentally relevant concentrations in both dissolved and particulate phases are explained.

In Chapter 4, batch experiments with activated and deactivated sludge originating from continuous flow porous-pot reactors operating at SRTs of 5, 10, and 15 days are 


\section{P a g e | $\mathbf{1 0}$}

conducted in order to investigate the sorption kinetics and distinguish physicochemical sorption and biosorption. The effect of SRT and the biomass concentration on sorption kinetics is also studied. Selected MCs shows high sorption affinity to the non-active biomass during the first $30 \mathrm{~min}$ of the experiment, which is gradually reduced until equilibrium is reached. Desorption results shows two distinct stages, a very rapid desorption within 20 min followed by a slow desorption stage. Biosorption study indicates that the soluble concentrations of target compounds decreased rapidly for selected MCs similar to the sorption study; however, the soluble and solid phase concentrations continues to decrease slowly during the length of the experiment which indicates the possible biodegradation of these compounds in both phases. Finally, mathematical models are applied to describe the sorption and desorption mechanism and Freundlich isotherms with values of $1 / \mathrm{n}$ close to 1 are found to best fit the results which demonstrate that all tested concentrations result on the linear part of the Freundlich isotherm. Calculation of the Freundlich constant, $\mathrm{K}_{\mathrm{F}}$ and distribution coefficient, $\mathrm{K}_{\mathrm{d}}$ exhibits the greater tendency of EE2 and TCS for sorption, compared to BPA. The results of this study indicates that the SRT has a clear effect on the sorption kinetics where the highest sorption rate constant is achieved for a SRT of 10 days for all three target substances. This could be due to change of the morphology of the biomass from reactors operating at different SRTs. 


\section{P a g e $\mid \mathbf{1 1}$}

Chapter 5 describes the fate of selected MCs in simulated AS systems. In this chapter biodegradation and sorption were investigated at the $\mu \mathrm{g} / \mathrm{L}$ range for EE2, BPA, and TCS. The effects of SRT, HRT and the biomass concentration on sorption and removal of MCs were also studied. The result of batch study in chapter 4 is used to compare with the sorption rates estimated using the concentration of MCs in solid and liquid phases from continuous-flow reactors. The sorption kinetic data are modeled using intra-particle diffusion model, pseudo-first-order and pseudo-second-order equations. The operation of continuous-flow AS systems in the presence of $20 \mu \mathrm{g} / \mathrm{L}$ of MCs indicated that $90-98,63-91$ and $97-98 \%$ of BPA, EE2 and TCS, respectively, can be removed during the AS process in systems operating at SRT of 5-15 d and HRT of 4-10 h. Determination of MCs in the dissolved and particulate phase and calculation of their mass flux showed that biotransformation was the principal removal mechanism of selected MCs. Statistical analysis revealed that both SRT and HRT had a significant effect on the fate of MCs where highest biotransformation removal rate was found for TCS and BPA in reactors operating at higher SRTs whereas the lower rate of 58\% was found for EE2 in the reactor operating at SRT of $5 \mathrm{~d}$ and HRT of $4 \mathrm{~h}$. The MCs removal rate in the presence of nitrification inhibitor illustrated the role of heterotrophs versus autotrophs in fate of MCs. It was found that heterotrophs were most likely responsible for the degradation of selected MCs. 


\section{P a g e | $\mathbf{1 2}$}

In Chapter 6, mathematical models were applied to describe the degradation mechanism of selected MCs. In this chapter the mixed liquor aliquots were decanted from reactors at beginning of each experimental phase and the active fraction of the mixed liquor was determined. The biological degradation rate constants $\left(\mathrm{K}_{\mathrm{m}}, \mathrm{K}_{\mathrm{ms}}, \mathrm{K}_{\mathrm{mp}}\right)$ as well as the concentration of active $\mathrm{MC}$ degraders $\left(\mathrm{X}_{\mathrm{C}}\right)$ were estimated from fitting the analytical solution to the measured data found in previous chapter by minimizing the sum of the squares of the weighted derivatives $\chi^{2}$ between measurements and the calculated model results. The AQUASIM and Excel software were used in this study for parameter estimation and model comparison. The result of $\mathrm{X}_{\mathrm{C}}$ estimation showed that the SRT plays an important role in formation of the biomass capable of degrading selected MCs. It is also observed that the MCs degraders are naturally present in the AS system even at low SRTs, however the concentration of $\mathrm{X}_{\mathrm{C}}$ is much lower in SRTs of $5 \mathrm{~d}$ comparing to SRT 15 d. Evaluation of various biodegradation kinetic models showed poor agreement between measured data and modeled values except for pseudo-second-order model with degradation by active MCs degraders only in soluble phase. The result of this study could be seen in the context, where the active MCs degraders are proposed to reduce the variability of $\mathrm{K}_{\mathrm{m}}$ in AS systems operating at different operational conditions.

Finally, Chapter 7 presents all conclusions drawn from this research in regards to fate of MCs in AS system and biodegradation kinetic models that describe their fate as well as possible future extensions to this thesis. 
Figure 1-2, illustrates the structure of this thesis as well as the summary of chapters and published or submitted journal papers.

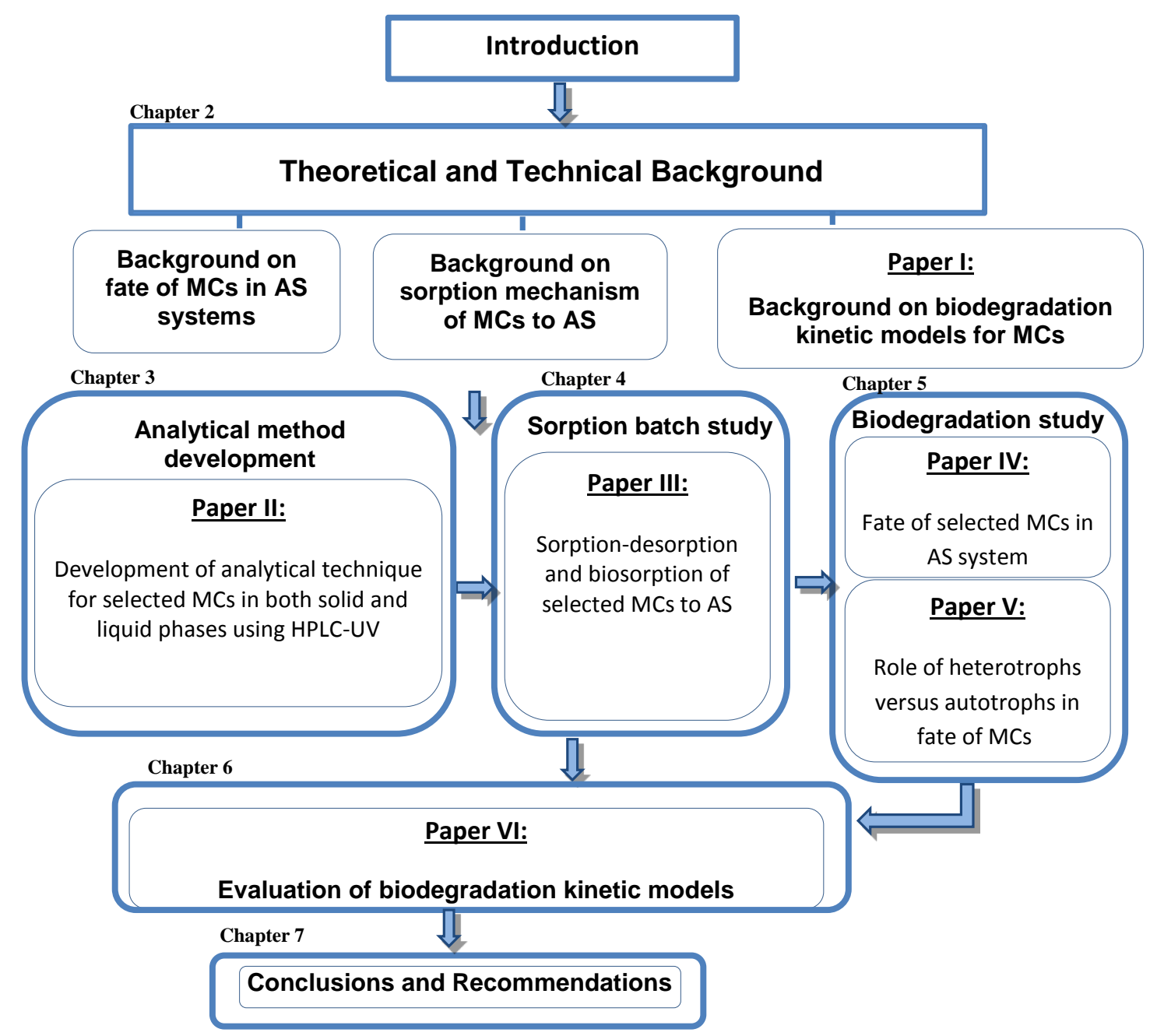

Figure 1-2. Structure of this thesis and summary of chapters 


\subsection{References}

Dann AB, Hontela A. Triclosan: environmental exposure, toxicity and mechanisms of action. J Appl Toxicol 2011; 31: 285-311.

Deblonde T, Cossu-Leguille C, Hartemann P. Emerging pollutants in wastewater: a review of the literature. Int J Hyg Environ Health 2011; 214: 442-8.

Feng Y, Zhang Z, Gao P, Su H, Yu Y, Ren N. Adsorption behavior of EE2 (17 alphaethinylestradiol) onto the inactivated sewage sludge: kinetics, thermodynamics and influence factors. J Hazard Mater 2010; 175: 970-6.

Kang JH, Katayama Y, Kondo F. Biodegradation or metabolism of bisphenol A: from microorganisms to mammals. Toxicology 2006; 217: 81-90.

Lee J, Lee BC, Ra JS, Cho J, Kim IS, Chang NI, et al. Comparison of the removal efficiency of endocrine disrupting compounds in pilot scale sewage treatment processes. Chemosphere 2008; 71: 1582-92.

Margot J, Kienle C, Magnet A, Weil M, Rossi L, de Alencastro LF, et al. Treatment of micropollutants in municipal wastewater: ozone or powdered activated carbon? Sci Total Environ 2013; 461-462: 480-98.

Melcer H, Klecka G. Treatment of wastewaters containing bisphenol A: state of the science review. Water Environ Res 2011; 83: 650-66.

Nie Y, Qiang Z, Zhang H, Adams C. Determination of endocrine-disrupting chemicals in the liquid and solid phases of activated sludge by solid phase extraction and gas chromatography-mass spectrometry. J Chromatogr A 2009; 1216: 7071-80.

Plahuta M, Tišler T, Toman M. J, Pintar A. Efficiency of advanced oxidation processes in lowering bisphenol A toxicity and oestrogenic activity in aqueous samples. Archives of Industrial Hygiene and Toxicology. 65, 2014, pp. 77.

Pomati F, Orlandi C, Clerici M, Luciani F, Zuccato E. Effects and interactions in an environmentally relevant mixture of pharmaceuticals. Toxicol Sci 2008; 102: 12937.

Prasse C, Wagner M, Schulz R, Ternes TA. Oxidation of the antiviral drug acyclovir and its biodegradation product carboxy-acyclovir with ozone: kinetics and identification of oxidation products. Environ Sci Technol 2012; 46: 2169-78.

Quinn B, Gagne F, Blaise C. Evaluation of the acute, chronic and teratogenic effects of a mixture of eleven pharmaceuticals on the cnidarian, Hydra attenuata. Sci Total Environ 2009; 407: 1072-9.

Radjenovic J, Petrovic M, Barcelo D. Fate and distribution of pharmaceuticals in wastewater and sewage sludge of the conventional activated sludge (CAS) and advanced membrane bioreactor (MBR) treatment. Water Res 2009; 43: 831-41. 


\section{P a g e | 15}

Roig B. Pharmaceuticals in the environment. Current knowledge and need assessment to reduce presence and impact: IWA Publishing, 2010.

Samaras VG, Stasinakis AS, Mamais D, Thomaidis NS, Lekkas TD. Fate of selected pharmaceuticals and synthetic endocrine disrupting compounds during wastewater treatment and sludge anaerobic digestion. J Hazard Mater 2013; 244245: 259-67.

Seyhi B, Drogui P, Buelna G, Blais JF. Modeling of sorption of bisphenol A in sludge obtained from a membrane bioreactor process. Chemical Engineering Journal 2011; 172: 61-67.

Stasinakis AS, Kordoutis CI, Tsiouma VC, Gatidou G, Thomaidis NS. Removal of selected endocrine disrupters in activated sludge systems: effect of sludge retention time on their sorption and biodegradation. Bioresour Technol 2010; 101: 2090-5.

Stevens-Garmon J, Drewes JE, Khan SJ, McDonald JA, Dickenson ER. Sorption of emerging trace organic compounds onto wastewater sludge solids. Water Res 2011; 45: 3417-26.

Zhao J, Li Y, Zhang C, Zeng Q, Zhou Q. Sorption and degradation of bisphenol A by aerobic activated sludge. J Hazard Mater 2008; 155: 305-11. 
P a g e | 16

\section{Chapter 2: Technical Background}

\section{Summary $^{1}$}

This technical background presents the literature review explaining the different removal pathways of MCs in typical sewage treatment condition and the different operational conditions and factors which influence the removal efficiency of these compounds. Besides, three specific compounds that represent the broad range of MCs in environment are identified and a broad description of selected MCs is provided, detailing their most relevant physico-chemical properties which influence their fate and behaviour along sewage treatment. The literature were also reviewed for the kinetic models that can be used to describe transformation of MCs (volatilization and photodegradation were considered negligible) in an AS process.

\footnotetext{
${ }^{1}$ Part of this chapter has been submitted for publication to WER journal and published in WEFTEC 2011:

Banihashemi B, Droste RL. Evaluation of Biodegradation Kinetics Models for Microconstituents Under Typical Sewage Treatment Conditions. Water Environment Federation 2011: 5049-5061.
} 
P a g e | 17

\subsection{Introduction to Microconstituents}

Microconstituents (MCs), also referred to in the literature as "emerging contaminants", "Compounds of Emerging Concern (CECs)", "Emerging pollutants", "Trace Organic Compounds (TOrCs)", consist of a vast and expanding array of anthropogenic as well as natural substances which commonly exist in waters and environment at trace level concentrations, ranging from a few $\mathrm{ng} / \mathrm{L}$ to several $\mu \mathrm{g} / \mathrm{L}$. These compounds present in the environment as long as they have been made and their ability to mimic endogenous hormones has been known since at least the 1930's (Walker and Janney, 1930) and more importantly by the fish deformation report in UK in 1990s (Desbrow et al., 1998). However, thanks to recent developments in analytical techniques their occurrence can be monitored in various environmental samples at very low concentrations.

The presence of MCs in lakes, rivers, drinking water and their fate in wastewater treatment plants (WWTPs) as major point sources are a growing concern since some of these substances persist at detectable levels in WWTP effluents, and discharge into the rivers (Anderson, 2005; Ashton et al., 2004). Because of this growing interest, scientists have studied the environmental fate and toxicology properties of MCs (Melcer and Klecka, 2011; Radjenovic et al., 2009; Samaras et al., 2013) and although no legal limits have been established yet, regulatory authorities around the world have conducted monitoring programs and risk assessments of different MCs for future guidelines of 


\section{P a g e | 18}

concentration limits of MCs in water bodies or in discharged WWTPs effluent (Roig, 2010); Advanced Industrial Science and Technology, 2007; Environment Canada and Health Canada, 2008; European Commission, 2008).

MCs can be classified as natural and synthetic compounds which cover broad range of compounds from hormones excreted by humans and animals to pharmaceuticals and personal care products (PPCPs), combustion by-products and metals. The following paragraphs describe the categories of MCs which has been found in the literature.

Pharmaceuticals and personal care products: In the late 1970s, the human drugs have been found in environmental samples (Hignite and Azarnoff, 1977). The effect of these compounds in the environment started to be focused in 1990s, when it was discovered that some of these compounds interfere with ecosystems at very low concentration (Halling-Sorensen et al., 1998). Pharmaceuticals are not completely metabolized by humans or animals; as a result, they are excreted via urine and faeces as unchanged parent compounds and as metabolites or conjugates (Heberer, 2002a). Personal care products can be found in products used for beautification and personal hygiene (skin care products, soaps). Man-made organic chemicals such as sunscreen agents, antimicrobial disinfectants (e.g., triclosan, TCS), and preservatives, are also classified as PPCPs, which are introduced to the aquatic environment during regular use (Ternes et al., 2003). 
P a g e | 19

Brominated flame retardants (BFRs): BFRs, such as hexabromocyclododecanes (HBCDs), polybrominated diphenyl ethers (PBDEs), and tetrabromobisphenol-A (TBBPA), have been used in consumer products for a long time to reduce fire-related injury and property damage. Recently, due to their occurrence in the environment and in human biota, the fate and removal methods for this emerging class of chemicals have been studied (Segev et al., 2009).

Steroid Hormones: Steroid hormones are a group of compounds that control the endocrine and immune systems. Natural hormones are classified as estrogens (e.g., estradial), progestagents, androgens (e.g., androstenedione), and corticoids (e.g., cortisol). Other synthetic hormones such as ethinylestradiol and mestranol have also been produced that can be considered as endogenous compounds. Among these compounds, estrone (E1), 17 $\beta$-estradiol (E2), estriol (E3) and 17 $\alpha$-ethinylestradiol (EE2) have received more scientific attention since they are considered to be the most important contributors to estrogenicity of treated wastewater and surface waters (Fernandez et al., 2007; Hamid and Eskicioglu, 2012).

Plasticizer and Industrial Material: Plasticizers are used to make plastics last longer and improve the flexibility of plastics. Plasticizers can also be used as perfume fixatives in production of cosmetic and personal care products (e.g., baby products). The plastic monomer and plasticizer bisphenol A (BPA) are one of worldwide produced 


\section{P a g e $\mid \mathbf{2 0}$}

chemicals that have been used extensively in recent years. BPA is used in the production of polycarbonate plastics and epoxy resins used in many consumer products.

Pesticides and Surfactant: A pesticide is an organic compound (or mixture of compounds) that have been used to remove pest's problems by several ways such as prevention, destruction, repulse or mitigation. Today, many different classes of pesticides are used which can be beneficial to humans such as chlorinated hydrocarbons, triazines, organphosphoric compounds, and substituted urea. Despite the positive effects from their usage, the extensive use of pesticides resulted in serious environmental contamination and health problems.

Disinfectants: The use of antiseptics and disinfectants can be found in hospitals and other health care settings for different daily applications which demonstrate broad antibacterial activities (Magee, 2012). A broad diversity of active chemical agents is found in these products, including alcohols, phenols, iodine, and chlorine that have been used for a long period of time (Magee, 2012).

Musks and fragrances: The term musk is used to describe a various range of chemically defined substances, which has a common, distinct, and typical flavour but are widely different in their chemical structure. These musk compounds comprise representatives occurring naturally in animals and plants as well as artificial substances posing musk-like odour properties. Synthetic musk and fragrances could be found in soaps, perfumes, air fresheners, detergents, fabric softeners and other household cleaning 


\section{P a g e | 21}

products. Many of these products are ultimately end up in sewers. Intrinsically, a large proportion will pass through the WWTP and discharge to rivers (Sun et al., 2014). There are four synthetic musk fragrances accounting for $95 \%$ of those used. These are the nitromusks (musk xylene, used in detergents and soaps, and musk ketone, used in cosmetics) and two polycyclic musks.

Metals: Metals (inorganic MCs) are natural components that can be found in aquatic systems and most of them are important elements to maintain human and animal lives. Although burning fossil fuels and smelting of metallic ores would provide energy, essential metals and minerals to human, but also it can be harmful to human at the toxic concentration, such as cadmium, mercury or lead.

\subsection{Occurrence and Transformation of MCs in the Environment}

The environmental and health effects of MCs are receiving increased attention from scientists, regulators, and the public due to their profound impacts on the health of all life forms. It should be emphasized that not all MCs are substances that can affect the endocrine system in humans and animals. To better understand the effect of MCs on the environment, their fate and pathways in the environment need to be studied.

MCs can be discharged into wastewaters by the general population due to the use of products containing them. Some degradation or transformation of these compounds take place at WWTPs and then final dilution of the WWTP effluent by receiving waters occurs. Some of the MCs are volatile and escape to the atmosphere; others are adsorbed 


\section{P a g e | 22}

or absorbed by solids or biosolids and finally migrate to landfills along with sludge produced in WWTPs. Effluents from municipal WWTPs have been implicated as a major source to surface waters (Andersen et al., 2005; Kasprzyk-Hordern et al., 2009). WWTPs receive MCs from sources including plastics, plant material, cleaning products, pesticides, household chemicals and consumer products, natural and synthetic hormones excreted by humans, and PPCPs washed from the body or flushed to the sanitary sewer. Studies showed a good correlation between MCs concentrations in wastewater and their production amounts and usage/consumption patterns (Kasprzyk-Hordern et al., 2008). WWTPs might also treat industrial, livestock or hospital effluents and stormwater runoff that contain MCs. Some of these compounds specially pharmaceuticals can be metabolized to varying degrees and reached the WWTPs in conjugated forms. However, these conjugated MCs could later be transformed into free (unconjugated) forms by bacterial populations present in WWTP (Gomes et al., 2009).

WWTPs were designed and upgraded with the principal aim of eliminating easily or moderately biodegradable carbon, nitrogen and phosphorus compounds which regularly present in the influent at milligram per liter concentrations. However, MCs in raw wastewaters are generally in the range of $\mu \mathrm{g} / \mathrm{L}$ to $\mathrm{ng} / \mathrm{L}$, in addition, their chemical and physical properties, vary greatly (Le-Minh et al., 2010; Ziylan and Ince, 2011), which influence their fate during the treatments and consequently their removal efficiencies. Although wastewater treatment processes remove some MCs to some extent, resistant 


\section{P a g e $\mid \mathbf{2 3}$}

chemicals may remain at detectable levels in WWTP effluents. Through the effluent discharge to surface water or groundwater, MCs may be diluted or degraded by physical or biological processes, but some persist in the environment or might be detected due to constant loading.

The occurrence of MCs in the environment has been studied by a plethora of reports and the typical concentrations and most detected MCs were identified (Aris et al., 2014; Klecka et al., 2009; Luo et al., 2014; Verlicchi et al., 2012).

Studies on the presence of MCs in WWTP influent showed high occurrence concentrations of some pharmaceutical compounds such as acetaminophen, caffeine, ibuprofen (IBP), naproxen and salicylic acid, antibacterial agent (TCS), surfactant (nonylphenol) and one industrial chemical (Bis(2-ethylhexyl) phthalate, DEHP) in the concentration range between 0.1 and $10 \mu \mathrm{g} / \mathrm{L}$. In addition, ibuprofen, atenolol, caffeine and nonylphenol were found to have the highest concentrations in WWTP influent. The concentrations of most MCs in effluent were one to two orders of magnitude lower than those in influent and ranged from 0.001 to $1 \mu \mathrm{g} / \mathrm{L}$ (Luo et al., 2014).

MCs were also monitored in surface water and carbamazepine, sulfamethoxazole and TCS were the most frequently reported compounds in surface water (Luo et al., 2014). The maximum concentrations of $36.8,9.8,17.0$ and $1121.4 \mu \mathrm{g} / \mathrm{L}$ were detected for ibuprofen, ketoprofen, gemfibrozil (GEM) and caffeine, respectively. The review paper by Luo et al. (2014) showed that MCs occurs in the natural water bodies of the densely 


\section{P a g e $\mid \mathbf{2 4}$}

populated regions more severely due to the massive usage of these chemicals by the large population. The fate study on MCs in rivers reveled that natural attenuation of MCs is the result of river water dilution, or sorption to solids, and not degradation (Gómez et al., 2012). Carbamazepine, sulfamethoxazole, caffeine and TCS were the most commonly detected compounds in groundwater with reported concentration of less than $100 \mathrm{ng} / \mathrm{L}$. It was also found that the concentrations of MCs in drinking water are dependent on water sources, seasons and the type of drinking water treatment systems (Luo et al., 2014).

\subsection{Choosing Target MCs}

MCs consist of a broad range of compounds from PPCBs, pesticides, metals to EDCs. Goals in this proposed research are to study specific compounds that represent the broad range of MCs in the environment. Different factors have been considered to find the best representatives: (a) well-studied MCs to compare our results with available studies in the literature, (b) physical and chemical properties of MCs, (c) available analytical methodology, (d) known negative impact on environment, (e) presence in conventional WWTP effluent and water bodies especially in the Canadian environment, and finally (f)

the cost of study. In order to simplify our kinetic models in AS WWTPs, only compounds with very low volatility that are biodegradable have been chosen. 
P a g e $\mid \mathbf{2 5}$

\subsubsection{Presence in Canadian environment}

Burnison et al. (2002) investigated EDCs in municipal sewage effluents in Ontario and found that the major estrogenic substances were natural and synthetic human hormones (17ß-estradiol, E1, and EE2), alkylphenolics, and occasionally BPA (an industrial contaminant) and a polar metabolic breakdown product of estriol/estrone. Fernandez et al. (2007) also measured the 30 primarily estrogenic organic wastewater contaminants in several influent and effluent wastewater samples in Canada and showed that EE2 was the more frequently detected synthetic estrogens/progesterone in the effluent occurring at or below 5 to up to $178 \mathrm{ng} / \mathrm{L}$, other steroidal estrogens were E1>E2>E3 which were all $<20 \mathrm{ng} / \mathrm{L}$.

Bennie (2008) investigated the acidic pharmaceuticals in surface waters of selected Ontario watersheds and found out that Ibuprofen, gemfibrozil, naproxen and TCS were detected in surface waters with maximum concentrations of 1590, 103, 753 and $428 \mathrm{ng} / \mathrm{L}$, respectively. Lishman et al. (2006) also studied 10 acidic pharmaceuticals, TCS and six polycyclic musks in twelve WWTPs discharging into the Thames River and found that PPCPs enter Canadian waterways at trace levels (e.g., TCS $0.01-4.01 \mu \mathrm{g} / \mathrm{L}$ in influent samples and $0.01-0.324 \mu \mathrm{g} / \mathrm{L}$ in effluent samples), and WWTPs can only reduce some of them in a significant proportion. They also found that the mean influents concentration of IBP, GEM, and diclofenac (DCF) were 8.45, 0.453 and $0.204 \mu \mathrm{g} / \mathrm{L}$, respectively, while mean effluent concentrations were $0.384,0.246$, and $0.194 \mu \mathrm{g} / \mathrm{L}$, respectively. 


\section{P a g e $\mid \mathbf{2 6}$}

Servos et al. (2005) investigated the presence of selected PPCPs in drinking water in Ontario, and they showed that the highest levels of TCS in southern Ontario source water were 34 and $150 \mathrm{ng} / \mathrm{L}$, respectively. Lee and Peart (2000a) conducted a large-scale study on BPA contamination in Canadian sewage treatment plants (STPs) and found BPA contamination in all of 72 sewage samples. The concentration of BPA ranged from 0.08 to $4.98 \mu \mathrm{g} / \mathrm{L}$ for the influent, and from 0.01 to $1.08 \mu \mathrm{g} / \mathrm{L}$ for the effluent and 0.033 36.7 $\mu \mathrm{g} / \mathrm{g}$ for sewage sludge. Mohapatra et al. (2011) measured BPA in samples from an urban community Quebec WWTP located in Quebec City and the results showed that BPA was present in the influent and the effluent with mean concentrations of $1.68 \mu \mathrm{g} / \mathrm{L}$ and $0.41 \mu \mathrm{g} / \mathrm{L}$, respectively.

Ternes et al. (1999) studied the occurrence of natural estrogens and synthetic contraceptives in Germany and Canadian STP discharges and found a median concentration of $0.009 \mu \mathrm{g} / \mathrm{L}$ for EE2 in the WWTPs effluents. Chan et al. (2002) investigated the existence of EDCs in industrial wastewater samples in Toronto and found the widely divergent concentrations ranging from $<0.01$ to $195 \mu \mathrm{g} / \mathrm{L}$ for 4 -tertoctylphenol (OP), from $<0.1$ to $253 \mu \mathrm{g} / \mathrm{L}$ for nonylphenol (NP), from $<2$ to $117,570 \mu \mathrm{g} / \mathrm{L}$ for nonylphenol ethoxylates (NPEO), and from $<0.01$ to $149 \mu \mathrm{g} / \mathrm{L}$ for BPA in the wastewater samples.

Boyd et al. (2003) investigated PPCPs in surface and treated waters in Ontario and found concentrations of naproxen in the Mississippi River and Lake Pontchartrain from 


\section{P a g e $\mid \mathbf{2 7}$}

22 to $107 \mathrm{ng} / \mathrm{L}$. Hao et al. (2006) also studied the occurrence of pharmaceutical and EDCs in source and finished drinking water in Ontario and found carbamazapine, gemfibrozil, ibuprofen, BPA, lincomycin, naproxen, monensin, sulfamethoxazole, tylosin, trimethoprin, bezafibrate, and acetamindophenol in source and drinking water samples. In one of the most recent studies in Ontario, Kleywegt et al. (2011) found carbamazepine, gemfibrozil, ibuprofen, and BPA in finished drinking water at concentration of 4 to 10 times lower than those measured in the source water. Lishman et al. (2006) conducted a study to investigate polycyclic and nitro musks in Canadian municipal wastewater and found out that the maximum influent concentrations of polycyclic and nitro musks were 7,030 and $158 \mathrm{ng} / \mathrm{L}$ for Galaxolide and ketone, respectively. The maximum secondary effluent concentrations were found to be 2,000 $\mathrm{ng} / \mathrm{L}$ for Galaxolide and $51 \mathrm{ng} / \mathrm{L}$ for musk ketone.

In another study, Jeffries et al. (2010) showed the presence of organic contaminants and potential fish health impact in two rivers in Alberta. In their study, synthetic estrogens and natural hormones were detected near wastewater effluents and it was suggested that synthetic estrogens and natural hormones has potential health impacts in male long-nose dace.

\subsubsection{Chemical-physical properties}

Once a MC is released into wastewater, it will be scattered between the different environmental media (e.g., water, soil, surface, sediment) due to its physico-chemical 


\section{P a g e $\mid \mathbf{2 8}$}

properties, such as volatility, solubility, lipophilicity, acidity, and sorption potential. Moreover, depending on its resistance to biologically or abiotically degradation processes, it can remain in WWTPs and discharge to the environment through the effluent. Joss et al. (2006) showed that a significant amount of a compound will be stripped in a bioreactor with fine bubble aeration if Henry's constant $(\mathrm{H})>0.003$. Therefore, it can be concluded that stripping process during wastewater treatment is in general not relevant for the removal of those MCs that has low Henry's constant (Suárez et al., 2008b). However, in activated sludge processes intensified volatilization behavior could be found due to the additional air supply and removal of some MCs can occur (Suarez et al., 2010).

Acidity (i.e., dissociation constant $\mathrm{pK}_{\mathrm{a}}$ ) indicates if a specific ionic interaction is or is not relevant for the sorption potential of a given compound. Moreover, for compounds containing functional groups which can be protonated and de-protonated, the $\mathrm{pH}$ value might play a crucial role. Schäfer et al. (2011) indicated that the phenolic hydroxyl group of hormones can dissociate at the $\mathrm{pH}$ above the acid dissociation constant $(\mathrm{pKa})$ and the compounds would become negatively charged. Therefore, the removal of MCs can also be expected due to the charge repulsion between negatively charged compounds and biomass in the activated sludge reactors.

The octanol-water partition coefficient $\left(\mathrm{K}_{\mathrm{ow}}\right)$ is an indication of the substance hydrophobicity (lipophilicity) and thus it indicates if a specific compound tends to 


\section{P a g e $\mid \mathbf{2 9}$}

migrate from the aqueous phase into the lipophilic cell membrane of lipid fraction of the biomass. Ter Laak et al. (2005) have observed that compounds exert: (a) low sorption potential if $\log K_{o w}<2.5$, (b) medium sorption potential if $\log K_{\text {ow }}$ between 2.5 and 4.0, and, (c) high sorption potential if $\log \mathrm{K}_{\mathrm{ow}}>4.0$.

The sorption potential of a given MC is identified by the solid-water distribution coefficient $\left(\mathrm{K}_{\mathrm{d}}\right)$, which includes two driving forces for sorption: acidity and lipophilicity. Joss et al. (2006) showed that compounds can only sorbs significantly onto primary and secondary sludge if they have $\mathrm{K}_{\mathrm{d}}$ values higher than $500 \mathrm{~L} / \mathrm{kg}$. Carballa et al. (2007) also found that in sludge treatment process, sorption could be neglected if the $\mathrm{K}_{\mathrm{d}}$ value is less than $1 \mathrm{~L} / \mathrm{kg}$. They also indicated that the amount of MCs that can be sorbed to the sludge is not only dependent on the distribution coefficient but also on the concentration of solids. Suárez et al. (2008a) showed that based on partition coefficient between solid and liquid phase values and biodegradability of MCs, their removal in WWTPs can be predicted. They suggested that the effect of HRT and SRT on MCs removal could be different when the compound has moderate, high, or low $\mathrm{K}_{\mathrm{d}}$ and biodegradation constant values.

Chemical structure of MCs also plays an important role in determining the biodegradability of MCs which depends on the complexity of the compound (e.g. monocyclic or polycyclic) and its functional groups (e.g. halogen groups). In general, linear compounds with short side chains, unsaturated aliphatic compounds, and 


\section{P a g e $\mid \mathbf{3 0}$}

compounds possessing electron donating functional groups can be easily degraded. Whereas, compounds with long, highly branched side chains, saturated or polycyclic compounds, and compounds possessing sulfate, halogen or electron withdrawing functional groups would be more persistence (Tadkaew et al., 2011). Nevertheless, no obvious relationship between chemical structure, functional groups and the removal of MCs were identified. For example, although ibuprofen and ketoprofen have similar chemical structures, their removal rate in WWTPs are different, with ibuprofen $(>90 \%$ removal) being eliminated more efficiently (Camacho-Muñoz et al., 2012).

\subsubsection{Health and environment concern}

The structure of the compound and different segment attached to initial molecule would affect toxicity of organochlorine pesticides. In many cases, compounds are known as moderately toxic to mammals and highly toxic to aquatic organism (e.g., Aldrin, and heptachlor). Organophosphates can also have neurotoxic effects on humans. For instance, methyl parathion could interact with double-stranded deoxyribonucleic acid (DNA) and could produce chromatid exchange in human lymphocytes (Blasiak et al., 1995).

Studies on single compounds have shown that for environmental relevant concentrations of most pharmaceuticals, acute toxicity on aquatic organisms are not likely to occur (Choi et al., 2008; Zhang et al., 2008); however, several studies have shown possible toxicity to non-target organisms due to combined and synergistic effects of MCs at environmentally relevant concentrations (Pomati et al., 2008; Quinn et al., 


\section{P a g e | $\mathbf{3 1}$}

2009). On the other hand, since several aquatic species are exposed to these compounds for their entire life cycle, chronic toxicity of pharmaceuticals is a great concern. Brown et al. (2007) reported the bioaccumulation of diclofenac, ibuprofen, and gemfibrozil in fish blood of rainbow trout. Studies have been reported estrogenic activity as well as mutagenic and genotoxic potential of gemfibrozil (Isidori et al., 2009). Finally, Thomas and Foster (2005) and Costanzo et al. (2005) showed that the release of antibiotics and their metabolites into the environment could develop bacterial resistance to antibiotics in aquatic ecosystems.

Steroid hormones can cause feminization of male fish even at concentrations close to detection limit for advanced analytical systems. For instance, at concentration of $4 \mathrm{ng} / \mathrm{L}$ of EE2, the development of normal secondary sexual characteristics on male fathead minnows was prevented (Lange et al., 2001). Adverse effects of steroids have also been reported in other organism such as amphibians, reptiles or invertebrate. Steroids can also affect humans, for example, EE2 has been linked with prostate cancer development (Hess-Wilson and Knudsen, 2006).

The ability of EE2 to affect the endocrine system of exposed biota were illustrated in previous studies and altering sex determination, delaying sexual maturity, and decreasing secondary sexual characteristics even at low concentrations (ng/L) were reported (Dzieweczynski and Hebert, 2013; Liu et al., 2012; Silva et al., 2012). 


\section{P a g e | 32}

Some surfactants and personal products such as NP are considered as EDCs. Studies showed that growth of the mysid crustacean Americamysis bahia can be disrupted by environmentally relevant concentrations of NP (Hirano et al., 2009). Some intervention studies have been done on toxicity of MCs, and toxicity of TCS in algae, invertebrates, and fish have been reported (Dussault et al., 2008). Kumar et al. (2009) also reported the endocrine disrupting ability of this compound. Recently, TCS was detected in the plasma of dolphins at concentration ranging between 0.025 to $0.27 \mathrm{ng} / \mathrm{g}$ wet weights indicating its bioaccumulation in marine mammals (Fair et al., 2009).

A well-known plasticizer, BPA is one of the most worldwide produced chemicals and is a known endocrine disruptor. From preliminary studies, BPA has been considered as a weak environmental estrogen; however, more recent studies found that BPA is similar in potency to estradiol in stimulating some cellular responses. In addition, recent evidence indicates that BPA could affect the various endocrine-related pathways. Adverse effects of BPA on the reproduction of wildlife, including annelids, mollusks, crustaceans, insects, fish, and amphibians, as well as on the embryonic development and the induction of genetic aberrations in crustaceans and amphibians has been shown by (Oehlmann et al., 2009).

Studies have also reported that BPA can act as an estrogen agonist and disrupt normal cell function after entering the human body (Wozniak et al., 2005), as well as an androgen antagonist (Lee et al., 2003). Rubin and Soto (2009) reported that BPA may 


\section{P a g e $\mid \mathbf{3 3}$}

affect human development throughout the fetal period, and may be carcinogenic, potentially resulting in the precursors of breast cancer. Because of estrogenic activity of BPA, sperm count and activity reduction, toxicity to liver and obesity by affecting fat-cell activity has been reported (European Food Safety Authority, EFSA, 2006). Moreover, exposure to $\mathrm{BPA}$ has been related to chronic disease conditions in humans such as cardiovascular disease and diabetes (Lang et al., 2008). It has also been shown that BPAcontaining products in dental composite resin, food filling using polyvinyl chloride gloves, production of heat-sensitive facsimile paper, adhesives for reinforcing circuit boards and manufacturing of wind turbine systems could result in occupational photosensitive dermatitis, and allergies (Rasmussen, 2006).

In April 2008, Health Canada declared BPA "CEPA toxic" (CEPA is the Canadian Environmental Protection Act). The designation arose because of concerns about potential neuro- developmental and behavioural effects at doses ranging from those equal to current levels in the general public at doses 1-2 orders of magnitude greater.

\subsubsection{Characterization of selected MCs}

To address all the requirements and factors of representative MCs, EE2, BPA and TCS have been chosen as target compounds in this study. These representatives are wellknown and well-studied compounds, have known negative impacts on the environment, have been found in Canadian WWTP effluent and water bodies and based on their physico-chemical properties can cover wide range of MCs in the environment. Carballa 


\section{P a g e $\mid \mathbf{3 4}$}

et al. (2008) identified representative MCs by considering their physico-chemical and biological properties and suggested that EE2, BPA, TCS and some other organic MCs can be used as representative compounds. Rauch-Williams et al. (2010) also identified the short list of indicator TOrC to characterize the performance of secondary treatment processes. The indicator candidates were selected based on three key criteria; frequency of occurrence, analytical amenability, and bio-physicochemical properties and they suggested BPA and TCS among some other TOrC to be monitored in WWTPs (RauchWilliams et al., 2010). Cotton et al. (2010) conducted a systematic approach for evaluating CECs to determine what CECs to monitor, determine CEC levels, and identify a CEC control approach. They concluded the proposed CECs based on literature review, regulatory documents, laboratory standards and compounds representing different categories (e.g., pharmaceuticals, industrial compounds, steroids) and they proposed EE2 and TCS among some other CECs in their final prioritized CEC monitoring list. To better understand the importance of selected compounds in this study, the fate of selected MCs is discussed here.

EE2 is a synthetic hormone that has attracted considerable attention in the literature due to its contribution to endocrine disrupting activity in WWTP effluent (Jeffries et al., 2010; Vajda et al., 2008). EE2 could be discharged to sewer from human sources in either gluconorides or sulphates conjugated forms (Koh et al., 2008); however the conjugate steroids could later be transformed into free (unconjugated) forms by bacterial 


\section{P a g e $\mid \mathbf{3 5}$}

populations present in WWTP that are capable of producing-glucuronidase and arylsulfatase enzymes (Gomes et al., 2009). EE2 adsorption onto AS particles in municipal WWTP might be an important removal pathway in WWTP due to its nonpolar behaviour and hydrophobic properties (Andersen et al., 2005; Cirja et al., 2007; Zhou et al., 2010). WWTPs influent concentrations of EE2 range from below detection to $70 \mathrm{ng} / \mathrm{L}$ (Atkinson et al., 2012; Clara et al., 2005b; Vethaak et al., 2005). Biodegradation has been reported as the most substantial estrogen removal method in AS wastewater treatment (Muller et al., 2008), however, studies showed that presence of EE2 in WWTP effluent at concentration levels of $6 \mathrm{ng} / \mathrm{L}$ might cause estrogenic effects on fathead minnow populations (Kidd et al., 2007; Parrott and Blunt, 2005).

TCS (2,4,40-trichloro-20-hydroxydiphenyl ether; Irgasan) is a broad spectrum antibacterial agent which can be found in many personal care products such as hand disinfecting soaps, medical skin creams, dental products, deodorants, toothpastes (Dann and Hontela, 2011). The use of personal care products containing TCS and the disposal of these products caused TCS contamination in wastewater, streams, seawater, sediments, fish, blood, urine and human milk (Allmyr et al., 2006; Kinney et al., 2008; Queckenberg et al., 2010). TCS can hinder both gram negative and gram positive bacteria by inhibiting the NADH-dependent enoyl-[acyl-carrier protein] reductase, a key enzyme responsible for fatty acid synthesis (Sivaraman et al., 2004). It was found that TCS could also be harmful to AS bacteria (Neumegen et al., 2005). An aid to the development of cross- 


\section{P a g e | $\mathbf{3 6}$}

resistance to antibiotics (Drury et al., 2013) and the formation of chlorodioxins and other toxic metabolites during TCS photodegradation are two of many concerns about the widespread contamination of TCS in the environment (Aranami and Readman, 2007; Braoudaki and Hilton, 2004; Buth et al., 2009; Dann and Hontela, 2011). Furthermore, studies even suggested that TCS is potentially a weak androgen and exerts both estrogenic and androgenic effects on human breast cancer cells (Gee et al., 2008). The TCS concentrations in WWTP influent and effluent were studied by many researchers and ranged from $0.01-16 \mu \mathrm{g} / \mathrm{L}$ in influent and $0.01-2.7 \mu \mathrm{g} / \mathrm{L}$ in effluent, suggesting removal efficiencies of 58-97\% for trickling filter plants and 95-98\% for activated sludge plants (Bester, 2003; Lishman et al., 2006; Nakada et al., 2010; Thomas and Foster, 2005). The high octanol-water partition coefficient of TCS, $\log \mathrm{K}_{\mathrm{ow}}$ of 4.5-4.8 (Lopez-Avila and Hites, 1980; Ying et al., 2007), could lead to 30-50\% TCS removal due to sorption onto biosolids in WWTPs (Bester, 2003; Chalew and Halden, 2009; Heidler and Halden, 2007; Singer et al., 2002).

BPA is a building compound for the manufacturing of plastics, epoxy resins, and polycarbonate resins. BPA is an endocrine disrupter (Fujimoto et al., 2006; vom Saal and Myers, 2008) and might be as effective as estradiol in triggering some receptor responses (Stahlhut et al., 2009). BPA might also act as an androgen receptor antagonist (Urbatzka et al., 2007). $\mathrm{K}_{\mathrm{d}}$ values for BPA are reported in various studies in the literature and ranged from $0.07 \mathrm{~L} / \mathrm{g}$ TSS up to $1 \mathrm{~L} / \mathrm{g}$ TSS (Clara et al., 2004). The Henry's law constant 


\section{$\mathrm{P}$ ag e $\mid \mathbf{3 7}$}

for BPA is $1 \times 10^{-10} \mathrm{~atm} \cdot \mathrm{m}^{3} / \mathrm{mol}$ (Staples et al., 1998b) and volatility of BPA can thereby be considered negligible in WWTPs. Lee et al. (2004) studied the BPA concentrations in Canadian WWTPs and observed BPA in all 30 sewage samples with concentration ranging from 0.16 to $28.1 \mu \mathrm{g} / \mathrm{L}$ (median $0.75 \mu \mathrm{g} / \mathrm{L}$ ) in the influents and from 0.01 to 17.3 $\mu \mathrm{g} / \mathrm{L}$ (median $0.13 \mu \mathrm{g} / \mathrm{L}$ ) in the effluent. The observed influent-to-effluent reduction in the five municipal WWTPs in Canada showed 70-76\% for BPA indicating that it is not completely eliminated during wastewater treatment (Fernandez et al., 2007; Mohapatra et al., 2011). BPA was also found in municipal sewage sludge, in the range of 0.104-0.312 $\mu \mathrm{g} / \mathrm{g}$ in Canada (Mohapatra et al., 2011), 1.86-0.02 $\mu \mathrm{g} / \mathrm{g}$ in Greek (Samaras et al., 2013; Stasinakis et al., 2008), and $0.4 \mu \mathrm{g} / \mathrm{g}$ in Spain (Vega-Morales et al., 2010).

There are four major processes that could cause the removal of MCs from the liquid phase. These are volatilization, photolysis, sorption to wastewater sludge, and biodegradation. Table 2-1 and Figure 2-1 show the physico-chemical characteristics and biodegradability of the selected compounds. The wide range of sorption capacity $\left(\mathrm{K}_{\mathrm{d}}\right)$ and biodegradation potential $\left(\mathrm{K}_{\mathrm{m}}\right)$ from low, moderate to high in selected MCs shows that the fate of these compounds in secondary treatment systems could be varied based on operational parameters such as SRT and HRT.

With a low vapour pressure and a Henry's law constant ranging from $1.5 \times 10^{-7}$ to $7.9 \times 10^{-12}$ atm. $\mathrm{m}^{3} / \mathrm{mol}$ for the selected MCs (Table 2-1), removal of these compounds by volatilization can be considered negligible. Depending on $\mathrm{pH}$, photolysis of these targets 


\section{P a g e | 38}

could be a significant removal mechanism, especially above pH 8 (Tixier et al., 2002). By adjusting the $\mathrm{pH}$ to $7-8$ in the lab test and conducting the test in the dark, losses due photolysis is expected to be negligible. Thus, only sorption and biodegradation is studied during the experiment. 
Table 2-1 Physico-chemical characteristics and biodegradability of selected MCs

\begin{tabular}{|c|c|c|c|c|c|c|c|c|c|c|c|}
\hline Category & Compound & Notation & CAS No & MW & $\begin{array}{l}\text { Molecular } \\
\text { formula }\end{array}$ & $\begin{array}{l}\text { Solubility } \\
\text { (mg/L) }\end{array}$ & $\mathrm{H}\left(\mathrm{atm} \cdot \mathrm{m}^{3} \cdot \mathrm{mol}^{-1}\right)$ & $\mathrm{pK}_{\mathrm{a}}$ & $\log \mathrm{K}_{\mathrm{ow}}$ & $\log K_{d}$ & $\begin{array}{c}\mathrm{K}_{\mathrm{m}} \\
\left(\mathrm{L} \cdot \mathrm{g}^{-1} \mathrm{ss} \cdot \mathrm{d}^{-1}\right)\end{array}$ \\
\hline Plasticizer & Bisphenol A & BPA & $80-05-7$ & 228.29 & $\mathrm{C}_{15} \mathrm{H}_{16} \mathrm{O}_{2}$ & 120 & $1.0 \times 10^{-11}$ & $9.86-10$ & $3.18-3.7^{\mathrm{a}}$ & $1-2.5$ & $5-113^{d}$ \\
\hline Hormones & $\begin{array}{c}17 \alpha- \\
\text { ethinylestradiol }\end{array}$ & EE2 & $57-63-6$ & 296.41 & $\mathrm{C}_{20} \mathrm{H}_{24} \mathrm{O}_{2}$ & $4.8-11.3$ & $7.9 \times 10^{-12}$ & $\begin{array}{l}10.5- \\
10.7 \\
\end{array}$ & $3.6-4.15^{\mathrm{b}}$ & $2.3-2.8$ & $2.5-18.9^{\mathrm{e}}$ \\
\hline Antiseptic & Triclosan & TCS & $3380-34-5$ & 289.54 & $\mathrm{C}_{12} \mathrm{H}_{7} \mathrm{Cl}_{3} \mathrm{O}_{2}$ & 10 & $1.5 \times 10^{-7}$ & 7.9 & $4.5-4.8^{c}$ & $0.75-0.9$ & $30-288^{f}$ \\
\hline
\end{tabular}

MW: molecular weight; $\mathrm{S}_{\mathrm{w}}$ : solubility in water $\left(\mathrm{mg} \cdot \mathrm{L}^{-1}\right) ; \mathrm{H}$ : Henry coefficient $\left(\mathrm{atm} \cdot \mathrm{m}^{3} \cdot \mathrm{mol}^{-1}\right)$; $\mathrm{pK}_{\mathrm{a}}$ : dissociation constant; $\mathrm{K}_{\mathrm{ow}}$ : octanol-water partition coefficient; $\mathrm{K}_{\mathrm{d}}$ : sludge-water distribution coefficient; $\mathrm{K}_{\mathrm{m}}$ : pseudo first-order degradation constant $\left(\mathrm{L} \cdot \mathrm{g}^{-1} \mathrm{SS} \cdot \mathrm{day}^{-1}\right)$

${ }^{a}$ (Borrirukwisitsak et al., 2012; Robinson et al., 2009), ${ }^{\mathrm{b}}$ (Robinson et al., 2009), ${ }^{\mathrm{c}}$ (Lopez-Avila and Hites, 1980; Ying et al., 2007), ${ }^{\mathrm{d}}$ (Stasinakis et al., 2010; Urase and Kikuta, 2005; Zhao et al., 2008), ${ }^{\mathrm{e}}$ (Urase and Kikuta, 2005; Ziels et al., 2014), ${ }^{\mathrm{f}}$ (Stasinakis et al., 2010)

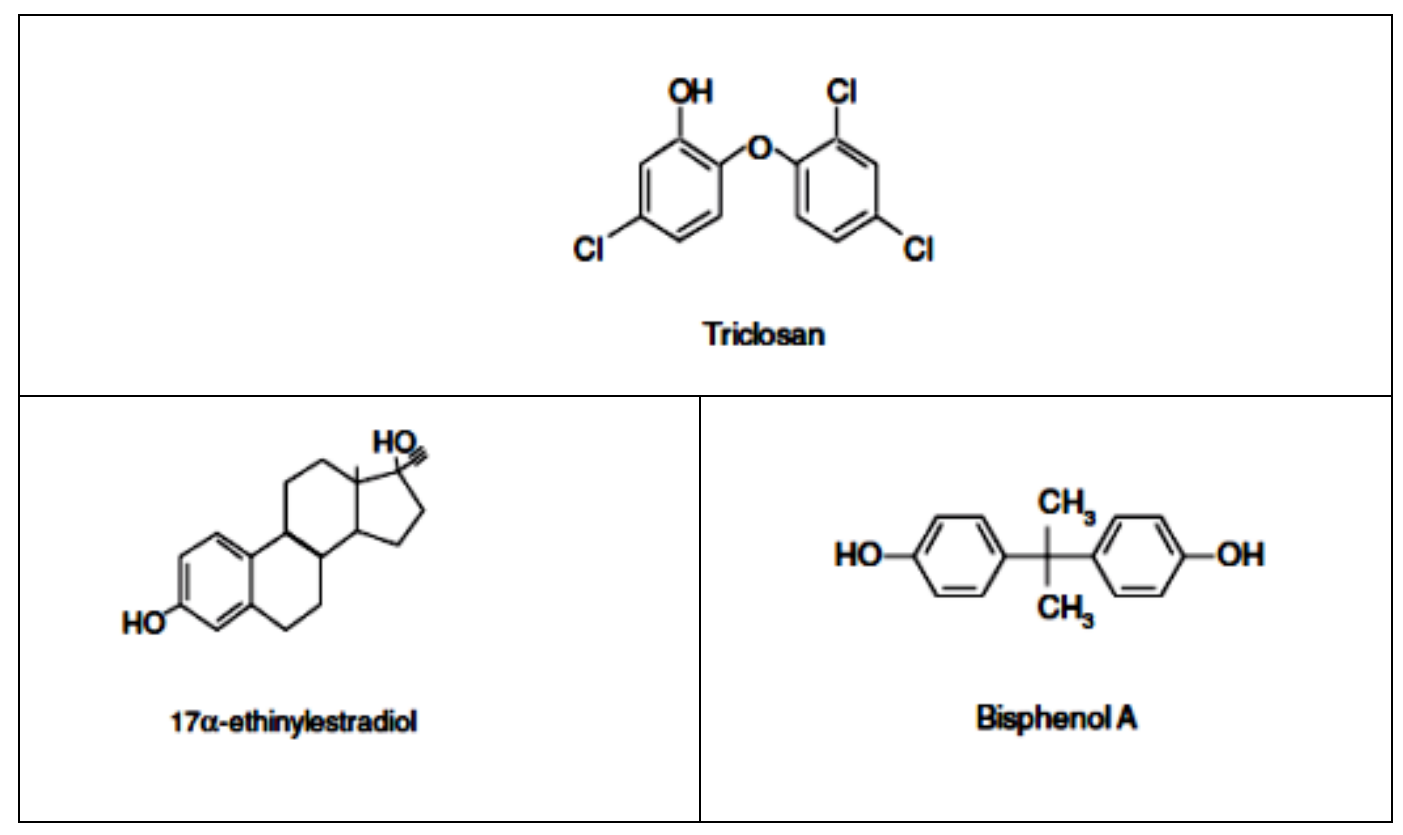

Figure 2-1. Chemical structures of selected MCs 


$$
\text { P a g e } \mid \mathbf{4 0}
$$

\subsection{Sorption Studies Review}

Sorption onto particulate matter is an important removal mechanism when organic MCs are tended significantly to partition onto primary and secondary sludge. Two mechanisms are assumed to be relevant for sorption onto particulate matter: absorption (MCs move from the aqueous phase and enter into the lipophilic cell membrane of biomass or into the lipid fraction of the sludge due to their hydrophobicity) and adsorption (MCs are retained onto solids surface due to electrostatic interactions between positively charged compounds and the negatively charged surface of biomass cells). A common method to measure the fraction of PPCPs sorbed onto sludge is the use of $\mathrm{K}_{\mathrm{d}}$ $(\mathrm{L} / \mathrm{kg})$, and it can be done by investigating the ratio between the concentrations of MCs in the solid and liquid phases at equilibrium conditions. Joss et al. (2006) showed that compounds can only sorbs significantly onto primary and secondary sludge if they have $\mathrm{K}_{\mathrm{d}}$ values higher than $500 \mathrm{~L} / \mathrm{kg}$. Carballa et al. (2007) also found that in sludge treatment process, sorption can be neglected if the $\mathrm{K}_{\mathrm{d}}$ value is less than $1 \mathrm{~L} / \mathrm{kg}$.

$\mathrm{K}_{\mathrm{d}}$ value, combines two driving forces for sorption: acidity $\left(\mathrm{pK}_{\mathrm{a}}\right)$ which indicates if a specific ionic interaction is relevant for the sorption potential of a given compound and the $\mathrm{K}_{\mathrm{ow}}$, which is an indication of the substance's hydrophobicity and determines the bioavailability of a compound in aquatic environment. Hydrophobic compounds have high $\mathrm{K}_{\mathrm{ow}}$ value which indicates poor hydro-solubility and high tendency to sorb on organic material of sludge matrix (Yoon et al., 2004). Studies showed that the compounds 


\section{P a g e | 41}

with $\log \mathrm{K}_{\mathrm{ow}}<2.5$ have high bioavailability and their sorption to AS is not expected to contribute significantly to the removal of the pollutant via excess sludge withdrawal. For chemicals having $\log \mathrm{K}_{\mathrm{ow}}$ between 2.5 and 4, moderate sorption is expected and finally, organic compounds with $\log \mathrm{K}_{\mathrm{ow}}$ higher than 4 , show high sorption potential (Ter Laak et al., 2005).

Studies showed that pharmaceuticals that do not have functional groups (e.g., $-\mathrm{OH},-$ $\mathrm{COOH}$, or $-\mathrm{NH}_{2}$ functional groups) tend to not be charged at neutral $\mathrm{pH}$; hence, the sorption for this class of pharmaceuticals is probably caused by nonspecific sorption interactions. Several studies were conducted to assess the adsorption behaviour of estrogens on AS. Schäfer et al. (2002) showed that in the concentration range of 5-500 ng/L radio labelled E1 and E2, adsorption to AS was linear. Mes (2007) also indicated that the adsorption percentage is dependent on the biomass concentration. Another study showed that in wastewater, containing SS concentration of $2-5 \mathrm{~g} / \mathrm{L}$, spiked with radio labelled EE2, only $20 \%$ of EE2 remained in the aqueous phase after one hour, when $20 \%$ mineralisation was observed, concluding that $60 \%$ was bound to the sludge (Layton et al., 2000). Zhao et al. (2008) studied the sorption of BPA by aerobic AS, and showed that the sorption could be well described by both Freundlich and linear models. Increasing mixed liquor suspended solids (MLSS) concentration or temperature decreased the BPA sorption on the sludge and the sorption of BPA was mainly a physical process. The studies showed that the 4-n-NP and TCS are significantly sorbed on the suspended solids, 


\section{P a g e $\mid \mathbf{4 2}$}

while BPA was sorbed to a lesser extent. Clara et al. (2004) studied the adsorption of BPA, E2, and EE2 to activated and inactivated sludge from WWTPs and found that within a contact time of $24 \mathrm{~h}$, no difference between the adsorption to activated and inactivated sludge could be detected.

In published studies dealing with MCs sorption in sludge, mixed liquor has been considered as a two-compartment system, corresponding to two states for MCs: sorbedto-particles and aqueous (Carballa et al., 2008; Dionisi et al., 2006). MCs sorption equilibria in environmental samples including sludge are often modelled by Freundlich isotherms with a Freundlich coefficient close to 1, which is equivalent to a linear isotherm (Arias-Estévez et al., 2007; Hung et al., 2004). As a consequence, the equilibrium of sorption to particles is usually assumed to fit linear equations (Dionisi et al., 2006; Kasprzyk-Hordern et al., 2008) as well as the equilibrium of sorption to dissolved/colloidal matter (DCM) (Barret et al., 2010a; Zhou et al., 2007). Although some studies showed that enhanced coagulation could remove MCs by 20-70 percent (Lai et al., 2000) where the main removal mechanism is sorption of MCs onto coagulant surface, adsorption kinetics to inorganic SS have only been modeled using $\mathrm{K}_{\mathrm{ow}}$ and $\mathrm{K}_{\mathrm{d}}$ values and not coupled with different MCs fate models in recent studies.

A majority of published models for the environmental fate of MCs assume that equilibrium is reached instantaneously between sorbed and dissolved MCs. Some studies proposed a general model with sorption-desorption dynamic processes (Lai et al., 2000; 


\section{P a g e $\mid \mathbf{4 3}$}

Lindblom et al., 2009) where different stages have been suggested in this process: the first stage or rapid mixing, the second stage which is decrease in sorption due to gradual exhaustion of binding sites and desorption of MCs into the aqueous phase as a last stage. Based on these studies, it is found that sorption depends on the total concentration of solids, $\mathrm{X}_{\mathrm{T}}$ before equilibrium is established, in contrast when the equilibrium between sludge and water phase for dissolved compounds exists, e.g., due to longer SRT compared to HRT in AS systems, only newly generated sludge is available as active sites for sorption.

Many studies dealing with emerging contaminates focus only on adsorption and biosorption of MCs to active and non-active AS by measuring the MCs concentration in the liquid phase (Clara et al., 2004; Feng et al., 2010; Seyhi et al., 2011), only in the last few years researchers started to study the change of MCs concentration in the solid phase at very low concentrations (Nie et al., 2009; Stevens-Garmon et al., 2011; Zhao et al., 2008). Furthermore, although the solid concentration in AS systems, as an active binding site to MCs, showed evident effect on sorption isotherm in the literature (Barret et al., 2010b; Zhao et al., 2008), however in these studies solid concentrations in batch reactors were mostly prepared by diluting the MLSS to desired concentrations and the effect of biomass characteristics such as morphology of the biomass, the floc size, shape and density of AS at different SRTs were mainly ignored. 
P a g e $\mid \mathbf{4 4}$

\subsection{Biodegradation Studies Review}

Biodegradability of MCs will depend on their bioavailability, i.e. the potential of microorganisms to interact with them, which is related to the solubility of trace pollutants in the aqueous phase (in general very low), but also on the chemical structure of the compound. In this way, complex structures or toxic groups will make the breaking down of molecules more difficult. In order to have a measurement of the degree of biodegradability of MCs, the kinetic constant $\left(\mathrm{K}_{\mathrm{m}}\right)$ can be experimentally determined. As a consequence of the very low substrate concentrations, the approach commonly used to model the kinetic behaviour of MCs is pseudo-second-order degradation (Joss et al., 2006) with direct proportionality of the transformation rate to the soluble substance concentration, as well as to the sludge concentration, although in a system operated under steady-state conditions the sludge concentration can be considered as constant. According to Joss et al.'s study, three groups were identified related to their degradation constants $\mathrm{K}_{\mathrm{m}}$ : a) compounds with $\mathrm{K}_{\mathrm{m}}<0.1 \mathrm{~L} / \mathrm{g} \mathrm{SS}$.d are not removed to a significant extent ( $<20 \%$ ), b) compounds with $K_{m}>10 \mathrm{~L} / \mathrm{g}$ SS.d are transformed by $>90 \%$, and c) compounds with $\mathrm{K}_{\mathrm{m}}$ between 0.1-10 L/g SS.d have moderate removal.

Suárez et al. (2008a) studied the relationship between HRT, SRT, $K_{d}$, and $K_{m}$ and they suggested that those compounds that have high pseudo-second-order biodegradation kinetic constant and low $\mathrm{K}_{\mathrm{d}}$ values such as BPA are efficiency transformed independently of HRT or SRT. Compounds with low $\mathrm{K}_{\mathrm{m}}$ and high $\mathrm{K}_{\mathrm{d}}$ values are retained mostly in the 


\section{P a g e $\mid \mathbf{4 5}$}

bioreactor by sorption and biotransformed at sufficient SRT. Compounds that have low or medium $\mathrm{K}_{\mathrm{m}}$ and medium $\mathrm{K}_{\mathrm{d}}$ values, such as EE2, are moderately transformed independently of HRT and slightly dependent on SRT, and finally, compounds that have low $\mathrm{K}_{\mathrm{m}}$ and $\mathrm{K}_{\mathrm{d}}$ values, such as carbamazepine, remain untreated and unchanged, regardless of SRT or HRT of the system. Based on high $\mathrm{K}_{\mathrm{d}}$ and $\mathrm{K}_{\mathrm{m}}$ values of TCS, Singer et al. (2002) reported that approximately $79 \%$ of TCS in wastewater was biodegraded; $15 \%$ was sorbed into biosolids, and $6 \%$ was released into the receiving water bodies. Several studies have reported removal of TCS by different biological treatment processes (Kanda R Fau - Griffin et al., 2003), including AS (Federle et al., 2002), rotating biological contactors and trickling filters (Thompson et al., 2005). Unlike TCS, greater than $90 \%$ of removal has been reported for BPA (Staples et al., 1998a) and its metabolites (Buser et al., 1999). Samaras et al. (2013) studied the biodegradation of BPA, NP and TCS and found that $85 \%$ of BPA and $81 \%$ of TCS were removed due to biotransformation process, while NP was biologically transformed to a lesser degree (up to $56 \%$ ) in two WWTPs using activated sludge.

The factors affecting the biodegradation of MCs and the removal performance of different bioreactors were also studied in the literature (Luo et al., 2014). It was found that compounds such as naproxen were not removed in conventional WWTPs, while membrane bioreactor (MBR) treatment led to their elimination (Kimura et al., 2007). It was assumed that the poor removal in conventional activated sludge (CAS) is due to their 


\section{P a g e $\mid \mathbf{4 6}$}

complex molecules including two aromatic rings that make these compounds more resistant to degradation processes. Radjenovic et al. (2009) showed that MBR systems effectively remove MCs including those that are resistant to activated sludge processes. Similar results were found by Spring et al. (2007) and they concluded that the ability of MBR system to retain sludge, the membrane surface and the longer SRT in MBRs may promote microbial degradation of the MCs. Full-scale MBR system also showed high elimination (> 90\%) of MCs (Beier et al., 2011; Trinh et al., 2012). Nevertheless, some compounds such as carbamazepine, diazepam, diclofenac, fluoxetine, gemfibrozil were incompletely removed (24-68\%). Kovalova et al. (2012) investigated the removal of pharmaceuticals at a pilot-scale MBR to treat hospital effluent and indicated that the large fraction $(80 \%)$ of the influent was persistent on iodinated contrast media.

Cirja et al. (2007) has studied the removal of some MCs based on their chemical structure and proposed three classifications for PPCPs, a) those that are easily removed by both CAS and MBR, b) compounds which are not efficiently removed in both systems and c) compounds that are not satisfactorily removed by CAS but well removed by MBR. Burgess et al. (2005) showed that the bioavailability of the organic pollutants in aqueous environment is influenced by the presence of different forms of organic carbon like cellulose or humic acids.

Cirja et al. (2007) reported that the removal of MCs from wastewater could be varied when acidity or alkalinity of the aqueous environment is different. Some studies showed 


\section{P a g e $\mid \mathbf{4 7}$}

that depending on the $\mathrm{pK}_{\mathrm{a}}$ values, pharmaceuticals could exist in various protonation states because of $\mathrm{pH}$ variation in the aquatic environment. Therefore some researchers such as Cirja et al. (2007) suggested that the control of $\mathrm{pH}$ value might be a solution for the removal of MCs in WWTPs.

HRT is the amount of time that MCs are in contact with biomass; therefore, it affects the biodegradation and sorption process. Fernandez-Fontaina et al. (2012) suggested that those MCs with slow/intermediate kinetics will experience less effective biodegradation at shorter HRTs. Huang et al. (2008) also found minor removal of MCs at HRT range of 5 to $14 \mathrm{~h}$, while higher HRT increased MCs accumulation in the waste sludge. Kirk et al. (2002) reported high removal efficiency of E1, E2 and EE2 when HRT increased from 25 to $13 \mathrm{~h}$ at UK WWTPs. In contrast, Servos et al. (2005) found no statistical correlation $\left(\mathrm{r}^{2}<0.53\right)$ between HRT or SRT and hormone or estrogenicity removal for nine conventional secondary plants and three tertiary plants in Canada. Gros et al. (2007) studied the removal efficiency of different groups of MCs in 6 WWTPs with AS systems of different HRTs in Spain and found that the plants with the highest HRTs (25-33 h) have the highest removal efficiency, while plants with an HRT of $8 \mathrm{~h}$ had no or poor removal of most of the selected compounds.

Temperature variation can also play an important role for biodegradation, sorption and volatilization of MCs. Temperature influences the solubility and other physicochemical properties of MCs as well as the ecology of the bacterial community. Vieno et 


\section{P a g e $\mid \mathbf{4 8}$}

al. (2006) reported that the removal of MCs, i.e. ibuprofen, was higher during the summer time when the temperature reached $17^{\circ} \mathrm{C}$ in comparison to the winter season when temperature was $7^{\circ} \mathrm{C}$. Generally, higher MCs removal rate was observed at warmer temperature due to promoted microbial activities (Nie et al., 2012; Qiang et al., 2013). However, high temperature levels $\left(45^{\circ} \mathrm{C}\right)$ could lead to lower MCs removal due to disrupted metabolic activity at such an elevated temperature (Hai et al., 2011). On the other hand, Suarez et al. (2010) showed that MCs elimination is independent of temperature fluctuation. Effects of temperature variation were explored in a lab-scale MBR treating wastewater containing selected MCs (Hai et al., 2011).

In AS systems, biodegradation and biotransformation are possible only by microorganisms that could reproduce themselves during the designed SRT (Zhang et al., 2008). Long SRT will increase the diversity of the microorganisms by increasing the diversification of the microbial community or by diversification of the available enzymes within the microbial community (Clara et al., 2005a). It was proposed that at short SRT $(<8$ d) slowly growing bacteria are removed from the system and in this case, the biodegradation is less significant and adsorption to sludge will be more important (Jacobsen et al., 1993). Wick et al. (2009) found higher removal of beta blockers and psycho-activate drugs in AS system operating at SRT of $18 \mathrm{~d}$ compared to the same treatment with shorter SRT of $12 \mathrm{~h}$. Higher SRT also showed $10 \%$ higher removal efficiency for fluoxetine, citalopram and ethinylestradiol (Suarez et al., 2010). Stasinakis 


\section{P a g e $\mid \mathbf{4 9}$}

et al. (2010) investigated the removal of MCs in reactors operating at SRTs of 3, 10, and $20 \mathrm{~d}$ and found enhanced biodegradation for NP and TCS at SRT of $20 \mathrm{~d}$.

Ternes et al. (2004b) investigated the effect of SRT on MCs removal and reported that SRTs of 5-15 days are required for biological transformation of benzafibrate, sulfamethoxazole, ibuprofen, and acetylsalicylic acid. In another study, Clara et al. (2005a) found that the critical SRT of 10 days is required for removal of BPA, benzafibrate, and natural estrogens. Koh et al. (2008) stated that sludge loading is a key parameter influencing the removal of estrogens from WWTPs. He suggested that microorganisms prefer to degrade other organic compounds over estrogens. Therefore, researchers proposed that reactor cascade provide better E1 and E2 removal rates than a completely stirred tank (Joss et al., 2004b). In contrast, some researchers showed that no noticeable effects on removal efficiency of the targeted MCs by varying the sludge age between 10 and 60-80 d (Joss et al., 2005). Stasinakis et al. (2010) also found no removal enhancement of BPA at reactor operating at SRT of $20 \mathrm{~d}$.

Ammonia oxidizing bacteria (AOB) can co-metabolize MCs as well as the slow growing bacteria. However, there are limited and debatable information on the role of autotrophs on MCs biodegradation in AS systems operating at different SRTs (Larcher and Yargeau, 2013; Zhou and Oleszkiewicz, 2010). It was concluded that the AOB are responsible for the degradation of estrone, estradiol, and ethinylestradiol (Ren et al., 2007). Some studies also reported some MCs and EDCs could have higher removal in 


\section{P a g e $\mid \mathbf{5 0}$}

nitrifying AS (Kreuzinger et al., 2004). Natural estrogens are thought to be biodegraded via a pathway where bacteria can use the conversion for growth, as EE2 is thought to be biodegraded by co-metabolism, in which an organic compound is modified but not utilised for bacterial growth (Vader et al., 2000). Nitrifying sludge is shown to be responsible for biotrasforming EE2 due to use of enzyme ammonium monooxygenase, which insert oxygen into C-H bonds. Vader et al. (2000) showed that the AOB transformed EE2 to more hydrophilic metabolites in about six days, while EE2 was not degraded when sludge with a very low nitrifying capacity was used. There is limited information on the role of autotrophs in MCs biodegradation. Nitrifier-enriched AS was used in batch degradation of BPA to investigate the effect of ammonia oxidizing bacteria, AOB (Kim et al., 2007). It was observed that BPA concentration was decreased with the oxidation of ammonium to nitrate by nitrifying sludge. However, in presence of nitrification inhibitors, allylthiourea (ATU), BPA reduction decreased significantly. Gaulke et al. (2008) suggested that EE2 at high concentration (mg/L) is co-metabolically degraded by AOB but EE2 removal at low concentration found in municipal conventional AS systems is not due to co-metabolic degradation by AOB, or to abiotic nitration, but most likely due to heterotrophic bacteria. This result was also verified by other authors (Racz et al., 2012; Zhou and Oleszkiewicz, 2010). In contrast, Khunjar et al. (2011) studied the role of $\mathrm{AOB}$ versus heterotrophic bacteria during biotransformation of EE2 and showed that AOB activity was an important contributor towards EE2 biodegradation 


\section{$P$ a g e $\mid \mathbf{5 1}$}

and the metabolites formed by AOBs during EE2 biodegradation can be mineralized by heterotrophic cultures.

Lee et al. (1998) studied biodegradation of sorbed MCs and they suggested that the adsorption to solid phase might not decrease the biodegradability of the compounds when the sorbing surface is the biomass itself. Drewes et al. (2005) studied the removal of BPA and EE2 in WWTPs and concluded that their removal rates are dependent on the total mass of EE2 and BPA and is strongly correlated with the biochemical oxygen demand (BOD) loading and the SRT. Many researchers dealing with MCs assume that the degradation only happens in the liquid phase (Lindblom et al., 2009; Plosz et al., 2010; Pomiès et al., 2013). Although there are some studied that suggests dissolved and sorbed MCs could be biodegraded with different or same rates (Byrns, 2001; Cowan et al., 1993;

Lee et al., 1998; Urase and Kikuta, 2005); but these authors considered biodegradation of the sorbed MCs based only on successful calibration of a mathematical model, or indirect experimental observations, and these assumptions are poorly justified experimentally

Biodegradation of the selected MCs has been reported by mixed cultures in WWTPs (Kanda R Fau - Griffin et al., 2003; Thompson et al., 2005). Weber et al. (2005) found that almost $100 \%$ of EE2 can be removed by using a mixed culture of microbes $(A$. xylosoxidans and Ralstonia picketii). Moreover, bacteria, such as Sphingomonas strain KC8, Novosphingobium tardaugens (ARI-1), Rhodococcus zopfii, Rhodococcus equi, 


\section{P a g e $\mid \mathbf{5 2}$}

Proteobacteria, Actinobacteria, and Bacteroidetes, were found to degrade estrogenic compounds at STPs (Roh and Chu, 2010; Yu et al., 2011b).

Inhibition effect of some MCs on AS biomass was also reported in the literature. Pasquini et al. (2013) reported that TCS altered the bacterial growth at concentrations measured in wastewater by investigating the toxicity of TCS on E. coli and comparing EPS production in reactors with and without MCs addition. In contrast, other studies reported no deterioration of AS systems performance in the presence of TCS at low $\mu \mathrm{g} / \mathrm{L}$ concentration (Federle et al., 2002; Stasinakis et al., 2010).

\subsection{Biodegradation Kinetics Models for MCs in AS Systems}

Modeling of AS systems has made dramatic strides in the " 80 s and '90s with the development of IWA's AS models (ASMs). Table 2-2 presents the Peterson matrix for a model that is similar to the IWA's ASM1 (developed in the 80s) which forms the backbone of many other models for the AS process.

Table 2-2 Model of the AS Process for Carbon Removal

\begin{tabular}{|l|l|l|l|l|l|l|l|l|}
\hline Component $\rightarrow$ & $\mathrm{i}$ & 1 & 2 & 3 & 4 & 5 & 6 & Process Rate, $r_{\mathrm{j}}$ \\
\hline $\mathrm{j}$ & Process $\downarrow$ & $\mathrm{S}_{\mathrm{I}}$ & $S_{\mathrm{S}}$ & $X_{\mathrm{I}}$ & $X_{\mathrm{S}}$ & $X_{\mathrm{H}}$ & $S_{\mathrm{O}}$ & {$\left[\mathrm{ML}^{-3} \mathrm{~T}^{-1}\right]$} \\
\hline 1 & $\begin{array}{l}\text { Hydrolysis of } \\
\text { particulate organics }\end{array}$ & & 1 & & -1 & & & $\mathrm{k}_{\mathrm{h}} X_{\mathrm{S}}$ \\
\hline 2 & $\begin{array}{l}\text { Aerobic growth of } \\
\text { heterotrophs }\end{array}$ & $-\frac{1}{Y_{\mathrm{H}}}$ & & & 1 & $\frac{1-Y_{\mathrm{H}}}{Y_{\mathrm{H}}}$ & $\frac{\mu_{\mathrm{Hm}} S_{\mathrm{S}}}{K_{\mathrm{S}}+S_{\mathrm{S}}} X_{\mathrm{H}}$ \\
\hline 3 & $\begin{array}{l}\text { Decay of } \\
\text { heterotrophs }\end{array}$ & & $f_{\mathrm{XI}}$ & & -1 & $1-f_{\mathrm{XI}}$ & $b_{\mathrm{H}} X_{\mathrm{H}}$ \\
\hline
\end{tabular}




\section{P a g e $\mid \mathbf{5 3}$}

where $S_{I}$ is inert soluble COD $(\mathrm{mg} / \mathrm{L}), S_{S}$ is degradable soluble COD $(\mathrm{mg} / \mathrm{L}), X_{\mathrm{I}}$ is $\mathrm{nbd}$ particulate COD $(\mathrm{mg} / \mathrm{L}), X_{S}$ is degradable particulate organics $(\mathrm{mg} \mathrm{COD} / \mathrm{L}, \mathrm{mg} \mathrm{BOD} / \mathrm{L}), \mathrm{X}_{\mathrm{H}}$ is heterotrophs biomass $(\mathrm{mg} / \mathrm{L}), \mathrm{S}_{\mathrm{O}}$ is DO/DO saturation concentration $\left(\mathrm{mg} \mathrm{O}_{2} / \mathrm{L}\right), \mathrm{k}_{\mathrm{h}}$ is hydrolysis rate coefficient $\left(\mathrm{h}^{-1}, \mathrm{~g}\right.$ BOD/gTSS/h), $\mathrm{b}_{\mathrm{H}}$ is endogenous decay (lysis) coefficient of heterotrophy bacteria $\left(h^{-1}\right), Y_{H}$ is yield factor and $f_{X I}$ is fraction of non-biodegradable particulate COD released in biomass decay.

Biodegradation of $\mathrm{MCs}$ varies with respect to compounds properties, type of biological system designed to remove MCs and operating condition of that system. Biodegradation occurs in the aeration basin in AS systems and is governed by degradation kinetics. There are many different model formulations that have been found to fit biodegradation data for MCs in an AS treatment plant, e.g., zero-order, first-order, pseudo-first order or mixed second-order kinetics or various types of growth-based Monod or Haldane model formulations. A number of different approaches for modeling biological MC degradation in WWTPs found in the literature are presented in (Banihashemi and Droste, 2011) and are shown in Table 2-3.

Possible biological rate and growth rate formulations are also presented in Tables 2-4 and 2-5. The simplest zero- and first-order models assume that, for a given HRT, a fixed fraction of the micropollutant in the influent is removed independently of other water quality variables. In a zero-order reaction model, the removal rate is independent of the influent concentration while in the first-order case it is not. More commonly used models are first-order formulations dependent only on the liquid phase concentration of chemical or apparent first-order formulation where degradation occurs in both the soluble and sorbed phases. It was found that the amount of chemical available for biodegradation 
P a g e $\mid \mathbf{5 4}$

must be equal to the total amount of chemical in the reactor and not just the dissolved fraction (Cowan et al., 1993).

Table 2-3 Zero-, first- and pseudo first-order models for biological degradation of MCs found in the literature.

\begin{tabular}{|c|c|c|c|}
\hline Process & Type of process & Removal rate & Reference \\
\hline 1 & Zero-order & $\mathrm{K}_{\mathrm{m}}$ & \\
\hline 2 & First-order & $\mathrm{K}_{\mathrm{m}} \mathrm{C}$ & $\begin{array}{l}\text { (Shen et al., 2007);(Shi et al., 2004); (Li et } \\
\text { al., 2005); (Zhao et al., 2008); (Helbling et } \\
\text { al., 2012); (Zhou and Oleszkiewicz, 2010) }\end{array}$ \\
\hline 3 & First and pseudo-order & $\mathrm{K}_{\mathrm{m}} \mathrm{C}\left(1+\mathrm{K}_{\mathrm{d}} \mathrm{X}_{\mathrm{V}}\right)$ & (Shen et al., 2007); (Lindblom et al., 2009) \\
\hline $4 \mathrm{a}$ & Two first-order & $\mathrm{K}_{\mathrm{ms}} \mathrm{C}+\mathrm{K}_{\mathrm{mp}} \mathrm{X}_{\mathrm{v}}$ & (Cowan et al., 1993); (Byrns, 2001) \\
\hline $5 \mathrm{a}$ & Pseudo second-order & $\mathrm{K}_{\mathrm{m}} \mathrm{X}_{\mathrm{v}} \mathrm{C}$ & $\begin{array}{l}\text { (Stasinakis et al., 2010); (Kumar et al., } \\
\text { 2009); (Ziels et al., 2014); (Tan et al., } \\
\text { 2007); (Plosz et al., 2010); (Fernandez- } \\
\text { Fontaina et al., 2013); (Suarez et al., 2012) }\end{array}$ \\
\hline 5 & Pseudo second-order & $\mathrm{K}_{\mathrm{m}} \mathrm{X}_{\mathrm{T}} \mathrm{C}$ & $\begin{array}{l}\text { (Joss et al., 2006); (Press-Kristensen et al., } \\
\text { 2007); (Wick et al., 2009); (Maurer et al., } \\
\text { 2007); (Xue et al., 2010); (Abegglen et } \\
\text { al., 2009); }\end{array}$ \\
\hline $5 b$ & Pseudo second-order & $\mathrm{K}_{\mathrm{m}} \mathrm{X}_{\mathrm{H}} \mathrm{C}$ & $\begin{array}{l}\text { (Jacobsen and Arvin, 1996), (Majewsky et } \\
\text { al., 2011); (Plósz et al., 2012) }\end{array}$ \\
\hline $5 \mathrm{c}$ & Pseudo second-order & $\mathrm{K}_{\mathrm{m}} \mathrm{X}_{\mathrm{C}} \mathrm{C}$ & (Govind et al., 1991), (Lee et al., 1998) \\
\hline 6 & Haldane Model & $\begin{array}{l}\left(\mathrm{K}_{\mathrm{m}} \mathrm{X}_{\mathrm{V}} \mathrm{C}\right) \\
/\left(\mathrm{C}+\mathrm{K}_{\mathrm{s}}+\mathrm{C}^{2} / \mathrm{K}_{1}\right)\end{array}$ & (Tomei et al., 2008) \\
\hline 7 & Monod Model & $\mathrm{K}_{\mathrm{m}} \mathrm{C} /\left(\mathrm{C}+\mathrm{K}_{\mathrm{s}}\right)$ & $\begin{array}{l}\text { (Marfil-Vega et al., 2010); (Lee do et al., } \\
\text { 2012) }\end{array}$ \\
\hline
\end{tabular}

where $K_{m}$ is biodegradation rate coefficient; $C$ is concentration of dissolved $\mathrm{MC}(\mathrm{mg} / \mathrm{L})$; $X_{\mathrm{v}}$ is volatile SS concentration $(\mathrm{mg} / \mathrm{L}) ; X_{\mathrm{T}}$ is total concentration of solids $(\mathrm{mg} / \mathrm{L}) ; \mathrm{X}_{\mathrm{H}}$ is concentration of heterotroph biomass $(\mathrm{mg} / \mathrm{L}) ; X_{\mathrm{C}}$ is concentration of specific $\mathrm{MC}$ degraders $(\mathrm{mg} / \mathrm{L}) ; \mathrm{K}_{\mathrm{S}}$ is halfvelocity constant for soluble degradable substrate $(\mathrm{mg} / \mathrm{L})$ and $\mathrm{K}_{\mathrm{I}}$ is an inhibition constant.

The pseudo-second order expression takes into account mixed liquor SS (MLSS) and thus distinguishes between, e.g., an AS reactor (high MLSS) and an aerated lagoon (low MLSS). On the other hand, using these models would lead to a linear increase in the 
removal rate with the SS concentration independent of the sludge activity, but only active biomass can degrade substrates; therefore, it is recommended that studies incorporate active mass instead of MLSS or mixed liquor volatile suspended solids (MLVSS) in their formulations. Most studies do not report sufficient information to relate models or rate coefficients to active biomass; furthermore, assumptions are often not experimentally verified. Consequently only limited normalization is possible with reported data. It is further recommended that a national database be constructed where all pertinent experimental information is provided along with the biodegradation rate coefficient for each compound. Further consideration of possible degradation mechanisms and kinetics leads to the possible models given in Table 2-5.

Table 2-4 Growth kinetic models of biomass with substrate inhibition

\begin{tabular}{|l|l|}
\hline Haldane: & $\mu=\frac{\mu_{C m} C}{K_{C}+C+C^{2} / K_{I}}$ \\
\hline Andrews and Noack: & $\mu=\frac{\mu_{C m} C}{K c+\frac{K_{C}}{C}+\frac{C}{K_{I}}}$ \\
\hline Webb: & $\mu=\frac{\mu_{C m} S\left(1+\frac{C}{K}\right)}{C+K_{C}+C^{2} / K_{I}}$ \\
\hline Yano: & $\mu=\frac{\mu_{C m} C}{C+K_{C}+C^{2} / K_{I}\left(1+\frac{C}{K}\right)}$ \\
\hline Alba: & $\mu=\frac{\mu_{C m} \exp \left(-\frac{C}{K_{I}}\right)}{C+K_{C}}$ \\
\hline Tessier: & $\mu=\mu_{C m}\left[\exp \left(-\frac{C}{K_{I}}\right)-\exp \left(-\frac{C}{K}\right)\right]$ \\
\hline
\end{tabular}

where $\mu_{\mathrm{Cm}}$ is maximum growth rate of MC degrading biomass $\left(\mathrm{d}^{-1}\right) ; \mathrm{K}_{\mathrm{C}}$ is the half-velocity coefficient for MC degrading biomass ( $\mathrm{mg} / \mathrm{L}) ; \mathrm{S}$ is substrate concentration $(\mathrm{mg} / \mathrm{L})$. 
Table 2-5 Possible Rate Formulations for biological degradation of MCs

\begin{tabular}{|c|c|c|}
\hline No. & Model (r) & \\
\hline 1 & $\mathrm{~K}_{\mathrm{m}}$ & $\begin{array}{l}\text { Zero-order model, decay is independent of concentrations of biomass and the } \\
\text { chemical }\end{array}$ \\
\hline 2 & $\mathrm{~K}_{\mathrm{m}} \mathrm{C}$ & $\begin{array}{l}\text { First-order degradation independent of biomass concentration and only } \\
\text { applies to dissolved chemical }\end{array}$ \\
\hline $3 a$ & $\mathrm{~K}_{\mathrm{m}} \mathrm{C}\left(1+\mathrm{K}_{\mathrm{d}} \mathrm{X}_{\mathrm{V}}\right)$ & First-order but chemical decays in both the soluble and solid phases \\
\hline $3 b$ & $\mathrm{~K}_{\mathrm{m}} \mathrm{C}\left(1+\mathrm{K}_{\mathrm{d}} \mathrm{X}_{\mathrm{H}}\right)$ & $\begin{array}{l}\text { First-order but chemical decays in both the soluble and solid phases; }\left(\mathrm{X}_{\mathrm{I}}+\right. \\
\left.\mathrm{X}_{\mathrm{S}}\right) \text { is not subject to microbial attack }\end{array}$ \\
\hline $4 \mathrm{a}$ & $\mathrm{K}_{\mathrm{ms}} \mathrm{C}+\mathrm{K}_{\mathrm{mp}} \mathrm{K}_{\mathrm{d}} \mathrm{X}_{\mathrm{V}} \mathrm{C}$ & $\begin{array}{l}\text { First-order decay in both liquid and solid phases but different rate } \\
\text { coefficients }\end{array}$ \\
\hline $4 \mathrm{~b}$ & $\mathrm{~K}_{\mathrm{ms}} \mathrm{C}+\mathrm{K}_{\mathrm{mp}} \mathrm{K}_{\mathrm{d}} \mathrm{X}_{\mathrm{H}} \mathrm{C}$ & $\begin{array}{l}\text { First-order decay in both liquid and solid phases but different rate } \\
\text { coefficients; }\left(X_{I}+X_{S}\right) \text { is not subject to microbial attack }\end{array}$ \\
\hline $5 \mathrm{a}$ & $\mathrm{K}_{\mathrm{m}} \mathrm{X}_{\mathrm{V}} \mathrm{C}$ & Mixed second-order with degradation only in the soluble phase \\
\hline $5 b$ & $\mathrm{~K}_{\mathrm{m}} \mathrm{X}_{\mathrm{H}} \mathrm{C}$ & $\begin{array}{l}\text { Mixed second-order with degradation by active heterotrophs only in the } \\
\text { soluble phase }\end{array}$ \\
\hline $5 \mathrm{c}$ & $\mathrm{K}_{\mathrm{m}} \mathrm{X}_{\mathrm{C}} \mathrm{C}$ & $\begin{array}{l}\text { Mixed second-order with degradation by active MCs degraders only in the } \\
\text { soluble phase }\end{array}$ \\
\hline $6 \mathrm{a}$ & $\mathrm{K}_{\mathrm{m}} \mathrm{X}_{\mathrm{V}} \mathrm{C}\left(1+\mathrm{K}_{\mathrm{d}} \mathrm{X}_{\mathrm{V}}\right)$ & Mixed second-order with degradation in both the soluble and solid phases \\
\hline $6 \mathrm{~b}$ & $\mathrm{~K}_{\mathrm{m}} \mathrm{X}_{\mathrm{H}} \mathrm{C}\left(1+\mathrm{K}_{\mathrm{d}} \mathrm{X}_{\mathrm{V}}\right)$ & $\begin{array}{l}\text { Mixed second-order with degradation by active heterotrophs in both the } \\
\text { soluble and solid phases }\end{array}$ \\
\hline $6 \mathrm{c}$ & $\mathrm{K}_{\mathrm{m}} \mathrm{X}_{\mathrm{C}} \mathrm{C}\left(1+\mathrm{K}_{\mathrm{d}} \mathrm{X}_{\mathrm{V}}\right)$ & $\begin{array}{l}\text { Mixed second-order with degradation by active MCs degraders in both the } \\
\text { soluble and solid phases }\end{array}$ \\
\hline $7 \mathrm{a}$ & $\begin{array}{l}\mathrm{K}_{\mathrm{ms}} \mathrm{X}_{\mathrm{V}} \mathrm{C}+ \\
\mathrm{K}_{\mathrm{mp}} \mathrm{X}_{\mathrm{V}} \mathrm{K}_{\mathrm{d}} \mathrm{X}_{\mathrm{V}} \mathrm{C}\end{array}$ & $\begin{array}{l}\text { Mixed second-order with degradation in both the soluble and solid phases } \\
\text { with different rate coefficients in each phase. }\end{array}$ \\
\hline $7 b$ & $\begin{array}{l}\mathrm{K}_{\mathrm{mS}} \mathrm{X}_{\mathrm{H}} \mathrm{C} \\
+\mathrm{K}_{\mathrm{mp}} \mathrm{X}_{\mathrm{H}} \mathrm{K}_{\mathrm{d}} \mathrm{X}_{\mathrm{V}} \mathrm{C}\end{array}$ & $\begin{array}{l}\text { Mixed second-order with degradation in both the soluble and solid phases } \\
\text { with different rate coefficients for active heterotrophs in each phase }\end{array}$ \\
\hline $7 \mathrm{c}$ & $\begin{array}{l}\mathrm{K}_{\mathrm{ms}} \mathrm{X}_{\mathrm{C}} \mathrm{C} \\
+\mathrm{K}_{\mathrm{mp}} \mathrm{X}_{\mathrm{C}} \mathrm{K}_{\mathrm{d}} \mathrm{X}_{\mathrm{V}} \mathrm{C}\end{array}$ & $\begin{array}{l}\text { Mixed second-order with degradation in both the soluble and solid phases } \\
\text { with different rate coefficients foe active MCs degraders in each phase }\end{array}$ \\
\hline 8 & $\mathrm{~K}_{\mathrm{m}} \mathrm{X}_{\mathrm{H}} \mathrm{C}\left(1+\mathrm{K}_{\mathrm{d}} \mathrm{X}_{\mathrm{H}}\right)$ & $\begin{array}{l}\text { Chemical sorbed to inert particulates; }\left(X_{I}+X_{S}\right) \text { is not subject to microbial } \\
\text { attack }\end{array}$ \\
\hline 9 & $\begin{array}{l}\mathrm{K}_{\mathrm{ms}} \mathrm{X}_{\mathrm{H}} \mathrm{C}+ \\
\mathrm{K}_{\mathrm{mp}} \mathrm{X}_{\mathrm{H}}^{2} \mathrm{~K}_{\mathrm{d}} \mathrm{C}\end{array}$ & $\begin{array}{l}\text { Chemical sorbed to inert particulates }\left(X_{I}+X_{S}\right) \text { is not subject to microbial } \\
\text { attack. Degradation in both the soluble and solid phases with different rate } \\
\text { coefficients in each phase. }\end{array}$ \\
\hline 10 & $\frac{\mathrm{K}_{\mathrm{m}} \mathrm{C}}{\mathrm{K}_{\mathrm{c}}+\mathrm{C}}$ & $\begin{array}{l}\text { Monod rate formulation independent of biomass. Only applied to the soluble } \\
\text { phase. }\end{array}$ \\
\hline
\end{tabular}




\begin{tabular}{|l|l|l|}
\hline $11 \mathrm{a}$ & $\begin{array}{l}\mathrm{K}_{\mathrm{m}} \mathrm{X}_{\mathrm{V}} \mathrm{C} \\
\mathrm{K}_{\mathrm{c}}+\mathrm{C}\end{array}$ & $\begin{array}{l}\text { Monod rate formulation dependent on VSS biomass. Only applied to the } \\
\text { soluble phase. }\end{array}$ \\
\hline $11 \mathrm{~b}$ & $\frac{\mathrm{K}_{\mathrm{m}} \mathrm{X}_{\mathrm{H}} \mathrm{C}}{\mathrm{K}_{\mathrm{c}}+\mathrm{C}}$ & $\begin{array}{l}\text { Monod rate formulation dependent on active heterotroph biomass. Only } \\
\text { applied to the soluble phase }\end{array}$ \\
\hline $11 \mathrm{c}$ & $\frac{\mathrm{K}_{\mathrm{m}} \mathrm{X}_{\mathrm{C}} \mathrm{C}}{\mathrm{K}_{\mathrm{c}}+\mathrm{C}}$ & $\begin{array}{l}\text { Monod rate formulation dependent on active MCs degraders. Only applied to } \\
\text { the soluble phase }\end{array}$ \\
\hline
\end{tabular}

(Lindblom et al., 2009) also used a specific MC biomass model shown in Table 2-6 to be coupled with ASM1 to model the degradation of BPA.

Table 2-6 Petersen matrix for specific MC degrading biomass model (Lindblom et al., 2009)

\begin{tabular}{|c|c|c|c|c|c|c|c|c|c|}
\hline \multicolumn{2}{|c|}{ Component $\rightarrow$} & I & 1 & 2 & 3 & 4 & 5 & 6 & Process Rate, \\
\hline $\mathrm{j}$ & \multicolumn{2}{|l|}{ Process $\downarrow$} & $C$ & $C_{\mathrm{ps}}$ & $X_{\mathrm{I}}$ & $X_{\mathrm{S}}$ & $X_{\mathrm{C}}$ & $S_{\mathrm{O}}$ & {$\left[\mathrm{ML}^{-3} \mathrm{~T}^{-1}\right]$} \\
\hline 1 & \multicolumn{2}{|c|}{ Hydrolysis of particulate organics } & & & & -1 & & & $\mathrm{k}_{\mathrm{h}} X_{\mathrm{S}}$ \\
\hline 2 & \multicolumn{2}{|c|}{ Aerobic growth of MC biomass } & $-\frac{1}{Y_{\mathrm{C}}}$ & & & & 1 & $\frac{1-Y_{C}}{Y_{\mathrm{C}}}$ & $\frac{\mu_{\mathrm{Hm}} C}{K_{\mathrm{C}}+C} X_{\mathrm{C}}$ \\
\hline 3 & \multicolumn{2}{|c|}{ Decay of MC biomass } & & & $f_{\mathrm{XI}}$ & & -1 & $1-f_{\mathrm{XI}}$ & $b_{\mathrm{C}} X_{\mathrm{C}}$ \\
\hline 4 & \multicolumn{2}{|c|}{ Sorption } & -1 & 1 & & & & & $K_{d} \mathrm{X}_{\mathrm{V}} \mathrm{C}$ \\
\hline 5 & \multicolumn{2}{|l|}{ Desorption } & 1 & -1 & & & & & $K_{d e s} \mathrm{C}_{\mathrm{ps}}$ \\
\hline
\end{tabular}

where $K_{\text {des }}$ is a desorption rate coefficient $\left(\mathrm{d}^{-1}\right) ; \mathrm{K}_{\mathrm{d}}$ is a sorption rate coefficient (L/mg VSS/d); $\mathrm{Y}_{\mathrm{C}}$ is yield of biomass from metabolism of $\mathrm{MC}(-)$

In growth-based models, such as the ASMs, different biomass fractions responsible for different reactions are modeled explicitly as dynamic state variables. Not all the active biomass can degrade MCs in AS systems, so it is reasonable to assume specific microorganisms are responsible for degradation of MCs and they can be coupled with an ASM model. Studies have found that specific microorganisms may preferably degrade other substrates than MCs, e.g., that growth on easily degradable substrate might compete with degradation of MCs (Zhao et al., 2008). Therefore, a switching function should be 


\section{P a g e $\mid \mathbf{5 8}$}

used to switch off growth on MCs when easily degradable substrate concentration is high. Studies on MC removal using long SRTs suggested that nitrifying bacteria are also responsible for biodegradation or co-metabolism transformations, which leads to incorporating the nitrogenous bacteria into biodegradation kinetic models (Gaulke et al., 2008; Khunjar et al., 2011). Most of the studies in the literature were conducted at relatively high $\mathrm{MC}$ concentration and not at the environmentally relevant concentrations, which are in the range of 10 to $50 \mathrm{ng} / \mathrm{L}$ in wastewater influent. It has been found that laboratory tests using chemical concentrations greater than those found in nature may lead to erroneous conclusions about microbial transformations in nature or biotreatment systems (Alexander et al., 1988; Berg and Nyholm, 1996; Gaulke et al., 2008); therefore, it is suggested to implicate the models to low concentrations. Based on literature review new state model variables, which can be applied to ASM1 for MCs removal, are proposed (Banihashemi and Droste, 2011). Figure 2-2 shows the new model variables where $\mathrm{C}_{\mathrm{ps}}$ and $\mathrm{C}_{\mathrm{ps}}^{\prime}$ are concentrations of MCs in the solid phase at equilibrium state, $\mathrm{X}_{\mathrm{c}}$ is concentration of active MCs degrading biomass, $\mathrm{X}_{\mathrm{H}}$ is active heterotrophic biomass, $\mathrm{S}_{\mathrm{S}}$, $\mathrm{X}_{\mathrm{S}}$, and $\mathrm{X}_{\mathrm{I}}$ are concentration of substrate in terms of soluble COD, particulate COD and inert COD, respectively. In this model the sorption-desorption process was assumed as a dynamic process. 


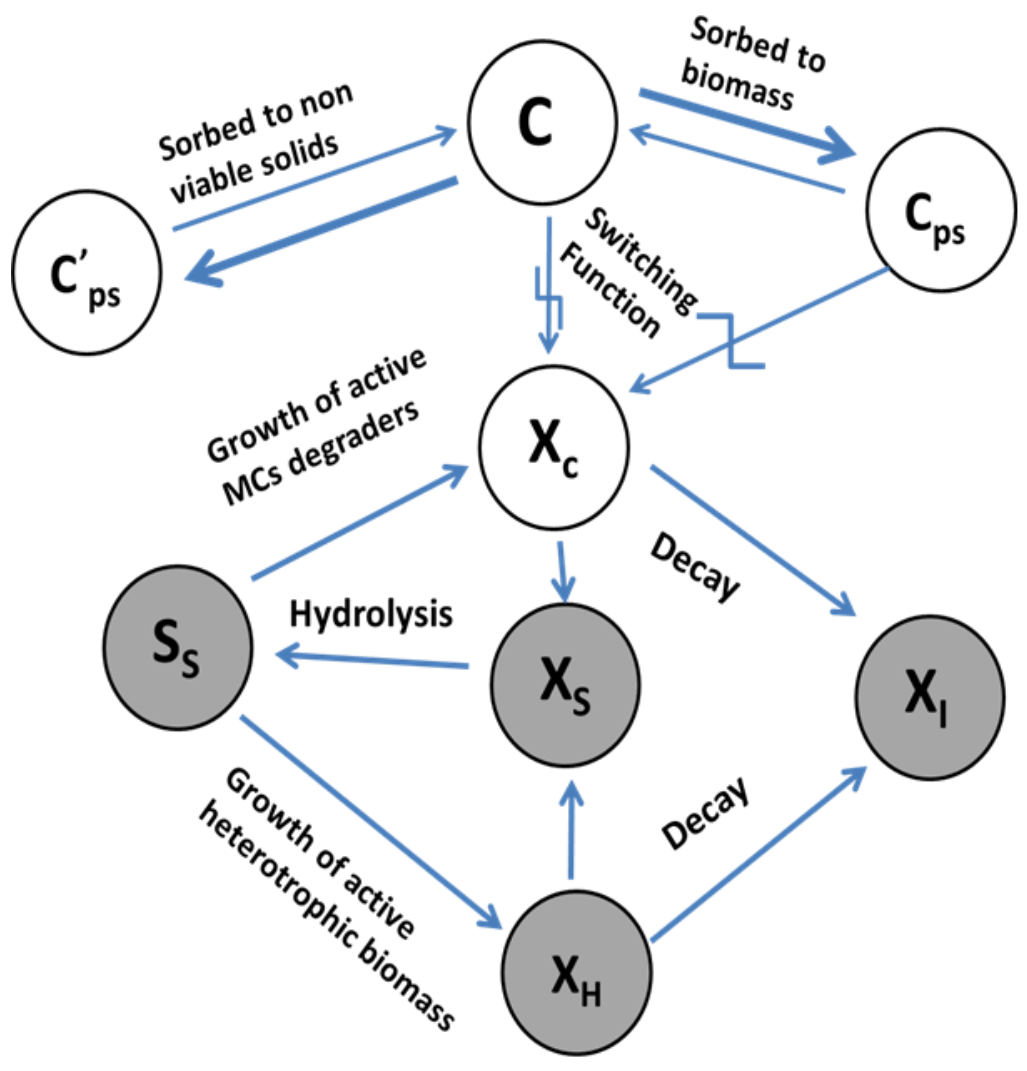

Figure 2-2. Proposed state model variables applied to ASM1 model after Lidblom 2009

\subsubsection{Microconstituents fate model development}

The general equation was developed in this study to represent the biodegradation rate of $\mathrm{MC}$ in batch study when compounds with very low volatility were used and sorption saturation exists. Sorption depends on the total concentration of solids, $\mathrm{X}_{\mathrm{V}}$, in the aeration basin or reactor.

$$
\text { Sorption }=\mathrm{K}_{\mathrm{d}} \mathrm{X}_{\mathrm{v}}\left(\mathrm{C}_{\mathrm{ps}}-\mathrm{C}_{\mathrm{p}}\right)
$$




\section{P a g e $\mid \mathbf{6 0}$}

where $\quad \mathrm{C}_{\mathrm{ps}}$ is saturation concentration of the substance in the particulate phase referred to the reactor volume $(\mathrm{mg} / \mathrm{L}) ; \mathrm{C}_{\mathrm{p}}$ is actual concentration of $\mathrm{MC}$ in the particulate phase referred to the volume of the reactor $(\mathrm{mg} / \mathrm{L})$ and is equal to $\mathrm{K}_{\mathrm{d}} \mathrm{X}_{\mathrm{v}} \mathrm{C} ; \mathrm{K}_{\mathrm{d}}$ is a mass transfer rate coefficient (L/mg.d).

Biodegradation is dependent on the concentration of active mass, $\mathrm{X}_{\mathrm{H}}$, in the aeration basin as well as the $\mathrm{MC}$ present in the liquid and solid phases $\left(\mathrm{C}\right.$ and $\left.\mathrm{C}_{\mathrm{p}}\right)$. Linear models that are first-order with respect to each of biomass and concentration of MC will be focused on in this development; historically they have been commonly found to describe biodegradation.

Biodegradation $=-\mathrm{K}_{\mathrm{ms}} \mathrm{X}_{\mathrm{H}} \mathrm{C}-\mathrm{K}_{\mathrm{mp}} \mathrm{X}_{\mathrm{H}} \mathrm{C}_{\mathrm{p}}$

where $\quad \mathrm{K}_{\mathrm{ms}}$ is a biodegradation rate coefficient for the $\mathrm{MC}$ in the liquid phase (L/mg.d); $K_{m p}$ is a biodegradation rate coefficient for the MC in the solid phase (L/mg.d). Using the above relations, a more general expression for removal of a MC with very low volatility in a batch or continuous flow PF reactor is

$$
\frac{d C}{d t}=\mathrm{K}_{\mathrm{d}} \mathrm{X}_{\mathrm{v}}\left(\mathrm{C}_{\mathrm{ps}}-\mathrm{C}_{\mathrm{p}}\right)-\mathrm{K}_{\mathrm{ms}} \mathrm{X}_{\mathrm{H}} \mathrm{C}-\mathrm{K}_{\mathrm{mp}} \mathrm{X}_{\mathrm{H}} \mathrm{C}_{\mathrm{p}}
$$

if saturation conditions exist with respect to sorption on solids the equation above becomes

$$
\frac{d C}{d t}=-\mathrm{K}_{\mathrm{ms}} \mathrm{X}_{\mathrm{H}} \mathrm{C}-\mathrm{K}_{\mathrm{mp}} \mathrm{X}_{\mathrm{H}} \mathrm{X}_{\mathrm{V}} \mathrm{K}_{\mathrm{d}} \mathrm{C}
$$

Another assumption implicit in the developments is that all sorbed MCs are equally subject to attack. It is not unreasonable to postulate that sorbed constituent associated 


\section{P a g e $\mid \mathbf{6 1}$}

with non-active solids (inert or degradable particulate substrate, $X_{I}$ and $X_{S}$, respectively) are less available for microbial attack. Eq. (2-4) would then be formulated as

$$
\frac{d C}{d t}=-\mathrm{K}_{\mathrm{ms}} \mathrm{X}_{\mathrm{H}} \mathrm{C}-\mathrm{K}_{\mathrm{mp}} \mathrm{X}_{\mathrm{H}} \mathrm{X}_{\mathrm{V}} \mathrm{K}_{\mathrm{d}} \mathrm{C} \frac{X_{H}}{X_{V}}=-\mathrm{K}_{\mathrm{ms}} \mathrm{X}_{\mathrm{H}} \mathrm{C}-\mathrm{K}_{\mathrm{mp}} \mathrm{X}_{\mathrm{H}}{ }^{2} \mathrm{~K}_{\mathrm{d}} \mathrm{C}
$$

Eq. (2-5) conveniently relates both solid and liquid phase degradation to the liquid concentration of MC.

In addition, many studies report an overall first-order rate formulation for MC degradation in WWTPs. Defining

$$
\mathrm{K}_{\mathrm{m}}=\mathrm{K}_{\mathrm{m}^{\prime}}\left(1+\mathrm{X}_{\mathrm{V}} \mathrm{K}_{\mathrm{d}}\right)
$$

Now Eq. (2-5) becomes

$$
\frac{\mathrm{dC}}{\mathrm{dt}}=-\mathrm{K}_{\mathrm{m}} \mathrm{X}_{\mathrm{H}} \mathrm{C}
$$

Finally, an overall first-order expression is obtained if

$$
\begin{aligned}
& \mathrm{K}_{\mathrm{M}}=\mathrm{K}_{\mathrm{m}^{\prime}} \mathrm{X}_{\mathrm{H}}\left(1+\mathrm{X}_{\mathrm{V}} \mathrm{K}_{\mathrm{d}}\right)=\mathrm{K}_{\mathrm{m}} \mathrm{X}_{\mathrm{H}} \\
& \frac{\mathrm{dC}}{\mathrm{dt}}=-\mathrm{K}_{\mathrm{M}} \mathrm{C}
\end{aligned}
$$

where $\quad \mathrm{K}_{\mathrm{M}}$ is an overall first-order rate constant for $\mathrm{MC}$ degradation $\left(\mathrm{d}^{-1}\right)$

Further consideration of possible degradation mechanisms and kinetics leads to the possible models given in Table 2-5. 
P a g e $\mid 62$

\subsubsection{Biodegradation models used in commercial modeling software}

There were no new models found for predicting the fate of MCs in WWTPs, but SimpleTreat, ASTreat, STP, and TOXCHEM+ models were reviewed in more detail to evaluate the use of these models for MC removal in AS systems (Banihashemi and Droste, 2011). These packages use first-order models or mixed second-order models as well as Monod models except for STP, which does not include the latter model. It is also recommended that these software models should include the Haldane model as one of the kinetic choices.

Biodegradation can be described with three different methods in SimpleTreat. A simple overall first-order model in SimpleTreat is Method I, which is based on the aqueous phase concentration of the MC. The note on the spreadsheet states that using this model implies that there is no degradation in the sorbed phase; however, the overall firstorder formulation could depend on sorbed phase degradation as well. The data source for the rate coefficient should have clearly demonstrated that there is no sorbed phase degradation.

In Method II in SimpleTreat the user specifies a first-order rate coefficient that is used for both aqueous and solid phase degradation kinetics. The $\mathrm{K}_{\mathrm{m}}$ input $\left(\mathrm{in}^{-1}\right)$ is multiplied by $\left(1+\mathrm{K}_{\mathrm{d}} \mathrm{X}_{\mathrm{V}}\right)$ within the program.

Method III in SimpleTreat is a Monod formulation of the form 


$$
\begin{gathered}
\text { P a g e } \mid \mathbf{6 3} \\
\mathrm{C}=\frac{\mathrm{K}_{\mathrm{C}}\left(1+\theta_{\mathrm{X}}+\mathrm{b}_{\mathrm{C}}\right)}{\theta_{\mathrm{X}}\left(\mu_{\mathrm{Cm}}-\mathrm{b}_{\mathrm{C}}\right)-1}
\end{gathered}
$$

where $\quad b_{C}$ is decay rate of specific microorganisms degrading the $\mathrm{MC}\left(\mathrm{d}^{-1}\right)$

SimpleTreat is limited in its ability to describe various physical features and operating conditions of AS processes that are related to MC removal kinetics. The model is limited to use as a screening tool and fixed values in the program are not generally representative of North American conditions.

Biodegradation can be described with two different models in STP models; first-order and mixed second-order model where degradation can happen in both soluble and solid phases. Unfortunately, STP's structure has built-in flaws where only data acquired for an MLVSS of $2000 \mathrm{mg} / \mathrm{L}$ is actually able to be simulated correctly. As conditions change from this MLVSS concentration, deviations will occur which affects both the partitioning coefficient and rate of biodegradation.

The structure of ASTreat is to limit biodegradation of a MC to its soluble phase for all models. The first-order model used is presented in Table 2-5, which is based solely on the soluble concentration of MC. The second-order model is the mixed second-order expression with one highly significant variation: the biodegradation reaction constant $\left(\mathrm{m}^{3} / \mathrm{g}-\mathrm{d}\right)$ for the second-order model is based on the active biomass concentration specifically degrading the $\mathrm{MC}\left(\mathrm{X}_{\mathrm{C}}\right)$ instead of the total biomass concentration, $\mathrm{X}_{\mathrm{V}}$ or the active heterotroph concentration, $\mathrm{X}_{\mathrm{H}}$. The second-order model in ASTreat is 


\section{P a g e $\mid 64$}

$r_{C}=-\mathrm{k}_{\mathrm{m}} \mathrm{X}_{\mathrm{C}} \mathrm{C}$

The active mass degrading the constituent $\left(\mathrm{X}_{\mathrm{C}}\right)$ is not related in any way to the active (heterotroph) mass in the aeration basin. It is calculated from user-defined parameters $\left(\mathrm{Y}_{\mathrm{C}}, \mathrm{b}_{\mathrm{C}}\right)$ in

$$
X_{C}=\frac{\theta_{X}}{\theta_{d}} \frac{Y_{C}\left(C_{0}-\mathrm{C}\right)}{1+b_{C} \theta_{X}}
$$

where $\mathrm{Y}_{\mathrm{C}}$ is yield factor of the active mass degrading the $\mathrm{MC}(\mathrm{g} / \mathrm{g}) ; \mathrm{b}_{\mathrm{C}}$ is endogenous decay rate of active mass degrading the $\mathrm{MC}\left(\mathrm{d}^{-1}\right) ; \mathrm{C}_{0}$ and $\mathrm{C}$ are influent and effluent soluble MC concentrations (mg/L), respectively.

The model does not implicitly assume that solids are being degraded in the sorbed phase as could be the case with the first-order model. The third model offered in ASTreat is a Monod formulation defined in the following equations.

$$
r_{C}=\frac{\mu_{C m} C}{K_{C}+C} \frac{X_{C}}{Y_{C}}
$$

where $\mu_{\mathrm{Cm}}$ is maximum growth rate of MC degrading biomass $\left(\mathrm{d}^{-1}\right) ; \mathrm{K}_{\mathrm{C}}$ is the halfvelocity coefficient for MC degrading biomass (mg/L)

There are two biodegradation models provided in TOXCHEM+: first-order and a Monod kinetic model. The original TOXCHEM+ models are provided in (Melcer et al., 1994) and (Parker et al., 1994). The first-order model used in TOXCHEM+ is:

$$
r_{C}=\mathrm{k}_{\mathrm{m}}^{\prime} \mathrm{X}_{\mathrm{V}} \mathrm{C}
$$




\section{P a g e $\mid \mathbf{6 5}$}

The above equation is based on soluble phase degradation only. As noted above, this model is readily changed by defining a modified rate coefficient.

$$
K_{m}=\mathrm{k}_{\mathrm{m}}^{\prime}\left(1+\mathrm{X}_{\mathrm{V}} \mathrm{K}_{\mathrm{d}}\right)
$$

Then the model becomes

$$
r_{C}=k_{m}^{\prime}\left(1+X_{V} K_{d}\right) \mathrm{C}=\mathrm{K}_{\mathrm{m}} \mathrm{X}_{\mathrm{V}} \mathrm{C}
$$

The Monod model used is the standard model

$$
r_{c}=\frac{\mu_{\mathrm{m}}}{\mathrm{Y}} \frac{\mathrm{C}}{\mathrm{K}_{\mathrm{C}}+\mathrm{C}} \mathrm{X}_{\mathrm{V}}
$$

which is equivalent to the Monod model in Table 2-5. If $\mathrm{C}$ is small compared to $\mathrm{K}_{\mathrm{C}}$, this model reverts to the first-order model with respect to concentration of chemical.

The demands for information in TOXCHEM are higher than for the other models reviewed but default values are available. The overall flexibility and ease of use make this program a good choice for modelling chemical fate. Based on kinetic formulation review in these models TOXCHEM+ and ASTreat are the recommended models for simulating chemical transformations. TOXCHEM+ is de facto the state-of-the-art package for evaluating the fate of $\mathrm{MCs}$ in comprehensive variety of WWTP configurations. 
P a g e | 66

\subsection{Summary and Conclusion}

Carbon removal governs the amount of biomass formed in a biological process regardless of configuration of the process for any of the biological nutrient removal options. In a MCs removal process, both the total concentration of SS in MLSS is responsible for sorption and the active biomass is responsible for metabolism of MCs. Not necessarily all of the active biomass is involved in metabolism of MCs; likewise, not all sorbed MCs are necessarily subject to microbial attack. Concentrations in the liquid phase and associated with solids are related by the partitioning factors, $\mathrm{pKa}$ and $\mathrm{K}_{\mathrm{d}}$, between liquid and particulate phase concentrations. It is indeed possible that the metabolism of a substance accumulated within the inorganic compounds and biomass matrix occurs at a rate different from its dispersed concentration in the liquid phase. Sorption of a MC to an inert or non-active organic particulate will reduce its exposure to microbial attack. Some MCs may only be amenable to microbial attack in the soluble phase; therefore, sorption of a MC to SS will reduce its maximum possible metabolism rate. Its concentration in the particulate phase will not, in general, be the same as that in the liquid phase. To further refine and define the kinetics, it is always necessary to research degradation in the solid and liquid phases.

Biodegradation is dependent on the concentration of active mass, $\mathrm{X}_{\mathrm{H}}$, in the aeration basin as well as the amounts of MC present in the liquid and solid phases. Studies that have examined $\mathrm{MC}$ degradation have been based on the traditional formulation relating 


\section{P a g e $\mid 67$}

degradation to MLVSS; however, inert particulates clearly would play no role in active metabolism. There are many different model formulations that have been found to fit biodegradation data for MCs in an AS treatment plant. More commonly used models are a first-order formulation dependent only on the liquid phase concentration of chemical or apparent first-order formulation where degradation occurs in both the soluble and sorbed phases. Linear models that are first-order with respect to each of biomass and concentration of MC were introduced in this study; other possible models that have been found to be valid have also been examined.

SimpleTreat, ASTreat, STP, and TOXCHEM+ models were reviewed in more detail in this study to evaluate the use of these models for MC removal in AS systems. These packages use first-order models or mixed second-order models as well as Monod models except for STP which does not include the latter model. It is also recommended that these software models should include the Haldane model as one of the kinetic choices. ASTreat and TOXCHEM+ are the recommended models for simulating chemical transformations.

\subsection{References}

Abegglen C, Joss A, McArdell CS, Fink G, Schlusener MP, Ternes TA, et al. The fate of selected micropollutants in a single-house MBR. Water Res 2009; 43: 2036-46.

Alexander HC, Dill DC, Smith LW, Guiney PD, Dorn P. Bisphenol a: Acute aquatic toxicity. Environmental Toxicology and Chemistry 1988; 7: 19-26.

Allmyr M, Adolfsson-Erici M, McLachlan MS, Sandborgh-Englund G. Triclosan in plasma and milk from Swedish nursing mothers and their exposure via personal care products. Sci Total Environ 2006; 372: 87-93. 
P a g e $\mid 68$

Andersen HR, Hansen M, Kjolholt J, Stuer-Lauridsen F, Ternes T, Halling-Sorensen B. Assessment of the importance of sorption for steroid estrogens removal during activated sludge treatment. Chemosphere 2005; 61: 139-46.

Anderson PD. Endocrine disrupting compounds and implications for wastewater treatment, 2005.

Aranami K, Readman JW. Photolytic degradation of triclosan in freshwater and seawater. Chemosphere 2007; 66: 1052-6.

Arias-Estévez M, Fernández-Gándara D, García-Falcón MS, García-Río L, Mejuto JC, Simal-Gándara J. Sorption of PAHs to Colloid Dispersions of Humic Substances in Water. Bulletin of Environmental Contamination and Toxicology 2007; 79: 251-254.

Aris AZ, Shamsuddin AS, Praveena SM. Occurrence of 17 $\alpha$-ethynylestradiol (EE2) in the environment and effect on exposed biota: a review. Environment International 2014; 69: 104-119.

Ashton D, Hilton M, Thomas KV. Investigating the environmental transport of human pharmaceuticals to streams in the United Kingdom. Sci Total Environ 2004; 333 : 167-84.

Atkinson SK, Marlatt VL, Kimpe LE, Lean DR, Trudeau VL, Blais JM. The occurrence of steroidal estrogens in south-eastern Ontario wastewater treatment plants. Sci Total Environ 2012; 430: 119-25.

Banihashemi B, Droste RL. Evaluation of Biodegradation Kinetics Models for Microconstituents Under Typical Sewage Treatment Conditions. Water Environment Federation 2011: 5049-5061.

Barret M, Carrere H, Latrille E, Wisniewski C, Patureau D. Micropollutant and sludge characterization for modeling sorption equilibria. Environ Sci Technol 2010a; 44: 1100-6.

Barret M, Patureau D, Latrille E, Carrere H. A three-compartment model for micropollutants sorption in sludge: methodological approach and insights. Water Res 2010b; 44: 616-24.

Beier S, Cramer C, Köster S, Mauer C, Palmowski L, Schröder HF, et al. Full scale membrane bioreactor treatment of hospital wastewater as forerunner for hot-spot wastewater treatment solutions in high density urban areas. Water Science and Technology 2011; 63: 66-71.

Bennie DT, Struger, J.S. Pharmaceuticals and personal care products (PPCP) in Canadian urban waters: Research and policy directions. Environment Canada, 2008.

Berg UT, Nyholm N. Biodegradability simulation studies in semicontinuous activated sludge reactors with low $(\mu \mathrm{g} / \mathrm{L}$ range) and standard (ppm range) chemical concentrations. Chemosphere 1996; 33: 711-735.

Bester K. Triclosan in a sewage treatment process-balances and monitoring data. Water Research 2003; 37: 3891-3896. 
Blasiak J, Kleinwachter V, Walter Z, Zaludova R. Interaction of organophosphorus insecticide methylparathion with calf thymus DNA and a synthetic DNA duplex. Z Naturforsch C 1995; 50: 820-3.

Borrirukwisitsak S, Keenan HE, Gauchotte-Lindsay C. Effects of salinity, $\mathrm{pH}$ and temperature on the octanol-water partition coefficient of bisphenol A. International Journal of Environmental Science and Development 2012; 3(5): 460-464.

Boyd GR, Reemtsma H, Grimm DA, Mitra S. Pharmaceuticals and personal care products (PPCPs) in surface and treated waters of Louisiana, USA and Ontario, Canada. Sci Total Environ 2003; 311: 135-49.

Braoudaki M, Hilton AC. Low level of cross-resistance between triclosan and antibiotics inEscherichia coliK-12 andE. coliO55 compared toE. coliO157. FEMS Microbiology Letters 2004; 235: 305-309.

Brown JN, Paxeus N, Forlin L, Larsson DG. Variations in bioconcentration of human pharmaceuticals from sewage effluents into fish blood plasma. Environ Toxicol Pharmacol 2007; 24: 267-74.

Burnison B, Servos M, Sherry J, Lee H-B, Van Der Kraak G, Metcalfe C, (2002). EDCs in municipal sewage effluents. Toxic Substances Research Initiative (TSRI 174) Final Report, Environment Canada and Health Canada.

Buser HR, Poiger T, Muller MD. Occurrence and environmental behavior of the chiral pharmaceutical drug ibuprofen in surface waters and in wastewater. Environmental Science \& Technology 1999; 33: 2529-2535.

Buth JM, Grandbois M, Vikesland PJ, McNeill K, Arnold WA. Aquatic photochemistry of chlorinated triclosan derivatives: potential source of polychlorodibenzo-pdioxins. Environ Toxicol Chem 2009; 28: 2555-63.

Byrns G. The fate of xenobiotic organic compounds in wastewater treatment plants. Water Res 2001; 35: 2523-33.

Camacho-Muñoz D, Martín J, Santos JL, Aparicio I, Alonso E. Effectiveness of conventional and low-cost wastewater treatments in the removal of pharmaceutically active compounds. Water, Air, and Soil Pollution 2012; 223: 2611-2621.

Carballa M, Fink G, Omil F, Lema JM, Ternes T. Determination of the solid-water distribution coefficient $(\mathrm{Kd})$ for pharmaceuticals, estrogens and musk fragrances in digested sludge. Water Res 2008; 42: 287-95.

Carballa M, Omil F, Lema JM. Calculation methods to perform mass balances of micropollutants in sewage treatment plants. application to pharmaceutical and personal care products (PPCPs). Environ Sci Technol 2007; 41: 884-90.

Chalew TE, Halden RU. Environmental Exposure of Aquatic and Terrestrial Biota to Triclosan and Triclocarban. J Am Water Works Assoc 2009; 45: 4-13. 
Chan J, Gris G, Lee H., Peart TE. Endocrine-Disrupting Chemicals in Industrial Wastewater Samples in Toronto, Ontario. Water Quality Research Journal of Canada 2002; 37 (2): 459 - 472.

Choi K, Kim Y, Jung J, Kim MH, Kim CS, Kim NH, et al. Occurrences and ecological risks of roxithromycin, trimethoprim, and chloramphenicol in the Han River, Korea. Environ Toxicol Chem 2008; 27: 711-9.

Cirja M, Zuehlke S, Ivashechkin P, Hollender J, Schaffer A, Corvini PF. Behavior of two differently radiolabelled 17alpha-ethinylestradiols continuously applied to a laboratory-scale membrane bioreactor with adapted industrial activated sludge. Water Res 2007; 41: 4403-12.

Clara M, Kreuzinger N, Strenn B, Gans O, Kroiss H. The solids retention time-a suitable design parameter to evaluate the capacity of wastewater treatment plants to remove micropollutants. Water Res 2005a; 39: 97-106.

Clara M, Strenn B, Gans O, Martinez E, Kreuzinger N, Kroiss H. Removal of selected pharmaceuticals, fragrances and endocrine disrupting compounds in a membrane bioreactor and conventional wastewater treatment plants. Water Res 2005b; 39: 4797-807.

Clara M, Strenn B, Saracevic E, Kreuzinger N. Adsorption of bisphenol-A, 17 betaestradiole and 17 alpha-ethinylestradiole to sewage sludge. Chemosphere 2004; 56: 843-51.

Costanzo SD, Murby J, Bates J. Ecosystem response to antibiotics entering the aquatic environment. Mar Pollut Bull 2005; 51: 218-23.

Cowan CE, Larson RJ, Feijtel TCJ, Rapaport RA. An improved model for predicting the fate of consumer product chemicals in wastewater treatment plants. Water Research 1993; 27: 561-573.

Dann AB, Hontela A. Triclosan: environmental exposure, toxicity and mechanisms of action. J Appl Toxicol 2011; 31: 285-311.

Desbrow C, Routledge EJ, Brighty GC, Sumpter JP, Waldock M. Identification of estrogenic chemicals in STW effluent. 1. Chemical fractionation and in vitro biological screening. Environmental Science \& Technology 1998; 32: 1549-1558.

Dionisi D, Bertin L, Bornoroni L, Capodicasa S, Papini MP, Fava F. Removal of organic xenobiotics in activated sludges under aerobic conditions and anaerobic digestion of the adsorbed species. Journal of Chemical Technology and Biotechnology 2006; 81: 1496-1505.

Drewes JE, Hemming J, Ladenburger SJ, Schauer J, Sonzogni W. An assessment of endocrine disrupting activity changes during wastewater treatment through the use of bioassays and chemical measurements. Water Environment Research 2005; 77: $12-23$. 
P a g e $\mathbf{7 1}$

Drury B, Scott J, Rosi-Marshall EJ, Kelly JJ. Triclosan exposure increases triclosan resistance and influences taxonomic composition of benthic bacterial communities. Environ Sci Technol 2013; 47: 8923-30.

Dussault EB, Balakrishnan VK, Sverko E, Solomon KR, Sibley PK. Toxicity of human pharmaceuticals and personal care products to benthic invertebrates. Environ Toxicol Chem 2008; 27: 425-32.

Dzieweczynski TL, Hebert OL. The effects of short-term exposure to an endocrine disrupter on behavioral consistency in male juvenile and adult siamese fighting fish. Archives of Environmental Contamination and Toxicology 2013; 64: 316326.

European Food Safety Authority, EFSA. Opinion of the scientific panel on food additives, flavourings, processing aids and materials in contact with Food on a request from the Commission related to 2,2-Bis(4-Hydroxyphenyl)Propane (Bisphenol A) Question number EFSA-Q-2005-100 Adopted on 29 November 2006, The EFSA Journal 2006; 428: 1 - 75.

Fair PA, Lee HB, Adams J, Darling C, Pacepavicius G, Alaee M, et al. Occurrence of triclosan in plasma of wild Atlantic bottlenose dolphins (Tursiops truncatus) and in their environment. Environ Pollut 2009; 157: 2248-54.

Federle TW, Kaiser SK, Nuck BA. Fate and effects of triclosan in activated sludge. Environ Toxicol Chem 2002; 21: 1330-7.

Feng Y, Zhang Z, Gao P, Su H, Yu Y, Ren N. Adsorption behavior of EE2 (17 alphaethinylestradiol) onto the inactivated sewage sludge: kinetics, thermodynamics and influence factors. J Hazard Mater 2010; 175: 970-6.

Fernandez-Fontaina E, Omil F, Lema JM, Carballa M. Influence of nitrifying conditions on the biodegradation and sorption of emerging micropollutants. Water Res 2012; 46: 5434-44.

Fernandez-Fontaina E, Pinho I, Carballa M, Omil F, Lema JM. Biodegradation kinetic constants and sorption coefficients of micropollutants in membrane bioreactors. Biodegradation 2013; 24: 165-77.

Fernandez MP, Ikonomou MG, Buchanan I. An assessment of estrogenic organic contaminants in Canadian wastewaters. Sci Total Environ 2007; 373: 250-69.

Fujimoto T, Kubo K, Aou S. Prenatal exposure to bisphenol A impairs sexual differentiation of exploratory behavior and increases depression-like behavior in rats. Brain Res 2006; 1068: 49-55.

Gaulke LS, Strand SE, Kalhorn TF, Stensel HD. 17 $\alpha$-ethinylestradiol Transformation via Abiotic Nitration in the Presence of Ammonia Oxidizing Bacteria. Environmental Science \& Technology 2008; 42: 7622-7627.

Gee RH, Charles A, Taylor N, Darbre PD. Oestrogenic and androgenic activity of triclosan in breast cancer cells. J Appl Toxicol 2008; 28: 78-91. 
Gomes RL, Scrimshaw MD, Lester JN. Fate of conjugated natural and synthetic steroid estrogens in crude sewage and activated sludge batch studies. Environ Sci Technol 2009; 43: 3612-8.

Gómez MJ, Herrera S, Solé D, García-Calvo E, Fernández-Alba AR. Spatio-temporal evaluation of organic contaminants and their transformation products along a river basin affected by urban, agricultural and industrial pollution. Science of The Total Environment 2012; 420: 134-145.

Govind R, Lai L, Dobbs R. Integrated model for predicting the fate of organics in wastewater treatment plants. Environmental Progress 1991; 10: 13-23.

Gros M, Petrović M, Barceló D. Wastewater treatment plants as a pathway for aquatic contamination by pharmaceuticals in the Ebro river basin (Northeast Spain). Environmental Toxicology and Chemistry 2007; 26: 1553-1562.

Hai FI, Tessmer K, Nguyen LN, Kang JG, Price WE, Nghiem LD. Removal of micropollutants by membrane bioreactor under temperature variation. Journal of Membrane Science 2011; 383: 144-151.

Halling-Sorensen B, Nors Nielsen S, Lanzky PF, Ingerslev F, Holten Lutzhoft HC, Jorgensen SE. Occurrence, fate and effects of pharmaceutical substances in the environment--a review. Chemosphere 1998; 36: 357-93.

Hamid H, Eskicioglu C. Fate of estrogenic hormones in wastewater and sludge treatment: A review of properties and analytical detection techniques in sludge matrix. Water Research 2012; 46: 5813-5833.

Hao C, Lissemore L, Nguyen B, Kleywegt S, Yang P, Solomon K. Determination of pharmaceuticals in environmental waters by liquid chromatography/electrospray ionization/tandem mass spectrometry. Analytical and Bioanalytical Chemistry 2006; 384: 505-13.

Heberer T. Occurrence, fate, and removal of pharmaceutical residues in the aquatic environment: a review of recent research data. Toxicol Lett 2002; 131: 5-17.

Heidler J, Halden RU. Mass balance assessment of triclosan removal during conventional sewage treatment. Chemosphere 2007; 66: 362-9.

Helbling DE, Johnson DR, Honti M, Fenner K. Micropollutant biotransformation kinetics associate with WWTP process parameters and microbial community characteristics. Environ Sci Technol 2012; 46: 10579-88.

Hess-Wilson JK, Knudsen KE. Endocrine disrupting compounds and prostate cancer. Cancer Lett 2006; 241: 1-12.

Hignite C, Azarnoff DL. Drugs and drug metabolites as environmental contaminants: chlorophenxoyisobutyrate and salicylic acid in sewage water effluent. Life Sci. 1977; 20: 337-342.

Hirano M, Ishibashi H, Kim JW, Matsumura N, Arizono K. Effects of environmentally relevant concentrations of nonylphenol on growth and 20-hydroxyecdysone levels 
in mysid crustacean, Americamysis bahia. Comp Biochem Physiol C Toxicol Pharmacol 2009; 149: 368-73.

Huang M, Li Y, Gu G. The effects of hydraulic retention time and sludge retention time on the fate of di-(2-ethylhexyl) phthalate in a laboratory-scale anaerobic-anoxicaerobic activated sludge system. Bioresour Technol 2008; 99: 8107-11.

Hung NV, Tateda M, Ike M, Fujita M, Tsunoi S, Tanaka M. Sorption of biodegradation end products of nonylphenol polyethoxylates onto activated sludge. Journal of Environmental Sciences 2004; 16: 564-569.

Isidori M, Bellotta M, Cangiano M, Parrella A. Estrogenic activity of pharmaceuticals in the aquatic environment. Environ Int 2009; 35: 826-9.

Jacobsen BN, Arvin E. Biodegradation kinetics and fate modelling of pentachlorophenol in bioaugmented activated sludge reactors. Water Research 1996; 30: 1184-1194.

Jacobsen BN, Nyholm N, Pedersen BM, Poulsen O, Ostfeldt P. Removal of Organic Micropollutants in Laboratory Activated-Sludge Reactors under Various Operating-Conditions - Sorption. Water Research 1993; 27: 1505-1510.

Jeffries KM, Jackson LJ, Ikonomou MG, Habibi HR. Presence of natural and anthropogenic organic contaminants and potential fish health impacts along two river gradients in Alberta, Canada. Environ Toxicol Chem 2010; 29: 2379-87.

Joss A, Andersen H, Ternes T, Richle PR, Siegrist H. Removal of Estrogens in Municipal Wastewater Treatment under Aerobic and Anaerobic Conditions: Consequences for Plant Optimization. Environmental Science \& Technology 2004; 38: 30473055.

Joss A, Keller E, Alder AC, Gobel A, McArdell CS, Ternes T, et al. Removal of pharmaceuticals and fragrances in biological wastewater treatment. Water Res 2005; 39: 3139-52.

Joss A, Zabczynski S, Gobel A, Hoffmann B, Loffler D, McArdell CS, et al. Biological degradation of pharmaceuticals in municipal wastewater treatment: proposing a classification scheme. Water Res 2006; 40: 1686-96.

Kanda R Fau - Griffin P, Griffin P Fau - James HA, James Ha Fau - Fothergill J, J F. Pharmaceutical and personal care products in sewage treatment works. J Environ Monit 2003; 5: 823-30.

Kasprzyk-Hordern B, Dinsdale RM, Guwy AJ. Multiresidue methods for the analysis of pharmaceuticals, personal care products and illicit drugs in surface water and wastewater by solid-phase extraction and ultra performance liquid chromatography-electrospray tandem mass spectrometry. Analytical and Bioanalytical Chemistry 2008; 391: 1293-308.

Kasprzyk-Hordern B, Dinsdale RM, Guwy AJ. The removal of pharmaceuticals, personal care products, endocrine disruptors and illicit drugs during wastewater treatment and its impact on the quality of receiving waters. Water Res 2009; 43: 363-80. 


\section{P a g e $\mid 74$}

Khunjar WO, Mackintosh SA, Skotnicka-Pitak J, Baik S, Aga DS, Love NG. Elucidating the relative roles of ammonia oxidizing and heterotrophic bacteria during the biotransformation of 17alpha-Ethinylestradiol and Trimethoprim. Environ Sci Technol 2011; 45: 3605-12.

Kidd KA, Blanchfield PJ, Mills KH, Palace VP, Evans RE, Lazorchak JM, et al. Collapse of a fish population after exposure to a synthetic estrogen. Proc Natl Acad Sci U S A 2007; 104: 8897-901.

Kim JY, Ryu K, Kim EJ, Choe WS, Cha GC, Yoo IK. Degradation of bisphenol A and nonylphenol by nitrifying activated sludge. Process Biochemistry 2007; 42: 14701474.

Kimura K, Hara H, Watanabe Y. Elimination of selected acidic pharmaceuticals from municipal wastewater by an activated sludge system and membrane bioreactors. Environ Sci Technol 2007; 41: 3708-14.

Kinney CA, Furlong ET, Kolpin DW, Burkhardt MR, Zaugg SD, Werner SL, et al. Bioaccumulation of pharmaceuticals and other anthropogenic waste indicators in earthworms from agricultural soil amended with biosolid or swine manure. Environ Sci Technol 2008; 42: 1863-70.

Kirk LA, Tyler CR, Lye CM, Sumpter JP. Changes in estrogenic and androgenic activities at different stages of treatment in wastewater treatment works. Environmental Toxicology and Chemistry 2002; 21: 972-979.

Klecka GM, Staples CA, Clark KE, Van der Hoeven N, Thomas DE, Hentges SG. Exposure analysis of bisphenol A in surface water systems in North America and Europe. Environ Sci Technol 2009; 43: 6145-50.

Kleywegt S, Pileggi V, Yang P, Hao C, Zhao X, Rocks C, et al. Pharmaceuticals, hormones and bisphenol $\mathrm{A}$ in untreated source and finished drinking water in Ontario, Canada--occurrence and treatment efficiency. Sci Total Environ 2011; 409: 1481-8.

Koh YK, Chiu TY, Boobis A, Cartmell E, Scrimshaw MD, Lester JN. Treatment and removal strategies for estrogens from wastewater. Environ Technol 2008; 29: 245-67.

Kovalova L, Siegrist H, Singer H, Wittmer A, McArdell CS. Hospital wastewater treatment by membrane bioreactor: Performance and efficiency for organic micropollutant elimination. Environmental Science and Technology 2012; 46: 1536-1545.

Kreuzinger N, Clara M, Strenn B, Kroiss H. Relevance of the sludge retention time (SRT) as design criteria for wastewater treatment plants for the removal of endocrine disruptors and pharmaceuticals from wastewater. Water Science and Technology 2004; 50: 149-156. 
Kumar AK, Mohan SV, Sarma PN. Sorptive removal of endocrine-disruptive compound (estriol, E3) from aqueous phase by batch and column studies: kinetic and mechanistic evaluation. J Hazard Mater 2009; 164: 820-8.

Lai KM, Johnson KL, Scrimshaw MD, Lester JN. Binding of waterborne steroid estrogens to solid phases in river and estuarine systems. Environmental Science \& Technology 2000; 34: 3890-3894.

Lang IA, Galloway TS, Scarlett A, Henley WE, Depledge M, Wallace RB, et al. Association of urinary bisphenol A concentration with medical disorders and laboratory abnormalities in adults. JAMA 2008; 300: 1303-10.

Lange R, Hutchinson TH, Croudace CP, Siegmund F, Schweinfurth H, Hampe P, et al. Effects of the synthetic estrogen 17 alpha-ethinylestradiol on the life-cycle of the fathead minnow (Pimephales promelas). Environ Toxicol Chem 2001; 20: 121627.

Larcher S, Yargeau V. Biodegradation of 17alpha-ethinylestradiol by heterotrophic bacteria. Environ Pollut 2013; 173: 17-22.

Layton AC, Gregory BW, Seward JR, Schultz TW, Sayler GS. Mineralization of Steroidal Hormones by Biosolids in Wastewater Treatment Systems in Tennessee U.S.A. Environmental Science \& Technology 2000; 34: 3925-3931.

Le-Minh N, Khan SJ, Drewes JE, Stuetz RM. Fate of antibiotics during municipal water recycling treatment processes. Water Res 2010; 44: 4295-323.

Lee do G, Zhao F, Rezenom YH, Russell DH, Chu KH. Biodegradation of triclosan by a wastewater microorganism. Water Res 2012; 46: 4226-34.

Lee HB, Peart TE. Bisphenol a contamination in Canadian municipal and industrial wastewater and sludge samples. Water Quality Research Journal of Canada 2000; 35: 283-298.

Lee HB, Peart TE, Chan J, Gris G. Occurrence of endocrine-disrupting chemicals in sewage and sludge samples in Toronto, Canada. Water Quality Research Journal of Canada 2004; 39: 57-63.

Lee HJ, Chattopadhyay S, Gong EY, Ahn RS, Lee K. Antiandrogenic effects of bisphenol A and nonylphenol on the function of androgen receptor. Toxicol Sci 2003; 75: 40-6.

Lee KC, Rittmann BE, Shi JC, McAvoy D. Advanced steady-state model for the fate of hydrophobic and volatile compounds in activated sludge. Water Environment Research 1998; 70: 1118-1131.

Li F, Yuasa A, Obara A, Mathews AP. Aerobic batch degradation of 17-beta estradiol (E2) by activated sludge: effects of spiking E2 concentrations, MLVSS and temperatures. Water Res 2005; 39: 2065-75.

Lindblom E, Press-Kristensen K, Vanrolleghem PA, Mikkelsen PS, Henze M. Dynamic experiments with high bisphenol-A concentrations modelled with an ASM model 
extended to include a separate XOC degrading microorganism. Water Res 2009; 43: 3169-76.

Lishman L, Smyth SA, Sarafin K, Kleywegt S, Toito J, Peart T, et al. Occurrence and reductions of pharmaceuticals and personal care products and estrogens by municipal wastewater treatment plants in Ontario, Canada. Sci Total Environ 2006; 367: 544-58.

Liu Y, Tam NFY, Guan Y, Gao B. Influence of a marine diatom on the embryonic toxicity of $17 \alpha$-ethynylestradiol to the abalone haliotis diversicolor supertexta. Water, Air, and Soil Pollution 2012; 223: 4383-4395.

Lopez-Avila V, Hites RA. Organic compounds in an industrial wastewater. Their transport into sediments. Environmental Science \& Technology 1980; 14: 13821390.

Luo YL, Guo WS, Ngo HH, Nghiem LD, Hai FI, Zhang J, et al. A review on the occurrence of micropollutants in the aquatic environment and their fate and removal during wastewater treatment. Science of The Total Environment 2014; 473: 619-641.

Magee P. 24 - Antiseptic drugs and disinfectants. In: Aronson JK, editor. Side Effects of Drugs Annual. Volume 34. Elsevier, 2012, pp. 377-383.

Majewsky M, Galle T, Yargeau V, Fischer K. Active heterotrophic biomass and sludge retention time (SRT) as determining factors for biodegradation kinetics of pharmaceuticals in activated sludge. Bioresour Technol 2011; 102: 7415-21.

Marfil-Vega R, Suidan MT, Mills MA. Abiotic transformation of estrogens in synthetic municipal wastewater: an alternative for treatment? Environ Pollut 2010; 158: 3372-7.

Maurer M, Escher BI, Richle P, Schaffner C, Alder AC. Elimination of beta-blockers in sewage treatment plants. Water Res 2007; 41: 1614-22.

Melcer H, Bell JP, Thompson DJ, Yendt CM, Kemp J, Steel P. Modeling Volatile Organic Contaminants' Fate in Wastewater Treatment Plants. Journal of Environmental Engineering 1994; 120: 588-609.

Melcer H, Klecka G. Treatment of wastewaters containing bisphenol A: state of the science review. Water Environ Res 2011; 83: 650-66.

Mes dTZD. Fate of estrogens in biological treatment of concentrated black water. [s.n.], [S.1.], 2007.

Mohapatra DP, Brar SK, Tyagi RD, Surampalli RY. Occurrence of bisphenol A in wastewater and wastewater sludge of CUQ treatment plant. Journal of Xenobiotics 2011; 1.

Muller M, Rabenoelina F, Balaguer P, Patureau D, Lemenach K, Budzinski H, et al. Chemical and biological analysis of endocrine-disrupting hormones and estrogenic activity in an advanced sewage treatment plant. Environ Toxicol Chem 2008; 27: 1649-58. 
Nakada N, Yasojima M, Okayasu Y, Komori K, Suzuki Y. Mass balance analysis of triclosan, diethyltoluamide, crotamiton and carbamazepine in sewage treatment plants. Water Sci Technol 2010; 61: 1739-47.

Neumegen RA, Fernandez-Alba AR, Chisti Y. Toxicities of triclosan, phenol, and copper sulfate in activated sludge. Environ Toxicol 2005; 20: 160-4.

Nie Y, Qiang Z, Zhang H, Adams C. Determination of endocrine-disrupting chemicals in the liquid and solid phases of activated sludge by solid phase extraction and gas chromatography-mass spectrometry. J Chromatogr A 2009; 1216: 7071-80.

Nie YF, Qiang ZM, Zhang HQ, Ben WW. Fate and seasonal variation of endocrinedisrupting chemicals in a sewage treatment plant with $\mathrm{A} / \mathrm{A} / \mathrm{O}$ process. Separation and Purification Technology 2012; 84: 9-15.

Oehlmann J, Schulte-Oehlmann U, Kloas W, Jagnytsch O, Lutz I, Kusk KO, et al. A critical analysis of the biological impacts of plasticizers on wildlife. Philos Trans R Soc Lond B Biol Sci 2009; 364: 2047-62.

Parker WJ, Bell JP, Melcer H. Modelling the fate of chlorinated phenols in wastewater treatment plants. Environmental Progress 1994; 13: 98-104.

Parrott JL, Blunt BR. Life-cycle exposure of fathead minnows (Pimephales promelas) to an ethinylestradiol concentration below $1 \mathrm{ng} / \mathrm{L}$ reduces egg fertilization success and demasculinizes males. Environ Toxicol 2005; 20: 131-41.

Pasquini L, Merlin C, Hassenboehler L, Munoz JF, Pons MN, Gorner T. Impact of certain household micropollutants on bacterial behavior. Toxicity tests/study of extracellular polymeric substances in sludge. Sci Total Environ 2013; 463-464: $355-65$.

Plósz BG, Langford KH, Thomas KV. An activated sludge modeling framework for xenobiotic trace chemicals (ASM-X): Assessment of diclofenac and carbamazepine. Biotechnology and Bioengineering 2012; 109: 2757-2769.

Plosz BG, Leknes H, Thomas KV. Impacts of competitive inhibition, parent compound formation and partitioning behavior on the removal of antibiotics in municipal wastewater treatment. Environ Sci Technol 2010; 44: 734-42.

Pomati F, Orlandi C, Clerici M, Luciani F, Zuccato E. Effects and interactions in an environmentally relevant mixture of pharmaceuticals. Toxicol Sci 2008; 102: 12937.

Pomiès M, Choubert JM, Wisniewski C, Coquery M. Modelling of micropollutant removal in biological wastewater treatments: a review. Sci Total Environ 2013; 443: 733-48.

Press-Kristensen K, Lindblom E, Henze M. Modelling as a tool when interpreting biodegradation of micro pollutants in activated sludge systems. Water Science and Technology 2007; 56: 11-16. 
Qiang Z, Dong H, Zhu B, Qu J, Nie Y. A comparison of various rural wastewater treatment processes for the removal of endocrine-disrupting chemicals (EDCs). Chemosphere 2013; 92: 986-992.

Queckenberg C, Meins J, Wachall B, Doroshyenko O, Tomalik-Scharte D, Bastian B, et al. Absorption, pharmacokinetics, and safety of triclosan after dermal administration. Antimicrob Agents Chemother 2010; 54: 570-2.

Quinn B, Gagne F, Blaise C. Evaluation of the acute, chronic and teratogenic effects of a mixture of eleven pharmaceuticals on the cnidarian, Hydra attenuata. Sci Total Environ 2009; 407: 1072-9.

Racz L, Muller JG, Goel RK. Fate of selected estrogens in two laboratory scale sequencing batch reactors fed with different organic carbon sources under varying solids retention times. Bioresour Technol 2012; 110: 35-42.

Radjenovic J, Petrovic M, Barcelo D. Fate and distribution of pharmaceuticals in wastewater and sewage sludge of the conventional activated sludge (CAS) and advanced membrane bioreactor (MBR) treatment. Water Res 2009; 43: 831-41.

Rasmussen LS. Postoperative cognitive dysfunction: incidence and prevention. Best Pract Res Clin Anaesthesiol 2006; 20: 315-30.

Rauch-Williams T, Hoppe-Jones C, Drewes JE. The role of organic matter in the removal of emerging trace organic chemicals during managed aquifer recharge. Water Res 2010; 44: 449-60.

Ren YX, Nakano K, Nomura M, Chiba N, Nishimura O. Effects of bacterial activity on estrogen removal in nitrifying activated sludge. Water Res 2007; 41: 3089-96.

Robinson BJ, Hui JP, Soo EC, Hellou J. Estrogenic compounds in seawater and sediment from Halifax Harbour, Nova Scotia, Canada. Environ Toxicol Chem 2009; 28: 18-25.

Roh H, Chu KH. A 17beta-estradiol-utilizing bacterium, Sphingomonas strain KC8: part I - characterization and abundance in wastewater treatment plants. Environ Sci Technol 2010; 44: 4943-50.

Roig B. Pharmaceuticals in the environment. Current knowledge and need assessment to reduce presence and impact: IWA Publishing, 2010.

Rubin BS, Soto AM. Bisphenol A: Perinatal exposure and body weight. Mol Cell Endocrinol 2009; 304: 55-62.

Samaras VG, Stasinakis AS, Mamais D, Thomaidis NS, Lekkas TD. Fate of selected pharmaceuticals and synthetic endocrine disrupting compounds during wastewater treatment and sludge anaerobic digestion. J Hazard Mater 2013; 244245: 259-67.

Schäfer AI, Akanyeti I, Semião AJC. Micropollutant sorption to membrane polymers: A review of mechanisms for estrogens. Advances in Colloid and Interface Science 2011; 164: 100-117. 
Schäfer AI, Mastrup M, Jensen RL. Particle interactions and removal of trace contaminants from water and wastewaters. Desalination 2002; 147: 243-250.

Segev O, Kushmaro A, Brenner A. Environmental impact of flame retardants (persistence and biodegradability). Int J Environ Res Public Health 2009; 6: 478-91.

Servos MR, Bennie DT, Burnison BK, Jurkovic A, McInnis R, Neheli T, et al. Distribution of estrogens, $17 \beta$-estradiol and estrone, in Canadian municipal wastewater treatment plants. Science of The Total Environment 2005; 336: 155170.

Seyhi B, Drogui P, Buelna G, Blais JF. Modeling of sorption of bisphenol A in sludge obtained from a membrane bioreactor process. Chemical Engineering Journal 2011; 172: 61-67.

Shen G, Huang J, Yu G. Measurement of the free concentrations of alkyl phenols and bisphenol A to determine their biodegradation kinetics by activated sludge. Chinese Science Bulletin 2007; 52: 2766-2770.

Shi J, Fujisawa S, Nakai S, Hosomi M. Biodegradation of natural and synthetic estrogens by nitrifying activated sludge and ammonia-oxidizing bacterium Nitrosomonas europaea. Water Res 2004; 38: 2322-9.

Silva P, Rocha MJ, Cruzeiro C, Malhão F, Reis B, Urbatzka R, et al. Testing the effects of ethinylestradiol and of an environmentally relevant mixture of xenoestrogens as found in the Douro River (Portugal) on the maturation of fish gonads-A stereological study using the zebrafish (Danio rerio) as model. Aquatic Toxicology 2012; 124-125: 1-10.

Singer H, Müller S, Tixier C, Pillonel L. Triclosan: Occurrence and Fate of a Widely Used Biocide in the Aquatic Environment: Field Measurements in Wastewater Treatment Plants, Surface Waters, and Lake Sediments. Environmental Science \& Technology 2002; 36: 4998-5004.

Sivaraman S, Sullivan TJ, Johnson F, Novichenok P, Cui G, Simmerling C, et al. Inhibition of the bacterial enoyl reductase FabI by triclosan: a structure-reactivity analysis of FabI inhibition by triclosan analogues. J Med Chem 2004; 47: 509-18.

Spring AJ, Bagley DM, Andrews RC, Lemanik S, Yang P. Removal of endocrine disrupting compounds using a membrane bioreactor and disinfection. Journal of Environmental Engineering and Science 2007; 6: 131-137.

Stahlhut RW, Welshons WV, Swan SH. Bisphenol A Data in NHANES Suggest Longer than Expected Half-Life, Substantial Nonfood Exposure, or Both. Environmental health perspectives 2009; 117: 784-789.

Staples CA, Dome PB, Klecka GM, Oblock ST, Harris LR. A review of the environmental fate, effects, and exposures of bisphenol A. Chemosphere 1998a; 36: 2149-2173. 
P a g e $\mid \mathbf{8 0}$

Staples CA, Dorn PB, Klecka GM, O'Block ST, Harris LR. A review of the environmental fate, effects, and exposures of bisphenol A. Chemosphere 1998b; 36: 2149-73.

Stasinakis AS, Gatidou G, Mamais D, Thomaidis NS, Lekkas TD. Occurrence and fate of endocrine disrupters in Greek sewage treatment plants. Water Res 2008; 42: 1796-804.

Stasinakis AS, Kordoutis CI, Tsiouma VC, Gatidou G, Thomaidis NS. Removal of selected endocrine disrupters in activated sludge systems: effect of sludge retention time on their sorption and biodegradation. Bioresour Technol 2010; 101: 2090-5.

Stevens-Garmon J, Drewes JE, Khan SJ, McDonald JA, Dickenson ER. Sorption of emerging trace organic compounds onto wastewater sludge solids. Water Res 2011; 45: 3417-26.

Suárez S, Carballa M, Omil F, Lema JM. How are pharmaceutical and personal care products (PPCPs) removed from urban wastewaters? Reviews in Environmental Science and Bio/Technology 2008a; 7: 125-138.

Suárez S, Carballa M, Omil F, Lema JM. How are pharmaceutical and personal care products (PPCPs) removed from urban wastewaters? Reviews in Environmental Science and Biotechnology 2008b; 7: 125-138.

Suarez S, Lema JM, Omil F. Removal of Pharmaceutical and Personal Care Products (PPCPs) under nitrifying and denitrifying conditions. Water Research 2010; 44: 3214-3224.

Suarez S, Reif R, Lema JM, Omil F. Mass balance of pharmaceutical and personal care products in a pilot-scale single-sludge system: influence of T, SRT and recirculation ratio. Chemosphere 2012; 89: 164-71.

Sun P, Casteel K, Dai H, Wehmeyer KR, Kiel B, Federle T. Distributions of polycyclic musk fragrance in wastewater treatment plant (WWTP) effluents and sludges in the United States. Sci Total Environ 2014.

Tadkaew N, Hai FI, McDonald JA, Khan SJ, Nghiem LD. Removal of trace organics by MBR treatment: The role of molecular properties. Water Research 2011; 45: 2439-2451.

Tan BL, Hawker DW, Muller JF, Leusch FD, Tremblay LA, Chapman HF. Modelling of the fate of selected endocrine disruptors in a municipal wastewater treatment plant in South East Queensland, Australia. Chemosphere 2007; 69: 644-54.

Ter Laak TL, Durjava M, Struijs J, Hermens JL. Solid phase dosing and sampling technique to determine partition coefficients of hydrophobic chemicals in complex matrixes. Environ Sci Technol 2005; 39: 3736-42.

Ternes TA, Joss A, Siegrist H. Peer Reviewed: Scrutinizing Pharmaceuticals and Personal Care Products in Wastewater Treatment. Environmental Science \& Technology 2004; 38: 392A-399A. 
Ternes TA, Knacker T, Oehlmann J. Personal care products in the aquatic environmentA neglected group of substances. UWSF-Zeitschrift fu“r Umweltchemie und O* kotoxikologie 2003; 15(3): 169-180.

Ternes TA, Stumpf M, Mueller J, Haberer K, Wilken RD, Servos M. Behavior and occurrence of estrogens in municipal sewage treatment plants--I. Investigations in Germany, Canada and Brazil. Sci Total Environ 1999; 225: 81-90.

Thomas PM, Foster GD. Tracking acidic pharmaceuticals, caffeine, and triclosan through the wastewater treatment process. Environmental Toxicology and Chemistry 2005; 24: 25-30.

Thompson A, Griffin P, Stuetz R, Cartmell E. The fate and removal of triclosan during wastewater treatment. Water Environ Res 2005; 77: 63-7.

Tixier C, Singer HP, Canonica S, Muller SR. Phototransfomation of ticlosan in surface waters: a relevant elimination process for this widely used biocide--laboratory studies, field measurements, and modeling. Environ Sci Technol 2002; 36: 34829.

Tomei MC, Annesini MC, Rita S, Daugulis AJ. Biodegradation of 4-nitrophenol in a two-phase sequencing batch reactor: concept demonstration, kinetics and modelling. Applied Microbiology and Biotechnology 2008; 80: 1105-12.

Trinh T, van den Akker B, Stuetz RM, Coleman HM, Le-Clech P, Khan SJ. Removal of trace organic chemical contaminants by a membrane bioreactor. Water Sci Technol 2012; 66: 1856-63.

Urase T, Kikuta T. Separate estimation of adsorption and degradation of pharmaceutical substances and estrogens in the activated sludge process. Water Res 2005; 39: 1289-300.

Urbatzka R, van Cauwenberge A, Maggioni S, Vigano L, Mandich A, Benfenati E, et al. Androgenic and antiandrogenic activities in water and sediment samples from the river Lambro, Italy, detected by yeast androgen screen and chemical analyses. Chemosphere 2007; 67: 1080-7.

Vader JS, van Ginkel CG, Sperling FM, de Jong J, de Boer W, de Graaf JS, et al. Degradation of ethinyl estradiol by nitrifying activated sludge. Chemosphere 2000; 41: 1239-43.

Vajda AM, Barber LB, Gray JL, Lopez EM, Woodling JD, Norris DO. Reproductive disruption in fish downstream from an estrogenic wastewater effluent. Environ Sci Technol 2008; 42: 3407-14.

Vega-Morales T, Sosa-Ferrera Z, Santana-Rodriguez JJ. Determination of alkylphenol polyethoxylates, bisphenol-A, 17alpha-ethynylestradiol and 17beta-estradiol and its metabolites in sewage samples by SPE and LC/MS/MS. J Hazard Mater 2010; 183: 701-11. 
P a g e $\mid \mathbf{8 2}$

Verlicchi P, Al Aukidy M, Zambello E. Occurrence of pharmaceutical compounds in urban wastewater: removal, mass load and environmental risk after a secondary treatment--a review. Sci Total Environ 2012; 429: 123-55.

Vethaak AD, Lahr J, Schrap SM, Belfroid AC, Rijs GB, Gerritsen A, et al. An integrated assessment of estrogenic contamination and biological effects in the aquatic environment of The Netherlands. Chemosphere 2005; 59: 511-24.

Vieno N, Tuhkanen T, Kronberg L. Removal of pharmaceuticals in drinking water treatment: effect of chemical coagulation. Environ Technol 2006; 27: 183-92.

vom Saal FS, Myers JP. Bisphenol A and risk of metabolic disorders. JAMA 2008; 300: 1353-5.

Walker BS, Janney JC. Estrogenic substances II An analysis of plant sources. Endocrinology 1930; 14: 389-392.

Weber S, Leuschner P, Kampfer P, Dott W, Hollender J. Degradation of estradiol and ethinyl estradiol by activated sludge and by a defined mixed culture. Applied Microbiology and Biotechnology 2005; 67: 106-12.

Wick A, Fink G, Joss A, Siegrist H, Ternes TA. Fate of beta blockers and psycho-active drugs in conventional wastewater treatment. Water Res 2009; 43: 1060-74.

Wozniak AL, Bulayeva NN, Watson CS. Xenoestrogens at picomolar to nanomolar concentrations trigger membrane estrogen receptor-alpha-mediated $\mathrm{Ca} 2+$ fluxes and prolactin release in GH3/B6 pituitary tumor cells. Environmental health perspectives 2005; 113: 431-439.

Xue W, Wu C, Xiao K, Huang X, Zhou H, Tsuno H, et al. Elimination and fate of selected micro-organic pollutants in a full-scale anaerobic/anoxic/aerobic process combined with membrane bioreactor for municipal wastewater reclamation. Water Res 2010; 44: 5999-6010.

Ying GG, Yu XY, Kookana RS. Biological degradation of triclocarban and triclosan in a soil under aerobic and anaerobic conditions and comparison with environmental fate modelling. Environ Pollut 2007; 150: 300-5.

Yoon Y, Westerhoff P, Yoon J, Snyder S. Removal of $17 \beta$ Estradiol and Fluoranthene by Nanofiltration and Ultrafiltration. Journal of Environmental Engineering 2004; 130: $1460-1467$.

Yu Y, Huang Q, Cui J, Zhang K, Tang C, Peng X. Determination of pharmaceuticals, steroid hormones, and endocrine-disrupting personal care products in sewage sludge by ultra-high-performance liquid chromatography-tandem mass spectrometry. Analytical and Bioanalytical Chemistry 2011; 399: 891-902.

Zhang Y, Geissen SU, Gal C. Carbamazepine and diclofenac: removal in wastewater treatment plants and occurrence in water bodies. Chemosphere 2008; 73: 1151-61.

Zhao J, Li Y, Zhang C, Zeng Q, Zhou Q. Sorption and degradation of bisphenol A by aerobic activated sludge. J Hazard Mater 2008; 155: 305-11. 


\section{P a g e $\mid \mathbf{8 3}$}

Zhou H, Huang X, Wang X, Zhi X, Yang C, Wen X, et al. Behaviour of selected endocrine-disrupting chemicals in three sewage treatment plants of Beijing, China. Environmental Monitoring and Assessment 2010; 161: 107-21.

Zhou JL, Liu R, Wilding A, Hibberd A. Sorption of selected endocrine disrupting chemicals to different aquatic colloids. Environ Sci Technol 2007; 41: 206-13.

Zhou X, Oleszkiewicz JA. Biodegradation of oestrogens in nitrifying activated sludge. Environ Technol 2010; 31: 1263-9.

Ziels RM, Lust MJ, Gough HL, Strand SE, Stensel HD. Influence of Bioselector Processes on 17alpha-Ethinylestradiol Biodegradation in Activated Sludge Wastewater Treatment Systems. Environ Sci Technol 2014.

Ziylan A, Ince NH. The occurrence and fate of anti-inflammatory and analgesic pharmaceuticals in sewage and fresh water: treatability by conventional and nonconventional processes. J Hazard Mater 2011; 187: 24-36. 
P a g e | 84

\section{Chapter 3: Analytical Methods}

\section{Summary}

The purpose of this chapter was to develop and optimize a simple and economical method for the extraction and determination of BPA, EE2 and TCS using highperformance liquid chromatography (HPLC) coupled with ultraviolent (UV) detection at environmentally relevant concentrations in both dissolved and particulate phases.

To clean-up and pre-concentrate the liquid sample, solid phase extraction (SPE) method was optimized for high recovery of selected MCs and good clean-up. For sludge samples, four extraction methods were compared for isolation of BPA from activated sludge samples and modified for EE2 and TCS. Analysis was performed by optimized procedures using HPLC-UV. MAE had the highest recovery among examined extraction methods. The recoveries of BPA, TCS and EE2 in liquid samples were found to be $106 \pm$ $2,95 \pm 6$ and $88 \pm 5 \%$, respectively. Also satisfactory recoveries were obtained in solid samples (>75\%), except for TCS, where recoveries of $55 \pm 6 \%$ were obtained. For this reason, recovery correction was made for TCS by dividing the observed concentrations by recovery rates. The limit of detection (LOD) of the target compounds in liquid and solid samples were $100 \mathrm{ng} / \mathrm{L}$ and $100 \mathrm{ng} / \mathrm{g}$, respectively.

\footnotetext{
${ }^{1}$ Part of this chapter has been published as:

Banihashemi B, Droste RL. Trace level determination of bisphenol-A in wastewater and sewage sludge by high-performance liquid chromatography and UV detection. Water Quality Research Journal of Canada 2013; 48: 133-144.
} 
P a g e | 85

\subsection{Introduction}

Several extraction procedures have been developed for the isolation of BPA from environmental samples. For liquid samples the most common method used is solid-phase extraction (Kuch and Ballschmiter, 2001; Lee et al., 2005), although liquid-liquid extraction (González-Casado et al., 1998; Varelis and Balafas, 2000), soxhlet extraction (Pryor et al., 2002), and solid-phase microextraction (Chang et al., 2005; Helaleh et al., 2001; Huang et al., 2005) have also been reported. Among these extraction techniques, SPE has the advantages of relative low solvent usage, good reproducibility and repeatability, and convenient operation (Gang et al., 2005). For solid samples, several extraction methods have been used, including pressurized liquid extraction (Agüera et al., 2003; Ferrer et al., 2011), supercritical fluid extraction (Lee and Peart, 2000b), MAE (Liu et al., 2004; Pedersen and Lindholst, 1999), soxhlet extraction (Zhao et al., 2008), soxtec extraction (Jeannot et al., 2002), and ultrasonic extraction (Petrovic et al., 2001; Petrovic et al., 2002). The microwave assisted extraction (MAE) technique has proven to be more efficient than the soxhlet extraction due to less solvent consumption and low extraction time (Diagne et al., 2002). The determination of BPA in WWTPs has been analyzed mostly by chromatographic methods either by liquid chromatography (LC) (Benijts et al., 2004; Carabias-Martínez et al., 2004; Motoyama et al., 1999) or by gas chromatography (GC) (Meesters and Schröder, 2002; Urase and Kikuta, 2005) with or without mass 


\section{P a g e $\mid \mathbf{8 6}$}

spectrometric (MS) detection. GC/MS as a commonly used method has been reported to have good sensitivity and low detection limit for BPA trace determination (Gatidou et al., 2007; Hernando et al., 2004; Petrovic et al., 2001); however, it requires a derivatization procedure, which generally takes up to several hours to be completed. On the contrary, the micropollutant analyses using HPLC with choice of detectors such as UV, fluorescence and electrochemical detection only requires a simple and rapid pre-treatment method (Sajiki, 2001). Mohapatra et al. (2011) reviewed the analytical methods in the literature and concluded that among the possible detection methods, MS detection, especially LC/MS showed significant selectivity when the target compound existed in a complex matrix such as sludge and sediments. High sensitivity and popularity of the LCMS/MS system makes it a powerful tool for quantifying BPA in very low concentrations, ng/L (Baugros et al., 2008; Laganà et al., 2004; Mohapatra et al., 2010; Seyhi et al., 2011). However, MS detector is a complex machine that requires skilled personnel for operation. Also it is not easy to maintain high stability of analytical results, especially for low concentrations of analyte (Hammarling et al., 2000; Le Blanc et al., 2009). Additionally, this detection method is not available in every environmental laboratory and it is costly. Therefore researchers have tried to develop analytical methods using widely used HPLC systems to make it more feasible for laboratory technicians to detect BPA in environmental samples (Clara et al., 2004; Hadjmohammadi and Saeidi, 2010; Naassner et al., 2002; Zhao et al., 2008). Nevertheless, most of these researchers have 
P a g e $\mid \mathbf{8 7}$

looked at higher BPA concentrations than those found in the environment and mainly in liquid samples or they have used other detection methods such as fluorescence instead of widely used UV detection.

The purpose of this study was to develop, optimise and fully validate a simple, fast and precise integrated extraction and analytical method for the trace determination of BPA in the dissolved and particulate phases of wastewater, as well as, in sewage sludge. SPE and HPLC-UV were used for liquid samples based on their availability and ease of operation, while MAE, high-pressure homogenizer (HPH), accelerated solvent extraction (ASE), ultrasonication extraction (USE), followed by SPE were applied and compared for solid samples before the HPLC analysis.

\subsection{Material and Methods}

\subsubsection{Chemicals}

Methanol $(\mathrm{MeOH})$, hexane, acetonitrile $(\mathrm{ACN})$, dichloromethane, and acetone used for cleaning and extraction purposes, were purchased from Fisher Scientific (ON, Canada) and were all of HPLC grade. BPA (>97\% purity assay) was obtained from Sigma-Aldrich (ON, Canada). BPA stock solution was prepared in 45\% ACN/55\% MilliQ water at $1 \mathrm{mg} / \mathrm{L}$ and was used to regularly prepare working standard solutions for calibration and spiking experiments. Supelclean LC-18 (3 mL, $500 \mathrm{mg})$ cartridges used for extraction and clean-up of samples were supplied by Sigma-Aldrich (Oakville, ON, 


\section{P a g e $\mid \mathbf{8 8}$}

Canada). The Zorbax Eclipse plus C18 chromatography column $(4.6 \mathrm{~mm} \times 150 \mathrm{~mm}, 5$ $\mu \mathrm{m})$ was purchased from Chromatographic Specialties Inc. (ON, Canada). All other

chemical used in this study were supplied by Fisher scientific (ON, Canada) and were of analytical grade. Milli-Q water was prepared in the laboratory using a Milli-Q/ Millipore system with Super-C carbon, Ion-Ex, and Orgonex-Q cartridges.

\subsubsection{Extraction of liquid samples}

To clean-up and pre-concentrate the liquid samples, the SPE method using commercial SPE cartridge (Supelclean LC-18) was optimized with regards to sample $\mathrm{pH}$, sample volume, washing and elution solvents, for high recovery of BPA and good cleanup. The LC-18 cartridge was chosen in this study due to its higher recovery and reproducibility found in the literature (Gatidou et al., 2007).

For the optimization experiments, a set of $100 \mathrm{~mL}$ wastewater effluent samples were collected from lab-scale porous pot reactor and filtered through a pre-ashed glass fiber filter $(\mathrm{GF} / \mathrm{C}$, pore size $0.45 \mu \mathrm{m})$. Then samples were spiked with the $1 \mathrm{~mL}$ of $1 \mathrm{mg} / \mathrm{L}$ BPA standard solution. The spiked samples were mixed in an ultrasonic bath for 15 min to ensure efficient distribution of the compounds in the solution. LC-18 cartridges fitted on a vacuum apparatus (CHROMABOND, Fishersci, ON, Canada) were used to isolate BPA from the spiked wastewater effluent samples. SPE requires four main steps: conditioning, sample loading, washing and elution. Each step can be optimized based on the compound properties and matrix effect to increase the recovery rate. Although many 


\section{P a g e $\mid \mathbf{8 9}$}

SPE procedures that are introduced in the literature such as EPA method 3535A, however these methods are not specific for every compounds nor for all cartridges and can only be used as a very good starting point. Therefore, the optimization of each step in SPE method is important if highest recovery of compound of interest is of concern. Conditioning the reversed phase cartridges such as LC-18, is usually proceeded with two tube-volumes of water-miscible organic solvent such as $\mathrm{MeOH}$, and followed by two tube-volumes of buffer solution or water. Sample loading was performed by applying vacuum pressure at flow rate of $5 \mathrm{~mL} / \mathrm{min}$. Studies have shown that the sample $\mathrm{pH}$ and total sample volume affect the extraction efficiency and sample recovery (Gatidou et al., 2007; Hadjmohammadi and Saeidi, 2010; Hennion, 2000); consequently, the sample pH and the breakthrough volume were optimized in this study. To remove unwanted impurities from the sample and enhance the selectivity in the separation step, the washing solution needs to be stronger than the sample matrix to remove impurities, while it must not be able to extract and remove the compound of interest. Hence, the method was optimized based on the solvent composition in the washing step. In the final step, the elution solvent was chosen to remove the compounds of interest from the tube packing and increase the recovery of BPA. It is generally accepted that using small aliquots is more efficient than using larger aliquots in the elution step; therefore, 3 aliquots of tube size volume $(3 \times 3 \mathrm{~mL})$ were chosen with drop-wise flow in the elution step. 


\section{P a g e $\mid \mathbf{9 0}$}

\subsubsection{Extraction of solid samples}

To find the proper extraction method with highest recovery, low cost and ease of operation, extraction of the target compounds from sewage sludge was performed and compared by ASE, MAE, USE, and HPH. Initially, a set of $100 \mathrm{~mL}$ mixed liquor suspended solids (MLSS) samples was homogenized and deactivated using sodium azide solution $(0.2 \% \mathrm{w} / \mathrm{w})$ to prevent biodegradation. This concentration has been shown to inhibit the biodegradation process without causing any cell lysis, and also it does not cause change to sludge hydrophobicity (Guellil et al., 1998; Xu et al., 2008; Yi and Harper, 2007). Deactivated samples were mixed on an orbital shaker for $2 \mathrm{~h}$ at $200 \mathrm{rpm}$, and then were centrifuged for $30 \mathrm{~min}$ at $10000 \mathrm{rpm} .2 \mathrm{~g}$ of wet sludge cake were collected, dried at $60^{\circ} \mathrm{C}$ for $12 \mathrm{~h}$ and spiked with $1 \mathrm{~mL}$ of $200 \mu \mathrm{g} / \mathrm{L} \mathrm{BPA}$ standard solution and allowed to accumulate in the biomass for $12 \mathrm{~h}$. These prepared dried sludge samples (0.2 g) were used for MAE and ASE extraction while wet sludge samples (2 g) were collected for USE and HPH extraction. Prior to extraction $5 \mathrm{~g}$ of anhydrous sodium sulfate was added to each sample to remove the moisture. Two additional control samples were prepared with the same procedure using Milli-Q water with no biomass and unspiked biomass to measure the BPA loss to the glassware, as well as calculating the background BPA level. To investigate any BPA loss during the drying procedure, wet sludge samples were also prepared. All samples were extracted using ASE, USE, HPH and MAE, and then extracts were filtered through $0.22 \mu \mathrm{m}$ filters (Millipore, nylon 


\section{P a g e |91}

hydrophilic), evaporated by gentle nitrogen gas to dryness and re-dissolved in $10 \mathrm{~mL}$ of $\mathrm{MeOH}$ for further treatment by SPE. Since the compound of interest is already in $\mathrm{MeOH}$ and might be eluted along with other impurities existed in sample, SPE extraction method was modified to increase the reaction time between the sample and bonding silica inside the cartridge by eliminating the vacuum pressure and using the gravity force in sample loading step.

The ASE system, Dionex ASE 200, was used to extract BPA from sludge samples. The samples were extracted in a 1:1 (v/v) mixture of acetone/hexane solvent solution (15 $\mathrm{mL}$ ). The procedure for ASE system for BPA extraction was reported in Gang et al. (2005). It consists of 5 min static time, two extraction cycles, 50\% flush, $120 \mathrm{~s}$ purge, and repeating the flush and purge twice. For ultrasound extraction, a sonifier system (Branson model S-450D) with frequency of $20 \mathrm{KHz}$ was used. A procedure for extracting nonvolatile and semi-volatile organic compounds from solids such as soils, sludges, and wastes is presented in EPA method 3550C (February, 2007). A 2 g wet sludge sample was extracted with 1:1 (v/v) acetone/hexane solvent solution $(100 \mathrm{~mL})$ three times, using ultrasonic extraction with $50 \%$ energy cycle for 10 min. MAE extraction was carried out with a Mars $5^{\circledR}$ (MW Accelerated Reaction System; CEM Corporation) MW oven. This extraction method uses MW energy to produce elevated temperature and pressure conditions in a closed vessel containing the sample and organic solvents to achieve analyte recoveries equivalent to those from Soxhlet extraction, using less solvent and 


\section{P a g e $\mid \mathbf{9 2}$}

taking significantly less time than the Soxhlet procedure. It is also validated on commercially-available solvent extraction systems in EPA method, SW-846-3546 (February 2007). The sample was extracted in a 1:1 (v/v) mixture of acetone/hexane solvent solution $(20 \mathrm{~mL})$ with MW power of $1200 \mathrm{~W}(100 \%)$ and the extraction was performed in the temperature-controlled mode. The extraction procedure was a modified protocol based on the method reported at Mohapatra et al. (2011). Temperature was ramped to $110^{\circ} \mathrm{C}$ for $10 \mathrm{~min}$, and then held at $110^{\circ} \mathrm{C}$ for $10 \mathrm{~min}$. The extract was removed from the cell and the procedure was repeated three times. High pressure homogenizing extraction was carried out with the EmulsiFlex-C3 homogenizer which is powered by an electric motor, homogenizing valve, pressurized tank (adjustable between 500 and 30000 psi or 35 and 2000 bar) and temperature control system by heat exchanger. $2 \mathrm{~g}$ of wet spiked sludge was extracted with $30 \mathrm{~mL}$ of $1: 1(\mathrm{v} / \mathrm{v})$ acetone/hexane solvent solution three times at $15000 \mathrm{psi}$.

BPA was detected by HPLC (Hewlett-Packard, HP 1100). The system consisted of the degasser (G1322A), a quaternary pump (G1311A), an ALS auto sampler (G1313A), a Colcomp column oven (G1314A) and multi-wavelength UV-VIS detector (G1365A). A ZORBAX Eclipse Plus C18 $(4.6 \times 150 \mathrm{~mm}, 5 \mu \mathrm{m})$ column was used. The HPLC detection method was optimized as a part of this study based on the organic mobile phase selection and injection volume. 
P a g e $\mid \mathbf{9 3}$

\subsection{Results and Discussion}

\subsubsection{Optimization of solid phase extraction}

Effluent samples of $100 \mathrm{~mL}$ volume were collected, filtered and spiked with $1 \mathrm{~mL}$ of $1 \mathrm{mg} / \mathrm{L}$ BPA standard solution to investigate the effect of sample $\mathrm{pH}$ on recovery of BPA. Generally, the speciation of weakly acidic compounds in aqueous solutions depends on the solution properties, such as its $\mathrm{pH}$ value. Acidification of water solution is likely to decrease the dissociation of weakly acidic analytes; this may lead to increasing extraction efficiency of the target compounds if the non-dissociated form binds strongly to the SPE cartridges. Also, the extraction efficiency of polar ionisable molecules using SPE columns is normally enhanced by suppressing ionization of the analytes by $\mathrm{pH}$ control of the sample. Since the pKa value of BPA is around 9.8-10, therefore at least a $2 \mathrm{pH}$ difference between the $\mathrm{pH}$ of the sample solution and $\mathrm{pKa}$ value of BPA is needed in order to prohibit the BPA from ionization. $\mathrm{pH}$ of samples was modified by adding $\mathrm{HCl}$ or $\mathrm{NaOH}$ to each sample before spiking with standard solution, and the recoveries of BPA samples with different pHs $(2,7$, and 11) were compared (Figure 3-1). $\mathrm{pH}$ control of the sample may also be advantageous if retention of ionizable polar interferences can be reduced by adjusting the sample $\mathrm{pH}$ to ensure the interferences are ionized and retained less strongly by the column. This can be the reason why $\mathrm{pH}$ of 2 had a higher recovery than $\mathrm{pH}$ of 7 for BPA. 


\section{P a g e $\mid \mathbf{9 4}$}

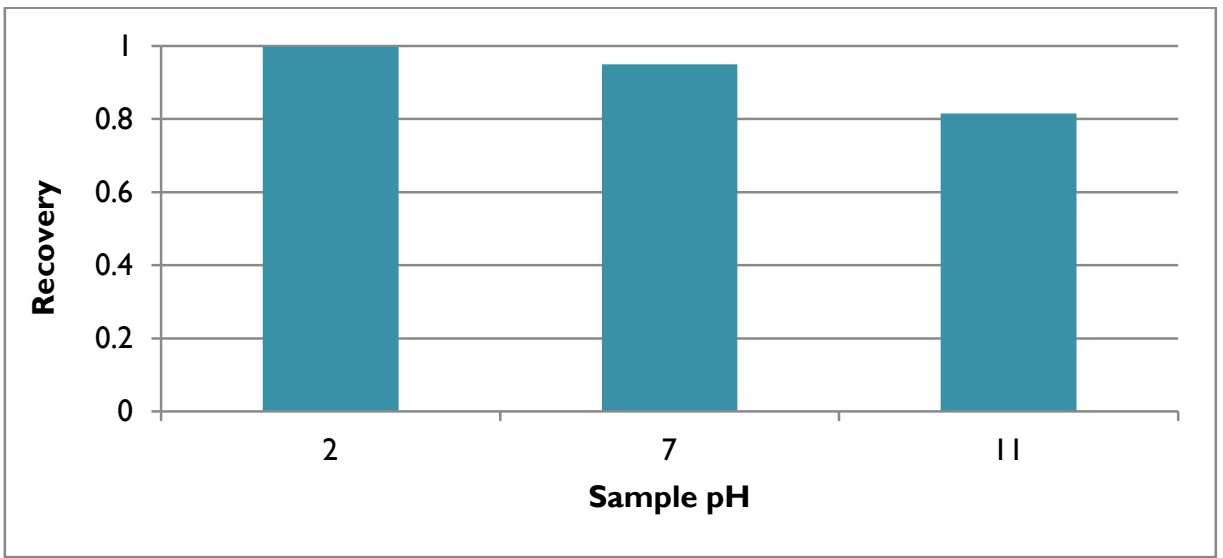

Figure 3-1. Effect of sample $\mathrm{pH}$ on recovery of BPA from wastewater effluent sample

Breakthrough volume is the volume at which a particular solute passing continuously through a column begins to elute and it is useful in determining the total column sorption capacity for a specific compound. The breakthrough volume determination is a very important step in BPA extraction and determination level since it demonstrates the preconcentration factor and capacity of the SPE cartridge used. In this study, Hennion's procedure (Hennion, 2000) was used to determine the breakthrough volume; therefore, the same amount of BPA standard solution was added to $10-1000 \mathrm{~mL}$ of wastewater effluent samples (adjusted to $\mathrm{pH}$ 2) and passed through the cartridge. The retained analyte was then eluted with $3 \mathrm{~mL}$ of $\mathrm{MeOH}$ three times, dried by a gentle stream of nitrogen gas reconstituted in $1 \mathrm{~mL}$ of $\mathrm{MeOH}$, and analyzed by HPLC system. Recoveries of samples were measured based on the height of the response chromatograph. The results showed that the recovery of BPA declined after the breakthrough volume of $100 \mathrm{~mL}$ (Figure 3-2). 
P a g e $\mid \mathbf{9 5}$

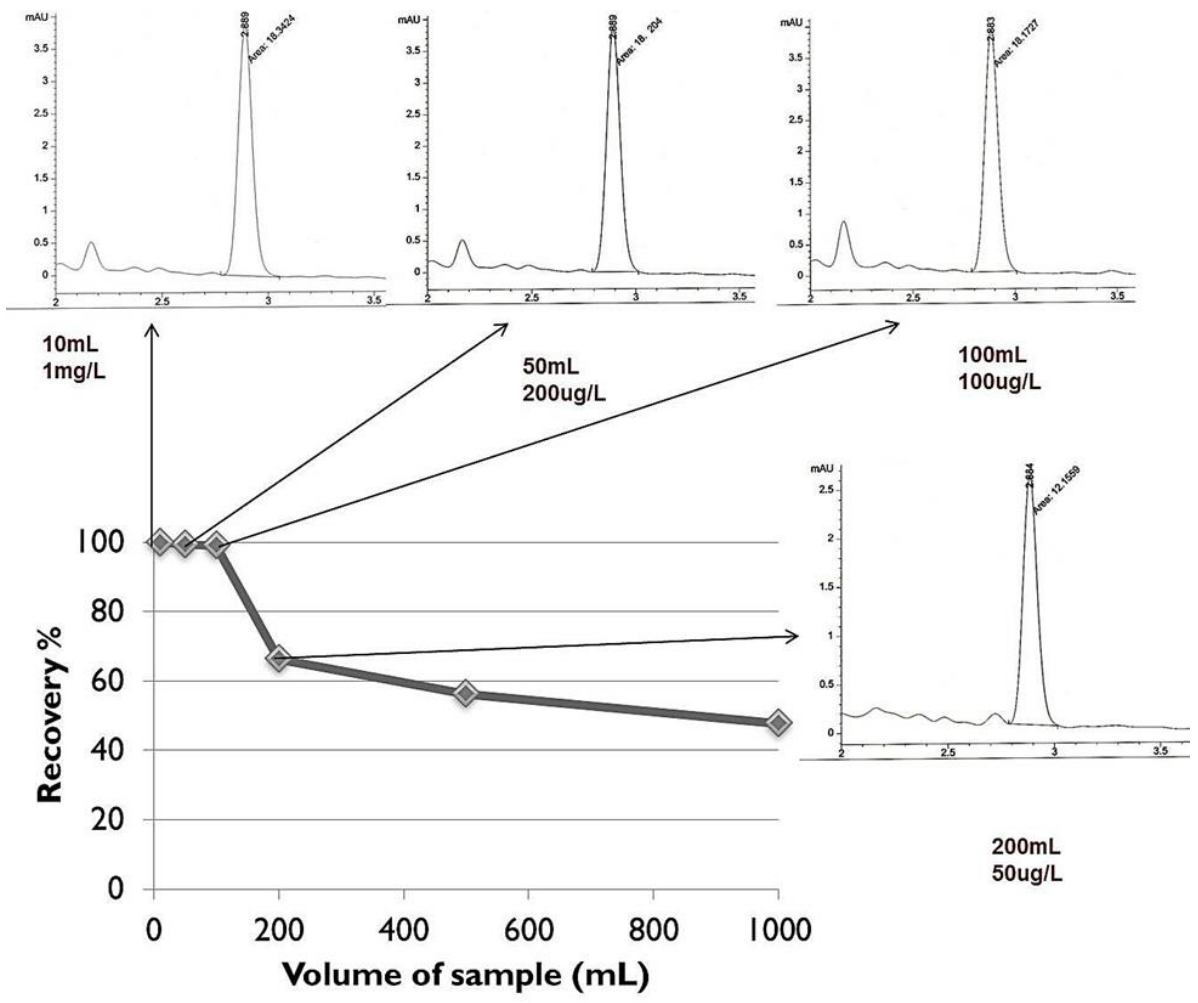

Figure 3-2. Effect of sample volume on recovery of BPA in SPE sample loading step

The washing solution needs to be stronger than the sample matrix to remove impurities, while it must not be able to extract and remove the compound of interest, therefore the proper percentage of solvent is needed to obtain the highest recovery of the compound of interest. Seven different MeOH/milli-Q water ratios (10, 20, 30, 40, 50, 60, $70 \%$ ) were chosen for optimizing the washing solution to remove the impurities and increase the recovery of BPA from wastewater effluent samples. The results show that the $30 \%$ methanol solution did not wash out the BPA from the cartridge bonding material while it removed the impurities of sample, therefore the maximum recovery was found when 30\% MeOH and 70\% Milli-Q water was used (Figure 3-3). 


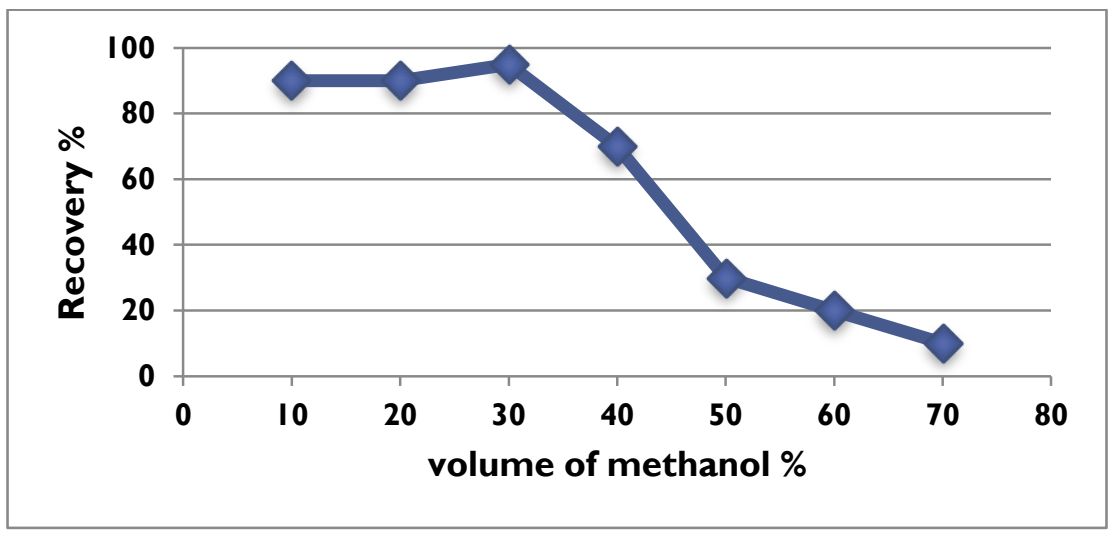

Figure 3-3. Effect of volume of $\mathrm{MeOH}$ in solvent solution on recovery of BPA in washing step

Analytes can be eluted using an organic solvent such as methanol, tetrahydrofuran, isopropanol, acetonitrile, acetone or ethyl acetate. In this study, there common water miscible organic solvents, $\mathrm{MeOH}, \mathrm{ACN}$ and acetone were used in the SPE elution step, and the recoveries of BPA using these solvents were studied. The recovery of BPA was compared based on the result of HPLC analysis (Figure 3-4). $\mathrm{MeOH}$ and ACN were both found suitable for elution based on their strong polarity characteristics; however, $\mathrm{MeOH}$ was chosen due to its lower cost.

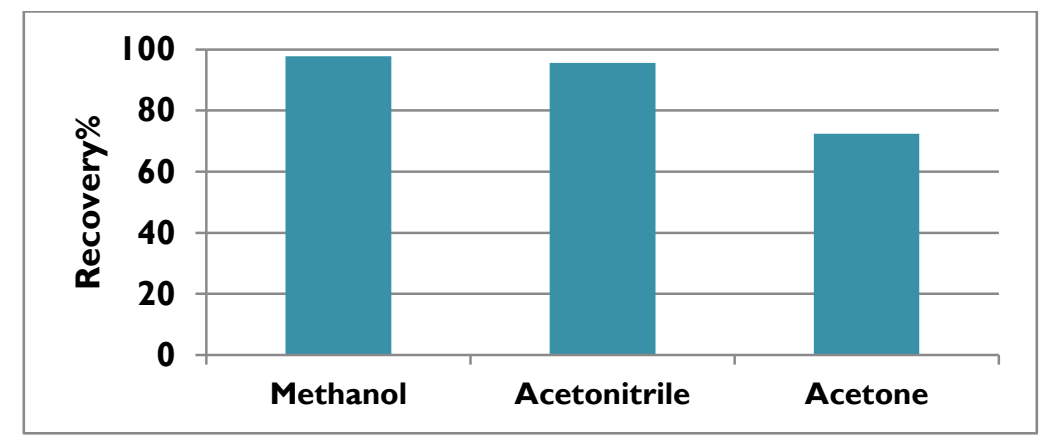

Figure 3-4. Effect of solvent selection on recovery of BPA in SPE elution step 


\section{P a g e $\mid \mathbf{9 7}$}

$\mathrm{MeOH}$ and $\mathrm{ACN}$ with or without buffer solution were reported as an adequate mobile phase to detect BPA. In this study, $\mathrm{ACN}$ was shown to have a lower noise level and increased the detection limit of BPA compared to $\mathrm{MeOH}$; therefore, it was chosen for optimization studies. To detect the optimum mobile phase solution, different ratios of milli-Q water/ACN with same injection volume were used and samples with same BPA concentration $(20 \mu \mathrm{g} / \mathrm{L})$ were compared for best peak shape, lower noise level and better calibration curve (Figure 3-5). In addition, sample volumes of 10, 20, 40 and $100 \mathrm{~mL}$ with the same concentration of BPA were injected into the HPLC and the effect of injection volumes were investigated (Figure 3-6).

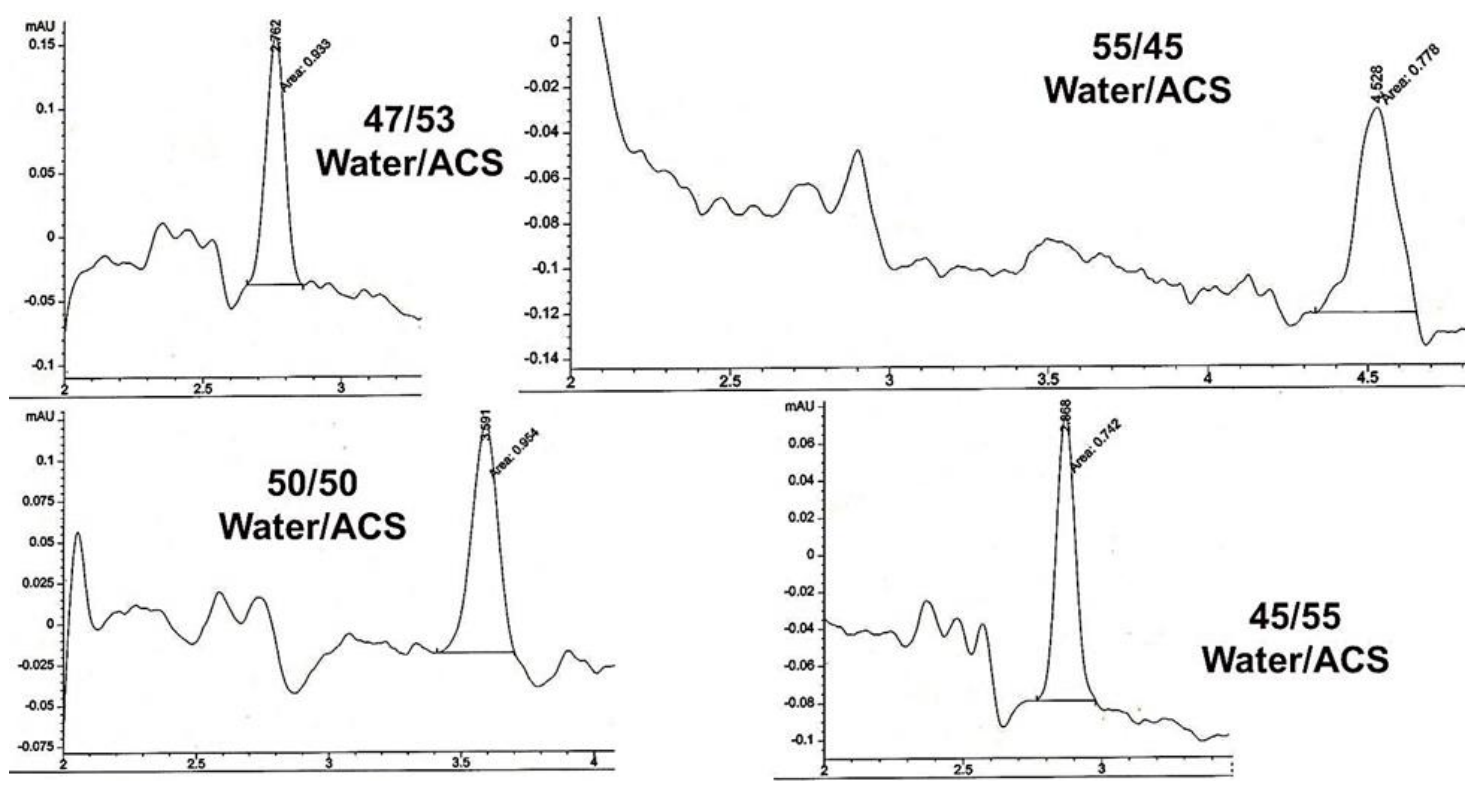

Figure 3-5. Effect of solvent ratio on recovery of BPA in HPLC-UV system 

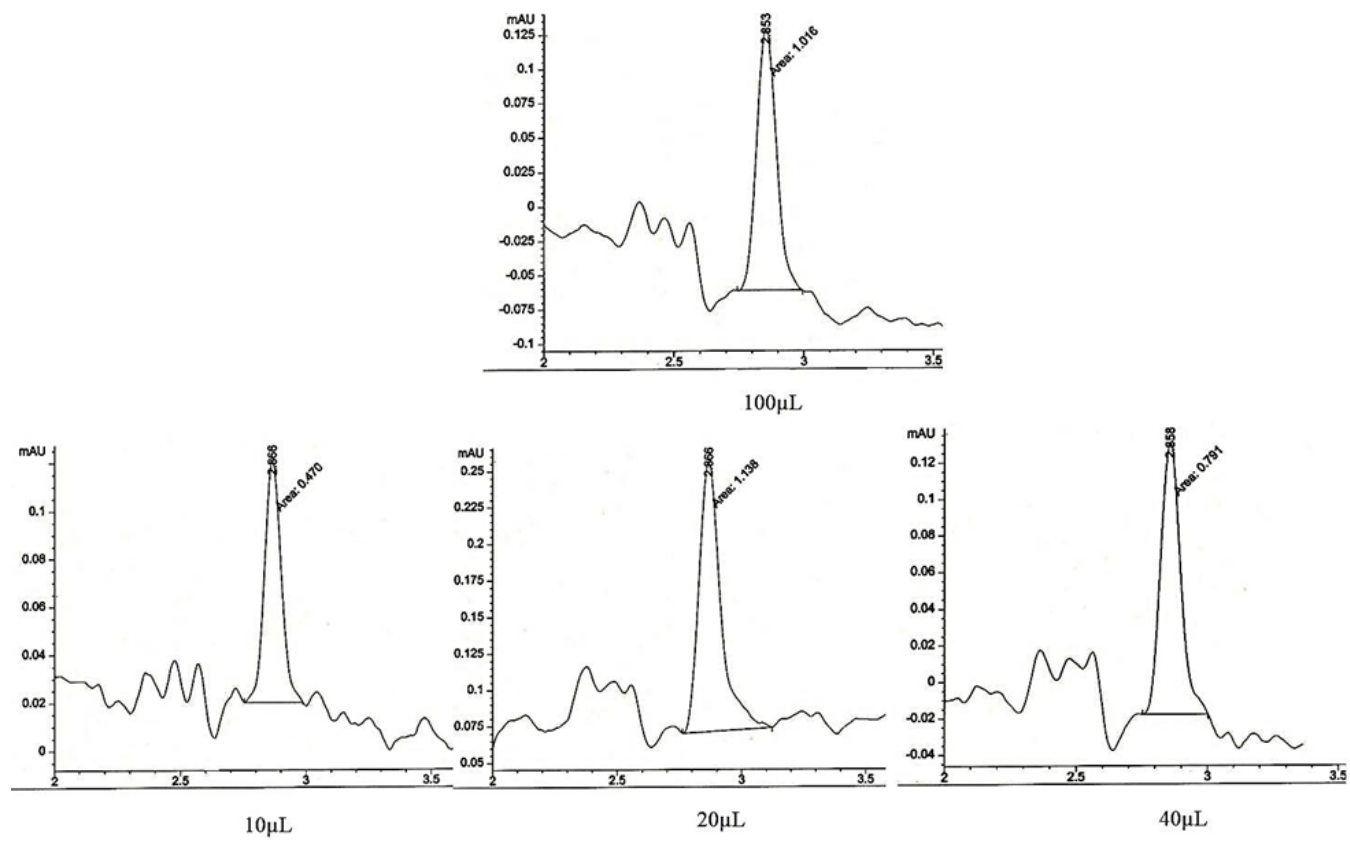

Figure 3-6. Effect of injection volume on recovery of BPA in HPLC-UV system

Table 3-1, summarizes the SPE and HPLC-UV optimized condition, which was found as a part of this work to detect BPA in environmentally relevant concentration in liquid samples. To study the efficiency of optimized SPE method for liquid samples, three replicate wastewater effluent samples, spiked at two trace level concentrations of 100 ng/L and $1 \mu \mathrm{g} / \mathrm{L}$, were cleaned-up and analyzed based on the described method. Recovery rates were determined to be $93 \pm 4.8$ and $102 \pm 3.3 \%$ for samples with 100 $\mathrm{ng} / \mathrm{L}$ and $1 \mu \mathrm{g} / \mathrm{L}$ BPA concentrations, respectively.

The same extraction method was applied to extracted solid samples prior to HPLC analysis for more clean-up and pre-concentration purposes with slightly modified steps. The vacuum pressure sample loading step was replaced by the gravity pressure loading to 
increase the retention time. In addition, to eliminate the sludge matrix effect and the solvent front peak effect on the BPA response peak, the mobile phase solvent of HPLC was replaced with less ACN content solvent (45\%ACN/55\%Milli-Q water) to decrease the polarity of solution and increase the elution time of BPA. These changes were shown in parenthesis in Table 3-1.

Table 3-1 SPE and analytical condition for liquid chromatography-ultraviolet analysis of BPA

\begin{tabular}{|c|c|}
\hline SPE Conditions & HPLC Conditions \\
\hline $\begin{array}{l}\text { Conditioning : } 5 \mathrm{~mL} \text { twice } \mathrm{MeOH} \text { and } \\
5 \mathrm{~mL} \text { twice milli-Q water }\end{array}$ & $\begin{array}{l}\text { Column: ZORBAX Eclipse Plus C18 } \\
4.6 \times 150 \mathrm{~mm}, 5 \mu \mathrm{m}\end{array}$ \\
\hline Loading: $100 \mathrm{~mL}$ at $10 \mathrm{~mL} / \mathrm{min}$ & Injection Volume: $10 \mu \mathrm{L}$ \\
\hline $\begin{array}{l}\text { Washing: } 5 \mathrm{~mL} \text { twice } \mathrm{MeOH} / \text { Water } \\
(30 / 70)\end{array}$ & $\begin{array}{l}\text { Mobile Phase: } 55 \% \text { ACN } / 45 \% \text { Milli-Q water } \\
\text { (45\%ACN/55\%Milli-Q water for sludge } \\
\text { samples) }\end{array}$ \\
\hline Dry with vacuum & Flowrate: $1 \mathrm{~mL} / \mathrm{min}$ \\
\hline Elution: $3 \mathrm{~mL} \mathrm{MeOH}$ three times & UV detection: $230 \mathrm{~nm}$ \\
\hline Dry with nitrogen gas & $\begin{array}{l}\text { Elution time: } 2.88 \mathrm{~min} \text { ( } 4.21 \mathrm{~min} \text { for sludge } \\
\text { samples) }\end{array}$ \\
\hline Dissolved in $1 \mathrm{~mL} \mathrm{MeOH}$ & Limit of Detection: $100 \mathrm{ng} / \mathrm{L}$ \\
\hline
\end{tabular}

\subsubsection{Results of method comparison for extraction of BPA in sludge samples}

The result of recovery study for BPA is presented in Table 3-2. Recoveries were evaluated by analyzing three replicates and then applying the following equation: 
P a g e | 100

Recovery $(\%)=\left(\mathrm{C}_{\mathrm{m}}-\mathrm{C}_{\mathrm{o}}\right) / \mathrm{C}_{\mathrm{s}} \times 100$

where, $\mathrm{C}_{\mathrm{m}}$ is the measured concentration of the BPA in the spiked sample, $\mathrm{C}_{\mathrm{o}}$ is the initial concentration of BPA in sludge sample, and $\mathrm{C}_{\mathrm{s}}$ is the concentration of BPA spiked.

Table 3-2 Spiked concentration of BPA in sludge samples, mean recovery, and relative standard deviation (RSD)

\begin{tabular}{|l|l|l|l|l|l|}
\hline $\begin{array}{c}\text { Extraction } \\
\text { Method }\end{array}$ & $\begin{array}{c}\text { Conc. in unspiked } \\
\text { sludge (ng/g) }\end{array}$ & $\begin{array}{c}\text { Spiked Conc. } \\
\text { (ng/g) }\end{array}$ & $\begin{array}{c}\text { Determined } \\
\text { concentration (ng/g) }\end{array}$ & $\begin{array}{c}\text { Mean recovery } \\
\text { rate (\%) }\end{array}$ & $\begin{array}{c}\text { RSD } \\
(\%)\end{array}$ \\
\hline ASE & 180 & 1000 & 725 & 55 & 9 \\
\hline MAE & 135 & 1000 & 1025 & 90 & 5 \\
\hline USE & 125 & 1000 & 845 & 73 & 6 \\
\hline HPH & 160 & 1000 & 700 & 53 & 5 \\
\hline
\end{tabular}

The results showed that the MAE method had the highest BPA recovery percentage followed by USE. Therefore, the MAE method was chosen in this study for further method validation and limit of detection (LOD) calculation. For the determination of the method LOD, $2 \mathrm{~g}$ of sludge sample was extracted and then spiked with $200 \mathrm{ng}$ of BPA. The LOD of BPA was calculated as three times the signal-to-noise ratio of the relative chromatograph. Limits of quantification (LOQ) were determined as 3.3 times of LOD. For the sludge samples, using the microwave-assisted extraction method, the obtained LOD and LOQ was found to be $100 \mathrm{ng} / \mathrm{g}$ dry weight and $330 \mathrm{ng} / \mathrm{g}$, respectively. 


\subsubsection{Validation of the method}

In order to evaluate the trueness of the method, mass balance experiments were conducted and concentrations of BPA in both liquid and solid phases were determined based on the analytical procedure presented in this study (Figure 3-7).

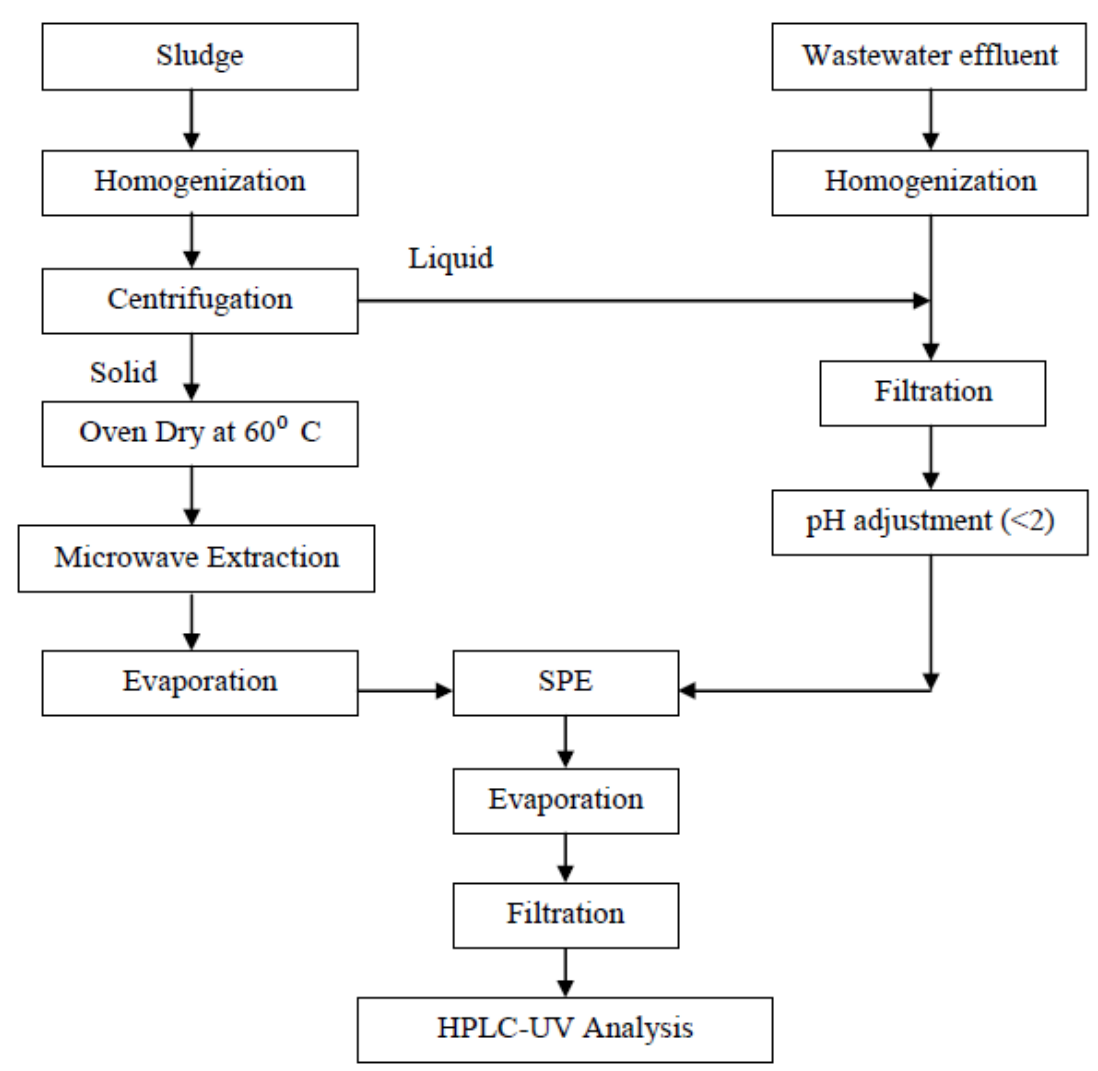

Figure 3-7. Schismatic diagram of analytical procedure for analysis of BPA in liquid and solid phases

The mass balance study was carried out with $100 \mathrm{~mL}$ of MLSS spiked samples. Three $100 \mathrm{~mL}$ aliquots of MLSS samples were collected from three porous pot reactors with varied solid retention time $(5,10$, and 15 days) and mean biomass concentration of 3145 , 


\section{P a g e $\mid \mathbf{1 0 2}$}

2763, and $1733 \mathrm{mg}$ volatile suspended solids (VSS)/L, respectively. Samples were homogenized, and deactivated using sodium azide solution $(0.2 \% \mathrm{w} / \mathrm{w})$. Deactivated samples were mixed on the orbital shaker for $2 \mathrm{~h}$ at $200 \mathrm{rpm}$, and spiked with BPA standard solution to the total concentration of $10 \mu \mathrm{g} / \mathrm{L}$. Samples were then mixed for $12 \mathrm{~h}$ to accumulate BPA in the biomass and subsequently were centrifuged for $30 \mathrm{~min}$ at $10000 \mathrm{rpm}$. The sludge cakes were carefully removed from the centrifuged tube and dried at $60^{\circ} \mathrm{C}$ for almost $12 \mathrm{~h}$ until constant weight was reached. The similar MLSS samples were collected and VSS concentrations were measured for calculating biomass concentration. The dried biomass was placed into microwave vessels and $5 \mathrm{~g}$ of sodium sulfate anhydrous was added and mixed to form a free floating powder. Later $20 \mathrm{~mL}$ of acetone/hexane $(1: 1, \mathrm{v} / \mathrm{v})$ solvent solution was imported to each vessel which was then put in the microwave for BPA extraction. The extraction procedure was carried out based on the MAE method described previously. After microwave extraction, the samples were evaporated with a gentle stream of nitrogen, re-dissolved into $10 \mathrm{~mL}$ of $\mathrm{MeOH}$, and were cleaned-up and pre-concentrated using the optimized SPE method. For liquid samples, the supernatant of centrifuged MLSS was filtered and $\mathrm{pH}$ of samples was adjusted to 2 for further treatment by SPE cartridges. After the SPE process, all liquid and solid samples were evaporated to dryness, re-dissolved in $1 \mathrm{~mL}$ of $45 \% \mathrm{ACN} / 55 \%$ Mili-Q water, and filtered through $0.22 \mu \mathrm{m}$ Milipore syringe filters before analyzing with HPLC. A set of un-spiked samples was collected for determination of background BPA level 


\section{P a g e $\mid \mathbf{1 0 3}$}

from each reactor and all recoveries were adjusted based on those results. Blank samples using distilled water were prepared to evaluate any BPA loss during the mass balance study for both liquid and solid samples. The results of blank sample analysis showed a mean recovery of $106 \pm 2 \%$ for all blank samples. Precision was assessed by analyzing repeatability and reproducibility of three replicates $(n=3)$ of MLSS samples from three different reactors $(k=3)$. All samples were analyzed three times using HPLC-UV. Precision and mean recovery data of the extraction and analytical procedure for MLSS samples are given in Table 3-3. The results demonstrate satisfactory precision of the analytical procedure for MLSS samples. RSDs were less than $8 \%$ for BPA in all samples, indicating good precision of the developed analytical methods for both liquid and solid samples. The recoveries ranged between $80-92 \%$ for all measured samples with an average recovery of $86 \%$. The results from the validation experiments were compared for any significant differences using one-way analysis of variance (ANOVA) and posthoc analysis (Tukey) (IBM SPSS for Windows, 2010). Statistical analysis of the results had shown that there is no significant difference between the recoveries of samples taken from the same reactor, also from reactors with highest and lowest biomass concentration (sludge retention times (SRTs) of 15 and 5 days); however, the recovery of samples from a reactor with SRT of 10 days was slightly higher than the other two reactors (Table 3-4). This was in agreement with Yi and Harper (2007) and could be due to a lower BPA 


\section{P a g e | 104}

sorption partition coefficient in sludge samples at SRT of 10 days and higher recovery level in liquid samples opposed to solid samples.

Table 3-3 Precision and mean recovery data of the extraction and analytical procedure to detect BPA in solid and liquid samples

\begin{tabular}{|c|c|c|c|}
\hline $\begin{array}{c}\text { Spiked Level } \\
(\mu \mathrm{g} / \mathrm{L})\end{array}$ & $\begin{array}{c}\text { Precision RSD (\%) } \\
\mathrm{n}=3, \mathrm{k}=3\end{array}$ & $\begin{array}{c}\text { Recovery } \\
(\%)\end{array}$ & $\begin{array}{c}\text { Standard } \\
\text { deviation }\end{array}$ \\
\hline 10 & 7.2 & 86 & 4.3 \\
\hline
\end{tabular}

Table 3-4 Result of one-way ANOVA and Tukey analysis for BPA recoveries from three porous pot reactors (Multiple Comparisons)

\begin{tabular}{|c|c|c|c|c|c|c|}
\hline \multirow[b]{2}{*}{$\begin{array}{c}\text { (I) } \\
\text { Reactor.Number }\end{array}$} & \multirow[b]{2}{*}{$\begin{array}{c}(\mathrm{J}) \\
\text { Reactor.Number }\end{array}$} & \multirow[b]{2}{*}{$\begin{array}{c}\text { Mean } \\
\text { Difference }(\mathrm{I}-\mathrm{J})\end{array}$} & \multirow[b]{2}{*}{ Std. Error } & \multirow[b]{2}{*}{ Sig. } & \multicolumn{2}{|c|}{$\begin{array}{l}\text { 95\% Confidence } \\
\text { Interval }\end{array}$} \\
\hline & & & & & $\begin{array}{l}\text { Lower } \\
\text { Bound }\end{array}$ & $\begin{array}{l}\text { Upper } \\
\text { Bound }\end{array}$ \\
\hline \multirow[t]{2}{*}{1} & 2 & $-0.06^{*}$ & 0.01 & 0.0 & -0.1 & -0.03 \\
\hline & 3 & 0.01 & 0.01 & 0.72 & -0.02 & 0.04 \\
\hline \multirow[t]{2}{*}{2} & 1 & $0.06^{*}$ & 0.01 & 0.0 & 0.03 & 0.1 \\
\hline & 3 & $0.07^{*}$ & 0.01 & 0.0 & 0.04 & 0.11 \\
\hline \multirow[t]{2}{*}{3} & 1 & -0.01 & 0.01 & 0.72 & -0.04 & 0.02 \\
\hline & 2 & $-0.07^{*}$ & 0.01 & 0.0 & -0.11 & -0.04 \\
\hline
\end{tabular}

* The mean difference is significant at the 0.05 level.

\subsection{Conclusion}

The combination of SPE and HPLC-UV analyses permitted a sensitive, reliable, and rapid determination of low level BPA concentration in wastewater and sludge samples. SPE parameters and HPLC conditions were optimized concerning sample $\mathrm{pH}$, volume, washing, elution solvents, HPLC injection volume and mobile phase. Four solid 


\section{P a g e $\mid \mathbf{1 0 5}$}

extraction techniques were compared in this study for trace determination of BPA in sludge samples and the results showed that the recovery of BPA in spiked samples ranged from 60 to $90 \%$ for ASE, HPH, USE, and MAE extraction methods. The MAE was proven to have the highest recovery and low solvent consumption. The optimized SPE condition for LC-18 cartridges was also reported in this work and demonstrated high recoveries for BPA detection in liquid samples. To validate the extraction and HPLC-UV analysis of BPA at trace level concentration, a mass balance study was performed and the results showed good recovery of BPA in all mass balance samples (average of $86 \%$ ). RSDs were found to be less than $8 \%$ for BPA in all samples, indicating the good precision of the developed analytical methods for both liquid and solid samples. The LOD for liquid and solid samples were found to be $100 \mathrm{ng} / \mathrm{L}$ and $100 \mathrm{ng} / \mathrm{g}$, respectively. Low-cost, fast, simple sample preparation, simplicity of HPLC-UV detection, as well as good repeatability and reproducibility make this method a useful tool for the routine analysis of BPA in wastewater and sludge samples.

\subsection{Modification of Analytical Method for TCS and EE2}

The sample preparation and SPE extraction procedure was modified to extract the TCS and EE2 more efficiently with previously described method. Three modifications were applied to sample preparation where oven dry process for sludge samples and $\mathrm{pH}$ adjustment for liquid samples were eliminated, respectively to improve the recovery of TCS. The SPE extraction procedure was also modified for microwaved extracted samples 


\section{P a g e | 106}

by further diluting the $10 \mathrm{~mL}$ extracted $\mathrm{MCs}$ in $\mathrm{MeOH}$ into $100 \mathrm{~mL}$ of $10 \% \mathrm{MeOH} / 90 \%$ MilliQ water solution prior to the loading step. After SPE process all liquid and solid samples were evaporated to dryness, re-dissolved in $1 \mathrm{~mL}$ of $45 \%$ ACN/55\% MilliQ water, and filtered through $0.22 \mu \mathrm{m}$ Milipore syringe filter before analyzing with high pressure liquid chromatography (HPLC).

Determination of selected MCs was also modified to detect TCS, EE2 and BPA simultaneously. ACN/water (45:55, v/v) as mobile phase was used as a binary gradient with a flow rate of $1 \mathrm{~mL} \mathrm{~min}^{-1}$ at room temperature and a pressure of about 65 bars. Ten $\mu \mathrm{L}$ of sample were injected and were eluted out of the column within 25 min. For measurement, an elution program starts with $45 \% / 55 \% \mathrm{ACN} /$ water for $10 \mathrm{~min}$, increased to 55\%/45\% ACN/water from 10 min until 25 min, and increased to $100 \% \mathrm{ACN}$ from 25 to 30 min. Table 3-5, summarizes the SPE and HPLC-UV optimized condition, which was found to detect selected MCs in environmentally relevant concentration. Based on the presented determination method, satisfactory precision with relative standard deviations (RSDs) less than 10\% for selected MCs was found. Recoveries of the method for wastewater and sewage sludge were determined by analysing fortified samples of each type of wastewater and sludge spiked in triplicate to $1 \mu \mathrm{g} / \mathrm{L}$ and $0.5 \mu \mathrm{g} / \mathrm{g}$ dry weight (d.w.), respectively. The recoveries of BPA, TCS and EE2 in liquid samples were found to be $106 \pm 2,95 \pm 6$ and $88 \pm 5 \%$, respectively. Also satisfactory recoveries were obtained in solid samples (>75\%), except for TCS, where recoveries of $55 \pm 6 \%$ were 
obtained. For this reason, recovery correction was made for TCS by dividing the observed concentrations by recovery rates. The limits of detection (LOD) of the target compounds in liquid and solid samples were $100 \mathrm{ng} / \mathrm{L}$ and $100 \mathrm{ng} / \mathrm{g}$, respectively.

Table 3-5 SPE and analytical condition for liquid chromatography-ultraviolet analysis of BPA

\begin{tabular}{|l|l|}
\hline SPE Conditions & HPLC Conditions \\
\hline $\begin{array}{l}\text { Conditioning : } 5 \mathrm{~mL} \text { twice } \mathrm{MeOH} \text { and } \\
5 \mathrm{~mL} \text { twice milli-Q water }\end{array}$ & $\begin{array}{l}\text { Column: ZORBAX Eclipse Plus C18 } \\
4.6 X 150 \mathrm{~mm}, 5 \mu \mathrm{m}\end{array}$ \\
\hline Loading: $100 \mathrm{~mL}$ at $10 \mathrm{~mL} / \mathrm{min}$ & Injection Volume: $10 \mu \mathrm{L}$ \\
\hline $\begin{array}{l}\text { Washing: } 5 \mathrm{~mL} \text { twice } \mathrm{MeOH} / \text { Water } \\
(30 / 70, \mathrm{v} / \mathrm{v})\end{array}$ & $\begin{array}{l}\text { Mobile Phase: } 55 \% \mathrm{ACN} / 45 \% \text { Milli-Q water } \\
\text { for } 10 \text { min, } 45 \% \mathrm{ACN} / 55 \% \mathrm{Milli}-\mathrm{Q} \text { water for } \\
15 \text { min, and } 100 \% \mathrm{ACN} \text { for } 5 \text { min }\end{array}$ \\
\hline Dry with vacuum & Flowrate: $1 \mathrm{~mL} / \mathrm{min}$ \\
\hline Elution: $3 \mathrm{~mL} \mathrm{MeOH}$ three times & UV detection: $230,4 \mathrm{~nm}$ Ref.: 360,80 \\
\hline Dry with nitrogen gas & $\begin{array}{l}\text { Elution time: } 4.21,5.85,21.5 \mathrm{~min} \text { for BPA, } \\
\text { EE2, and TCS, respectively }\end{array}$ \\
\hline Dissolved in $1 \mathrm{~mL} \mathrm{MeOH}$ & $\begin{array}{l}\text { Limit of Detection: } 100 \mathrm{ng} / \mathrm{L} \text { for liquid } \\
\text { samples and } 100 \mathrm{ng} / \mathrm{g} \text { for solid samples }\end{array}$ \\
\hline
\end{tabular}

\subsection{Conventional Chemical Analysis}

Total suspended solids, volatile suspended solids were analysed and recorded according to Standard Methods (2005). Temperature, dissolved oxygen and $\mathrm{pH}$ were measured daily using portable instruments (TermoOrion Medel 862A, US and Accument Model XL25, Fishersci, US). Ammonia (TNT 832 and TNT 830), chemical oxygen 
P a g e $\mid \mathbf{1 0 8}$

demand (TNT 821 and TNT 822), total phosphorus (TNT 843), total nitrogen, total Kjeldahl nitrogen and nitrate (TNT 880) concentrations were measured using HACH TNT vials and HACH DR 4000 UV-VIS Spectrophotometer. Total organic carbon (TOC) was analysed by an Apollo 9000 TOC Analyzer (Teledyne Tekmar, USA).

\subsection{References}

Agüera, A.; Fernández-Alba, A. R.; Piedra, L.; Mézcua, M.; Gómez, M. J. 2003 Evaluation of triclosan and biphenylol in marine sediments and urban wastewaters by pressurized liquid extraction and solid phase extraction followed by gas chromatography mass spectrometry and liquid chromatography mass spectrometry. Analytica Chimica Acta, 480, 193-205.

Alexander, H. C.; Dill, D. C.; Smith, L. W.; Guiney, P. D.; Dorn, P. 1988 Bisphenol a: Acute aquatic toxicity. Environmental Toxicology and Chemistry, 7, 19-26.

Alexander, M. 1985 Biodegradation of organic chemicals. Environmental Science \& Technology, 19, 106-111.

Baugros, J.-B.; Giroud, B.; Dessalces, G.; Grenier-Loustalot, M.-F.; Cren-Olivé, C. 2008 Multiresidue analytical methods for the ultra-trace quantification of 33 priority substances present in the list of REACH in real water samples. Analytica Chimica Acta, 607, 191-203.

Benijts, T.; Dams, R.; Lambert, W.; De Leenheer, A. 2004 Countering matrix effects in environmental liquid chromatography-electrospray ionization tandem mass spectrometry water analysis for endocrine disrupting chemicals. Journal of Chromatography A, 1029, 153-159.

Berg, U. T.; Nyholm, N. 1996 Biodegradability simulation studies in semicontinuous activated sludge reactors with low $(\mu \mathrm{g} / \mathrm{L}$ range) and standard (ppm range) chemical concentrations. Chemosphere, 33, 711-735.

Carabias-Martínez, R.; Rodríguez-Gonzalo, E.; Revilla-Ruiz, P. 2004 Determination of weakly acidic endocrine-disrupting compounds by liquid chromatography-mass spectrometry with post-column base addition. Journal of Chromatography A, 1056, 131-138.

Chang, C.-M.; Chou, C.-C.; Lee, M.-R. 2005 Determining leaching of bisphenol A from plastic containers by solid-phase microextraction and gas chromatography-mass spectrometry. Analytica Chimica Acta, 539, 41-47. 
Clara, M.; Strenn, B.; Saracevic, E.; Kreuzinger, N. 2004 Adsorption of bisphenol-A, $17 \beta$-estradiole and $17 \alpha$-ethinylestradiole to sewage sludge. Chemosphere, 56, 843-851.

Cousins, I. T.; Staples, C. A.; Kleĉka, G. M.; Mackay, D. 2002 A Multimedia Assessment of the Environmental Fate of Bisphenol A. Human and Ecological Risk Assessment: An International Journal, 8, 1107-1135.

Diagne, R. G.; Foster, G. D.; Khan, S. U. 2002 Comparison of Soxhlet and MicrowaveAssisted Extractions for the Determination of Fenitrothion Residues in Beans. Journal of Agricultural and Food Chemistry, 50, 3204-3207.

Ferrer, E.; Santoni, E.; Vittori, S.; Font, G.; Mañes, J.; Sagratini, G. 2011 Simultaneous determination of bisphenol A, octylphenol, and nonylphenol by pressurised liquid extraction and liquid chromatography-tandem mass spectrometry in powdered milk and infant formulas. Food Chemistry, 126, 360-367.

Fujimoto, T.; Kubo, K.; Aou, S. 2006 Prenatal exposure to bisphenol A impairs sexual differentiation of exploratory behavior and increases depression-like behavior in rats. Brain Res, 1068, 49-55.

Gang, S.; Gang, Y.; Zhenxiao, C.; Zulin, Z. 2005 Development of an analytical method to determine phenolic endocrine disrupting chemicals in sewage and sludge by GC/MS. Chinese Science Bulletin, 50, 2681-2687.

Gatidou, G.; Thomaidis, N. S.; Stasinakis, A. S.; Lekkas, T. D. 2007 Simultaneous determination of the endocrine disrupting compounds nonylphenol, nonylphenol ethoxylates, triclosan and bisphenol $\mathrm{A}$ in wastewater and sewage sludge by gas chromatography-mass spectrometry. Journal of Chromatography A, 1138, 32-41.

Gaulke, L. S.; Strand, S. E.; Kalhorn, T. F.; Stensel, H. D. 2008 17 $\alpha$-ethinylestradiol Transformation via Abiotic Nitration in the Presence of Ammonia Oxidizing Bacteria. Environmental Science \& Technology, 42, 7622-7627.

González-Casado, A.; Navas, N.; del Olmo, M.; Vílchez, J. L. 1998 Determination of Bisphenol A in Water by Micro Liquid-Liquid Extraction Followed by Silylation and Gas Chromatography-Mass Spectrometry Analysis. Journal of Chromatographic Science, 36, 565-570.

Guellil, A.; Block, J. C.; Urbain, V. 1998 Adaptation of the microbial adhesion to hydrocarbon test (MATH) for measuring activated sludge hydrophobicity. Water Science and Technology, 37, 359-362.

Hadjmohammadi, M.; Saeidi, I. 2010 Determination of bisphenol A in Iranian packaged milk by solid-phase extraction and HPLC. Monatshefte für Chemie / Chemical Monthly, 141, 501-506.

Hammarling, L.; Gustavsson, H.; Svensson, K.; Oskarsson, A. 2000 Migration of bisphenol-A diglycidyl ether (BADGE) and its reaction products in canned foods. Food Additives and Contaminants, 17, 937-943. 
Helaleh, M. I. H.; Fujii, S.; Korenaga, T. 2001 Column silylation method for determining endocrine disruptors from environmental water samples by solid phase microextraction. Talanta, 54, 1039-1047.

Hennion, M.-C. 2000 Chapter 1 Sample handling strategies for the analysis of organic compounds in environmental water samples, in: BarcelÓ, D. (Ed.), Techniques and Instrumentation in Analytical Chemistry. Elsevier, pp. 3-71.

Hernando, M. D.; Mezcua, M.; Gómez, M. J.; Malato, O.; Agüera, A.; Fernández-Alba, A. R. 2004 Comparative study of analytical methods involving gas chromatography-mass spectrometry after derivatization and gas chromatographytandem mass spectrometry for the determination of selected endocrine disrupting compounds in wastewaters. Journal of Chromatography A, 1047, 129-135.

Huang, M.; Jiang, G.; Cai, Y. 2005 Electrochemical preparation of composite polyaniline coating and its application in the determination of bisphenol A, 4-n-nonylphenol, 4-tert-octylphenol using direct solid phase microextraction coupled with high performance liquid chromatography. Journal of Separation Science, 28, 22182224.

Jeannot, R.; Sabik, H.; Sauvard, E.; Dagnac, T.; Dohrendorf, K. 2002 Determination of endocrine-disrupting compounds in environmental samples using gas and liquid chromatography with mass spectrometry. Journal of Chromatography A, 974, 143-159.

Krishnan, A. V.; Stathis, P.; Permuth, S. F.; Tokes, L.; Feldman, D. 1993 Bisphenol-A: an estrogenic substance is released from polycarbonate flasks during autoclaving. Endocrinology, 132, 2279-86.

Kuch, H. M.; Ballschmiter, K. 2001 Determination of endocrine-disrupting phenolic compounds and estrogens in surface and drinking water by HRGC-(NCI)-MS in the picogram per liter range. Environmental Science and Technology, 35, 32013206.

Laganà, A.; Bacaloni, A.; De Leva, I.; Faberi, A.; Fago, G.; Marino, A. 2004 Analytical methodologies for determining the occurrence of endocrine disrupting chemicals in sewage treatment plants and natural waters. Analytica Chimica Acta, 501, 7988.

Le Blanc, A.; Albrecht, C.; Bonn, T.; Fechner, P.; Proll, G.; Pröll, F.; Carlquist, M.; Gauglitz, G. 2009 A novel analytical tool for quantification of estrogenicity in river water based on fluorescence labelled estrogen receptor $\alpha$. Analytical and Bioanalytical Chemistry, 395, 1769-1776.

Lee, H.-B.; Peart, T. E.; Svoboda, M. L. 2005 Determination of endocrine-disrupting phenols, acidic pharmaceuticals, and personal-care products in sewage by solidphase extraction and gas chromatography-mass spectrometry. Journal of Chromatography A, 1094, 122-129. 
Lee, H. B.; Peart, T. E. 2000a Bisphenol a contamination in Canadian municipal and industrial wastewater and sludge samples. Water Quality Research Journal of Canada, 35, 283-298.

Lee, H. B.; Peart, T. E. 2000b Determination of bisphenol A in sewage effluent and sludge by solid-phase and supercritical fluid extraction and gas chromatography/mass spectrometry. Journal of AOAC International, 83, 290-297.

Liu, R.; Zhou, J. L.; Wilding, A. 2004 Microwave-assisted extraction followed by gas chromatography-mass spectrometry for the determination of endocrine disrupting chemicals in river sediments. Journal of Chromatography A, 1038, 19-26.

Meesters, R. J. W.; Schröder, H. F. 2002 Simultaneous determination of 4-nonylphenol and bisphenol A in sewage sludge. Analytical Chemistry, 74, 3566-3574.

Mohapatra, D. P.; Brar, S. K.; Tyagi, R. D.; Surampalli, R. Y. 2010 Physico-chemical pre-treatment and biotransformation of wastewater and wastewater Sludge - Fate of bisphenol A. Chemosphere, 78, 923-941.

Mohapatra, D. P.; Brar, S. K.; Tyagi, R. D.; Surampalli, R. Y. 2011 Occurrence of bisphenol $\mathrm{A}$ in wastewater and wastewater sludge of CUQ treatment plant. Journal of Xenobiotics, 1.

Motoyama, A.; Suzuki, A.; Shirota, O.; Namba, R. 1999 Direct determination of bisphenol a and nonylphenol in river water by column-switching semimicrocolumn liquid chromatography/electrospray mass spectrometry. Rapid Communications in Mass Spectrometry, 13, 2204-2208.

Naassner, M.; Mergler, M.; Wolf, K.; Schuphan, I. 2002 Determination of the xenoestrogens 4-nonylphenol and bisphenol $\mathrm{A}$ by high-performance liquid chromatography and fluorescence detection after derivatisation with dansyl chloride. Journal of Chromatography A, 945, 133-138.

Pedersen, S. N.; Lindholst, C. 1999 Quantification of the xenoestrogens 4-tert.octylphenol and bisphenol $\mathrm{A}$ in water and in fish tissue based on microwave assisted extraction, solid-phase extraction and liquid chromatography-mass spectrometry. Journal of Chromatography A, 864, 17-24.

Petrovic; Mira; Barcel; Dami. 2001 Determination of Phenolic Xenoestrogens in Environmental Samples by Liquid Chromatography with Mass Spectrometric Detection. Journal of AOAC International, 84, 1074-1085.

Petrovic, M.; Eljarrat, E.; López de Alda, M. J.; Barceló, D. 2002 Recent advances in the mass spectrometric analysis related to endocrine disrupting compounds in aquatic environmental samples. Journal of Chromatography A, 974, 23-51.

Prasanth, G. K.; Divya, L. M.; Sadasivan, C. 2010 Bisphenol-A can bind to human glucocorticoid receptor as an agonist: an in silico study. Journal of applied toxicology : JAT, 30, 769-74. 
Pryor, S. W.; Hay, A. G.; Walker, L. P. 2002 Nonylphenol in Anaerobically Digested Sewage Sludge from New York State. Environmental Science \& Technology, 36, 3678-3682.

Rubin, B. S.; Soto, A. M. 2009 Bisphenol A: Perinatal exposure and body weight. Molecular and cellular endocrinology, 304, 55-62.

Sajiki, J. 2001 Decomposition of bisphenol-A (BPA) by radical oxygen. Environment International, 27, 315-320.

Seyhi, B.; Drogui, P.; Buelna, G.; Blais, J. F. 2011 Modeling of sorption of bisphenol A in sludge obtained from a membrane bioreactor process. Chemical Engineering Journal, 172, 61-67.

Standard methods for the examination of water and wastewater : 21st edition Washington, DC: American Public Health Association, 2005.

Urase, T.; Kikuta, T. 2005 Separate estimation of adsorption and degradation of pharmaceutical substances and estrogens in the activated sludge process. Water Research, 39, 1289-1300.

Varelis, P.; Balafas, D. 2000 Preparation of 4,4'-(1-[2H6]methylethylidene)bis-[2,3,5,62H4]phenol and its application to the measurement of bisphenol $\mathrm{A}$ in beverages by stable isotope dilution mass spectrometry. Journal of Chromatography A, 883, 163-170.

Xu, K.; Harper Jr, W. F.; Zhao, D. 2008 17 $\alpha$-Ethinylestradiol sorption to activated sludge biomass: Thermodynamic properties and reaction mechanisms. Water Research, 42, 3146-3152.

Yi, T.; Harper Jr, W. F. 2007 The effect of biomass characteristics on the partitioning and sorption hysteresis of -ethinylestradiol. Water Research, 41, 1543-1553.

Zhao, J.; Li, Y.; Zhang, C.; Zeng, Q.; Zhou, Q. 2008 Sorption and degradation of bisphenol A by aerobic activated sludge. Journal of Hazardous Materials, 155, 305-311. 
P a g e | 113

\section{Chapter 4: Sorption-desorption and biosorption of MCs to AS}

Summary ${ }^{1}$ :

To better understand the fate of microconstituents (MCs) in an activated sludge (AS) system, sorption, biosorption, and desorption studies were investigated at $\mu \mathrm{g} / \mathrm{L}$ range for 17a-ethinylestradiol (EE2), bisphenol-A (BPA), and triclosan (TCS). Batch experiments with activated and deactivated sludge originating from continuous flow porous-pot reactors operating at solids retention times (SRTs) of 5, 10, and 15 days were conducted in order to investigate the sorption kinetics and distinguish physicochemical sorption and biosorption. The effect of SRT and the biomass concentration on sorption kinetics was also studied. Selected MCs showed high sorption affinity to the non-active biomass during the first $30 \mathrm{~min}$ of the experiment, which was gradually reduced until equilibrium was reached. Desorption results showed two distinct stages, a very rapid desorption within 20 min followed by a slow desorption stage. Biosorption study indicated that the soluble concentrations of target compounds decreased rapidly for selected MCs similar to the sorption study; however, the soluble and solid phase concentrations continued to decrease slowly during the length of the experiment which indicates the possible biodegradation of these compounds in both phases. Finally, mathematical models were

${ }^{1}$ This chapter has been published as:

Banihashemi B, Droste RL. Sorption-desorption and biosorption of bisphenol A, triclosan, and 17alpha-ethinylestradiol to sewage sludge. Sci Total Environ 2014; 487: 813-21. 


\section{P a g e | 114}

applied to describe the sorption mechanism and Freundlich sorption isotherms with values of $1 / \mathrm{n}$ close to 1 were found to best fit the results which demonstrate that all tested concentrations result on the linear part of the Freundlich isotherm. Calculation of the Freundlich constant, $\mathrm{K}_{\mathrm{F}}$ and distribution coefficient, $\mathrm{K}_{\mathrm{d}}$ exhibited greater tendency of EE2 and TCS for sorption, compared to BPA. The results of this study indicated that the SRT had a clear effect on the sorption kinetics where the highest sorption rate constant was achieved for a SRT of 10 days for all three target substances. This could be due to change of the morphology of the biomass from reactors operating at different SRTs. 


\section{P a g e | 115}

\subsection{Introduction:}

The occurrence and fate of toxic, biopersistent MCs in water sources and their removal in wastewater treatment plants (WWTPs) as major point sources are a growing concern since some of these substances remain at detectable levels in WWTP effluents which have been implicated as a major source to surface waters (Anderson, 2005). The environment in a WWTP biotreatment process, which is the most common form of wastewater treatment, is significantly different from the natural environment. The environment in a biotreatment reactor is rich in organics with a high concentration of suspended solids (SS) which includes a significant concentration of enriched microbes. Some MCs can be utilized as primary substrates but others are utilized as secondary substrates in conjunction with a primary substrate, i.e., co-metabolism. The partitioning of MCs between solid and liquid phases is also significant due to the large concentration of biomass and associated solids. Furthermore, stripping of volatile compounds is enhanced due to the intense aeration required in AS processes and the favourable environment for stripping in other processes such as a trickling filter. Accumulation of MCs on solids wasted from a biotreatment operation or losses of them through volatilization are not real treatments but nonetheless they are significant phenomena that affect the fate of MCs in biotreatment or throughout a WWTP.

Sorption processes to sludge are of special interest because the excess sludge extraction represents an important removal pathway and sorption is often the first stage in 


\section{P a g e | 116}

biological degradation. The present article focuses on the sorption-desorption and biosorption of BPA, EE2 and TCS to AS.

EE2 is a synthetic hormone that has attracted considerable attention in the literature due to its contribution to endocrine disrupting activity in WWTP effluent (Jeffries et al., 2010; Vajda et al., 2008). EE2 could be discharged to sewer from human sources in either

gluconorides or sulphates conjugated forms (Koh et al., 2008); however the conjugate steroids could later be transformed into free (unconjugated) forms by bacterial populations present in WWTP that are capable of producing-glucuronidase and arylsulfatase enzymes (Gomes et al., 2009). EE2 adsorption onto AS particles in municipal WWTP might be an important removal pathway in WWTP due to its nonpolar behaviour and hydrophobic properties (Andersen et al., 2005; Cirja et al., 2007; Zhou et al., 2010). WWTPs influent concentrations of EE2 range from below detection to $70 \mathrm{ng} / \mathrm{L}$ (Atkinson et al., 2012; Clara et al., 2005b; Vethaak et al., 2005). Biodegradation has been reported as the most substantial estrogen removal method in AS wastewater treatment (Muller et al., 2008), however, studies showed that presence of EE2 in WWTP effluent at concentration levels of $6 \mathrm{ng} / \mathrm{L}$ might cause estrogenic effects on fathead minnow populations (Kidd et al., 2007; Parrott and Blunt, 2005).

TCS (2,4,40-trichloro-20-hydroxydiphenyl ether; Irgasan) is a broad spectrum antibacterial agent which can be found in many personal care products such as hand disinfecting soaps, medical skin creams, dental products, deodorants, toothpastes (Dann 


\section{P a g e | 117}

and Hontela, 2011). The use of personal care products containing TCS and the disposal of these products caused TCS contamination in wastewater, streams, seawater, sediments, fish, blood, urine and human milk (Allmyr et al., 2006; Kinney et al., 2008; Queckenberg et al., 2010). TCS can hinder both gram negative and gram positive bacteria by inhibiting the NADH-dependent enoyl-[acyl-carrier protein] reductase, a key enzyme responsible for fatty acid synthesis (Sivaraman et al., 2004). It was found that TCS could also be harmful to AS bacteria (Neumegen et al., 2005). An aid to the development of crossresistance to antibiotics (Drury et al., 2013) and the formation of chlorodioxins and other toxic metabolites during TCS photodegradation are two of many concerns about the widespread contamination of TCS in the environment (Aranami and Readman, 2007; Braoudaki and Hilton, 2004; Buth et al., 2009; Dann and Hontela, 2011). Furthermore, studies even suggested that TCS is potentially a weak androgen and exerts both estrogenic and androgenic effects on human breast cancer cells (Gee et al., 2008). The TCS concentrations in WWTP influent and effluent were studied by many researchers and ranged from $0.01-16 \mu \mathrm{g} / \mathrm{L}$ in influent and $0.01-2.7 \mu \mathrm{g} / \mathrm{L}$ in effluent, suggesting removal efficiencies of $58-97 \%$ for trickling filter plants and $95-98 \%$ for activated sludge plants (Bester, 2003; Lishman et al., 2006; Nakada et al., 2010; Thomas and Foster, 2005). The high octanol-water partition coefficient of TCS $\log \mathrm{K}_{\mathrm{ow}}$ 4.5-4.8 (Lopez-Avila and Hites, 1980; Ying et al., 2007), could lead to 30-50\% TCS removal due 


\section{P a g e | 118}

to sorption onto biosolids in WWTPs (Bester, 2003; Chalew and Halden, 2009; Heidler and Halden, 2007; Singer et al., 2002).

BPA is a building compound for the manufacturing of plastics, epoxy resins, and polycarbonate resins. BPA is an endocrine disrupter (Fujimoto et al., 2006; vom Saal and Myers, 2008) and might be as effective as estradiol in triggering some receptor responses (Stahlhut et al., 2009). BPA might also act as an androgen receptor antagonist (Urbatzka et al., 2007). $\mathrm{K}_{\mathrm{d}}$ values for BPA are reported in various studies in the literature and ranged from $0.07 \mathrm{~L} / \mathrm{g}$ TSS up to $1 \mathrm{~L} / \mathrm{g}$ TSS (Clara et al., 2004). The Henry's law constant for BPA is $1 \times 10^{-10}$ atm. $\mathrm{m}^{3} / \mathrm{mol}$ (Staples et al., 1998b) and volatility of BPA can thereby be considered negligible in WWTPs. Lee et al. (2004) studied the BPA concentrations in Canadian WWTPs and observed BPA in all 30 sewage samples with concentration ranging from 0.16 to $28.1 \mu \mathrm{g} / \mathrm{L}$ (median $0.75 \mu \mathrm{g} / \mathrm{L}$ ) in the influents and from 0.01 to 17.3 $\mu \mathrm{g} / \mathrm{L}$ (median $0.13 \mu \mathrm{g} / \mathrm{L}$ ) in the effluent. The observed influent-to-effluent reduction in the five municipal wastewater treatment plants in Canada showed $70-76 \%$ for BPA indicating that it is not completely eliminated during wastewater treatment (Fernandez et al., 2007; Mohapatra et al., 2011). BPA was also found in municipal sewage sludge, in the range of $0.104-0.312 \mu \mathrm{g} / \mathrm{g}$ in Canada (Mohapatra et al., 2011), 1.86-0.02 $\mu \mathrm{g} / \mathrm{g}$ in Greek (Samaras et al., 2013; Stasinakis et al., 2008), and $0.4 \mu \mathrm{g} / \mathrm{g}$ in Spain (VegaMorales et al., 2010). 


\section{P a g e | 119}

A majority of published models for the environmental fate of MCs assume that equilibrium is reached instantaneously between sorbed and dissolved MCs. Some studies proposed a general model with sorption-desorption dynamic processes (Cowan et al., 1993; Lai et al., 2000; Lindblom et al., 2009) where different stages have been suggested in this process: the first stage or rapid mixing, the second stage which is decrease in sorption due to gradual exhaustion of binding site and desorption of MCs into the aqueous phase as a last stage.

Many studies dealing with emerging contaminates focus only on adsorption and biosorption of MCs to active and non-active AS by measuring the MCs concentration in the liquid phase (Clara et al., 2004; Feng et al., 2010; Seyhi et al., 2011), only in the last few years researchers started to study the change of MCs concentration in the solid phase at very low concentrations (Nie et al., 2009; Stevens-Garmon et al., 2011; Zhao et al., 2008). Furthermore, although the solid concentration in AS systems, as an active binding site to MCs, showed evident effect on sorption isotherm in the literature (Barret et al., 2010b; Zhao et al., 2008), however in these studies solid concentrations in batch reactors were mostly prepared by diluting the MLSS to desired concentrations and the effect of biomass characteristics such as morphology of the biomass, the floc size, shape and density of AS at different SRTs were mainly ignored. Therefore in this study the sorption-desorption and biosorption of BPA, TCS, and EE2 onto active AS or inactivated

sludge obtained from lab-scale porous-pot AS reactors were investigated in parallel by 
P a g e | 120

measuring the concentration of MCs in both liquid and solid phases in order to distinguish physicochemical sorption-desorption and biosorption processes.

\subsection{Material and Methods:}

\subsubsection{Chemical and reagents}

Methanol $(\mathrm{MeOH})$, hexane, acetonitrile $(\mathrm{ACN})$, dichloromethane, and acetone used for cleaning and extraction purposes, were purchased from VWR International, LLC (Canada) and were all of HPLC analytical grade. EE2, BPA, and TCS (HPLC grade, $>98 \%$ ) were purchased from Sigma-Aldrich, Canada. Table 4-1, shows the physicochemical properties of selected MCs in this study. Stock solutions of BPA, TCS, and EE2 were prepared in MilliQ water/ACN (55/45, v/v) at $1000 \mathrm{mg} / \mathrm{L}$ and kept at $4 \circ \mathrm{C}$. The working solutions were prepared daily by diluting the stock solution and were used for calibration and spiking experiments. MilliQ water was prepared in the laboratory using a MilliQ/ Millipore system with Super-C carbon, Ion-Ex, and Orgonex-Q cartridges. Supelclean LC-18 (3 mL, $500 \mathrm{mg}$ ) cartridges used for extraction and clean-up samples were supplied by Sigma-Aldrich (Oakville, ON, Canada). The Zorbax Eclipse plus C18 chromatography column $(4.6 \mathrm{~mm} \times 150 \mathrm{~mm}, 5 \mu \mathrm{m})$ was purchased from Chromatographic specialties Inc. (ON, Canada). All other chemical used in this study were supplied by Fisher Scientific (ON, Canada) and were of the highest purity commercially available. 
Table 4-1 Physico-chemical characteristics of selected MCs

\begin{tabular}{|c|c|c|c|c|c|c|}
\hline Compounds & $\mathrm{MW}$ & $\begin{array}{c}\text { Molecular } \\
\text { formula }\end{array}$ & $\begin{array}{c}\text { Solubility } \\
(\mathrm{mg} / \mathrm{L})\end{array}$ & $\begin{array}{c}\mathrm{H} \\
\left(\mathrm{atm} \cdot \mathrm{m}^{3} \cdot \mathrm{mol}^{-1}\right)\end{array}$ & $\mathrm{pK}$ & $\log \mathrm{K}_{\mathrm{ow}}$ \\
\hline $\mathrm{BPA}$ & 228.29 & $\mathrm{C}_{15} \mathrm{H}_{16} \mathrm{O}_{2}$ & 120 & $1.0 \times 10^{-11}$ & $9.86-10$ & $3.18-3.7^{\mathrm{a}}$ \\
\hline $\mathrm{EE} 2$ & 296.41 & $\mathrm{C}_{20} \mathrm{H}_{24} \mathrm{O}_{2}$ & $4.8-11.3$ & $7.9 \times 10^{-12}$ & $10.5-10.7$ & $3.6-4.15^{\mathrm{b}}$ \\
\hline TCS & 289.54 & $\mathrm{C}_{12} \mathrm{H}_{7} \mathrm{Cl}_{3} \mathrm{O}_{2}$ & 10 & $1.5 \times 10^{-7}$ & 7.9 & $4.5-4.8^{\mathrm{c}}$ \\
\hline
\end{tabular}

${ }^{a}$ (Borrirukwisitsak et al., 2012; Robinson et al., 2009)

b (Robinson et al., 2009)

c (Lopez-Avila and Hites, 1980; Ying et al., 2007)

\subsubsection{Activated sludge, synthetic wastewater and inactivation treatment}

The thickened waste AS (TWAS) inoculum was obtained from the Robert O. Pickard Environmental Center (ROPEC) wastewater treatment facility in Ottawa. The TWAS was diluted to reach the total SS (TSS) and volatile SS (VSS) concentrations of 3100 and $2300 \mathrm{mg} / \mathrm{L}$, respectively. Then, the diluted TWAS was incubated in three continuous flow 3 L porous pot reactors (Figure 4-1), fed with synthetic wastewater without any added MCs with typical hydraulic retention time (HRT) of 6 hours found in AS systems. These bioreactors are approved by United States Environmental Protection Agency (USEPA) for simulation test of AS system (EPA 712-C-08-004, October 2008). The SRT of each reactor was decreased gradually to reach the SRT of 5,10 , and $15 \mathrm{~d}$ by removing adequate mixed liquor VSS (MLVSS) daily from each reactor. The chemical oxygen demand (COD) and MLVSS in these reactors were then monitored to reach a stabilized condition. The synthetic wastewater (Table 4-2) is composed of distilled water, 


\section{P a g e | 122}

supplemented with nutrients, trace elements, and buffering compounds which is the modified version of what was described in the study by Zhao et al. (Zhao et al., 2008).

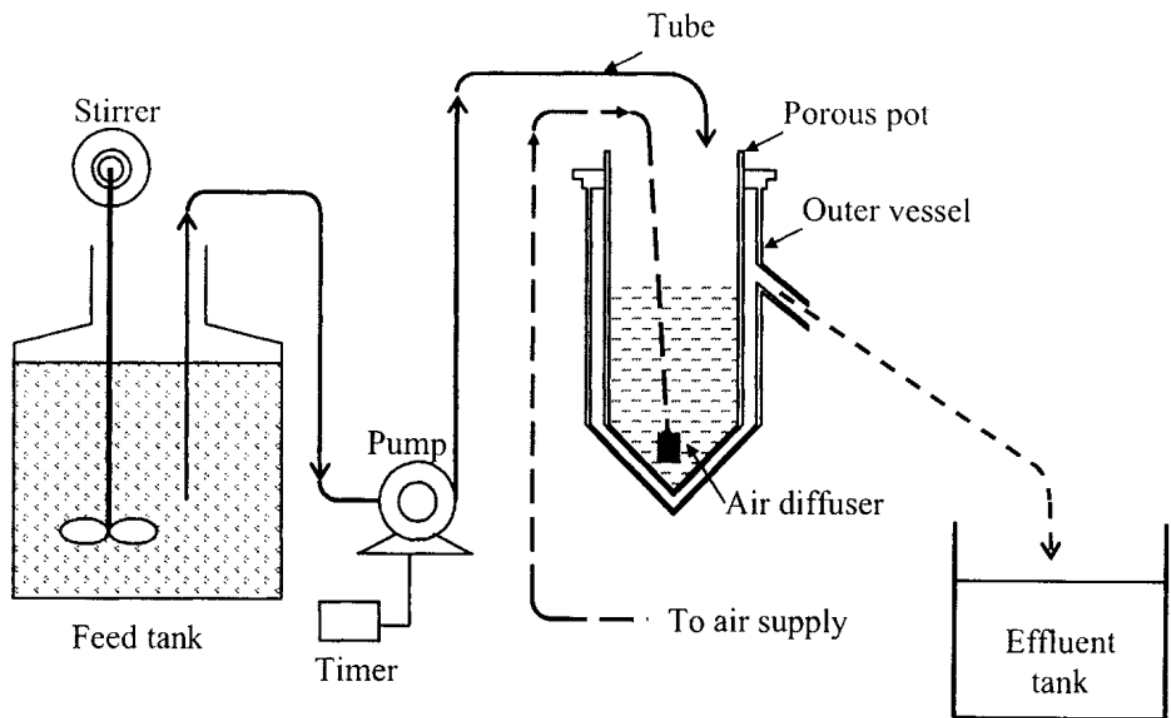

Figure 4-1. Porous pot system

Glucose, peptone and sodium acetate are used for simulating easily degradable substrate, complex organic carbon source and volatile fatty acids, respectively. Ammonium chloride is added as a nitrogen source for nitrifying bacteria and sodium bicarbonate and EDTA are used for alkalinity and preservation, respectively.

This synthetic wastewater had an average total COD of $410 \mathrm{mg} / \mathrm{L}$, which is considered as a typical COD found in domestic wastewater influent (Tchobanoglous, 2003). Total nitrogen, total phosphorus and total organic carbon of synthetic wastewater were measured and found to be 36,11 , and $173 \mathrm{mg} / \mathrm{L}$, respectively, resulting in a C:N:P ratio of approximately 100:20:6. The measured ammonia $\left(\mathrm{NH}_{3}\right)$, nitrate $\left(\mathrm{NO}_{3}-\mathrm{N}\right)$, 


\section{P a g e $\mid \mathbf{1 2 3}$}

temperature and $\mathrm{pH}$ of the influent were found to be $13 \mathrm{mg} / \mathrm{L}, 0.3 \mathrm{mg} / \mathrm{L}, 22^{\circ} \mathrm{C}$ and 6.9 , respectively.

Table 4-2 Composition of the synthetic wastewater

\begin{tabular}{|l|l|}
\hline Compound & Concentration $(\mathrm{mg} / \mathrm{L})$ \\
\hline $\mathrm{C}_{6} \mathrm{H}_{12} \mathrm{O}_{6}$ & 150 \\
\hline Peptone & 150 \\
\hline $\mathrm{NaAc}$ & 80 \\
\hline $\mathrm{NH}_{4} \mathrm{Cl}$ & 40 \\
\hline $\mathrm{KH}_{2} \mathrm{PO}_{4} \cdot 2 \mathrm{H}_{2} \mathrm{O}$ & 44.1 \\
\hline $\mathrm{MgSO}_{4} \cdot 7 \mathrm{H}_{2} \mathrm{O}$ & 20 \\
\hline $\mathrm{CaCl}_{2}$ & 10.6 \\
\hline $\mathrm{NaHCO}_{3}$ & 150 \\
\hline $\mathrm{FeCl}_{3} \cdot 6 \mathrm{H}_{2} \mathrm{O}$ & 0.45 \\
\hline $\mathrm{H}_{3} \mathrm{BO}_{3}$ & 0.045 \\
\hline $\mathrm{CuSO}_{4} \cdot 5 \mathrm{H}_{2} \mathrm{O}$ & 0.01 \\
\hline $\mathrm{KI}$ & 0.054 \\
\hline $\mathrm{MnCl}_{2} \cdot 4 \mathrm{H}_{2} \mathrm{O}$ & 0.036 \\
\hline $\mathrm{ZnSO}_{4} \cdot 7 \mathrm{H}_{2} \mathrm{O}$ & 0.036 \\
\hline $\mathrm{Na}_{2} \mathrm{MoO}_{4} \cdot 2 \mathrm{H}_{2} \mathrm{O}$ & 0.1 \\
\hline $\mathrm{CoCl}_{2} \cdot 6 \mathrm{H}_{2} \mathrm{O}$ & 0.01 \\
\hline $\mathrm{EDTA}$ & 3 \\
\hline
\end{tabular}

The MLVSS in each reactor was monitored by removing the adequate portion of mixed liquor from each reactor and measuring TSS and VSS concentration. It was found that the medium concentrations of MLVSS in reactors with SRTs of 5,10 and 15 days were 3145,2763 , and $1733 \mathrm{mg} \mathrm{VSS/L}$, respectively. To avoid the influence of microbial activity on the MCs sorption behavior onto AS, sodium azide solution $(0.2 \% \mathrm{w} / \mathrm{w})$ was 


\section{P a g e $\mid \mathbf{1 2 4}$}

used to prevent biodegradation by deactivating cytochrome oxidase. This concentration has been shown to inhibit the biodegradation process without causing any cell lysis, and also it does not cause change to sludge hydrophobicity (Guellil et al., 1998; Xu et al., 2008; Yi and Harper, 2007).

\subsubsection{Sorption experiments with activated and inactivated sludge}

Sorption batch experiments were performed to investigate MCs sorption to inactive AS obtained from 3 porous pot reactors. Two batch reactors from each porous pot reactor (2 L Erlenmeyer flasks) were operated for the sorption equilibrium study. Batch reactors were filled with inactive AS obtained from porous pot reactors with SRTs of 5, 10, and 15 days, respectively and half of the batch reactors were spiked with selected MCs to the final concentration of $10 \mu \mathrm{g} / \mathrm{L}$, whereas the other half were not spiked to determine the background concentration of selected MCs in obtained inactive AS. One control reactor was also filled with distilled water and same MCs concentration to quantify any potential abiotic losses. The batch reactors were wrapped in aluminum foil to prevent possible photodegradation and put on a shaker at $125 \mathrm{rpm}$ for $24 \mathrm{~h}$. Duplicate homogenized samples $(100 \mathrm{~mL})$ were taken at increasing time intervals at $0.25,0.5,1,2,4,6,10,18$, and $24 \mathrm{~h}$ for the determination of dissolved and particulate MCs and calculation of equilibrium time. To determine sorption isotherms six 1 L Erlenmeyer flasks (two flasks

for inactive AS taken from each porous-pot reactor) were filled with inactive AS and were exposed to the selected MCs at concentrations of 5, 10, 20, 50, 100 and $200 \mu \mathrm{g} / \mathrm{L}$. 


\section{P a g e | $\mathbf{1 2 5}$}

Batch reactors were put on a shaker, while samples were taken at equilibrium and MCs concentration were measured in the dissolved and solid phases. The same procedures were followed for the biosorption study with active and active AS and the results of two studies were compared. The mixed liquor SS (MLSS) and SRT effects were also examined using same concentration range of each target compound and MLSS concentrations of 1430,2750 , and $3540 \mathrm{mg} / \mathrm{L}$ from each reactor.

\subsubsection{Desorption experiments}

Desorption kinetic studies were also conducted by placing settled and washed MC saturated inactive AS at $10 \mu \mathrm{g} / \mathrm{L}$ in a batch reactor with synthetic wastewater which contains no MCs and measuring the concentration change in the liquid and solids phases over time. Mass balances were made for all sorption and desorption studies to ensure the integrity of the experiments.

Two batch reactors from each porous pot reactors were filled with inactive AS and half were spiked with selected MCs to the final concentration of $10 \mu \mathrm{g} / \mathrm{L}$. The batch reactors were put on a shaker at $125 \mathrm{rpm}$ to reach the sorption equilibrium time and MCs saturated inactive AS were centrifuged at $2000 \mathrm{rpm}$ for $10 \mathrm{~min}$ and washed with DI water. The settled and washed MC saturated inactive AS was then added to $1 \mathrm{~L}$ Erlenmeyer flasks and were filled with synthetic wastewater containing no MCs. The batch reactors were put on a shaker at $125 \mathrm{rpm}$ for $24 \mathrm{~h}$ and the homogenized samples $(100 \mathrm{~mL})$ were taken at increasing time intervals. To determine desorption isotherms, six 


\section{P a g e $\mid \mathbf{1 2 6}$}

1 L Erlenmeyer flasks were filled with MC saturated inactive AS at concentration of 5$200 \mu \mathrm{g} / \mathrm{L}$ and centrifuged at $2000 \mathrm{rpm}$ for $10 \mathrm{~min}$, The synthetic wastewater with no MCs was added to each Erlenmeyer flask and shaken for $12 \mathrm{~h}$ in the rotary shaker to reequilibrate the system. Samples were taken at equilibrium time and the concentrations in the liquid phase over the range of 5-200 $\mu \mathrm{g} / \mathrm{L}$ MC's concentrations were measured.

\subsubsection{Sample preparation and analytical methods}

Sample preparation and clean-up were performed for MC samples in both liquid and solid phases. One hundred $\mathrm{mL}$ of MLVSS samples were collected from batch reactors and centrifuged at $10000 \mathrm{rpm}$ for $30 \mathrm{~min}$, the supernatant liquid was then filtered through a pre-ashed glass fiber filter (GF/C, pore size $0.45 \mu \mathrm{m}$ ), acidified with HCL solution to a $\mathrm{pH}$ of 2 and stored at $4^{\circ} \mathrm{C}$ until further SPE treatment. For solid samples, sludge cake was carefully removed from the centrifuged tube and dried at $60^{\circ} \mathrm{C}$ for almost $12 \mathrm{~h}$ until a constant weight was reached. Five g of sodium sulfate anhydrous were added to the dried biomass and mixed to form a free floating powder before adding to microwave vessels. The microwave-assisted extraction procedure was carried out with a Mars $5^{\circledR}$ (MW Accelerated Reaction System; CEM Corporation) MW oven based on the method

described in a previously published study (Banihashemi and Droste, 2013). After the microwave extraction, the samples were evaporated with a gentle stream of nitrogen, redissolved into $10 \mathrm{~mL}$ of $\mathrm{MeOH}$, and were cleaned up and pre-concentrated using SPE. To cleanup and pre-concentrate the liquid samples, SPE method using commercial SPE 


\section{P a g e $\mid \mathbf{1 2 7}$}

cartridge (Supelclean LC-18) fitted on a vacuum apparatus (CHROMABOND, Fishersci, ON, Canada) were used to isolate MCs from prepared samples. The SPE extraction procedure was also a modified protocol published previously by the authors (Banihashemi and Droste, 2013). After SPE process all liquid and solid samples were evaporated to dryness, re-dissolved in $1 \mathrm{~mL}$ of $45 \%$ ACN/55\% MilliQ water, and filtered through $0.22 \mu \mathrm{m}$ Milipore syringe filter before analyzing with high pressure liquid chromatography (HPLC).

Determination of selected MCs was performed according to the procedures described by Banihashemi and Droste (2013) with some modification. The concentrations of target MCs were measured using a HPLC (Hewlett-Packard, HP 1100) equipped with ZORBAX Eclipse Plus C18 $(4.6 \times 150 \mathrm{~mm}, 5 \mu \mathrm{m})$ analytical column. The system consisted of the degasser (G1322A), a Quaternary pump (G1311A), an ALS auto sampler (G1313A), a Colcomp column oven (G1314A) and Multi Wavelength UV-VIS detector (G1314A). ACN/water (45:55, v/v) as mobile phase was used as a binary gradient with a

flow rate of $1 \mathrm{~mL} \mathrm{~min}^{-1}$ at room temperature and a pressure of about 65 bars. Ten $\mu \mathrm{L}$ of sample were injected and were eluted out of the column within $25 \mathrm{~min}$. For measurement, an elution program starts with $45 \% / 55 \% \mathrm{ACN} /$ water for $10 \mathrm{~min}$, increased to $55 \% / 45 \%$ $\mathrm{ACN} /$ water from $10 \mathrm{~min}$ until $25 \mathrm{~min}$, and increased to $100 \% \mathrm{ACN}$ from 25 to $30 \mathrm{~min}$. Table 4-3, summarizes the SPE and HPLC-UV optimized condition, which was found to detect selected MCs in environmentally relevant concentration. Based on the presented 


\section{P a g e | 128}

determination method, the recoveries of BPA, TCS and EE2 in liquid samples were found to be 100, 95 and 88 percent, respectively. Although the recoveries of selected MCs in the solid phase were slightly lower than what was found in liquid samples, all recoveries were higher than $75 \%$ in this study. TSS and VSS concentrations were also measured by collecting MLSS samples at the same time as sorption and desorption study to calculate biomass concentration. MLSS, MLVSS and $\mathrm{pH}$ values were recorded according to Standard Methods (2005).

Table 4-3 SPE and analytical condition for liquid chromatography-ultraviolet analysis of BPA

\begin{tabular}{|c|c|}
\hline SPE Conditions & HPLC Conditions \\
\hline $\begin{array}{l}\text { Conditioning : } 5 \mathrm{~mL} \text { twice } \mathrm{MeOH} \text { and } \\
5 \mathrm{~mL} \text { twice milli-Q water }\end{array}$ & $\begin{array}{l}\text { Column: ZORBAX Eclipse Plus C18, } \\
4.6 \times 150 \mathrm{~mm}, 5 \mu \mathrm{m}\end{array}$ \\
\hline Loading: $100 \mathrm{~mL}$ at $10 \mathrm{~mL} / \mathrm{min}$ & Injection Volume: $10 \mu \mathrm{L}$ \\
\hline $\begin{array}{l}\text { Washing: } 5 \mathrm{~mL} \text { twice } \mathrm{MeOH} / \text { Water } \\
(30 / 70, \mathrm{v} / \mathrm{v})\end{array}$ & $\begin{array}{l}\text { Mobile Phase: } 55 \% \text { ACN } / 45 \% \text { Milli-Q water } \\
\text { for } 10 \mathrm{~min}, 45 \% \mathrm{ACN} / 55 \% \text { Milli-Q water for } \\
15 \mathrm{~min} \text {, and } 100 \% \mathrm{ACN} \text { for } 5 \mathrm{~min}\end{array}$ \\
\hline Dry with vacuum & Flow-rate: $1 \mathrm{~mL} / \mathrm{min}$ \\
\hline Elution: $3 \mathrm{~mL} \mathrm{MeOH}$ three times & UV detection: 230,4 nm Ref.: 360,80 \\
\hline Dry with nitrogen gas & $\begin{array}{l}\text { Elution time: } 4.21,5.85,21.5 \mathrm{~min} \text { for BPA, } \\
\text { EE2, and TCS, respectively }\end{array}$ \\
\hline Dissolved in $1 \mathrm{~mL} \mathrm{MeOH}$ & $\begin{array}{l}\text { Limit of Detection: } 100 \mathrm{ng} / \mathrm{L} \text { for liquid } \\
\text { samples and } 100 \mathrm{ng} / \mathrm{g} \text { for solid samples }\end{array}$ \\
\hline
\end{tabular}




\section{P a g e $\mid \mathbf{1 2 9}$}

\subsubsection{Calculation methods}

MCs sorption equilibrium in environmental samples including sludge are often modelled by Freundlich isotherms with a Freundlich coefficient close to 1, which is equivalent to a linear isotherm (Arias-Estévez et al., 2007; Hung et al., 2004; Ivashechkin et al., 2004). As a consequence, the equilibrium of sorption to particles is usually assumed to fit linear equations (Carballa et al., 2007; Dionisi et al., 2006; Ternes et al., 2004a) as well as the equilibrium of sorption to dissolved/colloidal matter (DCM) (Barret et al., 2010b; Yamamoto et al., 2003; Zhou et al., 2007).

At equilibrium time, the quantity of MCs sorbed on the inactive AS, $\mathrm{q}_{\mathrm{e}}^{*}(\mu \mathrm{g} / \mathrm{g}$ TSS), is calculated with formula (4-1) and was used to investigate the recovery of selected MCs in the blank samples and possible sorption to glassware by comparing to the measured values:

$$
q_{e}^{*}=\frac{C_{0}-C_{e}}{T S S}
$$

where $C_{e}$ represented the equilibrium MCs concentration in water-phase $(\mu \mathrm{g} / \mathrm{L}) ; \mathrm{C}_{0}$, the initial MCs concentration in the water-phase $(\mu \mathrm{g} / \mathrm{L})$; TSS, total suspended solids in the mixed liquor $(\mathrm{mg} / \mathrm{L})$. The sorption characteristics were described by computation of isotherms and determination of characteristic values. Specific sorption coefficient $K_{d}(L / g$ TSS) is a frequently used characteristic value for the evaluation of the sorption behaviour. This distribution coefficient is defined as the ratio of equilibrium concentrations of a test 


\section{P a g e | $\mathbf{1 3 0}$}

substance in a two phase system consisting of an adsorbent and an aqueous phase and can be calculated with formula (4-2):

$$
K_{d}=\frac{q_{e}}{C_{e}}
$$

In this study the equilibrium sorption isotherms of MCs on the biomass using Linear, Freundlich and Langmuir models were studied. These isotherms describe measured MCs concentration in solid phase $\left(\mathrm{q}_{\mathrm{e}}\right)$ as a function of the equilibrium sorbate concentration in the bulk solution $\left(\mathrm{C}_{\mathrm{e}}\right)$. The Freundlich isotherm is described by Eq. (4-3).

$$
q_{e}=K_{f} C_{e^{\frac{1}{n}}}
$$

Reorganization of Eq. (4-3), leads to the linearized form of the Freundlich isotherm [Eq. (4-4)]:

$$
\ln q_{e}=\ln K_{f}+\frac{1}{n} \ln C_{e}
$$

where $K_{f}\left(\mu g^{(1-1 / n)} L^{1 / n} / g\right)$ is the Freundlich isotherm constant related to the sorption capacity and $\mathrm{n}$ shows the intensity of sorption. The Freundlich equation assumes that there are multiple types of sorption sites acting in parallel; therefore, different sorption free energy can be exhibited from each site. Huang and Sedlak (2001) also showed that the Freundlich equation is valid for heterogeneous sorption on a surface of sludge containing several sites.

Additionally, the sorption isotherm according to Langmuir was determined (Eq. 4-5):

$$
q_{e}=\frac{K_{L} \times C_{e}}{1+b C_{e}} \ln C_{e}
$$




\section{P a g e | 131}

where $\mathrm{K}_{\mathrm{L}}(\mathrm{L} / \mathrm{g}$ TSS) and $\mathrm{b}$ represent the Langmuir constants. The constant $\mathrm{b}$ in the Langmuir equation is related to the net enthalpy of the sorption process. In contrast to the Freundlich equation, the Langmuir sorption isotherm suggested that limited numbers of sites are available for monolayer sorption on a surface and assumes a homogenous distribution of sorption energy. By reorganization of Eq. (4-5), the linearized form of the Langmuir isotherm can be found (Eq. 4-6):

$$
\frac{C_{e}}{q_{e}}=\frac{b}{K_{L}} C_{e}+\frac{1}{K_{L}}
$$

\subsection{Results and Discussion}

\subsubsection{Sorption equilibrium to inactive AS}

Plots of adsorbed BPA, TCS, and EE2 on the inactivated sludge versus time for three MLSS concentrations of 3750, 2940, and $1855 \mathrm{mg}$ TSS/L at room temperature are shown in Figure 4-2. The selected MCs showed a great tendency to sorb into the biomass in the first $30 \mathrm{~min}$, followed by slow sorption reaction up to the equilibrium time. The contact times necessary to reach equilibrium between solid and liquid phases were found to be 2 , 4, and 6 hours for BPA, TCS, and EE2, respectively (Figure 4-2).

\subsubsection{Physicochemical sorption versus biosorption to inactive and active AS}

Activated and inactivated sludge were used in sorption experiments to distinguish between physicochemical sorption and biosorption. The changes in MCs concentrations 


\section{P a g e | 132}

in both liquid and solid phases during the $24 \mathrm{~h}$ of sorption experience using inactive AS with the initial MCs concentration of $10 \mu \mathrm{g} / \mathrm{L}$ are presented in Figure 4-2.
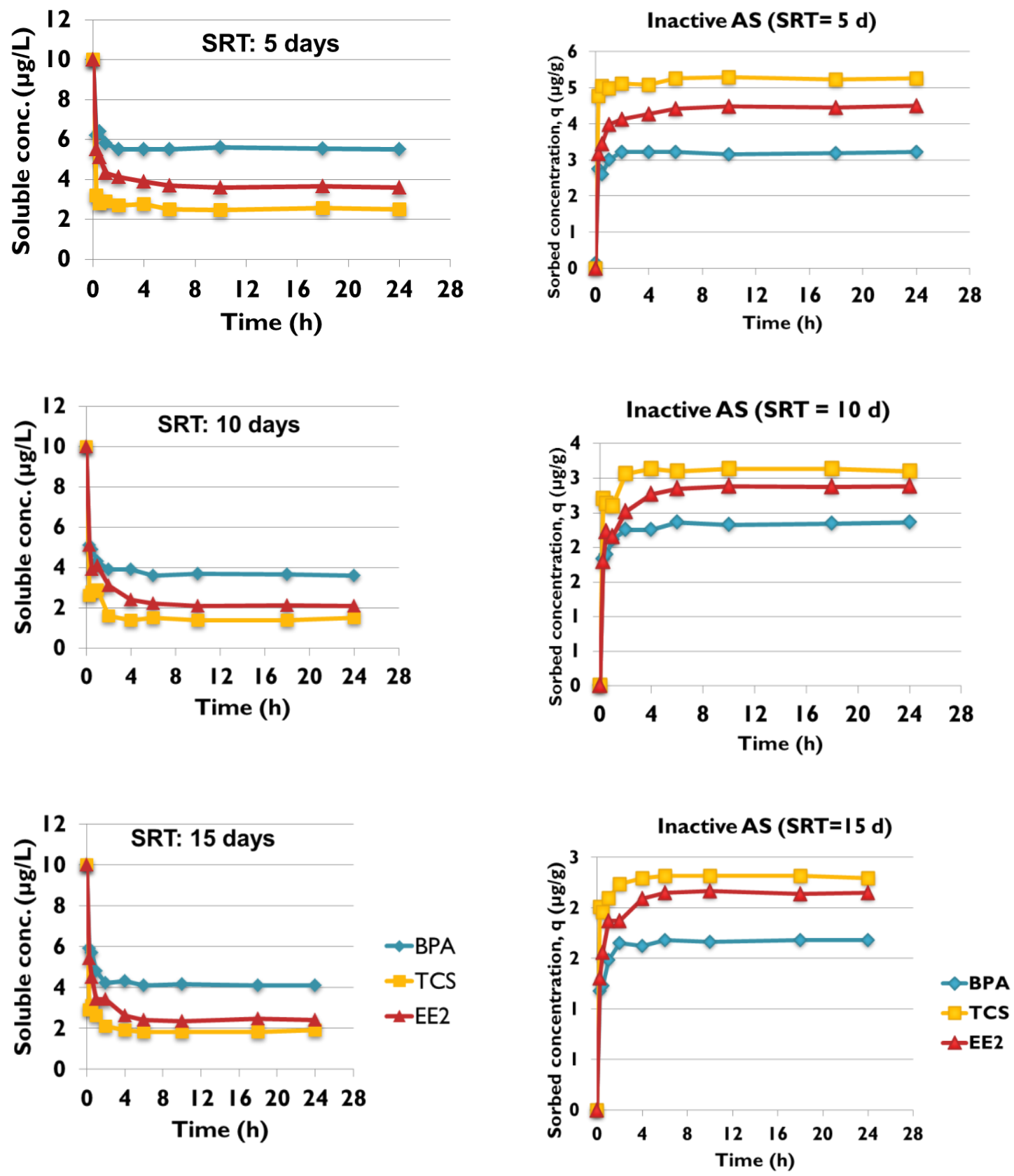

Figure 4-2. Concentration change of MCs in liquid and solid phases of inactive AS, sorption 


\section{P a g e $\mid \mathbf{1 3 3}$}

The result of this study suggested that equilibrium is reached between sorbed and dissolved MCs in all samples within a few hours. It was found that the sorption to the inactive AS consist of two stages, a rapid sorption to the biomass followed by a slight decrease in dissolved concentration until it reached equilibrium which is in agreement with the result reported in the literature for BPA sorption to sludge at relatively higher initial concentration (Seyhi et al., 2011).

At equilibrium, TCS showed greater tendency to sorb into the biomass followed by EE2 and BPA. These results could be explained by the higher octanol-water partition coefficient of TCS $\left(\log \mathrm{K}_{\mathrm{ow}}=4-4.8\right)$, compared to BPA $\left(\log \mathrm{K}_{\mathrm{ow}}=3.1-3.7\right)$, and EE2 $(\log$ $\mathrm{K}_{\mathrm{ow}}=3.6-4.6$ ). The MCs concentrations in liquid and solid phases were used to close the mass balance and investigate any abiotic losses during this study and less than $5 \%$ loss to the glassware was found during these experiments. The result of biosorption study with active AS (Figure 4-3) showed a similar result to inactive AS; however, the MCs concentration in the liquid phase continued to decrease after the equilibrium time found in the previous study. Similar results are reported in the literature dealing with higher concentration of these compounds (Chen et al., 2008; Clara et al., 2004; Feng et al., 2010; Seyhi et al., 2011) which would suggest physico-chemical sorption of selected MCs onto the sludge in the first 30 min of the experiment (rapid decrease stage) and biosorption or biodegradation of these compounds onto or by active AS (slow decrease). 


\section{P a g e | 134}

To investigate the possible biodegradability of sorbed MCs by AS, changes to the solid phase concentration of selected MCs were investigated in biosorption study with active AS (Figure 4-3).
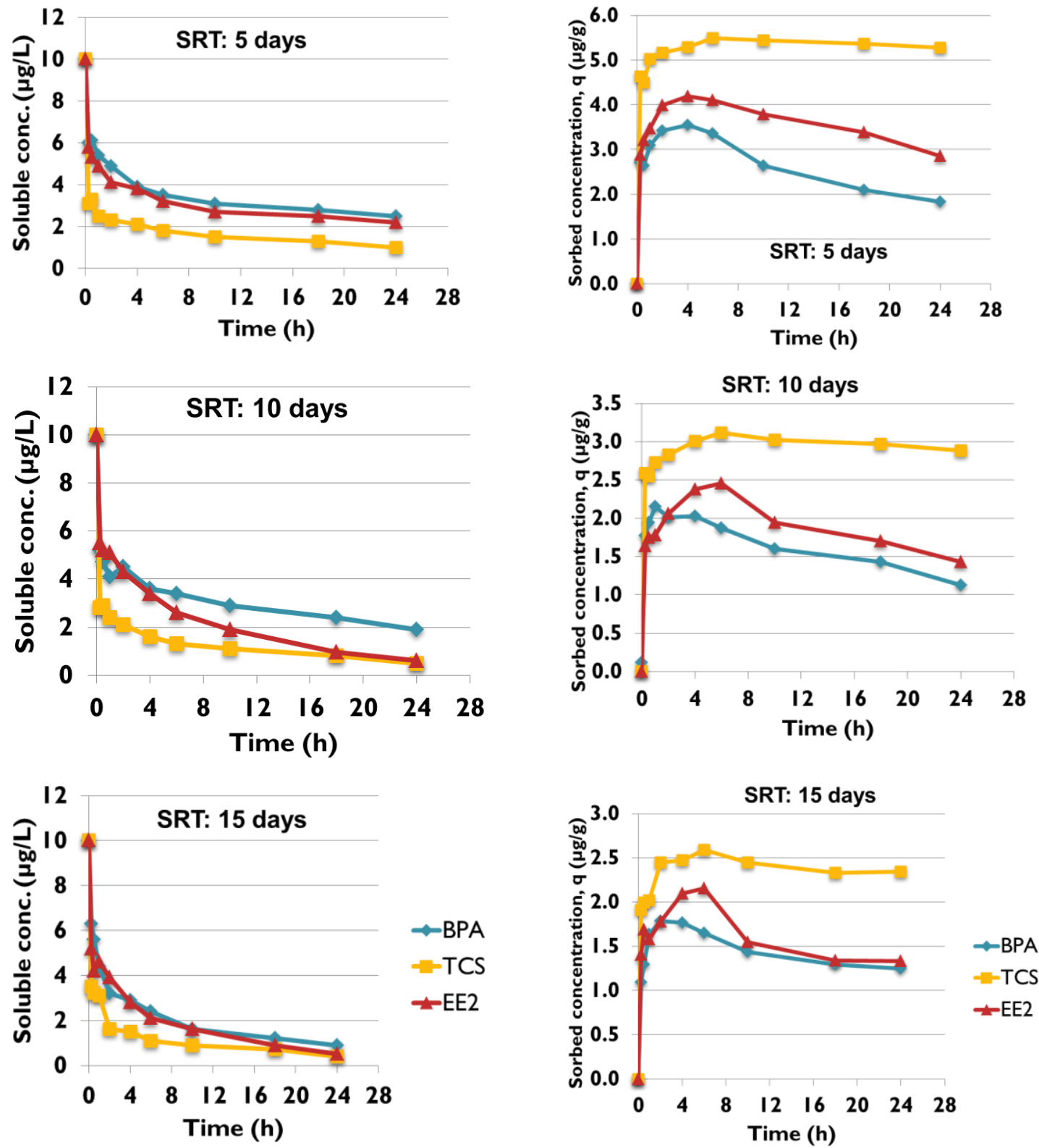

Figure 4-3. Concentration change of MCs in liquid and solid phases of active AS, biosorption 


\section{P a g e $\mid \mathbf{1 3 5}$}

It was found that the concentrations of sorbed MCs, except for TCS decreased even after the equilibrium time was reached due to possible degradation of sorbed MCs which is in agreement with the BPA sorption study on the sludge from the membrane bioreactor (Seyhi et al., 2011).

The different behaviour of sorbed TCS could be explained by inhibition effect of this compound on AS. Many researchers dealing with MCs assume that the degradation only happens in the liquid phase (Lindblom et al., 2009; Plosz et al., 2010; Pomiès et al., 2013). Although there are some studied that suggests dissolved and sorbed MCs could be biodegraded with separate or same rates (Byrns, 2001; Cowan et al., 1993; Lee et al., 1998; Urase and Kikuta, 2005); but these authors considered biodegradation of the sorbed MCs based only on successful calibration of a mathematical model, or indirect experimental observations, and these assumptions are poorly justified experimentally; therefore, more studies need to be done to closely investigate the possible biodegradation

or biotransformation of sorbed MCs into AS by carefully monitoring the ${ }^{14} \mathrm{C}$-radiolabeled MCs and their radioactivity within the biomass, ${ }^{14} \mathrm{C}-\mathrm{CO}_{2}$, and the substrate (Haudin et al., 2013; Jr et al., 1989; Sørensen et al., 2006).

The results of sorption and biosorption studies using different biomass obtained from reactors with SRTs of 5, 10, and 15 days were used to investigate the effect of SRTs on sorption characteristics of selected MCs (Figures 4-2 and 4-3). In the sorption study with inactive AS (Figure 4-2), the biomass that was obtained from the reactor with lowest SRT 


\section{P a g e | 136}

(5 d) had the lowest sorption potential, where 4575 , and $64 \%$ of BPA, TCS, and EE2 were removed from the liquid phase at equilibrium state, respectively. On the other hand the inactive AS obtained from reactors with higher SRTs, showed higher sorption potential, where 59, 82 and 76\% of BPA, TCS, and EE2 for AS with SRT of $15 \mathrm{~d}$ and 64, 84, and $79 \%$ of BPA, TCS, and EE2 for AS with SRT of $10 \mathrm{~d}$ were removed from the liquid phase at equilibrium state, respectively. Although the higher SRT indicates more biomass concentration in the reactor and possibly more available sorption sites for MCs, these findings suggested that not only the biomass concentration is an important factor in sorption process, but also the biomass characteristics such as morphology of the biomass

and the floc size, shape and density could play an important role in MCs sorption into the AS.

By comparing the change of MCs concentration in the liquid phase with the active biomass and different SRTs (Figure 4-3), it was observed that SRT had a clear effect on the possible biodegradation of sorbed MCs due to the density and the diversity of the biomass in higher SRT systems.

\subsubsection{Sorption and desorption kinetics of MCs onto inactive AS}

The sorption and desorption isotherms are illustrated in Figures 4-2 and 4-4. Desorption results showed two distinct stages, a very rapid desorption within 20 min followed by a slow desorption stage for all three compounds. It was observed that among the selected MCs, BPA had the highest desorption potential and 20-30\% of sorbed BPA 


\section{P a g e $\mid \mathbf{1 3 7}$}

was dissolved back into newly introduced wastewater within $4 \mathrm{~h}$ depending on type and age of the biomass used. The desorption potentials for TCS and EE2 were similar for all biomass samples for which $10-15 \%$ of sorbed EE2 and TCS were dissolved back into newly introduced wastewater within $2 \mathrm{~h}$.
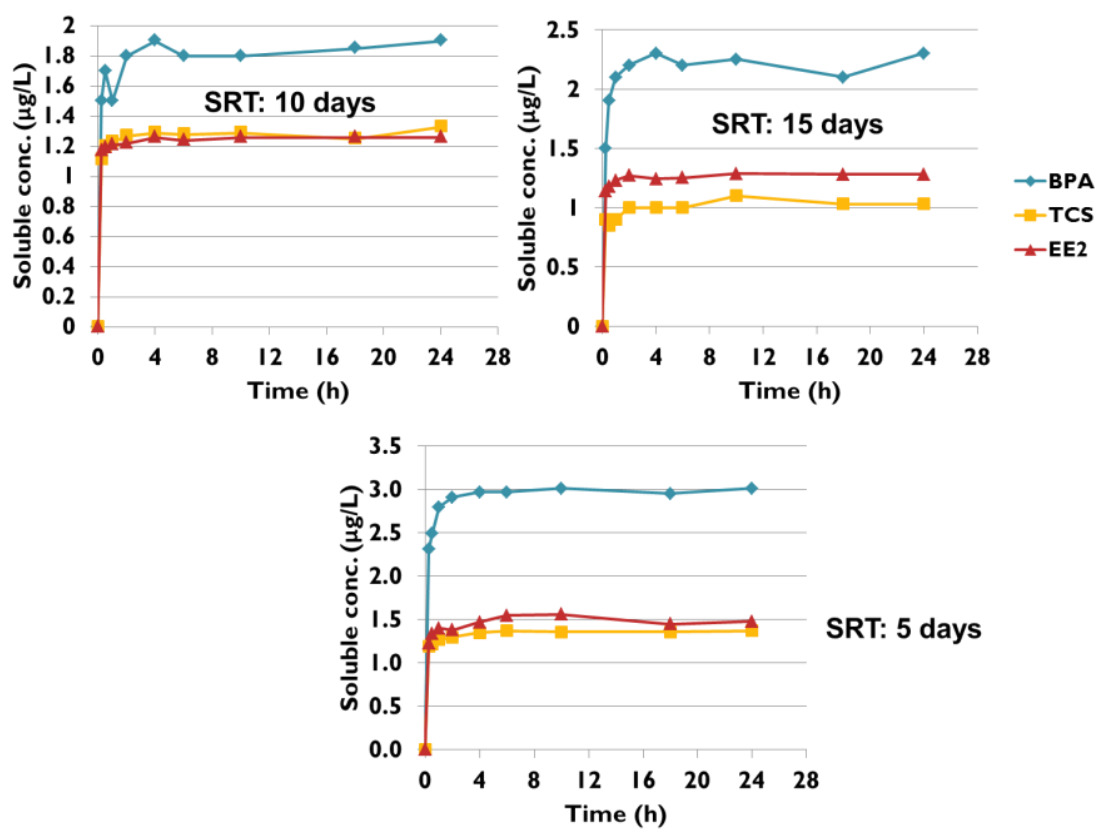

Figure 4-4. Concentration change of MCs in liquid phase of inactive AS, spiked at $10 \mu \mathrm{g} / \mathrm{L}$, desorption study

The sorption data were subjected to regression analysis using linear, Freundlich and Langmuir models (Table 4-4). The results indicated that both linear and Freundlich models fitted well with the experimental data with the correlation coefficients $\left(\mathrm{R}^{2}\right)$ greater than 0.98 . In the Freundlich models the Freundlich exponent $1 / \mathrm{n}$ was close to 1 ranging from 0.867-1.031 for all three compounds. Low correlation coefficients for Langmuir model for selected MCs indicated that the assumption of homogenous 


\section{P a g e | $\mathbf{1 3 8}$}

distribution of sorption energy in the model was not valid; therefore, no site limitation for monolayer sorption on a surface could be assumed.

Two semi-empirical expressions for partition coefficient $\left(\mathrm{K}_{\mathrm{d}}\right)$ as a function of octanol-water partition coefficient $\left(\mathrm{K}_{\mathrm{ow}}\right)$ were also used to calculate $\mathrm{K}_{\mathrm{d}}$ (Table 4-5), It was found that the estimation of $\mathrm{K}_{\mathrm{d}}$ value using $\mathrm{K}_{\mathrm{ow}}$ for MCs with the correlation of Mattermuller et al. (1980) was within $0.2 \log$ units for $\mathrm{K}_{\mathrm{d}}$ prediction. It must be cautioned that there is a significant influence of matrix characteristics and the experimental conditions imposed on $\mathrm{K}_{\mathrm{d}}$. Different coefficient and $\mathrm{n}$ values were also reported for selected MCs in the literature (Barret et al., 2010a; Chen et al., 2008; Clara et al., 2004) indicating the need of experimental determination of $\mathrm{K}_{\mathrm{d}}$ for each obtained biomass.

By comparing the results presented in Table 4-4, it was found that the SRT plays an important role in sorption kinetic determination; however, the biomass from the reactor with SRT of $10 \mathrm{~d}$, showed the highest $\mathrm{K}_{\mathrm{d}}$ values (L/g TSS) of $0.48,2.26$, and 1.37 for BPA, TCS, and EE2, respectively. This was in agreement with Yi and Harper (2007) and Hyland et al. (2012) and could be due to different morphology and biomass characteristic at SRT of 10 days. 
P a g e | 139

Table 4-4 Summery of sorption kinetic coefficients evaluated by different kinetic models

\begin{tabular}{|c|c|c|c|c|c|c|c|}
\hline \multicolumn{8}{|l|}{ BPA } \\
\hline \multirow[t]{2}{*}{ SRT (d) } & \multicolumn{3}{|l|}{ Freundlich model } & \multicolumn{2}{|c|}{ Linear model } & \multicolumn{2}{|c|}{ Langmuir model } \\
\hline & $K_{f}\left(\mu g^{(1-1 / n)} L^{1 / n} / g\right)$ & $1 / \mathrm{n}$ & $\mathrm{R}^{2}$ & $\mathrm{~K}_{\mathrm{d}}(\mathrm{L} / \mathrm{g})$ & $\mathrm{R}^{2}$ & $\mathrm{~K}_{\mathrm{L}}(\mathrm{L} / \mathrm{g})$ & $\mathrm{R}^{2}$ \\
\hline 15 & 0.435 & 0.918 & 0.989 & 0.351 & 0.987 & 0.663 & 0.086 \\
\hline 10 & 0.48 & 1.025 & 0.984 & 0.477 & 0.980 & 0.504 & 0.001 \\
\hline 5 & 0.468 & 0.867 & 0.997 & 0.319 & 0.991 & 0.515 & 0.345 \\
\hline \multicolumn{8}{|l|}{ TCS } \\
\hline \multirow[t]{2}{*}{ SRT (d) } & \multicolumn{3}{|l|}{ Freundlich model } & \multicolumn{2}{|c|}{ Linear model } & \multicolumn{2}{|c|}{ Langmuir model } \\
\hline & $\mathrm{K}_{\mathrm{f}}\left(\mu \mathrm{g}^{(1-1 / \mathrm{n})} \mathrm{L}^{1 / \mathrm{n}} / \mathrm{g}\right)$ & $1 / \mathrm{n}$ & $\mathrm{R}^{2}$ & $\mathrm{~K}_{\mathrm{d}}(\mathrm{L} / \mathrm{g})$ & $\mathrm{R}^{2}$ & $\mathrm{~K}_{\mathrm{L}}(\mathrm{L} / \mathrm{g})$ & $\mathrm{R}^{2}$ \\
\hline 15 & 1.035 & 1.1 & 0.995 & 1.591 & 0.990 & 1.082 & 0.703 \\
\hline 10 & 2.092 & 1.027 & 0.998 & 2.266 & 0.998 & 2.119 & 0.259 \\
\hline 5 & 2.019 & 1.005 & 0.995 & 2.018 & 0.993 & 2.033 & 0.003 \\
\hline \multicolumn{8}{|l|}{ EE2 } \\
\hline \multirow[t]{2}{*}{ SRT (d) } & \multicolumn{3}{|l|}{ Freundlich model } & \multicolumn{2}{|c|}{ Linear model } & \multicolumn{2}{|c|}{ Langmuir model } \\
\hline & $K_{f}\left(\mu g^{(1-1 / n)} L^{1 / n} / g\right)$ & $1 / \mathrm{n}$ & $\mathrm{R}^{2}$ & $\mathrm{~K}_{\mathrm{d}}(\mathrm{L} / \mathrm{g})$ & $\mathrm{R}^{2}$ & $\mathrm{~K}_{\mathrm{L}}(\mathrm{L} / \mathrm{g})$ & $\mathrm{R}^{2}$ \\
\hline 15 & 0.802 & 1.031 & 0.995 & 0.901 & 0.990 & 0.829 & 0.065 \\
\hline 10 & 1.389 & 0.98 & 0.997 & 1.368 & 0.993 & 1.332 & 0.00 \\
\hline 5 & 1.386 & 0.975 & 0.995 & 1.161 & 0.994 & 1.357 & 0.248 \\
\hline
\end{tabular}


P a g e | $\mathbf{1 4 0}$

Table 4-5 Calculation of partition coefficient $\left(\mathrm{K}_{\mathrm{d}}\right)$ as a function of octanol-water partition coefficient $\left(\mathrm{K}_{\mathrm{ow}}\right)$ based on semi-empirical equations

\begin{tabular}{|c|c|c|c|}
\hline Semi-empirical equations & $\log K_{d}$ & $\begin{array}{l}\qquad \log K_{d} \\
\text { found in this Study }\end{array}$ & Reference \\
\hline \multirow{4}{*}{$\begin{array}{c}\log \mathrm{K}_{\mathrm{d}}=0.67 \times \log \mathrm{K}_{\mathrm{ow}}+ \\
0.39\end{array}$} & BPA: $2.5-2.87$ & \multirow{3}{*}{$\mathrm{BPA}: 2.5-2.68$} & \multirow{4}{*}{ (Mattermuller et al., 1980) } \\
\hline & EE2: $2.8-2.9$ & & \\
\hline & TCS. 3436 & & \\
\hline & & \multirow[t]{2}{*}{ EE2: $2.9-3.1$} & \\
\hline \multirow{3}{*}{$\log \mathrm{K}_{\mathrm{d}}=0.58 \times \log \mathrm{K}_{\mathrm{ow}}+$} & BPA: $2.9-3.2$ & & \multirow{3}{*}{ (Jacobsen et al., 1993) } \\
\hline & EE2: $3.2-3.6$ & \multirow{2}{*}{ TCS: $3.2-3.4$} & \\
\hline & TCS: $3.7-3.9$ & & \\
\hline
\end{tabular}

Desorption kinetic coefficients of selected MCs were also presented in Table 4-6. Results indicated that the Freundlich and linear model could best fit the derived kinetic data for all obtained biomass base on high correlation coefficient $\left(\mathrm{R}^{2}>0.98\right)$. Higher desorption kinetic coefficients were also found for selected MCs compared to the sorption coefficients values. These results are in agreement with sorption study of selected pharmaceuticals onto AS in the literature (Yu et al., 2011a). Barret et al. (2011) also studied both the sorption and desorption kinetics of polycyclic aromatic hydrocarbons (PAHs) in activated sludge, and very rapid sorption and desorption kinetics were shown in comparison to biodegradation kinetics. In another study the comparison of adsorption and desorption halftimes of benzene derivatives into mesoporous carbon showed much faster desorption than adsorption (Marczewski et al., 2013). 
P a g e | 141

Table 4-6 Summery of desorption kinetic coefficients evaluated by different kinetic models

\begin{tabular}{|c|c|c|c|c|c|}
\hline \multicolumn{6}{|c|}{ BPA } \\
\hline \multirow[t]{2}{*}{ SRT (days) } & \multicolumn{3}{|c|}{ Freundlich model } & \multicolumn{2}{|c|}{ Linear model } \\
\hline & $\mathrm{K}_{\mathrm{f}}\left(\mu \mathrm{g}^{(1-1 / \mathrm{n})} \mathrm{L}^{1 / \mathrm{n}} / \mathrm{g}\right)$ & $1 / n$ & $\mathrm{R}^{2}$ & $\mathrm{~K}_{\mathrm{d}}(\mathrm{L} / \mathrm{g})$ & $\mathrm{R}^{2}$ \\
\hline 15 & 0.705 & 0.891 & 0.989 & 0.596 & 0.989 \\
\hline 10 & 1.182 & 0.978 & 0.998 & 1.083 & 0.980 \\
\hline 5 & 0.789 & 1.024 & 0.998 & 0.552 & 0.992 \\
\hline \multicolumn{6}{|c|}{ TCS } \\
\hline SRT (days) & \multicolumn{3}{|c|}{ Freundlich model } & \multicolumn{2}{|c|}{ Linear model } \\
\hline & $\mathrm{K}_{\mathrm{f}}\left(\mu \mathrm{g}^{(1-1 / \mathrm{n})} \mathrm{L}^{1 / \mathrm{n}} / \mathrm{g}\right)$ & $1 / \mathrm{n}$ & $\mathrm{R}^{2}$ & $\mathrm{~K}_{\mathrm{d}}(\mathrm{L} / \mathrm{g})$ & $\mathrm{R}^{2}$ \\
\hline 15 & 3.251 & 0.985 & 0.993 & 3.183 & 0.990 \\
\hline 10 & 4.102 & 1.121 & 0.998 & 3.963 & 0.984 \\
\hline 5 & 2.333 & 0.984 & 0.9915 & 2.288 & 0.988 \\
\hline \multicolumn{6}{|c|}{ EE2 } \\
\hline SRT (days) & \multicolumn{3}{|c|}{ Freundlich model } & \multicolumn{2}{|c|}{ Linear model } \\
\hline & $\mathrm{K}_{\mathrm{f}}\left(\mu \mathrm{g}^{(1-1 / \mathrm{n})} \mathrm{L}^{1 / \mathrm{n}} / \mathrm{g}\right)$ & $1 / \mathrm{n}$ & $\mathrm{R}^{2}$ & $\mathrm{~K}_{\mathrm{d}}(\mathrm{L} / \mathrm{g})$ & $\mathrm{R}^{2}$ \\
\hline 15 & 2.219 & 1.011 & 0.993 & 2.188 & 0.989 \\
\hline 10 & 3.983 & 1.028 & 0.986 & 3.756 & 0.992 \\
\hline 5 & 1.443 & 0.894 & 0.985 & 1.164 & 0.981 \\
\hline
\end{tabular}

The results of desorption study using different biomass obtained from reactors with SRTs of 5, 10, and 15 days were used to investigate the effect of SRTs on sorption characteristics of selected MCs (Figures 4 and Table 6). It was found that the biomass obtained from reactor with SRT of 10 days had the highest desorption kinetic coefficient 


\section{P a g e $\mid \mathbf{1 4 2}$}

for all three selected MCs, however, unlike the sorption study, the desorption was faster for EE2 and TCS at SRT of $15 \mathrm{~d}$ compared to SRT of $5 \mathrm{~d}$.

\subsection{Conclusions}

The results of sorption equilibrium study, suggested that equilibrium was reached within a few hours between sorbed and dissolved MCs. Mathematical models were also applied to describe the sorption mechanism and Freundlich sorption isotherms with values of $1 / \mathrm{n}$ close to 1 were found to best fit the results which demonstrate that all tested concentrations result on the linear part of the Freundlich isotherm. Calculation of Freundlich constant, $\mathrm{K}_{\mathrm{F}}$ and distribution coefficient, $\mathrm{K}_{\mathrm{d}}$ exhibited the greater tendency of EE2 and TCS for sorption, compared to BPA. The results of this study indicated that the SRT had a clear effect on the sorption kinetics where the highest sorption constant was achieved for a SRT of $10 \mathrm{~d}$ for all three target substances. This could be due to change of the morphology of the biomass from reactors operating at different SRTs. By comparing the results of sorption and biosorption studies, two stages were found for MCs sorption to AS: physic-chemical sorption stage and biosorption or biodegradation. It was also observed that the biodegradation can also occur when MCs are sorbed to the biomass with TCS as an exception due to its inhibition effect. Therefore, the possible biodegradation of sorbed MCs can be incorporated into the existing biodegradation

models to improve MCs fate models. Furthermore, the results presented in this study indicate that the sorption and desorption kinetics of selected MCs are very rapid. 
P a g e $\mid \mathbf{1 4 3}$

Therefore, desorption kinetics cannot limit BPA, EE2, and TCS biodegradation in

biological treatment systems and the equilibrium state assumption is valid to represent sorption phenomena.

\subsection{References}

Standard methods for the examination of water and wastewater : 21st edition Washington, DC: American Public Health Association, 2005.

Allmyr M, Adolfsson-Erici M, McLachlan MS, Sandborgh-Englund G. Triclosan in plasma and milk from Swedish nursing mothers and their exposure via personal care products. Sci Total Environ 2006; 372: 87-93.

Andersen HR, Hansen M, Kjolholt J, Stuer-Lauridsen F, Ternes T, Halling-Sorensen B. Assessment of the importance of sorption for steroid estrogens removal during activated sludge treatment. Chemosphere 2005; 61: 139-46.

Anderson PD. Endocrine disrupting compounds and implications for wastewater treatment, 2005.

Aranami K, Readman JW. Photolytic degradation of triclosan in freshwater and seawater. Chemosphere 2007; 66: 1052-6.

Arias-Estévez M, Fernández-Gándara D, García-Falcón MS, García-Río L, Mejuto JC, Simal-Gándara J. Sorption of PAHs to Colloid Dispersions of Humic Substances in Water. Bulletin of Environmental Contamination and Toxicology 2007; 79: 251-254.

Atkinson SK, Marlatt VL, Kimpe LE, Lean DR, Trudeau VL, Blais JM. The occurrence of steroidal estrogens in south-eastern Ontario wastewater treatment plants. Sci Total Environ 2012; 430: 119-25.

Banihashemi B, Droste RL. Trace level determination of bisphenol-A in wastewater and sewage sludge by high-performance liquid chromatography and UV detection. Water Quality Research Journal of Canada 2013; 48: 133-144.

Barret M, Carrere H, Latrille E, Wisniewski C, Patureau D. Micropollutant and sludge characterization for modeling sorption equilibria. Environ Sci Technol 2010a; 44: $1100-6$.

Barret M, Carrere H, Patau M, Patureau D. Kinetics and reversibility of micropollutant sorption in sludge. J Environ Monit 2011; 13: 2770-4.

Barret M, Patureau D, Latrille E, Carrere H. A three-compartment model for micropollutants sorption in sludge: methodological approach and insights. Water Res 2010b; 44: 616-24. 
Bester K. Triclosan in a sewage treatment process-balances and monitoring data. Water Research 2003; 37: 3891-3896.

Borrirukwisitsak S, Keenan HE, Gauchotte-Lindsay C. Effects of salinity, pH and temperature on the octanol-water partition coefficient of bisphenol A. International Journal of Environmental Science and Development 2012; 3(5): 460-464.

Braoudaki M, Hilton AC. Low level of cross-resistance between triclosan and antibiotics inEscherichia coliK-12 andE. coliO55 compared toE. coliO157. FEMS Microbiology Letters 2004; 235: 305-309.

Buth JM, Grandbois M, Vikesland PJ, McNeill K, Arnold WA. Aquatic photochemistry of chlorinated triclosan derivatives: potential source of polychlorodibenzo-pdioxins. Environ Toxicol Chem 2009; 28: 2555-63.

Byrns G. The fate of xenobiotic organic compounds in wastewater treatment plants. Water Res 2001; 35: 2523-33.

Carballa M, Omil F, Lema JM. Calculation methods to perform mass balances of micropollutants in sewage treatment plants. application to pharmaceutical and personal care products (PPCPs). Environ Sci Technol 2007; 41: 884-90.

Chalew TE, Halden RU. Environmental Exposure of Aquatic and Terrestrial Biota to Triclosan and Triclocarban. J Am Water Works Assoc 2009; 45: 4-13.

Chen JH, Huang X, Lee DJ. Bisphenol A removal by a membrane bioreactor. Process Biochemistry 2008; 43: 451-456.

Cirja M, Zuehlke S, Ivashechkin P, Hollender J, Schaffer A, Corvini PF. Behavior of two differently radiolabelled 17alpha-ethinylestradiols continuously applied to a laboratory-scale membrane bioreactor with adapted industrial activated sludge. Water Res 2007; 41: 4403-12.

Clara M, Strenn B, Gans O, Martinez E, Kreuzinger N, Kroiss H. Removal of selected pharmaceuticals, fragrances and endocrine disrupting compounds in a membrane bioreactor and conventional wastewater treatment plants. Water Res 2005; 39: 4797-807.

Clara M, Strenn B, Saracevic E, Kreuzinger N. Adsorption of bisphenol-A, 17 betaestradiole and 17 alpha-ethinylestradiole to sewage sludge. Chemosphere 2004; 56: 843-51.

Cowan CE, Larson RJ, Feijtel TCJ, Rapaport RA. An improved model for predicting the fate of consumer product chemicals in wastewater treatment plants. Water Research 1993; 27: 561-573.

Dann AB, Hontela A. Triclosan: environmental exposure, toxicity and mechanisms of action. J Appl Toxicol 2011; 31: 285-311.

Dionisi D, Bertin L, Bornoroni L, Capodicasa S, Papini MP, Fava F. Removal of organic xenobiotics in activated sludges under aerobic conditions and anaerobic digestion 
of the adsorbed species. Journal of Chemical Technology and Biotechnology 2006; 81: 1496-1505.

Drury B, Scott J, Rosi-Marshall EJ, Kelly JJ. Triclosan exposure increases triclosan resistance and influences taxonomic composition of benthic bacterial communities. Environ Sci Technol 2013; 47: 8923-30.

Feng Y, Zhang Z, Gao P, Su H, Yu Y, Ren N. Adsorption behavior of EE2 (17 alphaethinylestradiol) onto the inactivated sewage sludge: kinetics, thermodynamics and influence factors. J Hazard Mater 2010; 175: 970-6.

Fernandez MP, Ikonomou MG, Buchanan I. An assessment of estrogenic organic contaminants in Canadian wastewaters. Sci Total Environ 2007; 373: 250-69.

Fujimoto T, Kubo K, Aou S. Prenatal exposure to bisphenol A impairs sexual differentiation of exploratory behavior and increases depression-like behavior in rats. Brain Res 2006; 1068: 49-55.

Gee RH, Charles A, Taylor N, Darbre PD. Oestrogenic and androgenic activity of triclosan in breast cancer cells. J Appl Toxicol 2008; 28: 78-91.

Gomes RL, Scrimshaw MD, Lester JN. Fate of conjugated natural and synthetic steroid estrogens in crude sewage and activated sludge batch studies. Environ Sci Technol 2009; 43: 3612-8.

Guellil A, Block JC, Urbain V. Adaptation of the microbial adhesion to hydrocarbon test (MATH) for measuring activated sludge hydrophobicity. Water Science and Technology 1998; 37: 359-362.

Haudin CS, Zhang Y, Dumeny V, Lashermes G, Bergheaud V, Barriuso E, et al. Fate of (14)C-organic pollutant residues in composted sludge after application to soil. Chemosphere 2013; 92: 1280-5.

Heidler J, Halden RU. Mass balance assessment of triclosan removal during conventional sewage treatment. Chemosphere 2007; 66: 362-9.

Huang CH, Sedlak DL. Analysis of estrogenic hormones in municipal wastewater effluent and surface water using enzyme-linked immunosorbent assay and gas chromatography/tandem mass spectrometry. Environmental Toxicology and Chemistry 2001; 20: 133-139.

Hung NV, Tateda M, Ike M, Fujita M, Tsunoi S, Tanaka M. Sorption of biodegradation end products of nonylphenol polyethoxylates onto activated sludge. Journal of Environmental Sciences 2004; 16: 564-569.

Hyland KC, Dickenson ER, Drewes JE, Higgins CP. Sorption of ionized and neutral emerging trace organic compounds onto activated sludge from different wastewater treatment configurations. Water Res 2012; 46: 1958-68.

Ivashechkin P, Corvini PF, Dohmann M. Behaviour of endocrine disrupting chemicals during the treatment of municipal sewage sludge. Water Sci Technol 2004; 50: 133-40. 
Jacobsen BN, Nyholm N, Pedersen BM, Poulsen O, Ostfeldt P. Removal of Organic Micropollutants in Laboratory Activated-Sludge Reactors under Various Operating-Conditions - Sorption. Water Research 1993; 27: 1505-1510.

Jeffries KM, Jackson LJ, Ikonomou MG, Habibi HR. Presence of natural and anthropogenic organic contaminants and potential fish health impacts along two river gradients in Alberta, Canada. Environ Toxicol Chem 2010; 29: 2379-87.

Jr GES, Turakhia MH, Lu C-J. Initiation of Micropollutant Biodegradation in Virgin GAC Columns. Journal (American Water Works Association) 1989; 81: 168-176.

Kidd KA, Blanchfield PJ, Mills KH, Palace VP, Evans RE, Lazorchak JM, et al. Collapse of a fish population after exposure to a synthetic estrogen. Proc Natl Acad Sci U S A 2007; 104: 8897-901.

Kinney CA, Furlong ET, Kolpin DW, Burkhardt MR, Zaugg SD, Werner SL, et al. Bioaccumulation of pharmaceuticals and other anthropogenic waste indicators in earthworms from agricultural soil amended with biosolid or swine manure. Environ Sci Technol 2008; 42: 1863-70.

Koh YK, Chiu TY, Boobis A, Cartmell E, Scrimshaw MD, Lester JN. Treatment and removal strategies for estrogens from wastewater. Environ Technol 2008; 29: 245-67.

Lai KM, Johnson KL, Scrimshaw MD, Lester JN. Binding of waterborne steroid estrogens to solid phases in river and estuarine systems. Environmental Science \& Technology 2000; 34: 3890-3894.

Lee HB, Peart TE, Chan J, Gris G. Occurrence of endocrine-disrupting chemicals in sewage and sludge samples in Toronto, Canada. Water Quality Research Journal of Canada 2004; 39: 57-63.

Lee KC, Rittmann BE, Shi JC, McAvoy D. Advanced steady-state model for the fate of hydrophobic and volatile compounds in activated sludge. Water Environment Research 1998; 70: 1118-1131.

Lindblom E, Press-Kristensen K, Vanrolleghem PA, Mikkelsen PS, Henze M. Dynamic experiments with high bisphenol-A concentrations modelled with an ASM model extended to include a separate XOC degrading microorganism. Water Res 2009; 43: 3169-76.

Lishman L, Smyth SA, Sarafin K, Kleywegt S, Toito J, Peart T, et al. Occurrence and reductions of pharmaceuticals and personal care products and estrogens by municipal wastewater treatment plants in Ontario, Canada. Sci Total Environ 2006; 367: 544-58.

Lopez-Avila V, Hites RA. Organic compounds in an industrial wastewater. Their transport into sediments. Environmental Science \& Technology 1980; 14: 13821390. 
Marczewski AW, Derylo-Marczewska A, Slota A. Adsorption and desorption kinetics of benzene derivatives on mesoporous carbons. Adsorption-Journal of the International Adsorption Society 2013; 19: 391-406.

Mattermuller C, Gujer W, Giger W, Stumm W. Non-Biological Elimination Mechanisms in a Biological Sewage-Treatment Plant. Progress in Water Technology 1980; 12: 299-314.

Mohapatra DP, Brar SK, Tyagi RD, Surampalli RY. Occurrence of bisphenol A in wastewater and wastewater sludge of CUQ treatment plant. Journal of Xenobiotics 2011; 1.

Muller M, Rabenoelina F, Balaguer P, Patureau D, Lemenach K, Budzinski H, et al. Chemical and biological analysis of endocrine-disrupting hormones and estrogenic activity in an advanced sewage treatment plant. Environ Toxicol Chem 2008; 27: 1649-58.

Nakada N, Yasojima M, Okayasu Y, Komori K, Suzuki Y. Mass balance analysis of triclosan, diethyltoluamide, crotamiton and carbamazepine in sewage treatment plants. Water Sci Technol 2010; 61: 1739-47.

Neumegen RA, Fernandez-Alba AR, Chisti Y. Toxicities of triclosan, phenol, and copper sulfate in activated sludge. Environ Toxicol 2005; 20: 160-4.

Nie Y, Qiang Z, Zhang H, Adams C. Determination of endocrine-disrupting chemicals in the liquid and solid phases of activated sludge by solid phase extraction and gas chromatography-mass spectrometry. J Chromatogr A 2009; 1216: 7071-80.

Parrott JL, Blunt BR. Life-cycle exposure of fathead minnows (Pimephales promelas) to an ethinylestradiol concentration below $1 \mathrm{ng} / \mathrm{L}$ reduces egg fertilization success and demasculinizes males. Environ Toxicol 2005; 20: 131-41.

Plosz BG, Leknes H, Thomas KV. Impacts of competitive inhibition, parent compound formation and partitioning behavior on the removal of antibiotics in municipal wastewater treatment. Environ Sci Technol 2010; 44: 734-42.

Pomiès M, Choubert JM, Wisniewski C, Coquery M. Modelling of micropollutant removal in biological wastewater treatments: a review. Sci Total Environ 2013; 443: 733-48.

Queckenberg C, Meins J, Wachall B, Doroshyenko O, Tomalik-Scharte D, Bastian B, et al. Absorption, pharmacokinetics, and safety of triclosan after dermal administration. Antimicrob Agents Chemother 2010; 54: 570-2.

Robinson BJ, Hui JP, Soo EC, Hellou J. Estrogenic compounds in seawater and sediment from Halifax Harbour, Nova Scotia, Canada. Environ Toxicol Chem 2009; 28: $18-25$.

Samaras VG, Stasinakis AS, Mamais D, Thomaidis NS, Lekkas TD. Fate of selected pharmaceuticals and synthetic endocrine disrupting compounds during wastewater treatment and sludge anaerobic digestion. J Hazard Mater 2013; 244245: 259-67. 


\section{P a g e | 148}

Seyhi B, Drogui P, Buelna G, Blais JF. Modeling of sorption of bisphenol A in sludge obtained from a membrane bioreactor process. Chemical Engineering Journal 2011; 172: 61-67.

Singer H, Müller S, Tixier C, Pillonel L. Triclosan: Occurrence and Fate of a Widely Used Biocide in the Aquatic Environment: Field Measurements in Wastewater Treatment Plants, Surface Waters, and Lake Sediments. Environmental Science \& Technology 2002; 36: 4998-5004.

Sivaraman S, Sullivan TJ, Johnson F, Novichenok P, Cui G, Simmerling C, et al. Inhibition of the bacterial enoyl reductase FabI by triclosan: a structure-reactivity analysis of FabI inhibition by triclosan analogues. J Med Chem 2004; 47: 509-18.

Sørensen SR, Schultz A, Jacobsen OS, Aamand J. Sorption, desorption and mineralisation of the herbicides glyphosate and MCPA in samples from two Danish soil and subsurface profiles. Environ Pollut 2006; 141: 184-94.

Stahlhut RW, Welshons WV, Swan SH. Bisphenol A Data in NHANES Suggest Longer than Expected Half-Life, Substantial Nonfood Exposure, or Both. Environmental health perspectives 2009; 117: 784-789.

Staples CA, Dorn PB, Klecka GM, O'Block ST, Harris LR. A review of the environmental fate, effects, and exposures of bisphenol A. Chemosphere 1998; 36: 2149-73.

Stasinakis AS, Gatidou G, Mamais D, Thomaidis NS, Lekkas TD. Occurrence and fate of endocrine disrupters in Greek sewage treatment plants. Water Res 2008; 42: 1796-804.

Stevens-Garmon J, Drewes JE, Khan SJ, McDonald JA, Dickenson ER. Sorption of emerging trace organic compounds onto wastewater sludge solids. Water Res 2011; 45: 3417-26.

Tchobanoglous G, Burton, F. L., Stensel, D. H. Wastewater engineering: treatment and reuse. New York: McGraw-Hill, 2003.

Ternes TA, Herrmann N, Bonerz M, Knacker T, Siegrist H, Joss A. A rapid method to measure the solid-water distribution coefficient $(\mathrm{Kd})$ for pharmaceuticals and musk fragrances in sewage sludge. Water Res 2004; 38: 4075-84.

Thomas PM, Foster GD. Tracking acidic pharmaceuticals, caffeine, and triclosan through the wastewater treatment process. Environmental Toxicology and Chemistry 2005; 24: 25-30.

Urase T, Kikuta T. Separate estimation of adsorption and degradation of pharmaceutical substances and estrogens in the activated sludge process. Water Res 2005; 39: 1289-300.

Urbatzka R, van Cauwenberge A, Maggioni S, Vigano L, Mandich A, Benfenati E, et al. Androgenic and antiandrogenic activities in water and sediment samples from the river Lambro, Italy, detected by yeast androgen screen and chemical analyses. Chemosphere 2007; 67: 1080-7. 
Vajda AM, Barber LB, Gray JL, Lopez EM, Woodling JD, Norris DO. Reproductive disruption in fish downstream from an estrogenic wastewater effluent. Environ Sci Technol 2008; 42: 3407-14.

Vega-Morales T, Sosa-Ferrera Z, Santana-Rodriguez JJ. Determination of alkylphenol polyethoxylates, bisphenol-A, 17alpha-ethynylestradiol and 17beta-estradiol and its metabolites in sewage samples by SPE and LC/MS/MS. J Hazard Mater 2010; 183: 701-11.

Vethaak AD, Lahr J, Schrap SM, Belfroid AC, Rijs GB, Gerritsen A, et al. An integrated assessment of estrogenic contamination and biological effects in the aquatic environment of The Netherlands. Chemosphere 2005; 59: 511-24.

vom Saal FS, Myers JP. Bisphenol A and risk of metabolic disorders. JAMA 2008; 300: 1353-5.

Xu K, Harper WF, Jr., Zhao D. 17alpha-Ethinylestradiol sorption to activated sludge biomass: thermodynamic properties and reaction mechanisms. Water Res 2008; 42: 3146-52.

Yamamoto H, Liljestrand HM, Shimizu Y, Morita M. Effects of physical-chemical characteristics on the sorption of selected endocrine disruptors by dissolved organic matter surrogates. Environ Sci Technol 2003; 37: 2646-57.

Yi T, Harper WF, Jr. The effect of biomass characteristics on the partitioning and sorption hysteresis of 17alpha-ethinylestradiol. Water Res 2007; 41: 1543-53.

Ying GG, Yu XY, Kookana RS. Biological degradation of triclocarban and triclosan in a soil under aerobic and anaerobic conditions and comparison with environmental fate modelling. Environ Pollut 2007; 150: 300-5.

Yu TH, Lin AY, Panchangam SC, Hong PK, Yang PY, Lin CF. Biodegradation and biosorption of antibiotics and non-steroidal anti-inflammatory drugs using immobilized cell process. Chemosphere 2011; 84: 1216-22.

Zhao J, Li Y, Zhang C, Zeng Q, Zhou Q. Sorption and degradation of bisphenol A by aerobic activated sludge. J Hazard Mater 2008; 155: 305-11.

Zhou H, Huang X, Wang X, Zhi X, Yang C, Wen X, et al. Behaviour of selected endocrine-disrupting chemicals in three sewage treatment plants of Beijing, China. Environmental Monitoring and Assessment 2010; 161: 107-21.

Zhou JL, Liu R, Wilding A, Hibberd A. Sorption of selected endocrine disrupting chemicals to different aquatic colloids. Environ Sci Technol 2007; 41: 206-13. 


\section{Chapter 5: Fate of MCs In Simulated AS Bioreactors}

\section{Summary :}

To understand the fate of microconstituents (MCs) in an activated sludge (AS) system, nine lab-scale continuous flow porous-pot bioreactors operating at various solids retention times (SRTs) and hydraulic retention times (HRTs) were studied. In this research biodegradation and sorption were investigated at the $\mu \mathrm{g} / \mathrm{L}$ range for $17 \alpha$ ethinylestradiol (EE2), bisphenol-A (BPA), and triclosan (TCS). The effects of SRT, HRT and the biomass concentration on sorption and removal of MCs were also studied. The selected MCs showed high sorption affinity to the non-active biomass with greater tendency of EE2 and TCS for sorption, compared to BPA. Mathematical models were applied to describe the sorption mechanism and Freundlich sorption isotherms with values of $1 / \mathrm{n}$ close to 1 and pseudo-second-order model were found to best fit the results. The results of this study indicated that the SRT had a clear effect on the sorption kinetics where the highest sorption constant was achieved for a SRT of 10 days for all three target substances. The operation of continuous-flow AS systems in the presence of $20 \mu \mathrm{g} / \mathrm{L}$ of MCs indicated that 90-98, 63-91 and 97-98\% of BPA, EE2 and TCS, respectively, can be removed during the AS process in systems operating at SRT of 5-15 d and HRT of 4-10 h. Determination of MCs in the dissolved and particulate phase and calculation of their mass flux showed that biotransformation was the principal removal mechanism of

\footnotetext{
${ }^{1}$ This chapter has been submitted for publications to the Journal of Hazardous Material
} 


\section{P a g e $\mid \mathbf{1 5 1}$}

selected MCs. Statistical analysis revealed that both SRT and HRT had a significant effect on the fate of MCs where highest biotransformation removal rate was found for TCS and BPA in reactors operating at higher SRTs whereas the lower rate of 58\% was found for EE2 in the reactor operating at SRT of $5 \mathrm{~d}$ and HRT of $4 \mathrm{~h}$. The MCs removal rate in the presence of nitrification inhibitor illustrated the role of heterotrophs versus autotrophs in fate of MCs. It was found that heterotrophs were most likely responsible for the degradation of selected MCs. 
P a g e $\mid \mathbf{1 5 2}$

\subsection{Introduction:}

The occurrence and fate of microconstituents (MCs) in lakes, rivers, drinking water and their removal in wastewater treatment plants (WWTPs) as major point sources are a growing concern since some of these substances remain at detectable levels in WWTP

effluents, and discharge into the rivers (Anderson, 2005; Ashton et al., 2004). Because of this growing interest, scientists have studied the environmental fate and toxicology properties of MCs (Melcer and Klecka, 2011; Radjenovic et al., 2009; Samaras et al., 2013) and although no legal limits have been established yet, regulatory authorities around the world have conducted monitoring programs and risk assessments of different MCs for future guidelines of concentration limits of MCs in water bodies or in discharged WWTPs effluent (Advanced Industrial Science and Technology, 2007; Environment Canada and Health Canada, 2011; European Commission, 2010; Roig, 2010).

Conventional wastewater treatment systems, such as activated sludge (AS) are not designed to remove MCs at very low concentration. In addition, advanced treatment methods, such as membrane bioreactor (Lee et al., 2008), advanced oxidation (Plahuta et al., 2014), ozonation or use of granulated activated carbon (Margot et al., 2013), are being explored. However; these treatment options are often expensive to install and operate and might only be feasible for larger WWTPs. Therefore, information on how various MCs are removed from current facilities need to be studied and opportunities to optimize and enhance their treatment need to be explored which requires understanding of 


\section{P a g e $\mid \mathbf{1 5 3}$}

the effect of operational condition, environmental parameters and compound specific properties on the fate of MCs in treatment processes.

Findings from multiple studies have demonstrated that sorption onto suspended solids (SS), biodegradation/biotransformation, chemical transformation (such as photodegradation), and volatilization are the primary removal mechanisms for MCs in wastewater treatment processes (Jelic et al., 2011; Verlicchi et al., 2012). Joss et al. (2006) showed that a significant amount of a compound will be stripped in a bioreactor with fine bubble aeration if Henry's constant $(\mathrm{H})>0.003\left(\mathrm{~atm} \cdot \mathrm{m}^{3} / \mathrm{mol}\right)$. Therefore, it can be concluded that stripping process during wastewater treatment is in general not relevant for the removal of those MCs that have low Henry's constant. Depending on $\mathrm{pH}$, photolysis of MCs could be a significant removal mechanism, especially above $\mathrm{pH} 8$ (Tixier et al., 2002). Because the $\mathrm{pH}$ range in WWTPs is usually in the range of 6.5-8, losses due to photolysis are expected to be negligible. Thus, sorption and biotransformation are considered as two primary removal pathways of $\mathrm{MCs}$ in most studies. Biodegradation of MCs is usually more difficult than biodegradation of natural microbial substrates due to the different molecular structure of MCs (Chong et al., 2008). Some MCs can be utilized as primary substrates but others are utilized as secondary substrates in conjunction with a primary substrate, i.e., co-metabolism. The partitioning of MCs between solid and liquid phases is also significant due to the large concentration of biomass and associated solids. 


\section{P a g e | 154}

Several synthetic organic compounds that have been classified as MCs are commonly detected in municipal and industrial wastewater and their occurrence has been well documented around the world. Among these, 17 -ethinylestradiol (EE2), Bisphenol A (BPA) and Triclosan (TCS) present significant research interest due to their extensive use and their physico-chemical and toxicological properties (Melcer and Klecka, 2011). Concentration levels of these MCs range between a few $\mathrm{ng} / \mathrm{L}$ to some $\mu \mathrm{g} / \mathrm{L}$ in wastewater (Atkinson et al., 2012; Fernandez et al., 2007; Lee et al., 2004; Mohapatra et al., 2011; Nakada et al., 2010; Stasinakis et al., 2008), surface water (Bennie, 2008; Klecka et al., 2009; Stasinakis et al., 2012), groundwater (Lapworth et al., 2012; Latorre et al., 2003) and drinking water (Heberer, 2002b; Vulliet et al., 2011), while concentrations up to $\mu \mathrm{g} / \mathrm{g}$ have been detected in sewage sludge and soil samples (Martin et al., 2012; Mohapatra et al., 2011).

BPA is a building compound for the manufacturing of plastics, epoxy resins, and polycarbonate resins. BPA is an endocrine disrupter (Fujimoto et al., 2006; vom Saal and Myers, 2008) and might be as effective as estradiol in triggering some receptor responses (Stahlhut et al., 2009). BPA might also act as an androgen receptor antagonist (Urbatzka et al., 2007). The observed influent-to-effluent reduction in five municipal WWTPs in Canada was $70-76 \%$ for BPA indicating that it is not completely eliminated during wastewater treatment (Fernandez et al., 2007; Mohapatra et al., 2011). Stasinakis et al. (2008) conducted one of the few studies that allows for a mass balance analysis of the 


\section{P a g e $\mid \mathbf{1 5 5}$}

mechanisms responsible for BPA removal during wastewater treatment. BallesterosGomez et al. (2007) measured BPA in four WWTPs in Spain and reported a BPA concentration of 0.96 to $1.6 \mathrm{mg} / \mathrm{L}$ in the influent and 0.26 to $0.36 \mathrm{mg} / \mathrm{L}$ in the effluent, whereas the overall BPA removal efficiencies were reported to be greater than $75 \%$. BPA was also found in municipal sewage sludge, in the range of $0.104-0.312 \mu \mathrm{g} / \mathrm{g}$ in Canada (Mohapatra et al., 2011), 1.86-0.02 $\mu \mathrm{g} / \mathrm{g}$ in Greek (Samaras et al., 2013; Stasinakis et al., 2008), and $0.4 \mu \mathrm{g} / \mathrm{g}$ in Spain (Vega-Morales et al., 2010).

EE2 is a synthetic hormone that has attracted considerable attention in the literature due to its contribution to endocrine disrupting activity in WWTP effluent which might cause estrogenic effects on fathead minnow populations (Hamid and Eskicioglu, 2012; Jeffries et al., 2010; Kidd et al., 2007; Vajda et al., 2008). Biodegradation has been reported as the most substantial estrogen removal method in AS wastewater treatment (Muller et al., 2008); however, EE2 adsorption onto AS particles in municipal WWTP might also be an important removal pathway in a WWTP due to its nonpolar behaviour and hydrophobic properties (Andersen et al., 2005; Cirja et al., 2007; Zhou et al., 2010).

TCS (2,4,40-trichloro-20-hydroxydiphenyl ether; Irgasan) is a broad spectrum antibacterial agent which can be found in many personal care products such as hand disinfecting soaps, medical skin creams, dental products, deodorants, toothpastes (Dann and Hontela, 2011). An aid to the development of cross-resistance to antibiotics (Drury et al., 2013) and the potential estrogenic and androgenic effects on human breast cancer 


\section{P a g e | 156}

cells (Gee et al., 2008) and fish bile (Rostkowski et al., 2011) are some indicative examples of endocrine disrupting activity of this compound. Removal efficiencies of 5897\% for trickling filter plants and $95-98 \%$ for AS plants were reported in the literature, mostly due to biodegradation and sorption onto biosolids (Bester, 2003; Chalew and Halden, 2009; Lishman et al., 2006; Nakada et al., 2010; Thomas and Foster, 2005). Nakada et al. (2010) investigated the behaviour of the TCS at two WWTPs and conducted one of the few mass balance studies on fate of TCS. In their study TCS was dominantly detected in the particulate phase especially in the early stage of treatment (up to $83 \%$ ) and was efficiently removed (over $90 \%$ ) in WWTPs.

Once a MC is released into wastewater, it will be introduced to the different environmental media in the AS system (e.g., water, biomass, solids) due to its physicochemical properties, such as volatility, solubility, lipophilicity, acidity, and sorption potential. Moreover, depending on its resistance to biologically or abiotically degradation processes, it can remain in WWTPs and discharge to the environment through the effluent. Studies showed that the compounds with octanol-water partition coefficient, log $\mathrm{K}_{\mathrm{ow}}<2.5$ have high bioavailability and their sorption to AS is not expected to contribute significantly to the removal of the pollutant via excess sludge withdrawal. For chemicals having $\log \mathrm{K}_{\mathrm{ow}}$ between 2.5 and 4, moderate sorption is expected and finally, organic compounds with $\log \mathrm{K}_{\mathrm{ow}}$ higher than 4, show high sorption potential (Ter Laak et al., 2005). Joss et al. (2006) showed that compounds can only sorb significantly onto primary 


\section{P a g e $\mid \mathbf{1 5 7}$}

and secondary sludges if they have sorption coefficient $\left(\mathrm{K}_{\mathrm{d}}\right)$ values higher than $500 \mathrm{~L} / \mathrm{kg}$. They identified three groups of compounds based on their pseudo-first-order degradation constants $K_{m}$ and showed that: a) compounds with $K_{m}<0.1$ L/g SS.d are not removed to a significant extent $(<20 \%)$, b) compounds with $\mathrm{K}_{\mathrm{m}}>10 \mathrm{~L} / \mathrm{g}$ SS.d are transformed by $>90 \%$, and c) compounds with $\mathrm{K}_{\mathrm{m}}$ between $0.1-10 \mathrm{~L} / \mathrm{g}$ SS.d have moderate removal. Carballa et al. (2007) also found that in sludge treatment process, sorption can be neglected if the $\mathrm{K}_{\mathrm{d}}$ value is less than $1 \mathrm{~L} / \mathrm{kg}$.

(Suárez et al., 2008a) showed that based on partition coefficient between solid and liquid phase values and biodegradability of MCs, their removal in WWTPs can be predicted. They suggested that the effect of hydraulic retention time (HRT) and sludge retention time (SRT) on MCs removal could be different when the compound has low, moderate, or high $\mathrm{K}_{\mathrm{d}}$ or $\mathrm{K}_{\mathrm{ow}}$ and biodegradation constant values. Table 5-1, shows the physico-chemical properties of selected MCs in this study as well as the possible effect of HRT and SRT on removal of these compounds in an AS system.

Although the presence of these MCs during wastewater treatment has been studied by a plethora of reports, significant differences on their concentration levels and removal rates as well as contradictory results on their fate have been reported (Deblonde et al., 2011; Stasinakis et al., 2010). On the other hand, it should be mentioned that the majority of environmental surveys previously undertaken have mainly been focused on dissolved 


\section{P a g e | $\mathbf{1 5 8}$}

concentrations of these compounds in wastewater at environmentally relevant concentrations (Feng et al., 2010; Radjenovic et al., 2009; Seyhi et al., 2011).

Table 5-1 Physico-chemical characteristics of selected MCs

\begin{tabular}{|c|c|c|c|c|c|c|}
\hline MCs & $\mathrm{S}_{\mathrm{w}}$ & $\mathrm{H}$ & $\mathrm{K}_{\mathrm{m}}$ & $\log \mathrm{K}_{\mathrm{ow}}$ & $\begin{array}{c}\text { Affecting } \\
\text { factor }\end{array}$ & $\begin{array}{c}\text { Effect on } \\
\text { removal }\end{array}$ \\
\hline BPA & 120 & $1.0 \times 10^{-11}$ & $5-113^{\mathrm{d}}$ & $3.18-3.7^{\mathrm{a}}$ & SRT, SS & + \\
\hline EE2 & $4.8-11.3$ & $7.9 \times 10^{-12}$ & $5-18.9^{\mathrm{e}}$ & $3.6-4.15^{\mathrm{b}}$ & SRT, SS & + \\
\hline TCS & 10 & $1.5 \times 10^{-7}$ & $30-288^{\mathrm{d}}$ & $4.5-4.8^{\mathrm{c}}$ & None & ++ \\
\hline
\end{tabular}

MW: molecular weight $(\mathrm{g} / \mathrm{mol}) ; \mathrm{S}_{\mathrm{w}}$ : solubility in water $(\mathrm{mg} / \mathrm{L}) ; \mathrm{H}$ : Henry coefficient $\left(\mathrm{atm} \cdot \mathrm{m}^{3} / \mathrm{mol}\right) ; \mathrm{K}_{\mathrm{ow}}$ : octanol-water partition coefficient; $\mathrm{K}_{\mathrm{m}}$ : pseudo-second-order degradation constant (L/gSS.day);

${ }^{\mathrm{a}}$ (Borrirukwisitsak et al., 2012; Robinson et al., 2009)

${ }^{\mathrm{b}}$ (Robinson et al., 2009), ${ }^{\mathrm{c}}$ (Lopez-Avila and Hites, 1980; Ying et al., 2007)

${ }^{\mathrm{d}}$ (Stasinakis et al., 2010), ${ }^{\mathrm{e}}$ (Ziels et al., 2014)

Only in the last few years have researchers started to study the MCs concentration in the solid phase at very low concentrations (Nie et al., 2009; Stasinakis et al., 2010; Stevens-Garmon et al., 2011; Zhao et al., 2008). In addition, there are limited data for the role of SRT and HRT in removal of targeted MCs (Stasinakis et al., 2010). (Kirk et al., 2002) reported high removal efficiency of EE2 when HRT increased from 2-5 to $13 \mathrm{~h}$ at UK WWTPs. In contrast, (Servos et al., 2005) found no statistical correlation $\left(\mathrm{R}^{2}<0.53\right)$ between HRT or SRT and hormone or estrogenicity removal for nine conventional secondary plants and three tertiary plants in Canada. (Gros et al., 2007) studied the removal efficiency of different groups of MCs in 6 WWTPs with AS systems of different 


\section{P a g e | $\mathbf{1 5 9}$}

HRTs in Spain and found that the plants with the highest HRTs (25-33 h) have the highest removal efficiency, while plants with an HRT of $8 \mathrm{~h}$ had no or poor removal of most of the selected compounds.

There are also limited and debatable information on the role of autotrophs on MCs biodegradation in AS systems operating at different SRTs (Larcher and Yargeau, 2013; Zhou and Oleszkiewicz, 2010). Nitrifier-enriched AS was used in batch degradation of BPA to investigate the effect of ammonia oxidizing bacteria, AOB (Kim et al., 2007). It was observed that BPA concentration was decreased with the oxidation of ammonium to nitrate by nitrifying sludge. However, in presence of nitrification inhibitors, allylthiourea (ATU), BPA reduction decreased significantly. Gaulke et al. (2008) suggested that EE2 at high concentration $(\mathrm{mg} / \mathrm{L})$ is co-metabolically degraded by AOB but EE2 removal at low concentration found in municipal conventional AS systems is not due to cometabolic degradation by $\mathrm{AOB}$, or to abiotic nitration, but most likely due to heterotrophic bacteria. This result was also verified by other authors (Racz et al., 2012; Zhou and Oleszkiewicz, 2010). In contrast, Khunjar et al. (2011) studied the role of AOB versus heterotrophic bacteria during biotransformation of EE2 and showed that AOB activity was an important contributor towards EE2 biodegradation and the metabolites formed by AOBs during EE2 biodegradation can be mineralized by heterotrophic cultures. 


\section{P a g e $\mid \mathbf{1 6 0}$}

Laboratory-scale investigations are useful because they offer the opportunity of evaluating different operating conditions in simulated secondary wastewater treatment systems in a controlled environment. Therefore, to evaluate the contradictory results that have been reported on the fate of selected MCs, the sorption and biotransformation of BPA, TCS, and EE2 in lab-scale porous-pot AS reactors were investigated in parallel by measuring the concentration of MCs in both liquid and solid phases and the effect of three HRTs, three SRTs and nitrification on fate of these compounds were evaluated. Statistical analyses were also performed to investigate the interaction effect of HRT and SRT on removal of the selected MCs in simulated AS systems.

\subsection{Material and Methods:}

\subsubsection{Experimental overview}

Three laboratory-scale porous-pot bioreactors were set up to simulate AS systems operating at different SRTs. These bioreactors were originally seeded with the AS obtained from City of Ottawa wastewater treatment facility and fed with synthetic wastewater and environmentally relevant concentration of selected MCs. The MCs concentrations in liquid and solid phases were monitored to investigate the fate of these compounds in simulated AS, as well as the effect of SRTs on their removal. The same procedures were repeated for three different HRTs to explore the effect of HRTs on removal of MCs. With a low vapour pressure and a Henry's law constant ranging from 
$1.5 \times 10^{-7}$ to $7.9 \times 10^{-12}$ atm. $\mathrm{m}^{3} / \mathrm{mol}$ for the selected MCs (Table 5-1), removal of these compounds by volatilization can be considered negligible. By adjusting the $\mathrm{pH}$ to 7 in the AS reactors and conducting the test in the dark, losses due photolysis can also be considered negligible. Thus, only sorption and biodegradation were studied during the experiment. The sorption batch tests were conducted to retrieve kinetic and equilibrium data. Finally nitrification inhibitors, ATU were added to reactors to study the role of nitrifiers versus heterotrophs during biotransformation of MCs. Another objective of this study was to examine if there is any relationship between the fate of MCs and operational conditions in AS by statistical methods. The experimental hypotheses was that increasing SRT and HRT would enhance the removal of selected MCs in AS system and this could be predicted by using the physico-chemical and biodegradation properties of these compounds. The second hypothesis was that nitrification contributes an important role towards MCs biodegradation. These hypotheses were examined using ANOVA statistical analysis. In addition, since this is a simulation test, it is assumed that results from this study could be extrapolated to predict elimination in full-scale treatment plants, provided that critical parameters such as temperature, SRT, HRT, $\mathrm{pH}$ and initial test substance concentrations are in the same range as in the full scale AS system.

\subsubsection{Activated sludge, synthetic wastewater and Porous-Pot Bioreactor}

The thickened waste AS (TWAS) inoculum was obtained from the Robert O. Pickard Environmental Center (ROPEC) wastewater treatment facility in Ottawa ON. The TWAS 


\section{P a g e $\mid \mathbf{1 6 2}$}

was diluted to reach the total SS (TSS) and volatile SS (VSS) concentrations of 3100 and $2300 \mathrm{mg} / \mathrm{L}$, respectively. Then, the diluted TWAS was incubated in three continuous flow $3 \mathrm{~L}$ porous pot reactors at $25^{\circ} \mathrm{C}$ (Figure 5-1), fed with synthetic wastewater without any added MCs with typical HRT of 6 hours found in AS systems. The HRT of reactors was kept at $6 \mathrm{~h}$ without removing MLVSS from the reactors for 10 days to allow the biomass to adapt themselves to the new environment. To maximize the microbial diversity and to simulate the nitrifying conditions, a small amount of mixed liquor VSS (MLVSS) from a nitrifying lab-scale bioreactor was added to each reactor during the inoculum preparation step. These bioreactors are approved by United States Environmental Protection Agency (USEPA) for simulation test of AS system and for biodegradation studies (EPA 712-C-08-004, Oct. 2008).

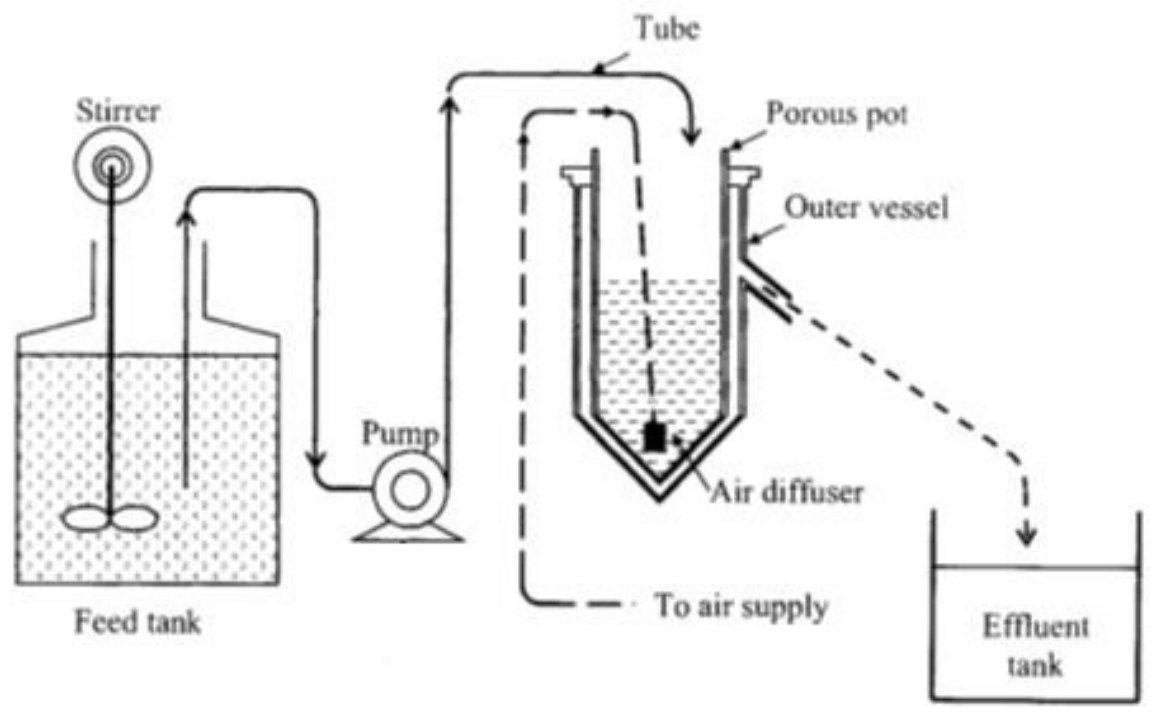

Figure 5-1. Porous pot system 


\section{P a g e | 163}

The porous pot system (Figure 5-2 and 5-3) consists of an inner, porous cylinder with a conical bottom held in a slightly larger vessel of the same shape, but made of an impervious plastic material. The material for the porous vessel is porous polyethylene of maximum pore size of $90 \mu \mathrm{m}$ and $2 \mathrm{~mm}$ thickness. Separation of the sludge from the treated organic medium is effected by differential passage through the porous wall. No settlement occurs and hence there is no sludge return.

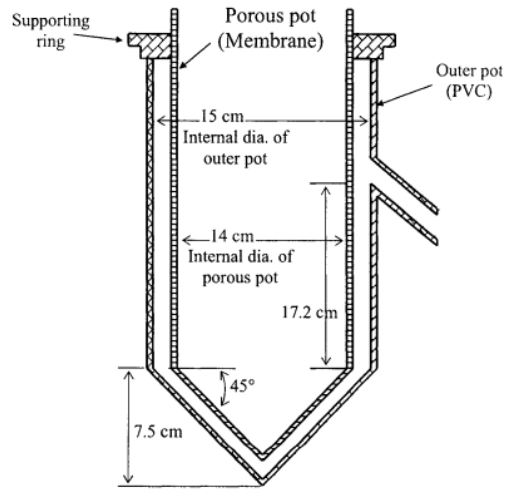

Figure 5-2. Porous pot aeration vessel details

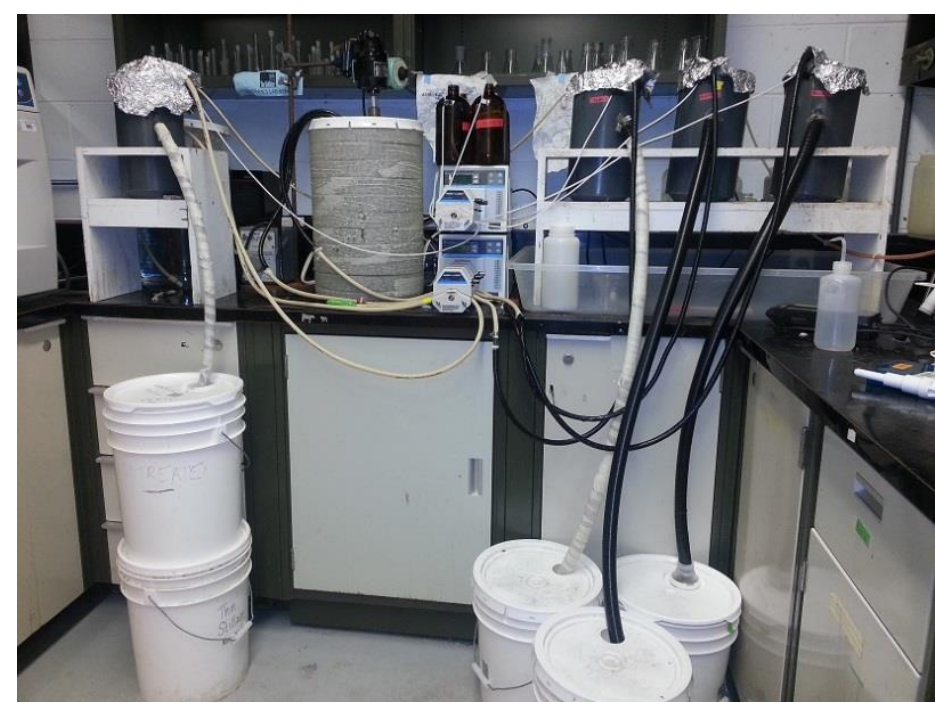

Figure 5-3. Experimental AS system 


\section{P a g e | 164}

The porous pots are allowed to attain steady state at an MLVSS level commensurate with the other key control parameters.

The SRT of each reactor was decreased gradually to reach the SRT of 5, 10, and $15 \mathrm{~d}$ by daily withdrawal of a predetermined volume (Eq. 5-1) of MLVSS from the reactors. The daily MLVSS volume to be removed was found to be 200, 300, and $600 \mathrm{~mL}$.

$$
Q_{w=} \frac{X_{V} V-Q X_{V e} \theta_{X}}{X_{V} \theta_{X}}
$$

where $\mathrm{X}_{\mathrm{v}}$ is VSS concentration $(\mathrm{mg} / \mathrm{L}), \mathrm{V}$ is volume of reactor $(\mathrm{L}), \mathrm{Q}_{\mathrm{w}}$ is the volume of mixed liquor to be removed each day $(\mathrm{L} / \mathrm{d}), \mathrm{Q}$ is influent flow rate $(\mathrm{L} / \mathrm{d}), \mathrm{X}_{\mathrm{Ve}}$ is VSS concentration in the effluent $(\mathrm{mg} / \mathrm{L})$, and $\theta_{\mathrm{X}}$ is SRT.

To account for the liquid portion of MLVSS that was removed, the same volume was replaced with effluent supernatant; therefore, the amount of soluble substrate remains unchanged during the biomass wastage. Since the reactors behave as completely mixed reactors this replacement serves to simply maintain the MLVSS of the systems without diluting the reactors (Figure 5-4).

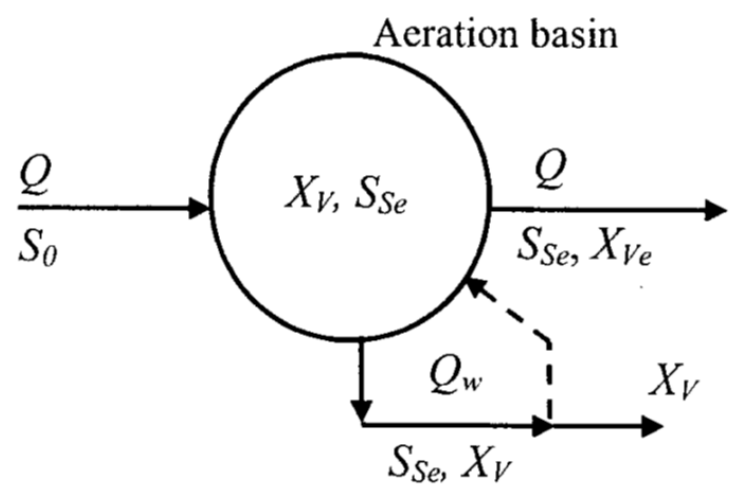

Figure 5-4. Schematic of the simulated AS system 


\section{P a g e | 165}

The chemical oxygen demand (COD) and MLVSS in these reactors were monitored three times a week to reach a stabilized condition. After reaching the steady state condition and before MCs were added, the reactors were kept at HRT of $6 \mathrm{~h}$ and designed SRTs for 6 months for biomass acclimatization to the feed (Phase A) and to conduct the sorption study and eliminating the existing MCs already sorbed to the incubated biomass. Up to the end of Phase A, target compounds concentration was reduced to values lower than methods' limits of detection (LODs).

The synthetic wastewater (Table 5-2) was composed of distilled water, supplemented with nutrients, trace elements, and buffering compounds which is the modified version of what was described in the study by Zhao et al. (Zhao et al., 2008). Glucose, peptone and sodium acetate were used for simulating easily degradable substrate, complex organic carbon source and volatile fatty acid, respectively. Ammonium chloride is added as a nitrogen source for nitrifying bacteria and sodium bicarbonate and ethylenediaminetetraacetic acid (EDTA) are used for alkalinity and preservation, respectively.

Three stock solutions ( $1 \mathrm{~L})$ were prepared to separate the carbon source, the nutrients, and the minerals in order to prevent any biodegradation. They were stored in the refrigerator at $<4^{\circ} \mathrm{C}$ for ten days. Each day $100 \mathrm{~mL}$ of each stock solution was added to the influent glass tank (30 L) and mixed with deionized water using mechanical mixer to meet the desired concentration of COD, nitrogen and phosphorus in the feed. The 


\section{P a g e | 166}

synthetic wastewater flow was driven by peristaltic pumps, while aeration and efficient mixing in aerobic reactors were provided using porous ceramic diffusers (Figure 5-1).

Table 5-2 Composition of the synthetic wastewater

\begin{tabular}{|l|l|}
\hline Compound & Concentration $(\mathrm{mg} / \mathrm{L})$ \\
\hline $\mathrm{C}_{6} \mathrm{H}_{12} \mathrm{O}_{6}$ & 150 \\
\hline Peptone & 150 \\
\hline $\mathrm{NaAc}$ & 80 \\
\hline $\mathrm{NH}_{4} \mathrm{Cl}$ & 40 \\
\hline $\mathrm{KH}_{2} \mathrm{PO}_{4} \cdot 2 \mathrm{H}_{2} \mathrm{O}$ & 44.1 \\
\hline $\mathrm{MgSO}_{4} \cdot 7 \mathrm{H}_{2} \mathrm{O}$ & 20 \\
\hline $\mathrm{CaCl}_{2}$ & 10.6 \\
\hline $\mathrm{NaHCO}_{3}$ & 200 \\
\hline $\mathrm{FeCl}_{3} \cdot 6 \mathrm{H}_{2} \mathrm{O}$ & 0.45 \\
\hline $\mathrm{H}_{3} \mathrm{BO}_{3}$ & 0.045 \\
\hline $\mathrm{CuSO}_{4} \cdot 5 \mathrm{H}_{2} \mathrm{O}$ & 0.01 \\
\hline $\mathrm{KI}$ & 0.054 \\
\hline $\mathrm{MnCl}_{2} \cdot 4 \mathrm{H}_{2} \mathrm{O}$ & 0.036 \\
\hline $\mathrm{ZnSO}_{4} \cdot 7 \mathrm{H}_{2} \mathrm{O}$ & 0.036 \\
\hline $\mathrm{Na}_{2} \mathrm{MoO}_{4} \cdot 2 \mathrm{H}_{2} \mathrm{O}$ & 0.1 \\
\hline $\mathrm{CoCl}_{2} \cdot 6 \mathrm{H}_{2} \mathrm{O}$ & 0.01 \\
\hline $\mathrm{EDTA}$ & 3 \\
\hline
\end{tabular}

The synthetic wastewater in the influent tank had an average total COD of $410 \pm 6.51$ $\mathrm{mg} / \mathrm{L}$ which is considered as a typical COD found in domestic wastewater influent (Tchobanoglous, 2003). Total Kjeldahl nitrogen (TKN), total phosphorus (TP) and total organic carbon (TOC) in the influent tank were measured and found to be $36 \pm 3.28,11 \pm$ 1.3 , and $173 \pm 28.9 \mathrm{mg} / \mathrm{L}$, respectively, which yields a C:N:P ratio of approximately 
P a g e $\mid \mathbf{1 6 7}$

100:20:6. The measured ammonia $\left(\mathrm{NH}_{3}\right)$, nitrate $\left(\mathrm{NO}_{3}-\mathrm{N}\right)$, temperature and $\mathrm{pH}$ of the influent were found to be $12.9 \pm 2.26 \mathrm{mg} / \mathrm{L}, 0.06 \pm 0.01 \mathrm{mg} / \mathrm{L}, 22 \pm 1.1^{\circ} \mathrm{C}$ and $6.9 \pm 0.33$, respectively.

\subsubsection{Batch sorption experiments}

Sorption batch experiments were performed to investigate MCs sorption to inactive AS obtained from 3 porous pot reactors operating at SRTs of 5, 10, and $15 \mathrm{~d}$ and HRT of

$6 \mathrm{~h}$. Two batch reactors from each porous pot reactor (2 L Erlenmeyer flasks) were conducted for the sorption equilibrium study. To avoid the influence of microbial activity on the MCs sorption behavior onto AS, sodium azide solution $(0.2 \% \mathrm{w} / \mathrm{w})$ was used to prevent biodegradation by paralyzing cytochrome oxidase. This concentration has been shown to inhibit the biodegradation process without causing any cell lysis, and also it does not cause change to sludge hydrophobicity (Guellil et al., 1998; Xu et al., 2008; Yi and Harper, 2007). The mixed liquor SS (MLSS) and SRT effects were also examined using same concentration range of each target compound and MLSS concentrations of 1430,2750 , and $3540 \mathrm{mg} / \mathrm{L}$ from each reactor. To determine sorption isotherms six $1 \mathrm{~L}$ Erlenmeyer flasks (two flasks for inactive AS taken from each porous-pot reactor) were filled with inactive AS and were exposed to the selected MCs at concentrations of 5, 10, 20, 50, 100 and $200 \mu \mathrm{g} / \mathrm{L}$. Adsorption kinetic can be helpful to understand the mechanisms of the sorption process and to control the efficiency of the process; therefore, 


\section{P a g e | 168}

the sorption rates were also evaluated and the kinetic data were modeled using intraparticle diffusion model, pseudo-first-order and pseudo-second-order equations.

Detailed description of the methods applied in the sorption tests is published previously by the authors (Banihashemi and Droste, 2014).

\subsubsection{Continuous-flow experiments}

The standard approach to biological treatment studies, commonly evaluates system performance at three SRTs and three HRTs for each sludge age, with identical feed concentration; therefore, after biomass acclimatization to the feed (Phase A), three HRTs of 4, 6 and $10 \mathrm{~h}$ combined with three SRTs of 5,10 and $15 \mathrm{~d}$ were examined (Phases B, C, and D). Table 5-3 shows the experimental operational conditions.

Table 5-3: Experimental operational conditions

\begin{tabular}{|c|c|c|c|c|c|c|c|c|c|c|}
\hline Condition & \multirow{2}{*}{ Unit } & \multicolumn{8}{|c|}{ Experimental Phases } \\
\cline { 3 - 11 } & & \multicolumn{3}{|c|}{ Phase B } & \multicolumn{3}{c|}{ Phase C } & \multicolumn{3}{c|}{ Phase D } \\
\hline HRT & Hours & 6 & 6 & 6 & 10 & 10 & 10 & 4 & 4 & 4 \\
\hline SRT & Days & 5 & 10 & 15 & 5 & 10 & 15 & 5 & 10 & 15 \\
\hline
\end{tabular}

To avoid biodegradation or any abiotic losses of the selected MCs before it is introduced into the test system, which might occur if the MC and sewage are premixed, the MCs solution and the sewage were dosed into the porous pot separately using amber glass and MasterFlex C-FLEX tubing for MC solution. The total flow rate into the reactor (sewage + MCs solution) was calculated based on Eq. (5-2).

$$
Q_{\text {total }}=\frac{\text { Volume of porous pot reactor }(\mathrm{mL})}{\text { Desired } H R T(h) \times 60(\mathrm{~min} / \mathrm{h})}
$$




\section{P a g e | 169}

The concentration of MCs solution to be dosed into a reactor was calculated based on the total flow, the desired concentration of MCs in the influent sewage $\left(C_{\text {inf }}=20 \mu \mathrm{g} / \mathrm{L}\right)$ and the pump convenient dosing rate of $0.83 \mathrm{~mL} / \mathrm{min}$ (Eq. 5-3)

$$
\text { Conc. of MCs dosing solution }(\mu \mathrm{g} / L)=\frac{Q_{\text {total }}(\mathrm{mL} / \mathrm{min}) \times C_{m}(\mu \mathrm{g} / \mathrm{L})}{0.83(\mathrm{ml} / \mathrm{min})}
$$

In order to establish that the units have reached steady state, are operating properly and acclimated to the selected MCs (stabilization period), test compounds in the effluent and overall performance of the units were regularly monitored at the early period of each phase. The stabilization periods for phase B, C and D were 47, 60 and $65 \mathrm{~d}$, respectively. A porous pot is considered to be at steady state if over a seven day period of operation at a set SRT; the coefficient of variation (standard deviation/mean) of the COD and MCs of its effluents is less than $20 \%$ (EPA 712-C-08-004, Oct. 2008). When the reactors have achieved steady state, nine samples were taken in the period of two weeks and the overall performance of the reactor and the concentration of $\mathrm{MCs}$ in liquid and solid phases (triplicate) were measured. During the experiments, all systems were maintained at $25^{\circ} \mathrm{C}$ by automatic thermostat, dissolved oxygen (DO) in aerobic reactors was kept above 4.0 $\mathrm{mg} / \mathrm{L}$ and $\mathrm{pH}$ was ranged to $7.2 \pm 0.3$. All reactors and tubes were covered with aluminum foil or tape to prevent any loss due to photodegradation (Figure 5-3).

One aerated control porous pot reactor was also monitored to check for any abiotic losses during the degradation study at each stage, where MCs and distilled water were added separately to the reactor without any sludge or synthetic wastewater. Only sorption 


\section{P a g e $\mid \mathbf{1 7 0}$}

onto membrane fibers could have a limited contribution, but the available surface is negligible compared to biomass. Bouju et al. (2011) added a pulse of radiolabelled diclofenac to a MBR and found only $0.03 \%$ of the applied radioactivity in the membrane after $300 \mathrm{~h}$. The result of control unit at each stage was used to measure any losses due to sorption to plastic influent tank, membrane and tubes and the sorption and biodegradation/biotransformation removal calculation were adjusted accordingly.

\subsubsection{Chemical and analytical method}

Methanol $(\mathrm{MeOH})$, hexane, acetonitrile $(\mathrm{ACN})$, dichloromethane, and acetone used for cleaning and extraction purposes, were purchased from VWR International, LLC (Canada) and were all of high-performance liquid chromatography (HPLC) analytical grade. EE2, BPA, and TCS (HPLC grade, >98\%) were purchased from Sigma-Aldrich, Canada. Stock solutions of BPA, TCS, and EE2 were prepared in MilliQ water/ACN $(55 / 45, \mathrm{v} / \mathrm{v})$ at $1000 \mathrm{mg} / \mathrm{L}$ and kept at $4^{\circ} \mathrm{C}$ for maximum of $60 \mathrm{~d}$. The working solutions were prepared daily by diluting the stock solution and were used for calibration and spiking experiments. MilliQ water was prepared in the laboratory using a MilliQ/ Millipore system with Super-C carbon, Ion-Ex, and Orgonex-Q cartridges. Supelclean LC-18 (3 mL, $500 \mathrm{mg}$ ) cartridges used for extraction and clean-up samples were supplied by Sigma-Aldrich (Oakville, ON, Canada). The Zorbax Eclipse plus C18 chromatography column $(4.6 \mathrm{~mm} \times 150 \mathrm{~mm}, 5 \mu \mathrm{m})$ was purchased from Chromatographic specialties Inc. (ON, Canada). All other chemical used in this study 


\section{P a g e | 171}

were supplied by Fisher Scientific (ON, Canada) and were of the highest purity commercially available.

To control the operation of continuous-flow AS systems, analyses of influent and effluent COD (dissolved and total), $\mathrm{NH}_{4}-\mathrm{N}, \mathrm{TN}, \mathrm{TKN}$, nitrate $\left(\mathrm{NO}_{3}-\mathrm{N}\right)$, VSS in the effluents, MLSS, MLVSS and mixed liquor total COD were regularly performed, according to Standard Methods (2005). Temperature, DO and $\mathrm{pH}$ values were also measured daily using portable instruments.

For the investigation of the fate of selected MCs in AS process, sample preparation and clean-up were performed using commercial SPE cartridge (Supelclean LC-18) and microwave-assisted extraction, Mars $5^{\circledR}$ (MW Accelerated Reaction System; CEM Corporation) for MC samples in both liquid and solid phases based on the method described in a previously published studies (Banihashemi and Droste, 2013; Banihashemi and Droste, 2014). Determination of selected MCs was performed using a HPLC (Hewlett-Packard, HP 1100) coupled with ultraviolet (UV) detection according to the procedures described by Banihashemi and Droste (2014). In brief, these analytical methods presented satisfactory precision with relative standard deviations (RSDs) less than $10 \%$ for selected MCs. Recoveries of the method for wastewater and sewage sludge were determined by analysing fortified samples of each type of wastewater and sludge spiked in triplicate to $1 \mu \mathrm{g} / \mathrm{L}$ and $0.5 \mu \mathrm{g} / \mathrm{g}$ dry weight (d.w.), respectively. The recoveries of BPA, TCS and EE2 in liquid samples were found to be $106 \pm 2,95 \pm 6$ and $88 \pm 5 \%$, 


\section{P a g e | 172}

respectively. Also satisfactory recoveries were obtained in solid samples (>75\%), except for TCS, where recoveries of $55 \pm 6 \%$ were obtained. For this reason, recovery correction was made for TCS by dividing the observed concentrations by recovery rates. The limits of detection (LOD) of the target compounds in liquid and solid samples were $100 \mathrm{ng} / \mathrm{L}$ and $100 \mathrm{ng} / \mathrm{g}$, respectively.

\subsubsection{Calculation methods}

The sorption characteristics were described by computation of isotherms and determination of characteristic values. Adsorption isotherms allow presenting the variation of sorption with respect to the concentration of sorbate in the bulk solution at constant temperature. Specific coefficient $\mathrm{K}_{\mathrm{d}}$ (L/g TSS) is a frequently used characteristic value for the evaluation of the sorption behaviour. This distribution coefficient is defined as the ratio of equilibrium concentrations of a test substance in a two phase system consisting of an adsorbent and an aqueous phase and can be calculated with Eq. (5-4):

$\mathrm{K}_{\mathrm{d}}=\frac{\mathrm{qe}_{\mathrm{e}}}{\mathrm{C}_{\mathrm{e}}}$

In this study the equilibrium sorption isotherms of MCs on the biomass using linear and Freundlich isotherm models were studied. Detailed calculation method and models

were discussed in a previously published paper by authors (Banihashemi and Droste, 2014). 


\section{P a g e $\mid \mathbf{1 7 3}$}

The kinetic models parameters were estimated by regression analysis method using excel software. The pseudo-first-order chemical sorption is described by Eq. (5-5) (Lagergren, 1898; Qiu et al., 2009)

$\frac{d q_{t}}{d t}=k_{1}\left(q_{e}-q_{t}\right)$

where $\mathrm{k}_{1}$ is the equilibrium rate constant of pseudo-first-order $\left(\mathrm{L} \mathrm{h}^{-1}\right), \mathrm{q}_{\mathrm{e}}\left(\mu \mathrm{g} \mathrm{g}^{-1}\right)$ the amount of MCs sorbed at equilibrium $\mathrm{q}_{\mathrm{t}}\left(\mu \mathrm{g} \mathrm{g}^{-1}\right)$ is the amount of MCs sorbed at any time. This model is based on the assumption that the rate is proportional to the number of free sites. By Integrating Eq. (5-5) with boundary conditions $\mathrm{q}_{\mathrm{t}}=0$ at $\mathrm{t}=0$ and $\mathrm{q}_{\mathrm{t}}=\mathrm{q}_{\mathrm{t}}$ at $\mathrm{t}$ $=\mathrm{t}$ gives Eq. (5-6) as follows:

$\ln \left(q_{e}-q_{t}\right)=\ln q_{e}-k_{1} t$

The values of $\mathrm{k}_{1}$ and $\mathrm{q}_{\mathrm{e}}$ are obtained from the slope and intercept of the plot of $\ln \left(\mathrm{q}_{\mathrm{e}}\right.$ $-\mathrm{q}_{\mathrm{t}}$ ) versus $\mathrm{t}$, respectively. For the rate constant of pseudo-second-order chemical sorption, Eq. (7) has been also applied (Ho and McKay, 1999)

$\frac{d q_{t}}{d t}=k_{2}\left(q_{e}-q_{t}\right)^{2}$

where $\mathrm{k}_{2}(\mathrm{~g} / \mu \mathrm{g} . \mathrm{h})$ is the equilibrium rate constant of pseudo-second-order, $\mathrm{q}_{\mathrm{e}}(\mu \mathrm{g} / \mathrm{g})$ is the amount of MCs sorbed at equilibrium, $\mathrm{q}_{\mathrm{t}}$ is the amount of MCs sorbed at time $\mathrm{t}$ $(\mu \mathrm{g} / \mathrm{g})$. After integration and rearrangement using boundary conditions $\left(\mathrm{q}_{\mathrm{t}}=0\right.$ at $\mathrm{t}=0$ and $\mathrm{q}_{\mathrm{t}}=\mathrm{q}_{\mathrm{t}}$ at $\left.\mathrm{t}=\mathrm{t}\right)$ Eq. $(5-7)$ becomes:

$\frac{t}{q_{t}}=\frac{1}{k_{2} q_{e}^{2}}+\frac{1}{q_{e}} t$ 


\section{P a g e | 174}

The values of $k_{2}$ and $q_{e}$ are obtained from the slope and intercept of the plot of $1 / q_{t}$ versus t, respectively.

The intra-particle diffusion model describes adsorption processes, where the rate of adsorption depends on the speed at which adsorbate diffuses towards adsorbent (i.e., the process is diffusion-controlled), which is presented by Eq. (5-9).

$q_{t}=k_{3}^{1 / 2}+c$

where, $\mathrm{k}_{3}$ is the rate constant of the intra-particle transport ( $\left.\mu \mathrm{g} / \mathrm{g} . \mathrm{h}\right)$ and $\mathrm{c}$ is the intercept (Weber and Chakravo.Rk, 1974). The intra-particle diffusion model values are obtained from the slope and intercept of the plot of $\mathrm{q}_{\mathrm{t}}$ versus $\mathrm{t}^{1 / 2}$.

Based on the concentrations in influent, effluent, and biosolids, the total removal rate, removal rate by sorption and removal rate by biotransformation/biodegradation were calculated in percentages for all selected MCs. Total removal rate was calculated by the following equation (5-10):

Total removal rate $=\frac{C_{\text {inf }}-C_{e f f}}{C_{\text {inf }}} \times 100$

where $\mathrm{C}_{\text {inf }}$ is the influent liquid phase concentration, $\mu \mathrm{g} / \mathrm{L} ; \mathrm{C}_{\text {eff }}$ is the effluent liquid phase concentration of $\mathrm{MC}$ from the reactor, $\mu \mathrm{g} / \mathrm{L}$.

Accumulation of MCs on solids wasted from an AS system is not a real treatment but nonetheless it is a significant phenomenon that affects the fate of MCs in biotreatment or throughout an AS process. Therefore, at the steady state and equilibrium state condition the sorption to the daily wasted sludge was calculated by Eq. (5-11): 
P a g e | 175

Removal rate by sorption $=\frac{C_{\text {Biosolids }} \times M L T S S \times Q_{\text {wasted }}}{C_{\text {inf }} \times Q_{\text {inf }}} \times 100 \%$

where $\mathrm{C}_{\text {Biosolids }}$ is the MCs concentration in the solid phase, $\mu \mathrm{g} / \mathrm{g}$; MLTSS, $\mathrm{g} / \mathrm{L} ; \mathrm{Q}_{\text {wasted }}$ is the volume of sludge wasted per day, L/d; $\mathrm{Q}_{\text {inf }}$ is the influent flow-rate, L/d.

Target MCs are considered thermodynamically stable and relatively non-volatile, while photodegradation was prohibited by experimental condition used, therefore by writing the mass balance around the reactors, the amount of MCs biotransformed / biodegraded in simulated AS was calculated by the following Eq. (5-12):

$M_{b}=\left(Q_{\text {in }} \times C_{\text {in }}\right)-\left(Q_{\text {eff }} \times C_{\text {eff }}\right)-\left(C_{\text {biosolids }} \times M L T S S \times Q_{\text {wasted }}\right)$

where $M_{b}$ is the mass of biotransformed MCs ( $\mu \mathrm{g} /$ day) and $Q_{\text {in }}$ and $Q_{\text {eff }}$ are the influent and effluent flow-rate (L/d).

\subsubsection{Statistical analysis}

Statistical data analyses were conducted to determine if the data collected for removal of targeted MCs were statistically different in selected operational conditions. Three null hypotheses were stated for statistical testing; no statistically difference exists between the removal rates of selected MCs in reactors operating at different SRTs and HRTs and no significant interaction, no statistically difference between the removal rates of selected MCs in reactors operating at different SRTs but at the same HRT, and finally no statistically difference between the removal rates of selected MCs in reactors with or without $\mathrm{AOB}$ inhibition at HRT of four hours. The percentage removal data for each 


\section{P a g e | $\mathbf{1 7 6}$}

operational condition were tested for normality using the Anderson-Darling test before evaluating the null hypotheses. One-way and two-ways analysis of variance (ANOVA) were used to evaluate these null hypotheses at the $5 \%$ significance level $(\mathrm{P}$-value $=0.05)$. In those cases where the null hypotheses was rejected, multiple comparison tests, Tukey, were performed to test the two tailed null hypotheses of all possible combinations of sample means obtained in the test and determine which are significantly different from which others. In these cases the P-values (significant) showed how significantly different the factors in each group were and statistically significant difference were defined as those with P-values less than or equal to 0.05 .

\subsection{Results and Discussion}

\subsubsection{Sorption to inactive AS}

Plots of adsorbed BPA, TCS, and EE2 on the inactivated sludge versus time for three MLSS concentrations of 3750, 2940, and $1855 \mathrm{mg}$ TSS/L at room temperature are shown in Figure 5-5. The selected MCs showed a great tendency to sorb into the biomass in the first $30 \mathrm{~min}$, followed by slow sorption reaction up to the equilibrium time which is in agreement with the result reported in the literature for BPA sorption to sludge at relatively higher initial concentration (Seyhi et al., 2011).. The contact times necessary to reach equilibrium between solid and liquid phases were found to be 2, 4, and 6 hours for 
BPA, TCS, and EE2, respectively (Figure 5-5). At equilibrium, TCS showed greater tendency to sorb into the biomass followed by EE2 and BPA.
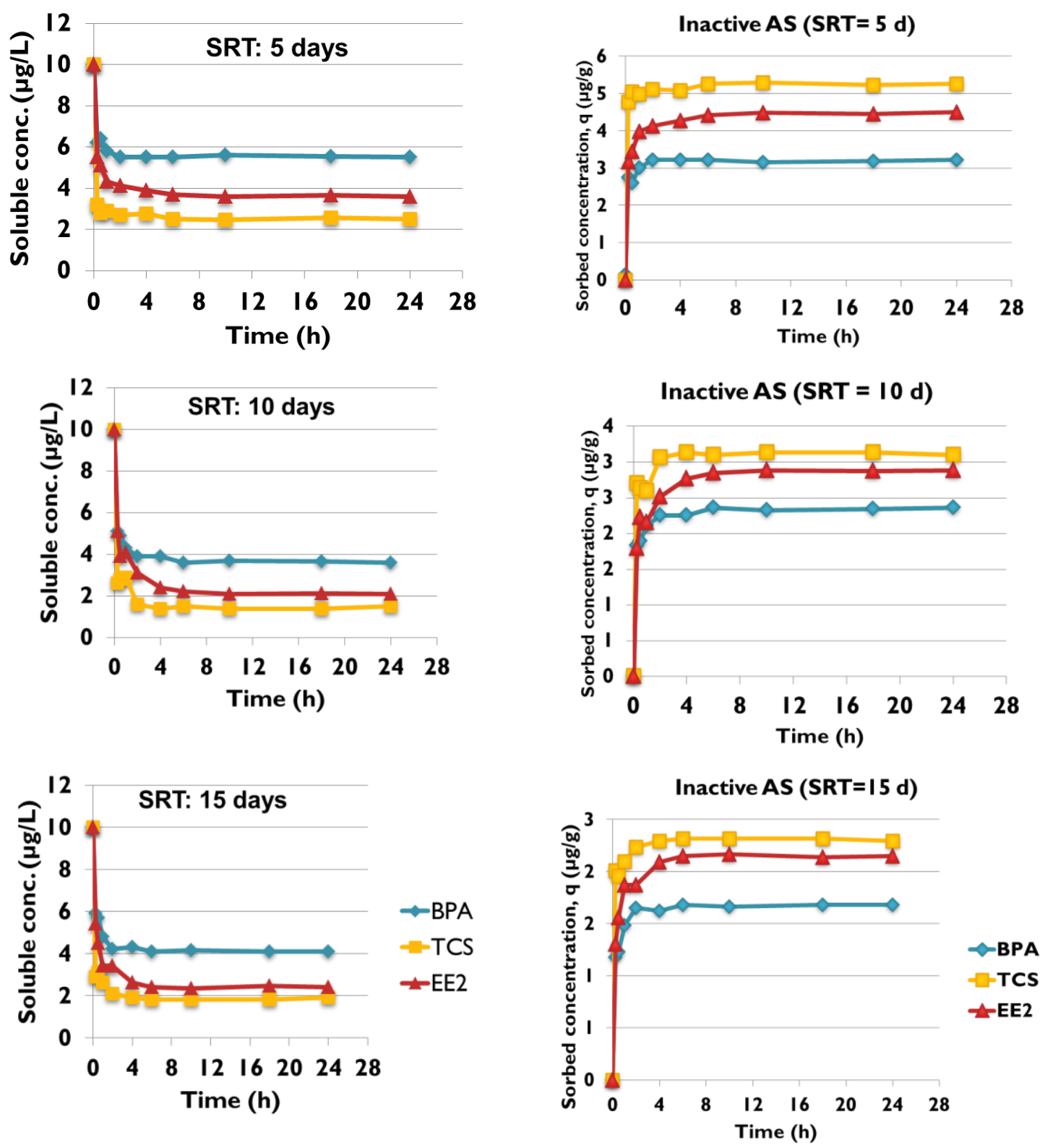

Figure 5-5. Concentration change of MCs in liquid and solid phases of inactive AS, sorption 


\section{P a g e | 178}

In the sorption study with inactive AS (Figure 5-5), the biomass that was obtained from the reactor with lowest SRT (5 d) had the lowest sorption potential, where 45, 75, and $64 \%$ of BPA, TCS, and EE2 were removed from the liquid phase at equilibrium state, respectively. On the other hand the inactive AS obtained from reactors with higher SRTs, showed higher and similar sorption potential, where 59, 82 and 76\% of BPA, TCS, and EE2 for AS with SRT of $15 \mathrm{~d}$ and 64, 84, and 79\% of BPA, TCS, and EE2 for AS with SRT of $10 \mathrm{~d}$ were removed from the liquid phase at equilibrium state, respectively. The sorption data were subjected to regression analysis using linear and Freundlich models (Table 5-4).

The results indicated that both linear and Freundlich models fitted well with the experimental data with the correlation coefficients $\left(\mathrm{R}^{2}\right)$ greater than 0.98 . By comparing the results presented in Table 5-4, it was found that the SRT plays an important role in sorption kinetic determination; however, the biomass from the reactor with SRT of $10 \mathrm{~d}$, showed the highest $\mathrm{K}_{\mathrm{d}}$ values (L/g TSS) of 0.48, 2.26, and 1.37 for BPA, TCS, and EE2, respectively. This was in agreement with Yi and Harper (2007) and Hyland et al. (2012) and could be due to different morphology and biomass characteristics at SRT of 10 days.

Kinetic coefficients obtained from the different kinetic models are summarized in Table 5-5. The best-fitting model was selected according to regression correlation coefficient value, $\mathrm{R}^{2}$. 
Table 5-4 Linear and Freundlich isotherm constants for the adsorption of MCs onto sludge

\begin{tabular}{|c|c|c|c|c|c|}
\hline \multicolumn{6}{|c|}{ BPA } \\
\hline SRT (d) & \multicolumn{3}{|c|}{ Freundich model } & \multicolumn{2}{|c|}{ Linear model } \\
\hline & $\mathrm{K}_{\mathrm{f}}\left(\mu \mathrm{g}^{(1-1 / \mathrm{n})} \mathrm{L}^{1 / \mathrm{n}} / \mathrm{g}\right)$ & $1 / \mathrm{n}$ & $\mathrm{R}^{2}$ & $\mathrm{~K}_{\mathrm{d}}(\mathrm{L} / \mathrm{g})$ & $\mathrm{R}^{2}$ \\
\hline 15 & 0.435 & 0.918 & 0.989 & 0.351 & 0.987 \\
\hline 10 & 0.48 & 1.025 & 0.984 & 0.477 & 0.980 \\
\hline 5 & 0.468 & 0.867 & 0.997 & 0.319 & 0.991 \\
\hline \multicolumn{6}{|c|}{ TCS } \\
\hline SRT (d) & \multicolumn{3}{|c|}{ Freundich model } & \multicolumn{2}{|c|}{ Linear model } \\
\hline & $\mathrm{K}_{\mathrm{f}}\left(\mu \mathrm{g}^{(1-1 / \mathrm{n})} \mathrm{L}^{1 / \mathrm{n}} / \mathrm{g}\right)$ & $1 / \mathrm{n}$ & $\mathrm{R}^{2}$ & $\mathrm{~K}_{\mathrm{d}}(\mathrm{L} / \mathrm{g})$ & $\mathrm{R}^{2}$ \\
\hline 15 & 1.035 & 1.1 & 0.995 & 1.591 & 0.990 \\
\hline 10 & 2.092 & 1.027 & 0.998 & 2.266 & 0.998 \\
\hline 5 & 2.019 & 1.005 & 0.995 & 2.018 & 0.993 \\
\hline \multicolumn{6}{|c|}{ EE2 } \\
\hline SRT (d) & \multicolumn{3}{|c|}{ Freundich model } & \multicolumn{2}{|c|}{ Linear model } \\
\hline & $\mathrm{K}_{\mathrm{f}}\left(\mu \mathrm{g}^{(1-1 / \mathrm{n})} \mathrm{L}^{1 / \mathrm{n}} / \mathrm{g}\right)$ & $1 / \mathrm{n}$ & $\mathrm{R}^{2}$ & $\mathrm{~K}_{\mathrm{d}}(\mathrm{L} / \mathrm{g})$ & $\mathrm{R}^{2}$ \\
\hline 15 & 0.802 & 1.031 & 0.995 & 0.901 & 0.990 \\
\hline 10 & 1.389 & 0.98 & 0.997 & 1.368 & 0.993 \\
\hline 5 & 1.386 & 0.975 & 0.995 & 1.161 & 0.994 \\
\hline
\end{tabular}

Higher correlation coefficients were obtained for pseudo-second-order model $\left(\mathrm{R}^{2}=\right.$ 0.998), which indicates that the pseudo-second-order model explains the adsorption kinetics most effectively. Seyhi et al. (2011) also found a good agreement with the pseudo-second-order model and the data obtained in the BPA sorption into the AS, however the pseudo-first-order model in their study had a relatively high $\mathrm{R}^{2}$ value which is in contrast to what was found in this study. The poor correlation coefficients obtained 


\section{P a g e $\mid \mathbf{1 8 0}$}

for the pseudo-first-order model could be explained by the assumption of this model that the rate is proportional to the number of free sites on the sludge.

Table 5-5 Summery of sorption kinetic coefficients evaluated by different kinetic models

\begin{tabular}{|c|c|c|c|c|c|c|}
\hline \multicolumn{9}{|c|}{ BPA } \\
\hline SRT (days) & \multicolumn{2}{|c|}{ Pseudo-first-order } & \multicolumn{2}{c|}{ Pseudo-Second-order } & \multicolumn{2}{c|}{ Intra-particle diffusion } \\
\hline & $\mathrm{k}_{1}(\mathrm{~L} / \mathrm{h})$ & $\mathrm{R}^{2}$ & $\mathrm{k}_{2}(\mathrm{~g} / \mu \mathrm{g} . \mathrm{h})$ & $\mathrm{R}^{2}$ & $\mathrm{k}_{3}(\mu \mathrm{g} / \mathrm{g} . \mathrm{h})$ & $\mathrm{R}^{2}$ \\
\hline 15 & -0.1 & 0.190 & 0.311 & 0.999 & 0.106 & 0.704 \\
\hline 10 & -0.146 & 0.640 & 0.422 & 0.998 & 0.108 & 0.650 \\
\hline 5 & -0.165 & 0.690 & 0.589 & 0.997 & 0.098 & 0.435 \\
\hline
\end{tabular}

\begin{tabular}{|c|c|c|c|c|c|c|}
\hline \multicolumn{9}{|c|}{ TRI } \\
\hline SRT (days) & \multicolumn{2}{|c|}{ Pseudo-first-order } & \multicolumn{2}{c|}{ Pseudo-Second-order } & \multicolumn{2}{c|}{ Intra-particle diffusion } \\
\hline & $\mathrm{k}_{1}(\mathrm{~L} / \mathrm{h})$ & $\mathrm{R}^{2}$ & $\mathrm{k}_{2}(\mathrm{~g} / \mu \mathrm{g} . \mathrm{h})$ & $\mathrm{R}^{2}$ & $\mathrm{k}_{3}(\mu \mathrm{g} / \mathrm{g} . \mathrm{h})$ & $\mathrm{R}^{2}$ \\
\hline 15 & -0.001 & 0.450 & 0.189 & 0.999 & 0.071 & 0.599 \\
\hline 10 & -0.124 & 0.310 & 0.320 & 0.998 & 0.111 & 0.540 \\
\hline 5 & -0.11 & 0.380 & 0.433 & 0.999 & 0.084 & 0.620 \\
\hline
\end{tabular}

\begin{tabular}{|c|c|c|c|c|c|c|}
\hline \multicolumn{9}{|c|}{ EE2 } \\
\hline SRT (days) & \multicolumn{2}{|c|}{ Pseudo-first-order } & \multicolumn{2}{c|}{ Pseudo-Second-order } & \multicolumn{2}{c|}{ Intra-particle diffusion } \\
\hline & $\mathrm{k}_{1}(\mathrm{~L} / \mathrm{h})$ & $\mathrm{R}^{2}$ & $\mathrm{k}_{2}(\mathrm{~g} / \mu \mathrm{g} . \mathrm{h})$ & $\mathrm{R}^{2}$ & $\mathrm{k}_{3}(\mu \mathrm{g} / \mathrm{g} . \mathrm{h})$ & $\mathrm{R}^{2}$ \\
\hline 15 & -0.186 & 0.800 & 0.221 & 0.998 & 0.153 & 0.611 \\
\hline 10 & -0.189 & 0.740 & 0.344 & 0.995 & 0.211 & 0.682 \\
\hline 5 & -0.145 & 0.490 & 0.462 & 0.997 & 0.250 & 0.650 \\
\hline
\end{tabular}


P a g e | $\mathbf{1 8 1}$

\subsubsection{Continuous-flow experiments}

\section{Operation of activated sludge systems}

Performance of reactors was evaluated by measuring the removal of total COD (tCOD), soluble COD (sCOD), TN, TKN, $\mathrm{NH}_{4}-\mathrm{N}, \mathrm{NO}_{3}-\mathrm{N}$, TSS and VSS from simulated AS reactors. Significant removal of tCOD (average COD removal > 95\%) and SS clarification (average $\mathrm{VSS}_{\mathrm{eff}}<3 \mathrm{mg} / \mathrm{L}$ ) was achieved in all AS systems operating at HRT of $6 \mathrm{~h}$ and various SRTs, during acclimatization period (Phase A). MLVSS concentration increased with increase of SRT, reaching values of 1666, 2518, and $3566 \mathrm{mg} / \mathrm{L}$ for reactors operating at SRT of 5, 10 and $15 \mathrm{~d}$, respectively. Almost complete nitrification was observed in phase $\mathrm{A}$, with mean removal rates of more than $95 \%$ and $85 \%$ for ammonia and TKN, respectively, in all three reactors. This result indicates that the preferable environment and sufficient $\mathrm{AOB}$ are present in all reactors to perform nitrification even in the reactor operating at lower SRT.

COD removal and nitrification were also monitored following the addition of MCs and a small deterioration of AS systems performance was noticed in the presence of the selected MCs (Figure 5-6); however; no significant variations of the MLVSS were observed prior and after spiking reactors with MCs.

It was observed that the COD removal in all three reactors was increased gradually as biomass was acclimated to the MCs indicating gradual biomass acclimatization to MCs and system's recovery. However; even after acclimation period, the COD removal was 


\section{P a g e | $\mathbf{1 8 2}$}

found to be less than the initial COD removal observed prior to addition of MCs with one exception (the reactor operating at SRT of $15 \mathrm{~d}$ ). The observed data indicate possible inhibition effect of MCs, especially TCS on AS biomass, which may alter the microorganism population and dictate the biomass to cope with new conditions and maintain its performance.

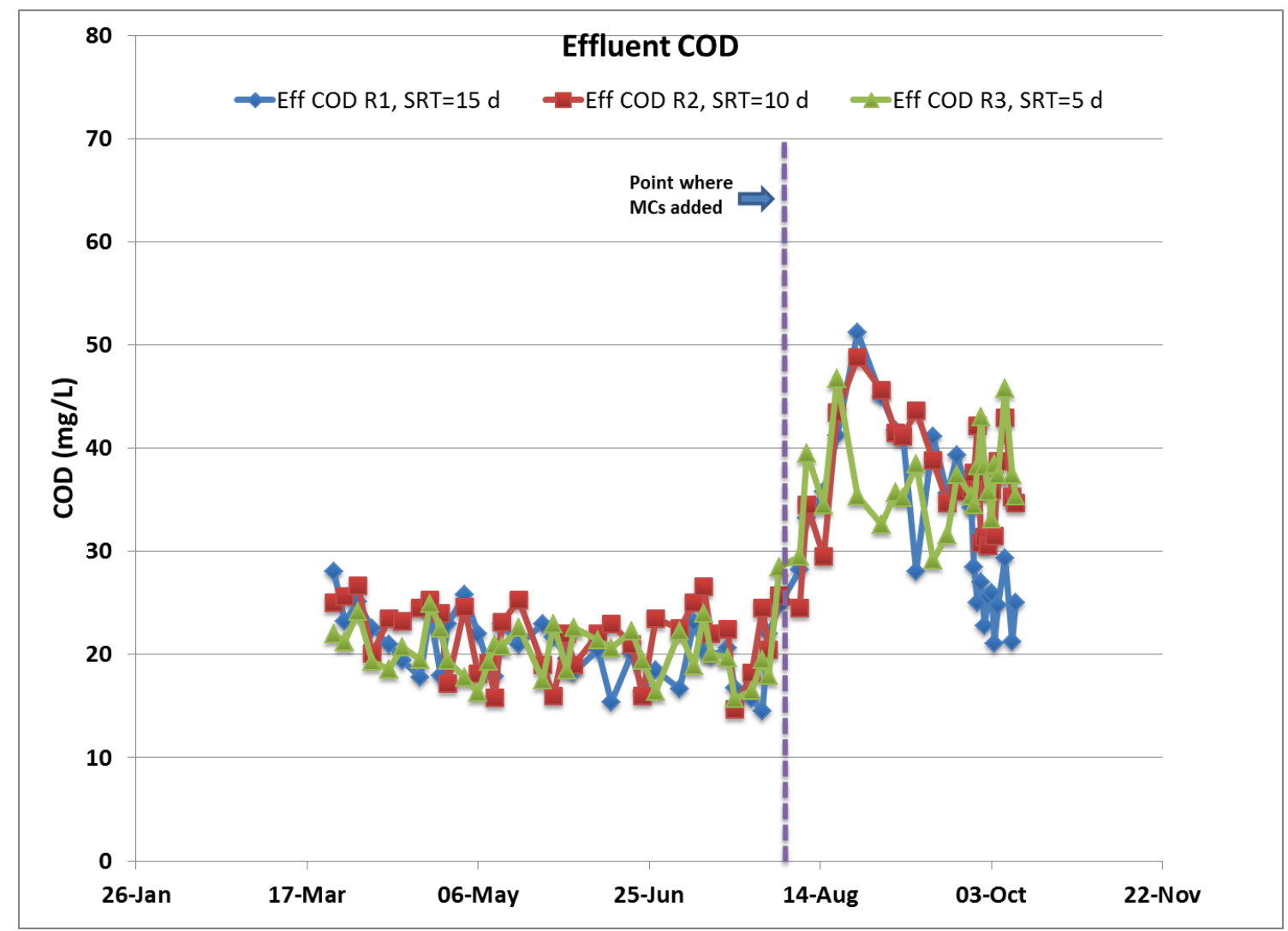

Figure 5-6. Concentration change of effluent COD in the presence of the selected MCs

This observation was in agreement with previous publications investigating toxicity of MCs at higher concentrations on AS (Seyhi et al., 2012). In their study the effect of BPA concentration on COD removal were investigated and it was observed that the 


\section{P a g e $\mid \mathbf{1 8 3}$}

higher concentration of BPA $(5 \mathrm{mg} / \mathrm{L})$ decreased the performance of the AS system, however for lower BPA concentration $(0-1 \mathrm{mg} / \mathrm{L})$ the COD removal was decreased after introducing BPA followed by a gradual increase as biomass acclimated to the BPA. It was found that TCS could also be harmful to AS bacteria at concentration more than 1.82 $\mathrm{mg} / \mathrm{L}$ (Neumegen et al., 2005) and to nitrifying bacteria at concentration as low as 500 $\mu \mathrm{g} / \mathrm{L}$ (Stasinakis et al., 2007). Pasquini et al. (2013) also reported that TCS altered the bacterial growth at concentrations measured in wastewater by investigating the toxicity of TCS on E. coli and comparing EPS production in reactors with and without MCs addition. In contrast, other studies reported no deterioration of AS systems performance in the presence of TCS at low $\mu \mathrm{g} / \mathrm{L}$ concentration (Federle et al., 2002; Stasinakis et al., 2010). Performance of simulated AS systems was also evaluated in this study. The data obtained at steady state from the nine experimental runs are summarized in Table 6 . Higher removal efficiency was observed for COD and ammonia in the reactor operating at SRT of $15 \mathrm{~d}$ and lowest removal rate was found in the reactor operating at HRT of $4 \mathrm{~h}$ and SRT of $5 \mathrm{~d}$. 
P a g e | 184

Table 5-6 Comparison of biological performance of experimental runs

\begin{tabular}{|c|c|c|c|c|c|c|c|c|c|c|}
\hline \multicolumn{2}{|c|}{ Runs } & \multicolumn{3}{|c|}{ Phase B } & \multicolumn{3}{|c|}{ Phase C } & \multicolumn{3}{|c|}{ Phase D } \\
\hline Parameter & Unit & 1 & 2 & 3 & 4 & 5 & 6 & 7 & 8 & 9 \\
\hline$Q$ & $L / d$ & $\begin{array}{l}11.22 \\
\pm 0.6\end{array}$ & $\begin{array}{c}12.52 \\
\pm 0.8\end{array}$ & $\begin{array}{c}11.5 \pm \\
1.0\end{array}$ & $\begin{array}{c}7.2 \pm \\
0.8\end{array}$ & $\begin{array}{c}7.15 \pm \\
0.4\end{array}$ & $\begin{array}{c}7.13 \pm \\
0.2\end{array}$ & $\begin{array}{c}18.6 \pm \\
0.5\end{array}$ & $\begin{array}{l}17.85 \\
\pm 1.1\end{array}$ & $\begin{array}{c}18.23 \\
\pm 0.4\end{array}$ \\
\hline HRT & $\mathrm{h}$ & 6 & 6 & 6 & 10 & 10 & 10 & 4 & 4 & 4 \\
\hline SRT & $d$ & 5 & 10 & 15 & 5 & 10 & 15 & 5 & 10 & 15 \\
\hline MLTSS & $\mathrm{mg} / \mathrm{L}$ & $\begin{array}{r}1677 \\
\pm 137\end{array}$ & $\begin{array}{r}2935 \\
\pm 133\end{array}$ & $\begin{array}{r}4005 \\
\pm 171\end{array}$ & $\begin{array}{c}1188 \pm \\
129\end{array}$ & $\begin{array}{c}1805 \pm \\
119\end{array}$ & $\begin{array}{c}2498 \pm \\
142\end{array}$ & $\begin{array}{c}2774 \pm \\
287\end{array}$ & $\begin{array}{c}4440 \pm \\
152\end{array}$ & $\begin{array}{c}5965 \pm \\
229\end{array}$ \\
\hline MLVSS & $\mathrm{mg} / \mathrm{L}$ & $\begin{array}{r}1563 \\
\pm 130\end{array}$ & $\begin{array}{r}2685 \\
\pm 121\end{array}$ & $\begin{array}{r}3601 \\
\pm 149\end{array}$ & $\begin{array}{c}1112 \pm \\
127\end{array}$ & $\begin{array}{c}1681 \pm \\
136\end{array}$ & $\begin{array}{c}2302 \pm \\
138\end{array}$ & $\begin{array}{c}2571 \pm \\
261\end{array}$ & $\begin{array}{c}4085 \pm \\
158\end{array}$ & $\begin{array}{c}5335 \pm \\
205\end{array}$ \\
\hline $\mathrm{tCOD}_{\text {reactor }}$ & $\mathrm{mg} / \mathrm{L}$ & $\begin{array}{r}1976 \\
\pm 275\end{array}$ & $\begin{array}{r}3556 \\
\pm 240\end{array}$ & $\begin{array}{l}4962 \\
\pm 419\end{array}$ & $\begin{array}{c}1398 \pm \\
164\end{array}$ & $\begin{array}{c}2093 \pm \\
247\end{array}$ & $\begin{array}{c}2920 \pm \\
158\end{array}$ & $\begin{array}{c}3322 \pm \\
300\end{array}$ & $\begin{array}{c}5347 \pm \\
256\end{array}$ & $\begin{array}{c}7007 \pm \\
481\end{array}$ \\
\hline $\mathrm{SCOD}$ reactor & $\mathrm{mg} / \mathrm{L}$ & $\begin{array}{r}41.2 \\
\pm 2.4\end{array}$ & $\begin{array}{r}38.2 \\
\pm 3.6\end{array}$ & $\begin{array}{c}33.3 \pm \\
4.1\end{array}$ & $\begin{array}{c}36.8 \pm \\
2.8\end{array}$ & $\begin{array}{c}27.4 \pm \\
2.1\end{array}$ & $\begin{array}{c}28.8 \pm \\
3.3\end{array}$ & $\begin{array}{c}52.2 \pm \\
1.9\end{array}$ & $\begin{array}{c}46.3 \pm \\
3.4\end{array}$ & $\begin{array}{c}28.1 \pm \\
4.8\end{array}$ \\
\hline$C O D_{\text {eff }}$ & $\mathrm{mg} / \mathrm{L}$ & $\begin{array}{r}37.7 \\
\pm 3.4\end{array}$ & $\begin{array}{c}35.6 \\
\pm 4\end{array}$ & $\begin{array}{c}25.9 \pm \\
3.5\end{array}$ & $\begin{array}{c}34.8 \pm \\
3.3\end{array}$ & $\begin{array}{c}24.3 \pm \\
1.7\end{array}$ & $\begin{array}{c}23.5 \pm \\
2.4\end{array}$ & $\begin{array}{c}46.1 \pm \\
6.7\end{array}$ & $\begin{array}{c}40 \pm \\
6.9\end{array}$ & $\begin{array}{c}24.8 \pm \\
5.6\end{array}$ \\
\hline $\mathrm{VSS}_{\text {eff }}$ & $\mathrm{mg} / \mathrm{L}$ & $\begin{array}{c}2.8 \pm \\
1.3\end{array}$ & $\begin{array}{c}2.7 \pm \\
1\end{array}$ & $\begin{array}{l}3 \pm \\
1.1\end{array}$ & $2.8 \pm 1$ & $\begin{array}{c}3.2 \pm \\
0.7\end{array}$ & $\begin{array}{c}3.1 \pm \\
1.5\end{array}$ & $2.8 \pm 1$ & $\begin{array}{c}3.2 \pm \\
0.7\end{array}$ & $\begin{array}{c}3.1 \pm \\
1.5\end{array}$ \\
\hline$T N-N_{\text {eff }}$ & $\mathrm{mg} / \mathrm{L}$ & $\begin{array}{r}36.7 \\
\pm 1.1\end{array}$ & $\begin{array}{r}36.8 \\
\pm 3.1\end{array}$ & $\begin{array}{c}35.6 \pm \\
2.5\end{array}$ & $\begin{array}{c}35.8 \pm \\
2.9\end{array}$ & $\begin{array}{c}35.4 \pm \\
1.5\end{array}$ & $\begin{array}{c}36.3 \pm \\
2.1\end{array}$ & $\begin{array}{c}36.4 \pm \\
0.57\end{array}$ & $\begin{array}{c}36.5 \pm \\
1.36\end{array}$ & $\begin{array}{c}36.3 \pm \\
0.33\end{array}$ \\
\hline TKN-N eff & $\mathrm{mg} / \mathrm{L}$ & $\begin{array}{c}5.2 \pm \\
0.8\end{array}$ & $\begin{array}{c}4.6 \pm \\
0.3\end{array}$ & $\begin{array}{c}5.4 \pm \\
0.4\end{array}$ & $\begin{array}{l}7.6 \pm \\
1.59\end{array}$ & $\begin{array}{l}6.4 \pm \\
0.29\end{array}$ & $\begin{array}{c}3.16 \pm \\
1.8\end{array}$ & $\begin{array}{c}6.38 \pm \\
0.86\end{array}$ & $\begin{array}{c}7.37 \pm \\
0.6\end{array}$ & $\begin{array}{c}2.94 \pm \\
0.5\end{array}$ \\
\hline $\mathrm{NH} 4-\mathrm{N}_{\text {eff }}$ & $\mathrm{mg} / \mathrm{L}$ & $\begin{array}{c}0.64 \\
\pm 0.1\end{array}$ & $\begin{array}{r}0.43 \\
\pm 0.1\end{array}$ & $\begin{array}{c}0.01 \pm \\
0.01\end{array}$ & $\begin{array}{c}3.27 \pm \\
0.84\end{array}$ & $\begin{array}{c}0.62 \pm \\
0.31\end{array}$ & $\begin{array}{c}0.14 \pm \\
0.08\end{array}$ & $\begin{array}{c}0.17 \pm \\
0.13\end{array}$ & $\begin{array}{c}0.83 \pm \\
0.55\end{array}$ & $\begin{array}{c}0.28 \pm \\
0.16\end{array}$ \\
\hline $\mathrm{NO}_{3}-\mathrm{N}_{\text {eff }}$ & $\mathrm{mg} / \mathrm{L}$ & $\begin{array}{c}30.6 \\
\pm 3\end{array}$ & $\begin{array}{l}31.7 \\
\pm 4.4\end{array}$ & $\begin{array}{c}29.4 \pm \\
3.3\end{array}$ & $\begin{array}{c}29.8 \pm \\
2.26\end{array}$ & $\begin{array}{c}30.56 \\
\pm 2.6\end{array}$ & $\begin{array}{r}33.18 \\
\pm 1.89\end{array}$ & $\begin{array}{r}30.04 \\
\pm 0.91\end{array}$ & $\begin{array}{r}29.15 \\
\pm 1.69\end{array}$ & $\begin{array}{r}33.46 \\
\pm 0.63\end{array}$ \\
\hline $\mathrm{pH}_{\text {reactor }}$ & N/A & $\begin{array}{l}7.21 \\
\pm 0.3\end{array}$ & $\begin{array}{l}6.92 \\
\pm 0.4\end{array}$ & $\begin{array}{c}7.02 \pm \\
0.2\end{array}$ & $\begin{array}{c}7.52 \pm \\
0.44\end{array}$ & $\begin{array}{c}6.88 \pm \\
0.21\end{array}$ & $\begin{array}{c}6.9 \pm \\
0.3\end{array}$ & $\begin{array}{c}7.33 \pm \\
0.2\end{array}$ & $\begin{array}{c}7.14 \pm \\
0.15\end{array}$ & $\begin{array}{c}7.29 \pm \\
0.31\end{array}$ \\
\hline Temp $_{\text {reactor }}$ & ${ }^{\circ} \mathrm{C}$ & $\begin{array}{c}25 \pm \\
0.3\end{array}$ & $\begin{array}{c}25 \pm \\
0.7\end{array}$ & $\begin{array}{c}25 \pm \\
0.6\end{array}$ & $\begin{array}{c}25 \pm \\
0.4\end{array}$ & $\begin{array}{c}25 \pm \\
0.1\end{array}$ & $\begin{array}{c}25 \pm \\
0.6\end{array}$ & $\begin{array}{c}25 \pm \\
0.2\end{array}$ & $\begin{array}{c}25 \pm \\
0.5\end{array}$ & $\begin{array}{c}25 \pm \\
0.8\end{array}$ \\
\hline
\end{tabular}

\section{Fate of selected MCs in simulated activated sludge process}

The concentrations of MCs in the effluent of the control reactor were monitored prior to introducing MCs into AS reactors. The results showed no abiotic losses for BPA and 
EE2; however, TCS was removed in the control unit by almost $50 \%$ indicating possible removal of TCS due to the operational set-up (Figure 5-7). To account for any abiotic losses in AS reactors, higher concentration of TCS $(50 \mu \mathrm{g} / \mathrm{L})$ were spiked into reactors and influent concentration of TCS were corrected accordingly.

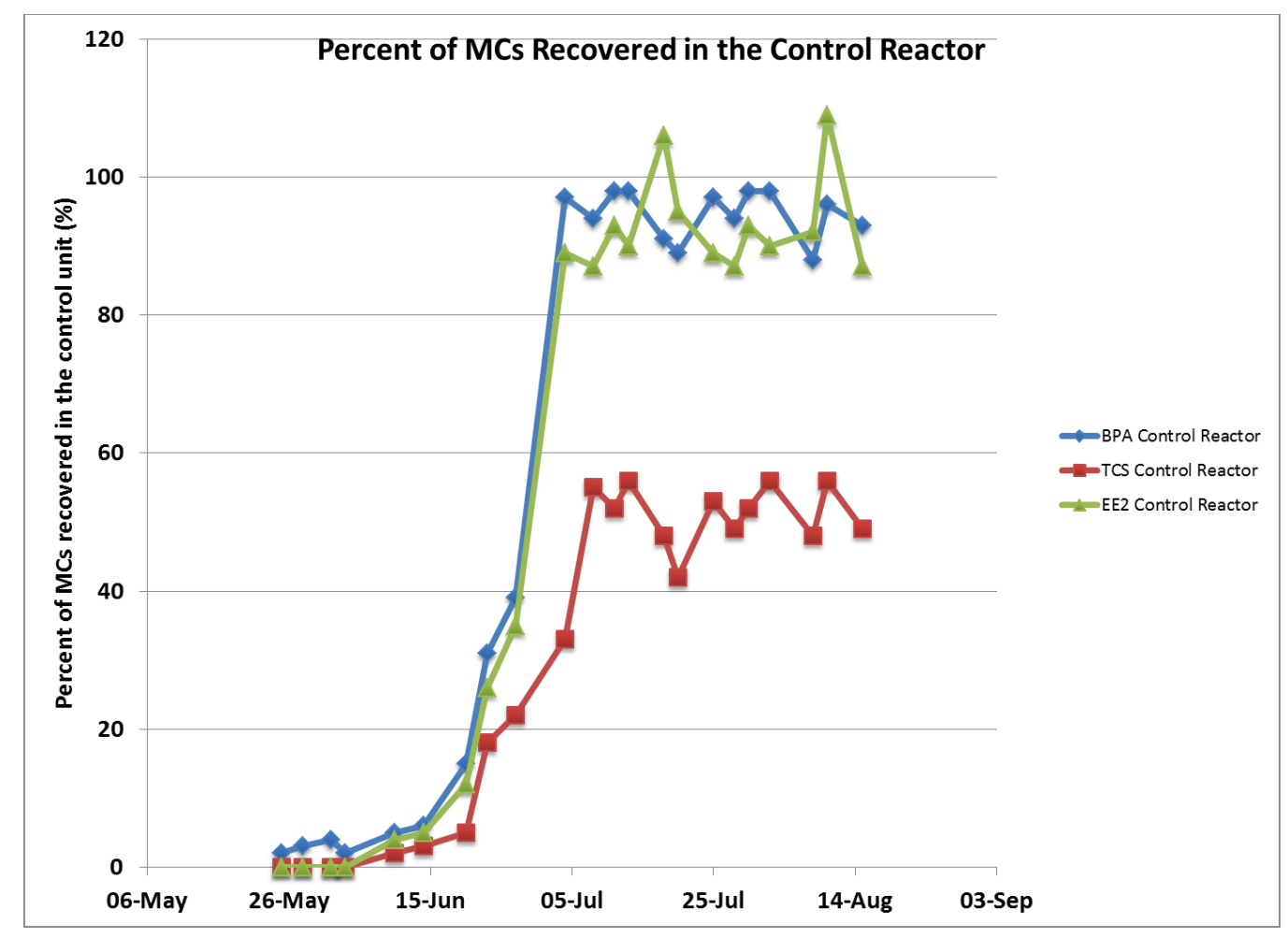

Figure 5-7. Recovery percentage of spiked MCs in the control reactor

Determination of MCs at the influents and effluents of porous-pot bioreactors showed that the major part of these compounds was removed during the AS process (Table 5-7). In all systems, mean TCS removal efficiency was greater than 97\% indicating that TCS could be easily removed in AS systems due to its high $\mathrm{K}_{\mathrm{d}}$ and biodegradation constant values. This result is in agreement with other studies reported in the literature for TCS 


\section{P a g e | 186}

removal in lab-scale AS (Stasinakis et al., 2010) and full-scale AS (Heidler and Halden, 2007; Lozano et al., 2013; Pasquini et al., 2014). The overall removal efficiency of BPA ranged between 90 and $98 \%$, where the highest removal rate was observed in reactor operating at SRT of $15 \mathrm{~d}$ and HRT of $10 \mathrm{~h}$ and the lowest removal rate were found at HRT of $4 \mathrm{~h}$ and SRTs of 5 and $10 \mathrm{~d}$ (Table 5-7). In previous studies investigating the BPA removal in AS systems removal rates fell in the range of 70-98\% (Fernandez et al., 2007; Mohapatra et al., 2011; Seyhi et al., 2012; Zhao et al., 2008).

In this study a wide range of EE2 removal rate was observed in reactors operating at different HRTs and SRTs. The removal rate for EE2 were in range of $63 \%$ at SRT of $5 \mathrm{~d}$ and HRT of $4 \mathrm{~h}$ to as high as $91 \%$ in reactor operating at SRT of $15 \mathrm{~d}$ and HRT of $10 \mathrm{~h}$ (Table 5-7). EE2 removal rates in WWTPs have been investigated in the literature and fell in the range of 34 to $98 \%$ (Cicek et al., 2007; Clouzot et al., 2008; Larcher and Yargeau, 2013; Miège et al., 2009). Furthermore, lab-scale studies reported contradictory results regarding the biological degradation of EE2 by conventional AS systems, varying from complete removal (Hashimoto and Murakami, 2009) to none at all (Weber et al., 2005).

To investigate the fate of the selected MCs in AS system, the mass balance analysis was performed for each compound and total MCs mass fluxes were determined using Eqs. (5-11 and 5-12). The result of mass balance analysis (Figures 5-8, 5-9, and 5-10) showed high biodegradation or biotransformation potential of selected MCs. 


\section{P a g e | $\mathbf{1 8 7}$}

Table 5-7 Mean total removal efficiency (\%) of selected MCs in simulated AS operating at different HRTs and SRTs ( $\mathrm{n}=$ number of determination)

\begin{tabular}{|c|c|c|c|c|c|c|c|c|c|c|}
\hline $\mathrm{HRT}=6 \mathrm{~h}$ & $\begin{array}{l}\text { BPA inf } \\
(\mu g / L)\end{array}$ & $\begin{array}{l}\text { BPA } \\
(\mu g / L)\end{array}$ & & $\begin{array}{l}\text { BPA }_{\text {Rem }} \\
\text { oval }(\%)\end{array}$ & $\begin{array}{l}\text { EE2 inf } \\
(\mu g / L)\end{array}$ & $\begin{array}{l}\text { EE2 eff } \\
(\mu \mathrm{g} / \mathrm{L})\end{array}$ & $\begin{array}{l}\text { EE2 Remov } \\
\text { al }(\%)\end{array}$ & $\begin{array}{l}\text { TCS inf } \\
(\mu \mathrm{g} / \mathrm{L})\end{array}$ & $\begin{array}{l}\text { TCS }_{\text {eff }} \\
(\mu \mathrm{g} / \mathrm{L})\end{array}$ & $\begin{array}{l}\mathrm{TCS}_{\text {Remov }} \\
\text { al }(\%)\end{array}$ \\
\hline & & & & & & & & & 0.41 & \\
\hline Reactor 1 (SRT= & 20.25 & 0.44 & \pm & 97.81 & 21.47 & $3.00 \pm$ & $85.95 \pm$ & 23.67 & \pm & $98.23 \pm$ \\
\hline 15 days) (n=27) & \pm 0.89 & 0.14 & & \pm 0.75 & \pm 1.18 & 0.47 & 2.33 & \pm 2.56 & $\begin{array}{l}0.08 \\
0.47\end{array}$ & 0.52 \\
\hline Reactor 2 (SRT= & 19.73 & 0.63 & \pm & 96.83 & 20.19 & $2.34 \pm$ & $88.51 \pm$ & 23.16 & \pm & $97.98 \pm$ \\
\hline 10 days) $(n=27)$ & \pm 1.02 & 0.25 & & \pm 1.33 & \pm 1.44 & 0.58 & 2.48 & \pm 3.84 & $\begin{array}{l}0.08 \\
0.56\end{array}$ & 0.41 \\
\hline $\begin{array}{l}\text { Reactor } 3 \text { (SRT= } \\
5 \text { days) }(n=27)\end{array}$ & $\begin{array}{l}20.11 \\
\pm 1.11 \\
\end{array}$ & $\begin{array}{l}0.98 \\
0.33\end{array}$ & \pm & $\begin{array}{l}95.22 \\
\pm 1.65 \\
\end{array}$ & $\begin{array}{l}20.47 \\
\pm 1.36\end{array}$ & $\begin{array}{l}5.94 \pm \\
1.03\end{array}$ & $\begin{array}{l}71.99 \pm \\
5.50\end{array}$ & $\begin{array}{l}22.95 \\
\pm 2.85 \\
\end{array}$ & $\begin{array}{l} \pm \\
0.07\end{array}$ & $\begin{array}{l}97.54 \pm \\
0.65\end{array}$ \\
\hline \multicolumn{11}{|l|}{$\mathrm{HRT}=10 \mathrm{~h}$} \\
\hline $\begin{array}{l}\text { Reactor } 1 \text { (SRT= } \\
15 \text { days) }(n=27)\end{array}$ & $\begin{array}{l}20.39 \\
\pm 0.71 \\
\end{array}$ & $\begin{array}{l}0.34 \\
0.08 \\
\end{array}$ & \pm & $\begin{array}{l}98.31 \\
\pm 0.39 \\
\end{array}$ & $\begin{array}{l}20.42 \\
\pm 0.81 \\
\end{array}$ & $\begin{array}{l}1.82 \pm \\
0.29\end{array}$ & $\begin{array}{l}91.05 \pm \\
1.63\end{array}$ & $\begin{array}{l}24.88 \\
\pm 2.94 \\
\end{array}$ & $\begin{array}{l}0.40 \\
\pm \\
0.08\end{array}$ & $\begin{array}{l}97.66 \pm \\
0.77\end{array}$ \\
\hline $\begin{array}{l}\text { Reactor } 2 \text { (SRT= } \\
10 \text { days) }(n=27)\end{array}$ & $\begin{array}{l}21.3 \pm \\
0.88\end{array}$ & $\begin{array}{l}0.75 \\
0.19\end{array}$ & \pm & $\begin{array}{l}96.29 \\
\pm 1.03 \\
\end{array}$ & $\begin{array}{l}19.85 \\
\pm 1.22 \\
\end{array}$ & $\begin{array}{l}2.99 \pm \\
0.59\end{array}$ & $\begin{array}{l}85.26 \pm \\
3.30\end{array}$ & $\begin{array}{l}25.16 \\
\pm 2.56 \\
\end{array}$ & $\begin{array}{l}0.56 \\
\pm \\
0.12\end{array}$ & $\begin{array}{l}97.75 \pm \\
0.48\end{array}$ \\
\hline $\begin{array}{l}\text { Reactor } 3 \text { (SRT= } \\
5 \text { days) }(n=27)\end{array}$ & $\begin{array}{l}20.56 \\
\pm 0.95 \\
\end{array}$ & $\begin{array}{l}0.44 \\
0.16 \\
\end{array}$ & \pm & $\begin{array}{l}97.87 \\
\pm 0.74 \\
\end{array}$ & $\begin{array}{l}19.66 \\
\pm 1.19 \\
\end{array}$ & $\begin{array}{l}6.66 \pm \\
0.47\end{array}$ & $\begin{array}{l}67.28 \pm \\
2.99\end{array}$ & $\begin{array}{l}23.69 \\
\pm 3.65 \\
\end{array}$ & $\begin{array}{l}0.58 \\
\pm \\
0.20\end{array}$ & $\begin{array}{l}97.66 \pm \\
0.77\end{array}$ \\
\hline \multicolumn{11}{|l|}{$H R T=4 h$} \\
\hline $\begin{array}{l}\text { Reactor } 1 \text { (SRT= } \\
15 \text { days) }(n=27)\end{array}$ & $\begin{array}{l}19.86 \\
\pm 0.65 \\
\end{array}$ & $\begin{array}{l}0.57 \\
0.23 \\
\end{array}$ & \pm & $\begin{array}{l}97.13 \\
\pm 1.17 \\
\end{array}$ & $\begin{array}{l}20.41 \\
\pm 0.97 \\
\end{array}$ & $\begin{array}{l}5.97 \pm \\
0.76\end{array}$ & $\begin{array}{l}70.73 \pm \\
3.84\end{array}$ & $\begin{array}{l}25.37 \\
\pm 1.71 \\
\end{array}$ & $\begin{array}{l}0.55 \\
\pm \\
0.10 \\
\end{array}$ & $\begin{array}{l}97.80 \pm \\
0.45\end{array}$ \\
\hline $\begin{array}{l}\text { Reactor } 2 \text { (SRT= } \\
10 \text { days) }(n=27)\end{array}$ & $\begin{array}{r}20.22 \\
\pm 0.89 \\
\end{array}$ & $\begin{array}{l}1.93 \\
0.49 \\
\end{array}$ & \pm & $\begin{array}{l}90.27 \\
\pm 2.66 \\
\end{array}$ & $\begin{array}{r}21.66 \\
\pm 1.11 \\
\end{array}$ & $\begin{array}{l}5.61 \pm \\
0.90\end{array}$ & $\begin{array}{l}72.48 \pm \\
4.62\end{array}$ & $\begin{array}{l}24.66 \\
\pm 4.15 \\
\end{array}$ & $\begin{array}{l}0.64 \\
\pm \\
0.15 \\
\end{array}$ & $\begin{array}{l}97.46 \pm \\
0.6\end{array}$ \\
\hline $\begin{array}{l}\text { Reactor } 3 \text { (SRT= } \\
5 \text { days) }(n=27)\end{array}$ & $\begin{array}{l}21.16 \\
\pm 1.56 \\
\end{array}$ & $\begin{array}{l}1.91 \\
0.48\end{array}$ & \pm & $\begin{array}{l}90.39 \\
\pm 2.48 \\
\end{array}$ & $\begin{array}{l}19.88 \\
\pm 2.03 \\
\end{array}$ & $\begin{array}{l}7.55 \pm \\
0.76\end{array}$ & $\begin{array}{l}63.01 \pm \\
3.48\end{array}$ & $\begin{array}{l}23.98 \\
\pm 2.59 \\
\end{array}$ & $\begin{array}{l}0.58 \\
\pm \\
0.10\end{array}$ & $\begin{array}{l}97.70 \pm \\
0.36\end{array}$ \\
\hline
\end{tabular}




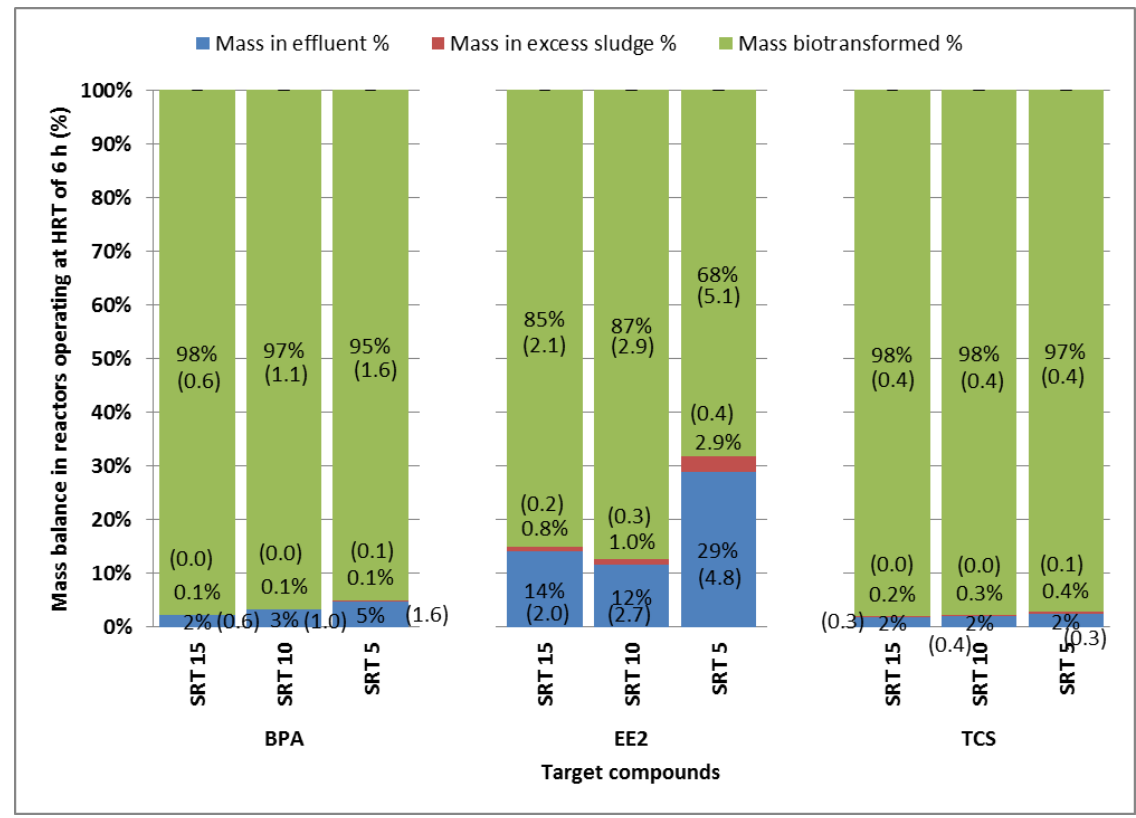

Figure 5-8. Mass balances (\%) of the target MCs in continuous-flow AS systems operating at HRT of $6 \mathrm{~h}$. Standard deviations are presented in parenthesis

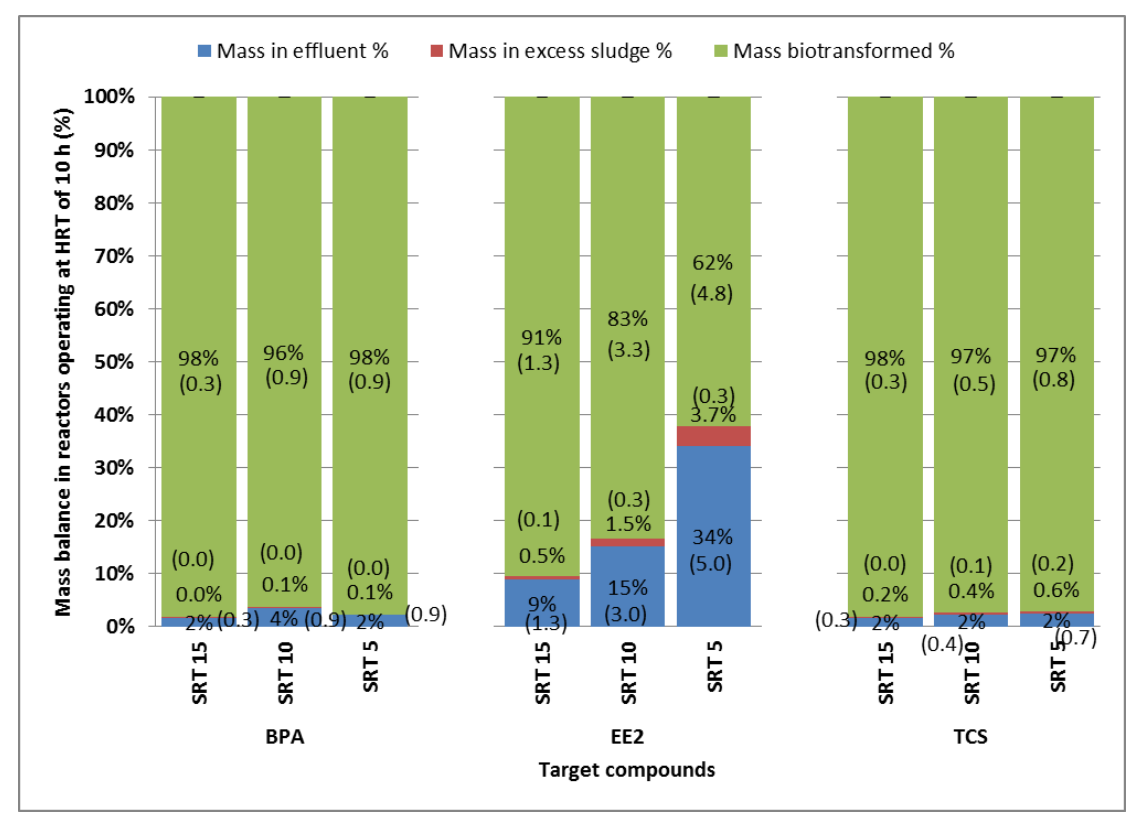

Figure 5-9. Mass balances (\%) of the MCs in continuous-flow AS systems operating at $\mathrm{HRT}=10 \mathrm{~h}$ 


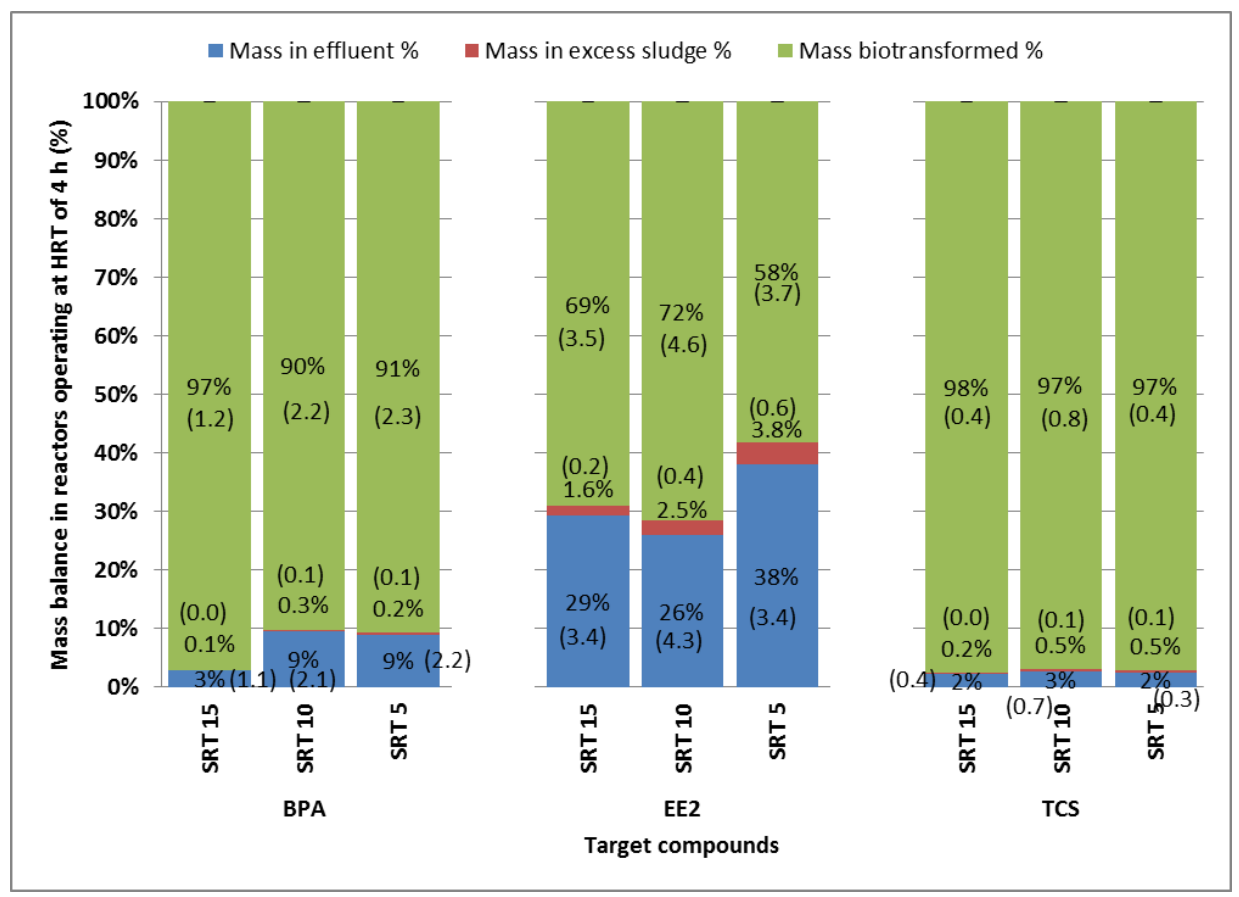

Figure 5-10. Mass balances (\%) of the MCs in continuous-flow AS systems operating at $\mathrm{HRT}=4 \mathrm{~h}$

The mean percentage of TCS that was removed by biotransformation in each experimental phase ranged between 97 and 98\%, while a wider range of mean percentages was calculated for BPA ranging between 90 and $98 \%$ depending on the operational conditions. The highest biotransformation removal rate was found for TCS and BPA in reactors operating at higher SRTs, whereas the lower biotransformation removal rate of $58 \%$ was found for EE2 in the reactor operating at SRT of $5 \mathrm{~d}$ and HRT of $4 \mathrm{~h}$. The mass flux observations in excess sludge showed that the removal of selected MCs due to the sludge disposal was minimal in all experimental runs. Similar results were observed in previous studies for BPA and TCS (Stasinakis et al., 2010; Zhao et al., 2008) and for EE2 (Joss et al., 2004a; Li et al., 2011; Muller et al., 2008; Zeng et al., 


\section{P a g e | 190}

2013). In contrast, some researchers found higher removal of TCS in full-scale AS systems due to sorption on the SS (Heidler and Halden, 2007; Nakada et al., 2010). Other researchers also suggested that the sorption of EE2 and TCS onto AS particles might also be an important removal pathway in WWTP due to its nonpolar behaviour and hydrophobic properties (Zhou et al., 2010). However, by comparing the results of labscale and full-scale AS with and without primary clarification, the higher sorption removal in full scale AS could be due to the sorption of selected MCs in primary clarifiers (Heidler and Halden, 2007; Stasinakis et al., 2007) and the high volume of excess sludge in full-scale AS systems.

Statistical evaluation of the data reported in Table 5-7, using two-way ANOVA, showed that there were significant statistical differences at a 95\% confidence level for mean MCs removal efficiency at different SRT and HRT values. Because there are two different explanatory variables (HRT and SRT) the effects on the outcome of a change in one variable may depend on the specific value of the other variable (interaction model). The result of interaction model (Table 5-8) showed the existence of the interaction between two explanatory variables $(\mathrm{P}$-value of $\mathrm{HRT} \times \mathrm{SRT}<0.05)$ indicating that some changes in both HRT and SRT must have an effect on the outcome. 
P a g e | 191

Table 5-8 Effects of HRT and SRT on total removal rate of MCs using Two-way ANOVA

Dependent Variable: BPA Removal

\begin{tabular}{|c|c|c|c|c|c|}
\hline Source & Type III Sum of Squares & df & Mean Square & $\mathrm{F}$ & Sig. \\
\hline Corrected Model & .209 & 8 & .026 & 106.786 & .000 \\
\hline HRT & .110 & 2 & .055 & 225.309 & .000 \\
\hline SRT & .058 & 2 & .029 & 117.647 & .000 \\
\hline $\mathrm{HRT}$ * SRT & .041 & 4 & .010 & 42.094 & .000 \\
\hline Error & .057 & 234 & .000 & & \\
\hline Corrected Total & .266 & 242 & & & \\
\hline \multicolumn{6}{|c|}{ Dependent Variable: EE2 Removal } \\
\hline Corrected Model & 2.325 & 8 & .291 & 228.118 & .000 \\
\hline HRT & .907 & 2 & .454 & 356.233 & .000 \\
\hline SRT & 1.218 & 2 & .609 & 478.202 & .000 \\
\hline$H R T$ * SRT & .199 & 4 & .050 & 39.018 & .000 \\
\hline Error & .298 & 234 & .001 & & \\
\hline Corrected Total & 2.623 & 242 & & & \\
\hline \multicolumn{6}{|c|}{ Dependent Variable: TCS Removal } \\
\hline Corrected Model & .004 & 8 & .001 & 14.334 & .000 \\
\hline HRT & .002 & 2 & .001 & 23.720 & .000 \\
\hline SRT & .002 & 2 & .001 & 20.730 & .000 \\
\hline $\mathrm{HRT}{ }^{*} \mathrm{SRT}$ & .001 & 4 & .000 & 6.443 & .000 \\
\hline Error & .009 & 234 & .000 & & \\
\hline Corrected Total & .013 & 242 & & & \\
\hline
\end{tabular}

Equivalently the result of this analysis showed that the HRT effects on the removal rate of selected MCs are not the same for all three SRTs and the SRT effects on the removal rate are not the same for all HRT values. The effects of three SRTs in reactors operating at the same HRT were also examined in this study and it was found that the increase of SRT to $15 \mathrm{~d}$ resulted in a significant increase of BPA removal rate for all examined HRTs $(\mathrm{P}$-value $<0.05)$, however no statistical differences between removal rates of BPA in reactors operating at SRT of 5 and $10 \mathrm{~d}$ were observed for HRT of $4 \mathrm{~h}$. The same results were reported in the study by Clara et al. (2005b) where they found the 


\section{P a g e | 192}

critical SRT of 10 days is required for removal of BPA. Regarding TCS, increase of SRT to $15 \mathrm{~d}$ resulted to a slight but significant increase of TCS removal (P-value <0.05) compared to that obtained at SRT of 10 and $5 \mathrm{~d}$, respectively, which is in agreement with other lab-scale study on the fate of TCS in AS system (Stasinakis et al., 2010). The results also showed a significant increase of EE2 removal rate when SRT increased from 5 to $15 \mathrm{~d}$; however, for reactors operating at HRT of $4 \mathrm{~h}$, no statistical differences were observed for removal rate in reactors operating at SRT of 10 and 15 d. Koh et al. (2009) also found similar results and suggested higher EE2 biodegradation (>70\%) at SRTs of 10-20 d and more than $80 \%$ biodegradation when SRT increased to over $20 \mathrm{~d}$. Other studies also support the influence of the SRT on removal of EE2 and found that EE2 removal efficiencies varied from 60 to $80 \%$ within an SRT range of 5 to 12 days, and from 25 to $70 \%$ within an SRT range of 20 to 42 days (Kreuzinger et al., 2004; Ziels et al., 2014).

Moreover, the statistical analysis for the effect of HRT on removal efficiency of the selected MCs, showed high removal efficiency of MCs when HRT increased from 4 to 10 $\mathrm{h}$ for all experimental runs. However, increasing the HRT from 6 to $10 \mathrm{~h}$ did not improve the EE2 removal efficiency significantly and it even decreases the removal efficiency of TCS. These results are in agreement with previous studied that showed high removal efficiency of MCs at higher HRT values (Gros et al., 2007; Kirk et al., 2002). Gros et al. 


\section{P a g e $\mid \mathbf{1 9 3}$}

(2010) and García-Galán et al. (2011) also reported better removal efficiency for MCs with a half-life lower than the operational HRT.

In terms of MCc sorption to the AS, the result of mass balance analysis indicated that the highest sorption achieved at reactor operating at the lowest SRT of $5 \mathrm{~d}$ and HRT of 4 h.

The one-way ANOVA multi comparison analysis on the removal efficiency of all experimental runs showed that the highest BPA removal efficiency achieved at reactor with HRTs of 4, 6, and $10 \mathrm{~h}$ and SRT of $15 \mathrm{~d}$, the highest EE2 removal efficiency achieved at reactor with HRT of $4 \mathrm{~h}$, SRT of $15 \mathrm{~d}$ and HRT of $6 \mathrm{~h}$ and SRT of $10 \mathrm{~d}$, while highest TCS removal occurred in reactor operating at HRT of $6 \mathrm{~h}$, SRT of 10 and $15 \mathrm{~d}$

and HRT of $10 \mathrm{~h}$ and SRT of $15 \mathrm{~d}$. By comparing the physico-chemical properties of selected MCs and possible factors affecting their fate in AS system with aforementioned results, it was found that the fate of selected MCs could not be predicted solely by considering their physico-chemical properties and treatment operational conditions and sludge type would play an important role in the fate of these compounds.

\section{MCs removal by heterotrophs vs. nitrifiers}

So far, it has been found that higher SRT values promote the establishment of a more diverse microbial population, as well as enrichment of slower growing microorganisms that could have a greater capacity for removing MCs (Verlicchi et al., 2012). However the fluctuating removal efficiencies found with increasing the SRT and the controversial 


\section{P a g e | 194}

conclusions on the role of autotrophs on MCs biodegradation in AS systems (Larcher and Yargeau, 2013; Zhou and Oleszkiewicz, 2010) illustrate the importance of microorganism determination responsible for biotransformation of selected MCs.

To investigate the roles of both heterotrophs and nitrifiers in MCs biotransformation, nitrification inhibitors (ATU) was added at concentration of $10 \mathrm{mg} / \mathrm{L}$ to simulated AS system operating at HRT of $4 \mathrm{~h}$ and various SRT (end of phase D). After adding ATU, the $\mathrm{NH}_{4}-\mathrm{N}, \mathrm{NO}_{3}-\mathrm{N}, \mathrm{TKN}, \mathrm{TN}$ and $\mathrm{COD}$ concentrations were monitored to evaluate the effectiveness of nitrification inhibition. The ammonia concentration was increased significantly in the effluent of AS systems and reached the steady concentration of 37.17 \pm 3.01 in four days, where TKN and TN concentrations were $38.53 \pm 2.56$ and $38.97 \pm$ $2.68 \mathrm{mg} / \mathrm{L}$, respectively. COD concentrations after and prior to presence of ATU were also monitored to determine whether ATU had an inhibitory effect on heterotrophic biomass. No deterioration of effluent COD was found when inhibitor was added, indicating that ATU only selectively inhibited nitrifiers, whereas heterotrophic biomass were still active in the reactor (data not shown).

The result of total removal efficiency of MCs with and without the nitrification inhibitor are shown in Figure 5-11 and Table 5-9, from which it could be seen that EE2 removal efficiencies increased after ATU addition in all three reactors operating at different SRTs. Lower BPA removal rate was also observed in the absence of ammonia inhibitor in reactors operating at SRTs of 5 and $10 \mathrm{~d}$; however, removal efficiency of 
BPA was lower in the presence of ATU. No significant differences were found for removal of TCS in reactors operating at SRTs of 5 and $15 \mathrm{~d}$.

In both nitrification-inhibited and uninhibited AS systems, nearly all the TCS was transformed meaning that heterotrophs were most likely responsible for the degradation of TCS, which agrees with the study by Lee do et al. (2012). Significantly different EE2 removals (P-value $<0.05$ ) were found in this study which could support the hypothesis that the majority of the EE2 removals were apparent where only heterotrophs were active.

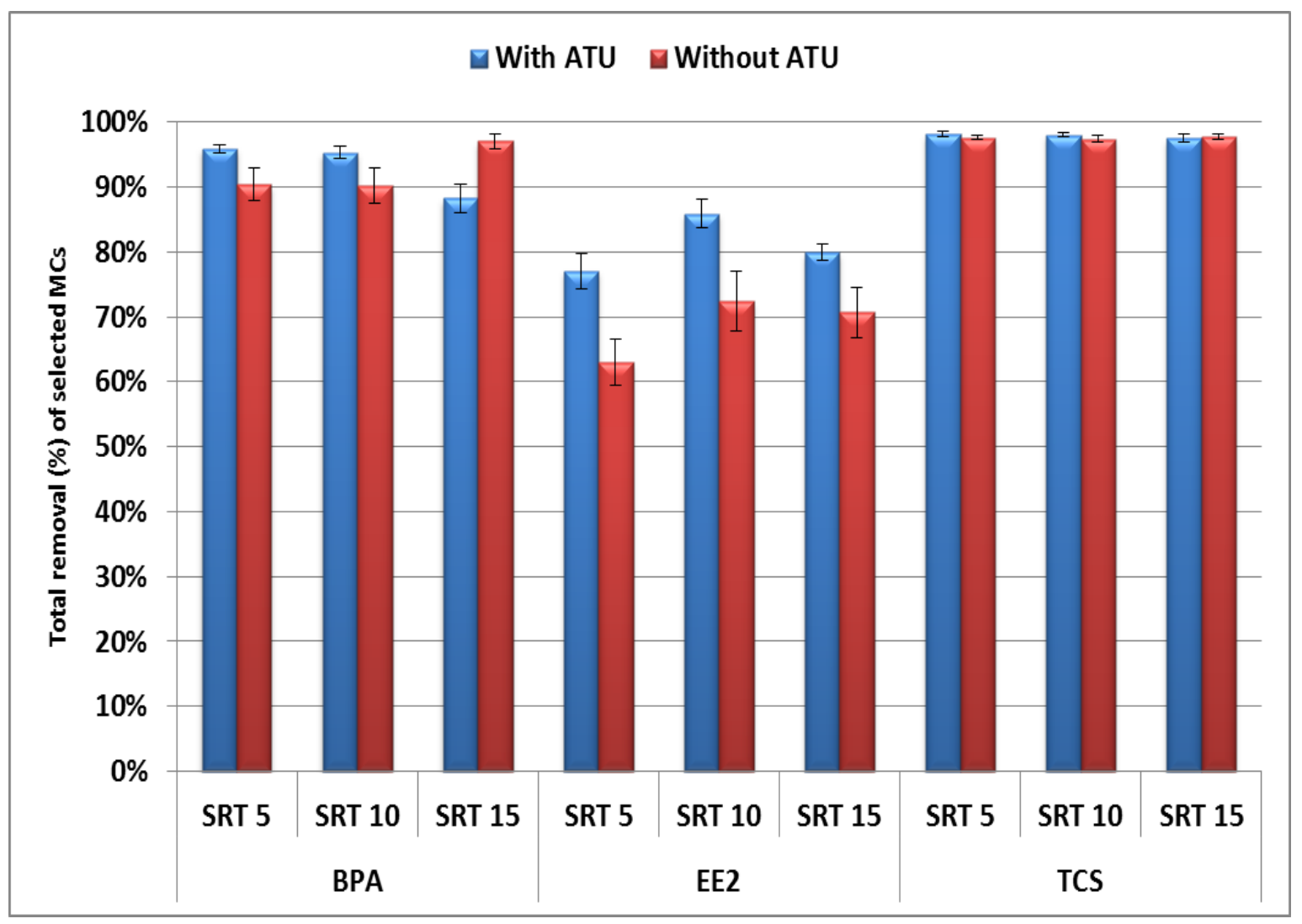

Figure 5-11. Total removal of selected MCs with and without ATU inhibitor in continuousflow AS systems operating at different SRTs 


\section{P a g e | $\mathbf{1 9 6}$}

Table 5-9 The effect of nitrification inhibition on total removal rate of MCs using two-way ANOVA (the inhibition factor was presented as 01 and 00 for presence and absence of ATU)

\begin{tabular}{|c|c|c|c|c|c|}
\hline \multirow[b]{2}{*}{ HRT4SRT.Inhibition } & \multirow[b]{2}{*}{$\mathrm{N}$} & \multicolumn{4}{|c|}{ Subset for alpha $=0.05$} \\
\hline & & 1 & 2 & 3 & 4 \\
\hline 5.00 & $\begin{array}{l}2 \\
7\end{array}$ & $63.00 \%$ & & & \\
\hline 15.00 & 2 & & $70.74 \%$ & & \\
\hline 10.00 & $\begin{array}{l}7 \\
2\end{array}$ & & $72.49 \%$ & & \\
\hline & 7 & & & & \\
\hline 5.01 & 9 & & & $77.12 \%$ & \\
\hline 15.01 & 9 & & & $79.98 \%$ & \\
\hline 10.01 & 9 & & & & $85.89 \%$ \\
\hline Sig. & & 1.000 & .827 & .356 & 1.000 \\
\hline \multicolumn{6}{|l|}{ TCS.HRT4.Removal } \\
\hline 10.00 & $\begin{array}{l}2 \\
7\end{array}$ & $97.46 \%$ & & & \\
\hline 15.01 & 9 & $97.58 \%$ & $97.58 \%$ & & \\
\hline 5.00 & 2 & $97.70 \%$ & $97.70 \%$ & $97.70 \%$ & \\
\hline 15.00 & $\begin{array}{l}7 \\
2\end{array}$ & $97.81 \%$ & $97.81 \%$ & $97.81 \%$ & \\
\hline 1001 & $\begin{array}{l}7 \\
9\end{array}$ & & $9803 \%$ & $9803 \%$ & \\
\hline 501 & 9 & & $50.00 \%$ & $98.21 \%$ & \\
\hline Sig. & & .434 & .165 & .081 & \\
\hline \multicolumn{6}{|l|}{ BPA.HRT4.Removal } \\
\hline 15.01 & 9 & $88.29 \%$ & & & \\
\hline 10.00 & 2 & $90.27 \%$ & & & \\
\hline 5.00 & $\begin{array}{l}7 \\
2\end{array}$ & $90.40 \%$ & & & \\
\hline & 7 & 80.4070 & & & \\
\hline 10.01 & 9 & & $95.40 \%$ & & \\
\hline 5.01 & 9 & & $95.95 \%$ & & \\
\hline 15.00 & 2 & & $97.13 \%$ & & \\
\hline Sig. & & .106 & .275 & & \\
\hline
\end{tabular}

Other studies also supports the observations in this study and showed that heterotrophic bacteria in the AS process have a variety of mono- and di-oxygenase 
enzymes that can significantly contribute to MCs transformation. (Gaulke et al., 2008; Racz et al., 2012; Yi and Harper, 2007; Zhou and Oleszkiewicz, 2010; Ziels et al., 2014). The higher removal efficiency of BPA in the absence of ATU at SRT of $15 \mathrm{~d}$ suggests that AOB might play a role in BPA removal. However further studies using DNA sequencing technique are preferred to identify of microorganisms prior and after ATU addition.

\subsection{Conclusions}

The results of sorption equilibrium study, suggested that that equilibrium was reached within a few hours between sorbed and dissolved MCs. The analysis of MCs sorption mechanism revealed that Freundlich sorption isotherms with values of $1 / \mathrm{n}$ close to 1 and pseudo-second-order model best fit the results. Calculation of Freundlich constant, $\mathrm{K}_{\mathrm{F}}$ and $\mathrm{K}_{\mathrm{d}}$ exhibited the greater tendency of EE2 and TCS for sorption, compared to BPA. The results of this study indicated that the SRT had a clear effect on the sorption kinetics where the highest sorption constant was achieved for a SRT of $10 \mathrm{~d}$ for all three target substances. The operation of continuous-flow AS systems in the presence of $20 \mu \mathrm{g} / \mathrm{L}$ of MCs indicated that 90-98, 63-91 and 97-98\% of BPA, EE2 and TCS, respectively, can be removed during the AS process in systems operating at SRT of 5-15 d and HRT of 4-10 h. Determination of MCs in the dissolved and particulate phase and calculation of their

mass flux showed that biotransformation was the principal removal mechanism of selected MCs. Statistical analysis revealed that both SRT and HRT had a significant 


\section{P a g e | 198}

effect on the fate of MCs where highest biotransformation removal rate was found for TCS and BPA in reactors operating at higher SRTs whereas the lowest rate of 58\% was found for EE2 in the reactor operating at SRT of $5 \mathrm{~d}$ and HRT of $4 \mathrm{~h}$. In both nitrification-inhibited and uninhibited AS systems, nearly all the TCS was transformed meaning that heterotrophs were most likely responsible for the degradation of TCS. The majority of the EE2 removals were apparent where only heterotrophs were active. The higher removal efficiency of BPA in the absence of ATU at SRT of $15 \mathrm{~d}$ suggests that AOB might play a role in BPA removal; however, it was found that heterotrophs were most likely responsible for the degradation of selected MCs.

By comparing the physico-chemical properties of selected MCs and possible factors affecting their fate in AS system with aforementioned results, it was found that the fate of selected MCs could not be predicted solely by considering their physico-chemical properties. Treatment operational conditions and sludge type would play an important role in the fate of these compounds. In terms of MCc sorption to the AS, the result of mass balance analysis indicated that the highest sorption achieved at reactor operating at lowest SRT of $5 \mathrm{~d}$ and HRT of $4 \mathrm{~h}$.

\subsection{References}

Standard methods for the examination of water and wastewater : 21st edition Washington, DC: American Public Health Association, 2005.

AIST (Advanced Industrial Science and Technology). AIST Risk Assessment Document Series No. 4 Bisphenol A. Research Center for Chemical Risk Management, 
Advanced Industrial Science and Technology Tsukuba West: Tsukuba, Ibaraki, Japan, 2007.

Andersen HR, Hansen M, Kjolholt J, Stuer-Lauridsen F, Ternes T, Halling-Sorensen B. Assessment of the importance of sorption for steroid estrogens removal during activated sludge treatment. Chemosphere 2005; 61: 139-46.

Anderson PD. Endocrine disrupting compounds and implications for wastewater treatment, 2005.

Ashton D, Hilton M, Thomas KV. Investigating the environmental transport of human pharmaceuticals to streams in the United Kingdom. Sci Total Environ 2004; 333: $167-84$.

Atkinson SK, Marlatt VL, Kimpe LE, Lean DR, Trudeau VL, Blais JM. The occurrence of steroidal estrogens in south-eastern Ontario wastewater treatment plants. Sci Total Environ 2012; 430: 119-25.

Ballesteros-Gomez A, Ruiz FJ, Rubio S, Perez-Bendito D. Determination of bisphenols $\mathrm{A}$ and $\mathrm{F}$ and their diglycidyl ethers in wastewater and river water by coacervative extraction and liquid chromatography-fluorimetry. Anal Chim Acta 2007; 603: 51-9.

Banihashemi B, Droste RL. Trace level determination of bisphenol-A in wastewater and sewage sludge by high-performance liquid chromatography and UV detection. Water Quality Research Journal of Canada 2013; 48: 133-144.

Banihashemi B, Droste RL. Sorption-desorption and biosorption of bisphenol A, triclosan, and 17alpha-ethinylestradiol to sewage sludge. Sci Total Environ 2014; 487: 813-21.

Bennie DT, Struger, J.S. Pharmaceuticals and personal care products (PPCP) in Canadian urban waters: Research and policy directions. Environment Canada, 2008.

Bester K. Triclosan in a sewage treatment process-balances and monitoring data. Water Research 2003; 37: 3891-3896.

Borrirukwisitsak S, Keenan HE, Gauchotte-Lindsay C. Effects of salinity, pH and temperature on the octanol-water partition coefficient of bisphenol A. International Journal of Environmental Science and Development 2012; 3(5): $460-464$.

Bouju H, Hommes G, Wintgens T, Malpei F, Corvini PF. The fate of 14C-radiolabelled diclofenac and 4'-hydroxydiclofenac in membrane bioreactor treatment of wastewater. Water Sci Technol 2011; 63: 2878-85.

Carballa M, Omil F, Lema JM. Calculation methods to perform mass balances of micropollutants in sewage treatment plants. application to pharmaceutical and personal care products (PPCPs). Environ Sci Technol 2007; 41: 884-90.

Chalew TE, Halden RU. Environmental Exposure of Aquatic and Terrestrial Biota to Triclosan and Triclocarban. J Am Water Works Assoc 2009; 45: 4-13. 


\section{P a g e $\mid \mathbf{2 0 0}$}

Cicek N, Londry K, Oleszkiewicz JA, Wong D, Lee Y. Removal of selected natural and synthetic estrogenic compounds in a Canadian full-scale municipal wastewater treatment plant. Water Environ Res 2007; 79: 795-800.

Cirja M, Zuehlke S, Ivashechkin P, Hollender J, Schaffer A, Corvini PF. Behavior of two differently radiolabelled 17alpha-ethinylestradiols continuously applied to a laboratory-scale membrane bioreactor with adapted industrial activated sludge. Water Res 2007; 41: 4403-12.

Clara M, Strenn B, Gans O, Martinez E, Kreuzinger N, Kroiss H. Removal of selected pharmaceuticals, fragrances and endocrine disrupting compounds in a membrane bioreactor and conventional wastewater treatment plants. Water Res 2005; 39: 4797-807.

Clouzot L, Marrot B, Doumenq P, Roche N. 17 $\alpha$-Ethinylestradiol: An endocrine disrupter of great concern. Analytical methods and removal processes applied to water purification. A review. Environmental Progress 2008; 27: 383-396.

Dann AB, Hontela A. Triclosan: environmental exposure, toxicity and mechanisms of action. J Appl Toxicol 2011; 31: 285-311.

Deblonde T, Cossu-Leguille C, Hartemann P. Emerging pollutants in wastewater: a review of the literature. Int J Hyg Environ Health 2011; 214: 442-8.

Drury B, Scott J, Rosi-Marshall EJ, Kelly JJ. Triclosan exposure increases triclosan resistance and influences taxonomic composition of benthic bacterial communities. Environ Sci Technol 2013; 47: 8923-30.

EC (European Commission). European Union Complete Risk Assessment including 2003 Risk Assessment Report and 2008 Addendum: 4,4'-Isopropylidenediphenol (Bisphenol-A): CAS No: 80-05-7, EINECS No: 201-245-8, Complete risk assessment in one document. 2010. http://esis.jrc.ec.europa.eu/.

Environment Canada and Health Canada. Screening Assessment for the Challenge: Phenol, 4,4' -(1-methylethylidene)bis- (Bisphenol A) Chemical Abstracts Service Registry Number 80-05-7 (April 2011). 2008www.ec.gc.ca/substances/ese/eng/challenge/batch2/batch2_80-05-7.cfm

Federle TW, Kaiser SK, Nuck BA. Fate and effects of triclosan in activated sludge. Environ Toxicol Chem 2002; 21: 1330-7.

Feng Y, Zhang Z, Gao P, Su H, Yu Y, Ren N. Adsorption behavior of EE2 (17 alphaethinylestradiol) onto the inactivated sewage sludge: kinetics, thermodynamics and influence factors. J Hazard Mater 2010; 175: 970-6.

Fernandez MP, Ikonomou MG, Buchanan I. An assessment of estrogenic organic contaminants in Canadian wastewaters. Sci Total Environ 2007; 373: 250-69.

Fujimoto T, Kubo K, Aou S. Prenatal exposure to bisphenol A impairs sexual differentiation of exploratory behavior and increases depression-like behavior in rats. Brain Res 2006; 1068: 49-55. 
García-Galán MJ, Díaz-Cruz MS, Barceló D. Occurrence of sulfonamide residues along the Ebro river basin. Removal in wastewater treatment plants and environmental impact assessment. Environment International 2011; 37: 462-473.

Gaulke LS, Strand SE, Kalhorn TF, Stensel HD. 17 $\alpha$-ethinylestradiol Transformation via Abiotic Nitration in the Presence of Ammonia Oxidizing Bacteria. Environmental Science \& Technology 2008; 42: 7622-7627.

Gee RH, Charles A, Taylor N, Darbre PD. Oestrogenic and androgenic activity of triclosan in breast cancer cells. J Appl Toxicol 2008; 28: 78-91.

Gros M, Petrović M, Barceló D. Wastewater treatment plants as a pathway for aquatic contamination by pharmaceuticals in the Ebro river basin (Northeast Spain). Environmental Toxicology and Chemistry 2007; 26: 1553-1562.

Gros M, Petrović M, Ginebreda A, Barceló D. Removal of pharmaceuticals during wastewater treatment and environmental risk assessment using hazard indexes. Environment International 2010; 36: 15-26.

Guellil A, Block JC, Urbain V. Adaptation of the microbial adhesion to hydrocarbon test (MATH) for measuring activated sludge hydrophobicity. Water Science and Technology 1998; 37: 359-362.

Hamid H, Eskicioglu C. Fate of estrogenic hormones in wastewater and sludge treatment: A review of properties and analytical detection techniques in sludge matrix. Water Research 2012; 46: 5813-5833.

Hashimoto T, Murakami T. Removal and degradation characteristics of natural and synthetic estrogens by activated sludge in batch experiments. Water Res 2009; 43: $573-82$.

Heberer T. Tracking persistent pharmaceutical residues from municipal sewage to drinking water. Journal of Hydrology 2002; 266: 175-189.

Heidler J, Halden RU. Mass balance assessment of triclosan removal during conventional sewage treatment. Chemosphere 2007; 66: 362-9.

Ho YS, McKay G. Pseudo-second order model for sorption processes. Process Biochemistry 1999; 34: 451-465.

Hyland KC, Dickenson ER, Drewes JE, Higgins CP. Sorption of ionized and neutral emerging trace organic compounds onto activated sludge from different wastewater treatment configurations. Water Res 2012; 46: 1958-68.

Jeffries KM, Jackson LJ, Ikonomou MG, Habibi HR. Presence of natural and anthropogenic organic contaminants and potential fish health impacts along two river gradients in Alberta, Canada. Environ Toxicol Chem 2010; 29: 2379-87.

Jelic A, Gros M, Ginebreda A, Cespedes-Sanchez R, Ventura F, Petrovic M, et al. Occurrence, partition and removal of pharmaceuticals in sewage water and sludge during wastewater treatment. Water Res 2011; 45: 1165-76.

Joss A, Andersen H, Ternes T, Richle PR, Siegrist H. Removal of Estrogens in Municipal Wastewater Treatment under Aerobic and Anaerobic Conditions: Consequences 
P a g e $\mid \mathbf{2 0 2}$

for Plant Optimization. Environmental Science \& Technology 2004; 38: 30473055.

Joss A, Zabczynski S, Gobel A, Hoffmann B, Loffler D, McArdell CS, et al. Biological degradation of pharmaceuticals in municipal wastewater treatment: proposing a classification scheme. Water Res 2006; 40: 1686-96.

Kidd KA, Blanchfield PJ, Mills KH, Palace VP, Evans RE, Lazorchak JM, et al. Collapse of a fish population after exposure to a synthetic estrogen. Proc Natl Acad Sci U S A 2007; 104: 8897-901.

Kirk LA, Tyler CR, Lye CM, Sumpter JP. Changes in estrogenic and androgenic activities at different stages of treatment in wastewater treatment works. Environmental Toxicology and Chemistry 2002; 21: 972-979.

Klecka GM, Staples CA, Clark KE, Van der Hoeven N, Thomas DE, Hentges SG. Exposure analysis of bisphenol A in surface water systems in North America and Europe. Environ Sci Technol 2009; 43: 6145-50.

Koh YK, Chiu TY, Boobis AR, Scrimshaw MD, Bagnall JP, Soares A, et al. Influence of operating parameters on the biodegradation of steroid estrogens and nonylphenolic compounds during biological wastewater treatment processes. Environ Sci Technol 2009; 43: 6646-54.

Kreuzinger N, Clara M, Strenn B, Kroiss H. Relevance of the sludge retention time (SRT) as design criteria for wastewater treatment plants for the removal of endocrine disruptors and pharmaceuticals from wastewater. Water Science and Technology 2004; 50: 149-156.

Lagergren S. About the theory of so-called adsorption of soluble substance. Kung Sven. Veten. Hand. 1898; 24: 1-39.

Lapworth DJ, Baran N, Stuart ME, Ward RS. Emerging organic contaminants in groundwater: A review of sources, fate and occurrence. Environ Pollut 2012; 163: 287-303.

Larcher S, Yargeau V. Biodegradation of 17alpha-ethinylestradiol by heterotrophic bacteria. Environ Pollut 2013; 173: 17-22.

Latorre A, Lacorte S, Barcelo D. Presence of nonylphenol, octyphenol and bisphenol a in two aquifers close to agricultural, industrial and urban areas. Chromatographia 2003; 57: 111-116.

Lee do G, Zhao F, Rezenom YH, Russell DH, Chu KH. Biodegradation of triclosan by a wastewater microorganism. Water Res 2012; 46: 4226-34.

Lee HB, Peart TE, Chan J, Gris G. Occurrence of endocrine-disrupting chemicals in sewage and sludge samples in Toronto, Canada. Water Quality Research Journal of Canada 2004; 39: 57-63.

Lee J, Lee BC, Ra JS, Cho J, Kim IS, Chang NI, et al. Comparison of the removal efficiency of endocrine disrupting compounds in pilot scale sewage treatment processes. Chemosphere 2008; 71: 1582-92. 
P a g e $\mid \mathbf{2 0 3}$

Li YM, Zeng QL, Yang SJ. Removal and fate of estrogens in an anaerobic-anoxic-oxic activated sludge system. Water Sci Technol 2011; 63: 51-6.

Lishman L, Smyth SA, Sarafin K, Kleywegt S, Toito J, Peart T, et al. Occurrence and reductions of pharmaceuticals and personal care products and estrogens by municipal wastewater treatment plants in Ontario, Canada. Sci Total Environ 2006; 367: 544-58.

Lopez-Avila V, Hites RA. Organic compounds in an industrial wastewater. Their transport into sediments. Environmental Science \& Technology 1980; 14: 13821390.

Lozano N, Rice CP, Ramirez M, Torrents A. Fate of Triclocarban, Triclosan and Methyltriclosan during wastewater and biosolids treatment processes. Water Res 2013; 47: 4519-27.

Margot J, Kienle C, Magnet A, Weil M, Rossi L, de Alencastro LF, et al. Treatment of micropollutants in municipal wastewater: ozone or powdered activated carbon? Sci Total Environ 2013; 461-462: 480-98.

Martin J, Camacho-Munoz D, Santos JL, Aparicio I, Alonso E. Occurrence of pharmaceutical compounds in wastewater and sludge from wastewater treatment plants: removal and ecotoxicological impact of wastewater discharges and sludge disposal. J Hazard Mater 2012; 239-240: 40-7.

Melcer H, Klecka G. Treatment of wastewaters containing bisphenol A: state of the science review. Water Environ Res 2011; 83: 650-66.

Miège C, Choubert JM, Ribeiro L, Eusèbe M, Coquery M. Fate of pharmaceuticals and personal care products in wastewater treatment plants - Conception of a database and first results. Environmental Pollution 2009; 157: 1721-1726.

Mohapatra DP, Brar SK, Tyagi RD, Surampalli RY. Occurrence of bisphenol A in wastewater and wastewater sludge of CUQ treatment plant. Journal of Xenobiotics 2011; 1.

Muller M, Rabenoelina F, Balaguer P, Patureau D, Lemenach K, Budzinski H, et al. Chemical and biological analysis of endocrine-disrupting hormones and estrogenic activity in an advanced sewage treatment plant. Environ Toxicol Chem 2008; 27: 1649-58.

Nakada N, Yasojima M, Okayasu Y, Komori K, Suzuki Y. Mass balance analysis of triclosan, diethyltoluamide, crotamiton and carbamazepine in sewage treatment plants. Water Sci Technol 2010; 61: 1739-47.

Neumegen RA, Fernandez-Alba AR, Chisti Y. Toxicities of triclosan, phenol, and copper sulfate in activated sludge. Environ Toxicol 2005; 20: 160-4.

Nie Y, Qiang Z, Zhang H, Adams C. Determination of endocrine-disrupting chemicals in the liquid and solid phases of activated sludge by solid phase extraction and gas chromatography-mass spectrometry. J Chromatogr A 2009; 1216: 7071-80. 


\section{P a g e | $\mathbf{2 0 4}$}

Pasquini L, Merlin C, Hassenboehler L, Munoz JF, Pons MN, Gorner T. Impact of certain household micropollutants on bacterial behavior. Toxicity tests/study of extracellular polymeric substances in sludge. Sci Total Environ 2013; 463-464: 355-65.

Pasquini L, Munoz JF, Pons MN, Yvon J, Dauchy X, France X, et al. Occurrence of eight household micropollutants in urban wastewater and their fate in a wastewater treatment plant. Statistical evaluation. Sci Total Environ 2014; 481: 459-68.

Plahuta M, Tišler T, Toman M. J, Pintar A. Efficiency of advanced oxidation processes in lowering bisphenol A toxicity and oestrogenic activity in aqueous samples. Archives of Industrial Hygiene and Toxicology. 65, 2014, pp. 77.

Qiu H, Lv L, Pan BC, Zhang QJ, Zhang WM, Zhang QX. Critical review in adsorption kinetic models. Journal of Zhejiang University-Science A 2009; 10: 716-724.

Racz L, Muller JG, Goel RK. Fate of selected estrogens in two laboratory scale sequencing batch reactors fed with different organic carbon sources under varying solids retention times. Bioresour Technol 2012; 110: 35-42.

Radjenovic J, Petrovic M, Barcelo D. Fate and distribution of pharmaceuticals in wastewater and sewage sludge of the conventional activated sludge (CAS) and advanced membrane bioreactor (MBR) treatment. Water Res 2009; 43: 831-41.

Robinson BJ, Hui JP, Soo EC, Hellou J. Estrogenic compounds in seawater and sediment from Halifax Harbour, Nova Scotia, Canada. Environ Toxicol Chem 2009; 28: 18-25.

Roig B. Pharmaceuticals in the environment. Current knowledge and need assessment to reduce presence and impact: IWA Publishing, 2010.

Rostkowski P, Horwood J, Shears JA, Lange A, Oladapo FO, Besselink HT, et al. Bioassay-directed identification of novel antiandrogenic compounds in bile of fish exposed to wastewater effluents. Environ Sci Technol 2011; 45: 10660-7.

Samaras VG, Stasinakis AS, Mamais D, Thomaidis NS, Lekkas TD. Fate of selected pharmaceuticals and synthetic endocrine disrupting compounds during wastewater treatment and sludge anaerobic digestion. J Hazard Mater 2013; $244-$ 245: 259-67.

Seyhi B, Drogui P, Buelna G, Blais JF. Modeling of sorption of bisphenol A in sludge obtained from a membrane bioreactor process. Chemical Engineering Journal 2011; 172: 61-67.

Seyhi B, Drogui P, Buelna G, Blais JF. Removal of bisphenol-A from spiked synthetic effluents using an immersed membrane activated sludge process. Separation and Purification Technology 2012; 87: 101-109.

Stahlhut RW, Welshons WV, Swan SH. Bisphenol A Data in NHANES Suggest Longer than Expected Half-Life, Substantial Nonfood Exposure, or Both. Environmental health perspectives 2009; 117: 784-789. 
Stasinakis AS, Gatidou G, Mamais D, Thomaidis NS, Lekkas TD. Occurrence and fate of endocrine disrupters in Greek sewage treatment plants. Water Res 2008; 42: 1796-804.

Stasinakis AS, Kordoutis CI, Tsiouma VC, Gatidou G, Thomaidis NS. Removal of selected endocrine disrupters in activated sludge systems: effect of sludge retention time on their sorption and biodegradation. Bioresour Technol 2010; 101: 2090-5.

Stasinakis AS, Mermigka S, Samaras VG, Farmaki E, Thomaidis NS. Occurrence of endocrine disrupters and selected pharmaceuticals in Aisonas River (Greece) and environmental risk assessment using hazard indexes. Environ Sci Pollut Res Int 2012; 19: 1574-83.

Stasinakis AS, Petalas AV, Mamais D, Thomaidis NS, Gatidou G, Lekkas TD. Investigation of triclosan fate and toxicity in continuous-flow activated sludge systems. Chemosphere 2007; 68: 375-381.

Stevens-Garmon J, Drewes JE, Khan SJ, McDonald JA, Dickenson ER. Sorption of emerging trace organic compounds onto wastewater sludge solids. Water Res 2011; 45: 3417-26.

Tchobanoglous G, Burton, F. L., Stensel, D. H. Wastewater engineering: treatment and reuse. New York: McGraw-Hill, 2003.

Thomas PM, Foster GD. Tracking acidic pharmaceuticals, caffeine, and triclosan through the wastewater treatment process. Environmental Toxicology and Chemistry 2005; 24: 25-30.

Urbatzka R, van Cauwenberge A, Maggioni S, Vigano L, Mandich A, Benfenati E, et al. Androgenic and antiandrogenic activities in water and sediment samples from the river Lambro, Italy, detected by yeast androgen screen and chemical analyses. Chemosphere 2007; 67: 1080-7.

Vajda AM, Barber LB, Gray JL, Lopez EM, Woodling JD, Norris DO. Reproductive disruption in fish downstream from an estrogenic wastewater effluent. Environ Sci Technol 2008; 42: 3407-14.

Vega-Morales T, Sosa-Ferrera Z, Santana-Rodriguez JJ. Determination of alkylphenol polyethoxylates, bisphenol-A, 17alpha-ethynylestradiol and 17beta-estradiol and its metabolites in sewage samples by SPE and LC/MS/MS. J Hazard Mater 2010; 183: 701-11.

Verlicchi P, Al Aukidy M, Zambello E. Occurrence of pharmaceutical compounds in urban wastewater: removal, mass load and environmental risk after a secondary treatment--a review. Sci Total Environ 2012; 429: 123-55.

vom Saal FS, Myers JP. Bisphenol A and risk of metabolic disorders. JAMA 2008; 300: 1353-5. 
Vulliet E, Cren-Olive C, Grenier-Loustalot MF. Occurrence of pharmaceuticals and hormones in drinking water treated from surface waters. Environmental Chemistry Letters 2011; 9: 103-114.

Weber S, Leuschner P, Kampfer P, Dott W, Hollender J. Degradation of estradiol and ethinyl estradiol by activated sludge and by a defined mixed culture. Applied Microbiology and Biotechnology 2005; 67: 106-12.

Weber TW, Chakravo.Rk. Pore and Solid Diffusion Models for Fixed-Bed Adsorbers. AIChE Journal 1974; 20: 228-238.

Xu K, Harper WF, Jr., Zhao D. 17alpha-Ethinylestradiol sorption to activated sludge biomass: thermodynamic properties and reaction mechanisms. Water Res 2008; 42: 3146-52.

Yi T, Harper WF, Jr. The effect of biomass characteristics on the partitioning and sorption hysteresis of 17alpha-ethinylestradiol. Water Res 2007; 41: 1543-53.

Ying GG, Yu XY, Kookana RS. Biological degradation of triclocarban and triclosan in a soil under aerobic and anaerobic conditions and comparison with environmental fate modelling. Environ Pollut 2007; 150: 300-5.

Zeng QL, Li YM, Yang SJ. Sludge Retention Time as a Suitable Operational Parameter to Remove Both Estrogen and Nutrients in an Anaerobic-Anoxic-Aerobic Activated Sludge System. Environmental engineering science 2013; 30: 161-169.

Zhao J, Li Y, Zhang C, Zeng Q, Zhou Q. Sorption and degradation of bisphenol A by aerobic activated sludge. J Hazard Mater 2008; 155: 305-11.

Zhou H, Huang X, Wang X, Zhi X, Yang C, Wen X, et al. Behaviour of selected endocrine-disrupting chemicals in three sewage treatment plants of Beijing, China. Environmental Monitoring and Assessment 2010; 161: 107-21.

Zhou X, Oleszkiewicz JA. Biodegradation of oestrogens in nitrifying activated sludge. Environ Technol 2010; 31: 1263-9.

Ziels RM, Lust MJ, Gough HL, Strand SE, Stensel HD. Influence of Bioselector Processes on 17alpha-Ethinylestradiol Biodegradation in Activated Sludge Wastewater Treatment Systems. Environ Sci Technol 2014. 


\section{Chapter 6: General Fate Model for MCs under Typical Sewage Treatment Conditions}

\section{Summary ${ }^{1}$ :}

Mathematical models developed for removal of microconstituents (MCs) in biological wastewater treatment have not incorporated developments in International Water Association (IWA) models. In this paper many kinetic models that can be used to describe transformation of MCs (volatilization and photodegradation were considered negligible) in an activated sludge (AS) process were evaluated and advantages and disadvantages of different models were outlined. Nine lab-scale continuous flow porouspot bioreactors operating at various solids retention times (SRTs) and hydraulic retention times (HRTs) were conducted to simulate AS systems and to evaluate the biodegradation kinetic models for the fate of 17 1 -ethinylestradiol (EE2), bisphenol-A (BPA), and triclosan (TCS) at the $\mu \mathrm{g} / \mathrm{L}$ range. Mathematical models were applied to describe the degradation mechanism of selected MCs and pseudo second-order model were found to best fit the results when active MCs degraders $\left(X_{C}\right)$ were used. It is found that biodegradation studies should incorporate $\mathrm{X}_{\mathrm{C}}$ and not mixed liquor suspended solids concentration (MLSS) in their kinetic formulations.

\footnotetext{
${ }^{1}$ This chapter has been prepared to submit for publication to the Water Research Journal
} 
P a g e $\mid \mathbf{2 0 8}$

\subsection{Introduction:}

The mathematical models developed for design and operation of biological wastewater treatment such as those from the International Water Association (IWA) were only developed to describe removal of chemical oxygen demand (COD), nitrogen and phosphorus and not concerned with specific chemical compounds. Consequently commercial modeling software for MCs removal in secondary wastewater treatment plants (WWTPs) have been developed, but the models used in these packages for microconstituents (MCs) with different physico-chemical properties and biodegradability have not incorporated developments in IWA models which present numerous possibilities that have not been evaluated (Banihashemi and Droste, 2011).

Although the presence of MCs during wastewater treatment has been studied by a plethora of reports, significant differences on their concentration levels and removal rates as well as contradictory results on their fate have been reported (Deblonde et al., 2011; Stasinakis et al., 2010). Most studies do not report sufficient information to evaluate the possible fate models for MCs removal and incorporate findings from other researchers; furthermore, assumptions are often not experimentally verified. Consequently, only limited normalization is possible to relate models or rate coefficients to experimental data. On the other hand, the majority of environmental surveys previously undertaken have mainly been focused on dissolved concentrations of these compounds in wastewater at environmentally relevant concentrations (Feng et al., 2010; Radjenovic et al., 2009; 
Seyhi et al., 2011). Only in the last few years have researchers begun to study the MCs concentration in the solid phase at very low concentrations (Nie et al., 2009; Stasinakis et al., 2010; Stevens-Garmon et al., 2011; Zhao et al., 2008) which is necessary for mass balance analysis. Banihashemi and Droste (2011) reviewed different literature models describing MCs removal in activated sludge (AS) system and stated that an explanation for the validity of proposed models is often lacking and future developments are necessary to improve modeling of MCs removal in WWTP.

Volatile agents were largely ignored in MCs fate models because they are mostly transferred to the atmosphere in an AS process. Because the $\mathrm{pH}$ range in WWTPs is usually in the range of $6.5-8$, losses due to photolysis are expected to be negligible. Therefore, sorption and biotransformation are considered as the two primary removal pathways of MCs in this study.

A major task of this research was to evaluate the kinetic models that have been used or can be used to describe the transformation of selected MCs, namely $17 \alpha-$ ethinylestradiol (EE2), bisphenol-A (BPA), and triclosan (TCS) in a biotreatment process, particularly an AS process.

A majority of published models for the environmental fate of MCs assume that equilibrium is reached instantaneously between sorbed and dissolved MCs. Some studies proposed a general model with sorption-desorption dynamic processes (Cowan et al., 1993; Lai et al., 2000; Lindblom et al., 2009) where different stages have been suggested 


\section{P a g e $\mid \mathbf{2 1 0}$}

in this process. MCs sorption equilibria in environmental samples including sludge are often modelled by Freundlich isotherms with a Freundlich coefficient close to 1, which is equivalent to a linear isotherm (Banihashemi and Droste, 2014; Stasinakis et al., 2010; Yi et al., 2011; Zhao et al., 2008). As a consequence, the equilibrium of sorption to particles is usually assumed to fit linear equations (Carballa et al., 2007; Feng et al., 2010) as well as the equilibrium of sorption to dissolved/colloidal matter (DCM) (Barret et al., 2010b; Zhou et al., 2007).

In a previous published study on sorption of BPA, TCS, and EE2 to AS sludge by authors, it was found that the contact times necessary to reach equilibrium between solid and liquid phases was 2, 4, and 6 hours for BPA, TCS, and EE2, respectively (Banihashemi and Droste, 2014). In their study, linear and Freundlich models fitted well with the experimental data with the correlation coefficients $\left(\mathrm{r}^{2}\right)$ greater than 0.98 and it was found that the SRT plays an important role in sorption kinetic determination. Furthermore, they concluded that desorption kinetics cannot limit BPA, EE2, and TCS biodegradation in biological treatment systems and the equilibrium state assumption is valid to represent sorption phenomena.

Biodegradation of $\mathrm{MCs}$ varies with respect to compounds properties, type of biological system designed to remove MCs and operating condition of that system. Biodegradation occurs in the aeration basin in AS systems and is governed by degradation kinetics where microbial biomass is a key parameter. There are many 


\section{P a g e | 211}

different model formulations that have been found to fit biodegradation data for MCs in an AS treatment plant, e.g., zero-order, first-order, pseudo-first-order or mixed secondorder kinetics or various types of growth-based Monod or Haldane model formulations. A number of different approaches for modeling biological MC degradation in WWTPs found in the literature are presented in Banihashemi and Droste (2011) and are shown in Table 6-1. Possible biological rate and growth rate formulations are also presented in Table 6-2. The simplest zero- and first-order models assume that, for a given hydraulic retention time (HRT) a fixed fraction of the MCs in the influent is removed independently of other water quality variables. In a zero-order reaction model, the removal rate is independent of the influent concentration while in the first-order case it is not. More commonly used models are first-order or pseudo second-order formulations dependent only on the liquid phase concentration of chemical or apparent first-order formulation where degradation occurs in both the soluble and sorbed phases (Banihashemi and Droste, 2011; Pomiès et al., 2013). However, it has been found that the amount of chemical available for biodegradation must be equal to the total amount of chemical in the reactor not just the dissolved fraction (Cowan et al., 1993).

The pseudo-first order expressions takes into account mixed liquor suspended solids (MLSS) and thus distinguishes between, e.g., an AS reactor (high MLSS) and an aerated lagoon (low MLSS). On the other hand, using these models would lead to a linear increase in the removal rate with the suspended solids (SS) concentration independent of 
the sludge activity, but only active biomass can degrade substrates; suggesting that the biodegradation rates should be expressed in terms of active biomass. While this has been achieved for COD transformation by classifying AS bacteria into heterotrophic and autotrophic fractions, the responsible microorganisms for MCs biotransformation is still unknown.

Table 6-1 Zero-, first- and pseudo first-order models for biological degradation of MCs found in the literature

\begin{tabular}{|c|c|c|c|}
\hline Process & Type of process & Removal rate & Reference \\
\hline 1 & Zero-order & $\mathrm{K}_{\mathrm{m}}$ & \\
\hline 2 & First-order & $\mathrm{K}_{\mathrm{m}} \mathrm{C}$ & $\begin{array}{l}\text { (Shen et al., 2007);(Shi et al., 2004); (Li et } \\
\text { al., 2005); (Zhao et al., 2008); (Helbling et } \\
\text { al., 2012); (Zhou and Oleszkiewicz, 2010) }\end{array}$ \\
\hline 3 & First and pseudo-order & $\mathrm{K}_{\mathrm{m}} \mathrm{C}\left(1+\mathrm{K}_{\mathrm{d}} \mathrm{X}_{\mathrm{V}}\right)$ & (Shen et al., 2007); (Lindblom et al., 2009) \\
\hline $4 \mathrm{a}$ & Two first-order & $\mathrm{K}_{\mathrm{ms}} \mathrm{C}+\mathrm{K}_{\mathrm{mp}} \mathrm{X}_{\mathrm{v}}$ & (Cowan et al., 1993); (Byrns, 2001) \\
\hline $5 \mathrm{a}$ & Pseudo second-order & $\mathrm{K}_{\mathrm{m}} \mathrm{X}_{\mathrm{v}} \mathrm{C}$ & $\begin{array}{l}\text { (Stasinakis et al., 2010); (Kumar et al., } \\
\text { 2009); (Ziels et al., 2014); (Tan et al., } \\
\text { 2007); (Plosz et al., 2010); (Fernandez- } \\
\text { Fontaina et al., 2013); (Suarez et al., 2012) }\end{array}$ \\
\hline 5 & Pseudo second-order & $\mathrm{K}_{\mathrm{m}} \mathrm{X}_{\mathrm{T}} \mathrm{C}$ & $\begin{array}{l}\text { (Joss et al., 2006); (Press-Kristensen et al., } \\
\text { 2007); (Wick et al., 2009); (Maurer et al., } \\
\text { 2007); (Xue et al., 2010); (Abegglen et } \\
\text { al., 2009); }\end{array}$ \\
\hline $5 b$ & Pseudo second-order & $\mathrm{K}_{\mathrm{m}} \mathrm{X}_{\mathrm{H}} \mathrm{C}$ & $\begin{array}{l}\text { (Jacobsen and Arvin, 1996), (Majewsky et } \\
\text { al., 2011); (Plósz et al., 2012) }\end{array}$ \\
\hline $5 \mathrm{c}$ & Pseudo second-order & $\mathrm{K}_{\mathrm{m}} \mathrm{X}_{\mathrm{C}} \mathrm{C}$ & (Govind et al., 1991), (Lee et al., 1998) \\
\hline 6 & Haldane Model & $\begin{array}{l}\left(\mathrm{K}_{\mathrm{m}} \quad \mathrm{X}_{\mathrm{V}} \mathrm{C}\right) \\
/\left(\mathrm{C}+\mathrm{K}_{\mathrm{s}}+\mathrm{C}^{2} / \mathrm{K}_{1}\right)\end{array}$ & (Tomei et al., 2008) \\
\hline 7 & Monod Model & $\mathrm{K}_{\mathrm{m}} \mathrm{C} /\left(\mathrm{C}+\mathrm{K}_{\mathrm{s}}\right)$ & $\begin{array}{l}\text { (Marfil-Vega et al., 2010); (Lee do et al., } \\
\text { 2012) }\end{array}$ \\
\hline
\end{tabular}

where $K_{m}$ is biodegradation rate coefficient; $C$ is concentration of dissolved $\mathrm{MC}(\mathrm{mg} / \mathrm{L}) ; X_{\mathrm{v}}$ is volatile SS concentration $(\mathrm{mg} / \mathrm{L}) ; X_{\mathrm{T}}$ is total concentration of solids $(\mathrm{mg} / \mathrm{L}) ; X_{\mathrm{H}}$ is concentration of heterotroph biomass $(\mathrm{mg} / \mathrm{L}) ; X_{C}$ is concentration of specific $M C$ degraders $(\mathrm{mg} / \mathrm{L}) ; \mathrm{K}_{\mathrm{S}}$ is halfvelocity constant for soluble degradable substrate $(\mathrm{mg} / \mathrm{L})$ and $\mathrm{K}_{\mathrm{I}}$ is an inhibition constant. 
Table 6-2 Possible rate formulations for biological degradation of MCs

\begin{tabular}{|c|c|c|}
\hline No. & Model (r) & \\
\hline 1 & $\mathrm{~K}_{\mathrm{m}}$ & $\begin{array}{l}\text { Zero-order model, decay is independent of concentrations of biomass and the } \\
\text { chemical }\end{array}$ \\
\hline 2 & $\mathrm{~K}_{\mathrm{m}} \mathrm{C}$ & $\begin{array}{l}\text { First-order degradation independent of biomass concentration and only applies } \\
\text { to dissolved chemical }\end{array}$ \\
\hline $3 \mathrm{a}$ & $\mathrm{K}_{\mathrm{m}} \mathrm{C}\left(1+\mathrm{K}_{\mathrm{d}} \mathrm{X}_{\mathrm{V}}\right)$ & First-order but chemical decays in both the soluble and solid phases \\
\hline $3 b$ & $\mathrm{~K}_{\mathrm{m}} \mathrm{C}\left(1+\mathrm{K}_{\mathrm{d}} \mathrm{X}_{\mathrm{H}}\right)$ & $\begin{array}{l}\text { First-order but chemical decays in both the soluble and solid phases; }\left(X_{I}+X_{S}\right) \\
\text { is not subject to microbial attack }\end{array}$ \\
\hline $3 \mathrm{c}$ & $\mathrm{K}_{\mathrm{m}} \mathrm{C}\left(1+\mathrm{K}_{\mathrm{d}} \mathrm{X}_{\mathrm{C}}\right)$ & First-order but chemical decays in both the soluble and solid phases \\
\hline $4 \mathrm{a}$ & $\mathrm{K}_{\mathrm{ms}} \mathrm{C}+\mathrm{K}_{\mathrm{mp}} \mathrm{K}_{\mathrm{d}} \mathrm{X}_{\mathrm{V}} \mathrm{C}$ & First-order decay in both liquid and solid phases but different rate coefficients \\
\hline $4 b$ & $\mathrm{~K}_{\mathrm{ms}} \mathrm{C}+\mathrm{K}_{\mathrm{mp}} \mathrm{K}_{\mathrm{d}} \mathrm{X}_{\mathrm{H}} \mathrm{C}$ & $\begin{array}{l}\text { First-order decay in both liquid and solid phases but different rate coefficients; } \\
\left(X_{I}+X_{S}\right) \text { is not subject to microbial attack }\end{array}$ \\
\hline $5 \mathrm{a}$ & $\mathrm{K}_{\mathrm{m}} \mathrm{X}_{\mathrm{V}} \mathrm{C}$ & Mixed second-order with degradation only in the soluble phase \\
\hline $5 \mathrm{~b}$ & $\mathrm{~K}_{\mathrm{m}} \mathrm{X}_{\mathrm{H}} \mathrm{C}$ & $\begin{array}{l}\text { Mixed second-order with degradation by active heterotrophs only in the soluble } \\
\text { phase }\end{array}$ \\
\hline $5 \mathrm{c}$ & $\mathrm{K}_{\mathrm{m}} \mathrm{X}_{\mathrm{C}} \mathrm{C}$ & $\begin{array}{l}\text { Mixed second-order with degradation by active MCs degraders only in the } \\
\text { soluble phase }\end{array}$ \\
\hline $6 \mathrm{a}$ & $\mathrm{K}_{\mathrm{m}} \mathrm{X}_{\mathrm{V}} \mathrm{C}\left(1+\mathrm{K}_{\mathrm{d}} \mathrm{X}_{\mathrm{V}}\right)$ & Mixed second-order with degradation in both the soluble and solid phases \\
\hline $6 \mathrm{~b}$ & $\mathrm{~K}_{\mathrm{m}} \mathrm{X}_{\mathrm{H}} \mathrm{C}\left(1+\mathrm{K}_{\mathrm{d}} \mathrm{X}_{\mathrm{V}}\right)$ & $\begin{array}{l}\text { Mixed second-order with degradation by active heterotrophs in both the soluble } \\
\text { and solid phases }\end{array}$ \\
\hline $6 \mathrm{c}$ & $\mathrm{K}_{\mathrm{m}} \mathrm{X}_{\mathrm{C}} \mathrm{C}\left(1+\mathrm{K}_{\mathrm{d}} \mathrm{X}_{\mathrm{V}}\right)$ & $\begin{array}{l}\text { Mixed second-order with degradation by active MCs degraders in both the } \\
\text { soluble and solid phases }\end{array}$ \\
\hline $7 \mathrm{a}$ & $\begin{array}{l}\mathrm{K}_{\mathrm{ms}} \mathrm{X}_{\mathrm{V}} \mathrm{C}+ \\
\mathrm{K}_{\mathrm{mp}} \mathrm{X}_{\mathrm{V}} \mathrm{K}_{\mathrm{d}} \mathrm{X}_{\mathrm{V}} \mathrm{C}\end{array}$ & $\begin{array}{l}\text { Mixed second-order with degradation in both the soluble and solid phases with } \\
\text { different rate coefficients in each phase. }\end{array}$ \\
\hline $7 \mathrm{~b}$ & $\begin{array}{l}\mathrm{K}_{\mathrm{ms}} \mathrm{X}_{\mathrm{H}} \mathrm{C} \\
+\mathrm{K}_{\mathrm{mp}} \mathrm{X}_{\mathrm{H}} \mathrm{K}_{\mathrm{d}} \mathrm{X}_{\mathrm{V}} \mathrm{C}\end{array}$ & $\begin{array}{l}\text { Mixed second-order with degradation in both the soluble and solid phases with } \\
\text { different rate coefficients for active heterotrophs in each phase }\end{array}$ \\
\hline $7 \mathrm{c}$ & $\begin{array}{l}\mathrm{K}_{\mathrm{ms}} \mathrm{X}_{\mathrm{C}} \mathrm{C} \\
+\mathrm{K}_{\mathrm{mp}} \mathrm{X}_{\mathrm{C}} \mathrm{K}_{\mathrm{d}} \mathrm{X}_{\mathrm{V}} \mathrm{C}\end{array}$ & $\begin{array}{l}\text { Mixed second-order with degradation in both the soluble and solid phases with } \\
\text { different rate coefficients foe active MCs degraders in each phase }\end{array}$ \\
\hline 8 & $\mathrm{~K}_{\mathrm{m}} \mathrm{X}_{\mathrm{H}} \mathrm{C}\left(1+\mathrm{K}_{\mathrm{d}} \mathrm{X}_{\mathrm{H}}\right)$ & $\begin{array}{l}\text { Chemical sorbed to inert particulates; }\left(X_{I}+X_{S}\right) \text { is not subject to microbial } \\
\text { attack }\end{array}$ \\
\hline 9 & $\begin{array}{l}\mathrm{K}_{\mathrm{ms}} \mathrm{X}_{\mathrm{H}} \mathrm{C}+ \\
\mathrm{K}_{\mathrm{mp}} \mathrm{X}_{\mathrm{H}}^{2} \mathrm{~K}_{\mathrm{d}} \mathrm{C}\end{array}$ & $\begin{array}{l}\text { Chemical sorbed to inert particulates }\left(X_{I}+X_{S}\right) \text { is not subject to microbial } \\
\text { attack. Degradation in both the soluble and solid phases with different rate } \\
\text { coefficients in each phase. }\end{array}$ \\
\hline 10 & $\frac{\mathrm{K}_{\mathrm{m}} \mathrm{C}}{\mathrm{K}_{\mathrm{c}}+\mathrm{C}}$ & $\begin{array}{l}\text { Monod rate formulation independent of biomass. Only applied to the soluble } \\
\text { phase. }\end{array}$ \\
\hline $11 \mathrm{a}$ & $\frac{\mathrm{K}_{\mathrm{m}} \mathrm{X}_{\mathrm{V}} \mathrm{C}}{\mathrm{K}_{\mathrm{c}}+\mathrm{C}}$ & $\begin{array}{l}\text { Monod rate formulation dependent on VSS biomass. Only applied to the soluble } \\
\text { phase. }\end{array}$ \\
\hline $11 \mathrm{~b}$ & $\frac{\mathrm{K}_{\mathrm{m}} \mathrm{X}_{\mathrm{H}} \mathrm{C}}{\mathrm{K}_{\mathrm{c}}+\mathrm{C}}$ & $\begin{array}{l}\text { Monod rate formulation dependent on active heterotroph biomass. Only applied } \\
\text { to the soluble phase }\end{array}$ \\
\hline $11 \mathrm{c}$ & $\frac{\mathrm{K}_{\mathrm{m}} \mathrm{X}_{\mathrm{C}} \mathrm{C}}{\mathrm{K}_{\mathrm{c}}+\mathrm{C}}$ & $\begin{array}{l}\text { Monod rate formulation dependent on active MCs degraders. Only applied to } \\
\text { the soluble phase }\end{array}$ \\
\hline
\end{tabular}




\section{P a g e $\mid \mathbf{2 1 4}$}

Furthermore some studies suggested that the slow growing specific bacteria and diversified enzymes would enhance the biodegradation of MCs in WWTPs that operate above the critical SRT of 10 days (Clara et al., 2005a). It was believed that the critical SRT is correlated to the nitrification process in AS. However; debatable information on the role of autotrophs on MCs biodegradation in AS systems operating at different SRTs has been reported (Larcher and Yargeau, 2013; Zhou and Oleszkiewicz, 2010).

A spectrum of three different MCs was chosen (Table 6-3) due to their extensive use and their physico-chemical and toxicological properties. Concentration levels of these MCs range between a few $\mathrm{ng} / \mathrm{L}$ to some $\mu \mathrm{g} / \mathrm{L}$ in wastewater (Atkinson et al., 2012; Fernandez et al., 2007; Lee et al., 2004; Mohapatra et al., 2011; Nakada et al., 2010; Stasinakis et al., 2008), surface water (Bennie, 2008; Klecka et al., 2009; Stasinakis et al., 2012), groundwater (Lapworth et al., 2012; Latorre et al., 2003) and drinking water (Heberer, 2002b; Vulliet et al., 2011), while concentrations up to $\mu \mathrm{g} / \mathrm{g}$ have been detected in sewage sludge and soil samples (Martin et al., 2012; Mohapatra et al., 2011). The study presented here focuses on evaluation of biodegradation kinetic models presented in Table 6-2 for selected MCs as well as estimating the concentration of specific MC degraders $\left(\mathrm{X}_{\mathrm{C}}\right)$ based on model validation which consists in comparing the simulated biodegradation result with a set of experimental data. 
P a g e | 215

Table 6-3 Physico-chemical characteristics of selected MCs

\begin{tabular}{|c|c|c|c|c|c|c|c|}
\hline MCs & CAS No & $\mathrm{MW}$ & $\begin{array}{c}\text { Molecular } \\
\text { formula }\end{array}$ & $\mathrm{S}_{\mathrm{w}}$ & $\mathrm{H}$ & $\mathrm{K}_{\mathrm{m}}$ & $\log \mathrm{K}_{\mathrm{ow}}$ \\
\hline BPA & $80-05-7$ & 228.29 & $\mathrm{C}_{15} \mathrm{H}_{16} \mathrm{O}_{2}$ & 120 & $1.0 \times 10^{-11}$ & $5-113^{\mathrm{d}}$ & $3.18-3.7^{\mathrm{a}}$ \\
\hline EE2 & $57-63-6$ & 296.41 & $\mathrm{C}_{20} \mathrm{H}_{24} \mathrm{O}_{2}$ & $4.8-11.3$ & $7.9 \times 10^{-12}$ & $\begin{array}{c}2.5- \\
18.9^{\mathrm{e}}\end{array}$ & $3.6-4.15^{\mathrm{b}}$ \\
\hline TCS & $3380-34-5$ & 289.54 & $\mathrm{C}_{12} \mathrm{H}_{7} \mathrm{Cl}_{3} \mathrm{O}_{2}$ & 10 & $1.5 \times 10^{-7}$ & $30-288^{\mathrm{f}}$ & $4.5-4.8^{\mathrm{c}}$ \\
\hline
\end{tabular}

MW: molecular weight $(\mathrm{g} / \mathrm{mol}) ; \mathrm{S}_{\mathrm{w}}$ : solubility in water $(\mathrm{mg} / \mathrm{L}) ; \mathrm{H}$ : Henry coefficient $\left(\mathrm{atm} \cdot \mathrm{m}^{3} / \mathrm{mol}\right) ; \mathrm{K}_{\mathrm{ow}}$ : octanol-water partition coefficient; $\mathrm{K}_{\mathrm{m}}$ : pseudo-second-order degradation constant (L/gSS.day);

a (Borrirukwisitsak et al., 2012; Robinson et al., 2009)

b (Robinson et al., 2009)

c (Lopez-Avila and Hites, 1980; Ying et al., 2007)

d (Stasinakis et al., 2010; Urase and Kikuta, 2005; Zhao et al., 2008)

${ }^{\mathrm{e}}$ (Urase and Kikuta, 2005; Ziels et al., 2014)

${ }^{\mathrm{f}}$ (Stasinakis et al., 2010)

\subsection{Methods}

\subsubsection{Bioreactors}

Three laboratory-scale porous-pot bioreactors were set up to simulate AS systems operating at different SRTs. These bioreactors were originally seeded with the AS obtained from City of Ottawa wastewater treatment facility and fed with synthetic wastewater for an acclimation period of six months. After biomass acclimatization to the feed (Phase A), environmentally relevant concentration of selected MCs were added to reactors and three HRTs of 4, 6 and $10 \mathrm{~h}$ combined with three SRTs of 5, 10 and $15 \mathrm{~d}$ 
were investigated (Phase B, C, and D). Table 6-4 shows the experimental operational conditions.

Table 6-4 Experimental operational conditions

\begin{tabular}{|c|c|c|c|c|c|c|c|c|c|c|}
\hline Condition & \multirow{2}{*}{ Unit } & \multicolumn{10}{|c|}{ Experimental Phases } \\
\cline { 3 - 10 } & & \multicolumn{4}{|c|}{ Phase B } & \multicolumn{3}{c|}{ Phase C } & \multicolumn{3}{c|}{ Phase D } \\
\hline HRT & Hours & 6 & 6 & 6 & 10 & 10 & 10 & 4 & 4 & 4 \\
\hline SRT & Days & 5 & 10 & 15 & 5 & 10 & 15 & 5 & 10 & 15 \\
\hline
\end{tabular}

\subsubsection{Biodegradation Experiments}

Bioreactors were fed with synthetic wastewater consists of a mixture of macro and micro nutrient as well as dextrose, peptone, and sodium acetate for simulating easily degradable substrate, complex organic carbon source and volatile fatty acid, respectively.

The synthetic wastewater in the influent tank had an average total chemical oxygen demand (COD) of $410 \pm 6.51 \mathrm{mg} / \mathrm{L}$ which is considered as a typical COD found in domestic wastewater influent (Tchobanoglous, 2003). Total Kjeldahl nitrogen (TKN), total phosphorus (TP) and total organic carbon (TOC) in the influent tank were measured and found to be $36 \pm 3.28,11 \pm 1.3$, and $173 \pm 28.9 \mathrm{mg} / \mathrm{L}$, respectively, which yields a C:N:P ratio of approximately 100:20:6. The measured ammonia $\left(\mathrm{NH}_{3}\right)$, nitrate $\left(\mathrm{NO}_{3}-\mathrm{N}\right)$, temperature and $\mathrm{pH}$ of the influent were found to be $12.9 \pm 2.26 \mathrm{mg} / \mathrm{L}, 0.06 \pm 0.01 \mathrm{mg} / \mathrm{L}$, $22 \pm 1.1^{\circ} \mathrm{C}$ and $6.9 \pm 0.33$, respectively.

To avoid biodegradation or any abiotic losses of the selected MCs before it is introduced into the test system, which might occur if the MC and sewage are premixed, 
BPA, EE2 and TCS (purchased from Sigma-Aldrich, Canada) and the sewage were dosed into the porous pot separately using amber glass and MasterFlex C-FLEX tubing resulting in an initial concentration of $20 \mu \mathrm{g} / \mathrm{L}$ for selected MCs. In order to establish that the units have reached the steady state, are operating properly and acclimated to the selected MCs (stabilization period), test compounds in the effluent and overall performance of the units were regularly monitored at the early period of each phase.

When the reactors achieved the steady state condition, nine samples were taken over a period of two weeks and the overall performance of the reactor and the concentration of MCs in liquid and solid phases (triplicate) were measured $(n=27)$. During the experiments, all systems were maintained at $25^{\circ} \mathrm{C}$ by automatic thermostat, dissolved oxygen (DO) in aerobic reactors was kept above $4.0 \mathrm{mg} / \mathrm{L}$ and mean $\mathrm{pH}$ was $7.2 \pm 0.3$. All reactors and tubes were covered with aluminum foil or tape to prevent any loss due to photodegradation

\subsubsection{Estimation of Active Heterotrophic Biomass}

The mixed liquor aliquots were decanted from reactors at beginning of each phase and the active fraction of the mixed liquor was determined in 35-day aerobic digestion batch tests by monitoring VSS according to detailed experimental and mathematical method developed in the literature (Ramdani et al., 2010; Ramdani et al., 2012). The following equations were used for the determinations of the active fraction of biomass. The concentration of sludge VSS at a given time of digestion is given by Eq. (6-1). 
$\operatorname{VSS}(t)=\operatorname{VSS}_{U}+\left(1-f_{\mathrm{H}}\right) \cdot \mathrm{X}_{\mathrm{H}}(0) \cdot \mathrm{e}^{\left(-b_{H} \cdot t\right)}$

where $\mathrm{X}_{\mathrm{H}}(0)=$ VSS concentration of the active biomass at time zero (mg VSS/L); $\operatorname{VSS}(\mathrm{t})=\mathrm{VSS}$ concentration at time $\mathrm{t}(\mathrm{mg} \operatorname{VSS} / \mathrm{L}) ; \operatorname{VSS}(0)=\mathrm{VSS}$ concentration at time zero $\left(\mathrm{mg}\right.$ VSS/L); $\mathrm{VSS}_{\mathrm{U}}=\mathrm{VSS}$ concentration at the end of the batch test $(\mathrm{mg} \mathrm{VSS} / \mathrm{L}) ; \mathrm{b}_{\mathrm{H}}$ $=$ endogenous decay rate $\left(\mathrm{d}^{-1}\right) ; \mathrm{f}_{\mathrm{H}}=$ endogenous residue fraction (assumed to be 0.2 ).

Once VSSu is measured, the $\mathrm{b}_{\mathrm{H}}$ and $\mathrm{X}_{\mathrm{H}}(0)$ values can be determined using nonlinear regression to fit Eq. (6-1) to the observed VSS versus time data. The fraction of active heterotrophic biomass can then be calculated by Eq. (6-2).

$$
f_{\mathrm{av}}=\frac{\mathrm{X}_{\mathrm{H}}(0)}{\operatorname{VSS}(0)}
$$

To evaluate the value of active heterotrophic biomass found from this method, the AS system simulation were performed for bioreactors by the use of the AS model no.1 (ASM1) within the wastewater treatment modeling software GPS-X from Hydromantis (Hamilton, Canada).

\subsubsection{Analytical method}

For the investigation of the fate of selected MCs in AS process, sample preparation and clean-up were performed using commercial SPE cartridge (Supelclean LC-18) and microwave-assisted extraction, Mars $5^{\circledR}$ (MW Accelerated Reaction System; CEM Corporation) for MC samples in both liquid and solid phases based on the method described in a previously published studies (Banihashemi and Droste, 2013; Banihashemi 
P a g e | 219

and Droste, 2014). Determination of selected MCs was performed using a HPLC (Hewlett-Packard, HP 1100) coupled with ultraviolet (UV) detection according to the procedures described by Banihashemi and Droste (2014). The recoveries of BPA, TCS and EE2 in liquid samples were found to be $106 \pm 2,95 \pm 6$ and $88 \pm 5 \%$, respectively. Also satisfactory recoveries were obtained in solid samples (>75\%), except for TCS, where recoveries of $55 \pm 6 \%$ were obtained. For this reason, recovery correction was

made for TCS by dividing the observed concentrations by recovery rates. The limits of detection (LOD) of the target compounds in liquid and solid samples were $100 \mathrm{ng} / \mathrm{L}$ and $100 \mathrm{ng} / \mathrm{g}$, respectively.

\subsubsection{Calculation methods}

Based on the concentrations in influent, effluent, and biosolids, the total removal rate, removal rate by sorption and removal rate by biotransformation/biodegradation were calculated in percentages for all selected MCs. Total removal rate was calculated by Eq. (6-3):

Total removal rate $=\frac{C_{\text {inf }}-C_{\text {eff }}}{C_{\text {inf }}} \times 100$

where $C_{\text {inf }}$ is the influent liquid phase concentration, $\mu \mathrm{g} / \mathrm{L} ; \mathrm{C}_{\text {eff }}$ is the effluent liquid phase concentration of $\mathrm{MC}$ from the reactor, $\mu \mathrm{g} / \mathrm{L}$.

Accumulation of MCs on solids wasted from an AS system is not a real treatment but nonetheless it is a significant phenomenon that affects the fate of MCs in biotreatment or 


\section{P a g e $\mid \mathbf{2 2 0}$}

throughout an AS process. Therefore, at the steady state and equilibrium state condition the sorption to the daily wasted sludge was calculated by Eq. (6-4):

Removal rate by sorption, $M_{\text {sor }}=\frac{C_{\text {Biosolids }} \times M L T S S \times Q_{\text {wasted }}}{C_{\text {inf }} \times Q_{\text {inf }}} \times 100 \%$

where $\mathrm{C}_{\mathrm{Biosolids}}$ is the MCs concentration in the solid phase, $\mu \mathrm{g} / \mathrm{g}$; MLTSS, $\mathrm{g} / \mathrm{L} ; \mathrm{Q}_{\text {wasted }}$ is the volume of sludge wasted per day, L/d; $Q_{\text {inf }}$ is the influent flow-rate, L/d.

Target MCs are considered thermodynamically stable and relatively non-volatile, while photodegradation was prohibited by the experimental condition used; therefore, by writing the mass balance around the reactors, the amount of MCs biotransformed / biodegraded in simulated AS was calculated by the following Eq. (6-5):

$M_{b}=\left(Q_{\text {in }} \times C_{\text {in }}\right)-\left(Q_{\text {eff }} \times C_{\text {eff }}\right)-\left(C_{\text {biosolids }} \times M L T S S \times Q_{\text {wasted }}\right)$

where $\mathrm{M}_{\mathrm{b}}$ is the mass of biotransformed MCs ( $\mu \mathrm{g} /$ day) and $\mathrm{Q}_{\text {in }}$ and $\mathrm{Q}_{\text {eff }}$ are the influent and effluent flow-rate (L/d).

Once the masses of biotransformed MCs were found, the biotransformation rates and kinetics coefficients can be calculated based on Eq. (6-6) for different systems using all possible models (detailed in Table 6-2).

$M_{b}=(r \times V)$

where $\mathrm{V}$ is the volume of the reactor $(\mathrm{L})$ and is equal to $3 \mathrm{~L}$ for all experimental runs.

Although $K_{m}$ can be calculated for some of the rate equations outlined in Table 6-2, finding the best representative $K_{m}$ that fits effectively to the different data sets found in 9 
experimental runs would require a parameter estimation technique. In addition, parameters in non-linear models such as Monod $\left(\mathrm{K}_{\mathrm{m}}, \mathrm{K}_{\mathrm{c}}\right)$ and unknown parameters of $\mathrm{K}_{\mathrm{ms}}, \mathrm{K}_{\mathrm{mp}}$ and $\mathrm{X}_{\mathrm{c}}$, which were not measured experimentally can be found using parameter estimation.

\subsubsection{Model parameter estimation and model validation}

The biological degradation rate constants $\left(\mathrm{K}_{\mathrm{m}}, \mathrm{K}_{\mathrm{ms}}, \mathrm{K}_{\mathrm{mp}}\right)$ as well as the concentration of active $\mathrm{MC}$ degraders $\left(\mathrm{X}_{\mathrm{c}}\right)$ were estimated from fitting the analytical solution of Eq. (66) to the measured data $(n=9)$ by minimizing the sum of the squares of the weighted derivatives $\chi^{2}$ (Eq. 6-7) between measurements and the calculated model results of $\mathrm{M}_{\mathrm{b}}$. AQUASIM and Excel software were used in this study for parameter estimation and model comparison.

$$
\chi^{2}=\sum_{i=1}^{n}\left(\frac{y_{\text {meas }, i}-y_{i}(p)}{\sigma_{\text {meas }}}\right)^{2}
$$

where $\sigma$ is the standard deviation of data and $\mathrm{y}_{\mathrm{i}}(\mathrm{P})$ is a function of $\mathrm{P}=\left(\mathrm{P}_{1}, \mathrm{P}_{2}, \ldots\right.$, $\mathrm{P}_{\mathrm{m}}$ ) which are model parameters.

In order to estimate parameters, all variables including constant (model parameters), real data (measured data) and state variables $\left(\mathrm{M}_{\mathrm{b}}\right)$ are defined in AQUASIM. The

minimization of the sum of chi squares is done with the constraints $P_{i, \min } \leq P_{i} \leq P_{i, \max }$. These two bounds are chosen based on the minimum and maximum value of model parameters calculated from analytical solution of Eq. (6-6) and engineering judgment. To 
P a g e $\mid \mathbf{2 2 2}$

better estimate the concentration of $\mathrm{X}_{\mathfrak{c}}$, another constraint was added to the program where $\mathrm{X}_{\mathrm{c}} \leq \mathrm{X}_{\mathrm{H}}$.

\subsection{Results and Discussion}

\subsubsection{MCs biodegradation results}

Performance of simulated AS systems was evaluated in this study. The data obtained at steady state from the nine experimental runs as well as concentration of $X_{\mathrm{H}}$ are summarized in Table 6-5. Significant removal of tCOD (average COD removal > 95\%) and SS clarification (average $\mathrm{VSS}_{\text {eff }}<3 \mathrm{mg} / \mathrm{L}$ ) was achieved in all AS systems operating at various HRTs and SRTs. However, higher removal efficiency was observed for COD and ammonia in the reactor operating at SRT of $15 \mathrm{~d}$ and the lowest removal rate was found in the reactor operating at HRT of $4 \mathrm{~h}$ and SRT of $5 \mathrm{~d}$. It was found that the mixed liquor volatile suspended solids (MLVSS) concentrations increased with increase of SRT, also higher values were found for rectors operating at higher HRTs.

To investigate the fate of the selected MCs in the AS system, the mass balance analysis was performed for each compound and total MCs mass fluxes were determined using Eqs. (6-4 and 6-5). The result of mass balance analysis (Table 6-6) showed high biodegradation or biotransformation potential of selected MCs.

The highest biotransformation removal rate was found for TCS and BPA in reactors operating at higher SRTs, whereas the lower biotransformation removal rate of 58\% was found for EE2 in the reactor operating at SRT of $5 \mathrm{~d}$ and HRT of $4 \mathrm{~h}$. 
Table 6-5 Comparison of biological performance of experimental runs

\begin{tabular}{|c|c|c|c|c|c|c|c|c|c|c|}
\hline \multicolumn{2}{|c|}{ Runs } & \multicolumn{3}{|c|}{ Phase B } & \multicolumn{3}{|c|}{ Phase C } & \multicolumn{3}{|c|}{ Phase D } \\
\hline Parameter & Unit & 1 & 2 & 3 & 4 & 5 & 6 & 7 & 8 & 9 \\
\hline$Q$ & $\mathrm{~L} / \mathrm{d}$ & $\begin{array}{l}11.22 \\
\pm 0.6\end{array}$ & $\begin{array}{l}12.52 \\
\pm 0.8\end{array}$ & $\begin{array}{c}11.5 \pm \\
1.0\end{array}$ & $\begin{array}{c}7.2 \pm \\
0.8\end{array}$ & $\begin{array}{c}7.15 \pm \\
0.4\end{array}$ & $\begin{array}{c}7.13 \pm \\
0.2\end{array}$ & $\begin{array}{c}18.6 \pm \\
0.5\end{array}$ & $\begin{array}{l}17.85 \\
\pm 1.1\end{array}$ & $\begin{array}{l}18.23 \\
\pm 0.4\end{array}$ \\
\hline HRT & $\mathrm{h}$ & 6 & 6 & 6 & 10 & 10 & 10 & 4 & 4 & 4 \\
\hline SRT & $d$ & 5 & 10 & 15 & 5 & 10 & 15 & 5 & 10 & 15 \\
\hline MLTSS & $\begin{array}{c}\mathrm{mg} / \\
\mathrm{L}\end{array}$ & $\begin{array}{r}1677 \\
\pm 137\end{array}$ & $\begin{array}{r}2935 \\
\pm 133\end{array}$ & $\begin{array}{r}4005 \\
\pm 171\end{array}$ & $\begin{array}{c}1188 \pm \\
129\end{array}$ & $\begin{array}{c}1805 \pm \\
119\end{array}$ & $\begin{array}{c}2498 \pm \\
142\end{array}$ & $\begin{array}{c}2774 \pm \\
287\end{array}$ & $\begin{array}{c}4440 \pm \\
152\end{array}$ & $\begin{array}{c}5965 \pm \\
229\end{array}$ \\
\hline MLVSS & $\begin{array}{c}\mathrm{mg} / \\
\mathrm{L}\end{array}$ & $\begin{array}{r}1563 \\
\pm 130\end{array}$ & $\begin{array}{r}2685 \\
\pm 121\end{array}$ & $\begin{array}{r}3601 \\
\pm 149\end{array}$ & $\begin{array}{c}1112 \pm \\
127\end{array}$ & $\begin{array}{c}1681 \pm \\
136\end{array}$ & $\begin{array}{c}2302 \pm \\
138\end{array}$ & $\begin{array}{c}2571 \pm \\
261\end{array}$ & $\begin{array}{c}4085 \pm \\
158\end{array}$ & $\begin{array}{c}5335 \pm \\
205\end{array}$ \\
\hline$X_{H}$ & $\begin{array}{c}\mathrm{mg} / \\
\mathrm{L}\end{array}$ & 1030 & 1502 & 1765 & 745 & 958 & 1151 & 1670 & 2290 & 2560 \\
\hline $\mathrm{X}_{\mathrm{H}} / \mathrm{MLVSS}$ & - & 0.66 & 0.56 & 0.49 & 0.67 & 0.57 & 0.5 & 0.65 & 0.56 & 0.48 \\
\hline $\mathrm{tCOD}_{\text {reactor }}$ & $\begin{array}{c}\mathrm{mg} / \\
\mathrm{L}\end{array}$ & $\begin{array}{r}1976 \\
\pm 275\end{array}$ & $\begin{array}{r}3556 \\
\pm 240\end{array}$ & $\begin{array}{r}4962 \\
\pm 419\end{array}$ & $\begin{array}{c}1398 \pm \\
164\end{array}$ & $\begin{array}{c}2093 \pm \\
247\end{array}$ & $\begin{array}{c}2920 \pm \\
158\end{array}$ & $\begin{array}{c}3322 \pm \\
300\end{array}$ & $\begin{array}{c}5347 \pm \\
256\end{array}$ & $\begin{array}{c}7007 \pm \\
481\end{array}$ \\
\hline $\mathrm{SCOD}_{\text {reactor }}$ & $\begin{array}{c}\mathrm{mg} / \\
\mathrm{L}\end{array}$ & $\begin{array}{r}41.2 \\
\pm 2.4\end{array}$ & $\begin{array}{r}38.2 \\
\pm 3.6\end{array}$ & $\begin{array}{c}33.3 \pm \\
4.1\end{array}$ & $\begin{array}{c}36.8 \pm \\
2.8\end{array}$ & $\begin{array}{c}27.4 \pm \\
2.1\end{array}$ & $\begin{array}{c}28.8 \pm \\
3.3\end{array}$ & $\begin{array}{c}52.2 \pm \\
1.9\end{array}$ & $\begin{array}{c}46.3 \pm \\
3.4\end{array}$ & $\begin{array}{c}28.1 \pm \\
4.8\end{array}$ \\
\hline$C O D_{\text {eff }}$ & $\begin{array}{c}\mathrm{mg} / \\
\mathrm{L}\end{array}$ & $\begin{array}{r}37.7 \\
\pm 3.4\end{array}$ & $\begin{array}{c}35.6 \\
\pm 4\end{array}$ & $\begin{array}{c}25.9 \pm \\
3.5\end{array}$ & $\begin{array}{c}34.8 \pm \\
3.3\end{array}$ & $\begin{array}{c}24.3 \pm \\
1.7\end{array}$ & $\begin{array}{c}23.5 \pm \\
2.4\end{array}$ & $\begin{array}{c}46.1 \pm \\
6.7\end{array}$ & $\begin{array}{c}40 \pm \\
6.9\end{array}$ & $\begin{array}{c}24.8 \pm \\
5.6\end{array}$ \\
\hline $\mathrm{VSS}_{\text {eff }}$ & $\begin{array}{c}\mathrm{mg} / \\
\mathrm{L}\end{array}$ & $\begin{array}{c}2.8 \pm \\
1.3\end{array}$ & $\begin{array}{c}2.7 \pm \\
1\end{array}$ & $\begin{array}{l}3 \pm \\
1.1\end{array}$ & $2.8 \pm 1$ & $\begin{array}{c}3.2 \pm \\
0.7\end{array}$ & $\begin{array}{c}3.1 \pm \\
1.5\end{array}$ & $2.8 \pm 1$ & $\begin{array}{c}3.2 \pm \\
0.7\end{array}$ & $\begin{array}{c}3.1 \pm \\
1.5\end{array}$ \\
\hline$T N-N_{\text {eff }}$ & $\begin{array}{c}\mathrm{mg} / \\
\mathrm{L}\end{array}$ & $\begin{array}{r}36.7 \\
\pm 1.1\end{array}$ & $\begin{array}{r}36.8 \\
\pm 3.1\end{array}$ & $\begin{array}{c}35.6 \pm \\
2.5\end{array}$ & $\begin{array}{c}35.8 \pm \\
2.9\end{array}$ & $\begin{array}{c}35.4 \pm \\
1.5\end{array}$ & $\begin{array}{c}36.3 \pm \\
2.1\end{array}$ & $\begin{array}{c}36.4 \pm \\
0.57\end{array}$ & $\begin{array}{c}36.5 \pm \\
1.36\end{array}$ & $\begin{array}{c}36.3 \pm \\
0.33\end{array}$ \\
\hline TKN-N eff & $\begin{array}{c}\mathrm{mg} / \\
\mathrm{L}\end{array}$ & $\begin{array}{c}5.2 \pm \\
0.8\end{array}$ & $\begin{array}{c}4.6 \pm \\
0.3\end{array}$ & $\begin{array}{c}5.4 \pm \\
0.4\end{array}$ & $\begin{array}{l}7.6 \pm \\
1.59\end{array}$ & $\begin{array}{l}6.4 \pm \\
0.29\end{array}$ & $\begin{array}{c}3.16 \pm \\
1.8\end{array}$ & $\begin{array}{c}6.38 \pm \\
0.86\end{array}$ & $\begin{array}{c}7.37 \pm \\
0.6\end{array}$ & $\begin{array}{c}2.94 \pm \\
0.5\end{array}$ \\
\hline $\mathrm{NH} 4-\mathrm{N}$ eff & $\begin{array}{c}\mathrm{mg} / \\
\mathrm{L}\end{array}$ & $\begin{array}{r}0.64 \\
\pm 0.1\end{array}$ & $\begin{array}{r}0.43 \\
\pm 0.1\end{array}$ & $\begin{array}{c}0.01 \pm \\
0.01\end{array}$ & $\begin{array}{c}3.27 \pm \\
0.84\end{array}$ & $\begin{array}{c}0.62 \pm \\
0.31\end{array}$ & $\begin{array}{c}0.14 \pm \\
0.08\end{array}$ & $\begin{array}{c}0.17 \pm \\
0.13\end{array}$ & $\begin{array}{c}0.83 \pm \\
0.55\end{array}$ & $\begin{array}{c}0.28 \pm \\
0.16\end{array}$ \\
\hline $\mathrm{NO}_{3}-\mathrm{N}_{\text {eff }}$ & $\begin{array}{c}\mathrm{mg} / \\
\mathrm{L}\end{array}$ & $\begin{array}{c}30.6 \\
\pm 3\end{array}$ & $\begin{array}{r}31.7 \\
\pm 4.4\end{array}$ & $\begin{array}{c}29.4 \pm \\
3.3\end{array}$ & $\begin{array}{c}29.8 \pm \\
2.26\end{array}$ & $\begin{array}{l}30.56 \\
\pm 2.6\end{array}$ & $\begin{array}{r}33.18 \\
\pm 1.89\end{array}$ & $\begin{array}{r}30.04 \\
\pm 0.91\end{array}$ & $\begin{array}{r}29.15 \\
\pm 1.69\end{array}$ & $\begin{array}{r}33.46 \\
\pm 0.63\end{array}$ \\
\hline $\mathrm{pH}_{\text {reactor }}$ & - & $\begin{array}{r}7.21 \\
\pm 0.3\end{array}$ & $\begin{array}{c}6.92 \\
\pm 0.4\end{array}$ & $\begin{array}{c}7.02 \pm \\
0.2\end{array}$ & $\begin{array}{c}7.52 \pm \\
0.44\end{array}$ & $\begin{array}{c}6.88 \pm \\
0.21\end{array}$ & $\begin{array}{c}6.9 \pm \\
0.3\end{array}$ & $\begin{array}{c}7.33 \pm \\
0.2\end{array}$ & $\begin{array}{c}7.14 \pm \\
0.15\end{array}$ & $\begin{array}{c}7.29 \pm \\
0.31\end{array}$ \\
\hline Temp $_{\text {reactor }}$ & ${ }^{\circ} \mathrm{C}$ & $\begin{array}{c}25 \pm \\
0.3\end{array}$ & $\begin{array}{c}25 \pm \\
0.7\end{array}$ & $\begin{array}{c}25 \pm \\
0.6\end{array}$ & $\begin{array}{c}25 \pm \\
0.4\end{array}$ & $\begin{array}{c}25 \pm \\
0.1\end{array}$ & $\begin{array}{c}25 \pm \\
0.6\end{array}$ & $\begin{array}{c}25 \pm \\
0.2\end{array}$ & $\begin{array}{c}25 \pm \\
0.5\end{array}$ & $\begin{array}{c}25 \pm \\
0.8\end{array}$ \\
\hline
\end{tabular}

The mass flux observations in excess sludge showed that the removal of selected MCs due to the sludge disposal was minimal in all experimental runs. Similar results 
were observed in previous studies for BPA and TCS (Stasinakis et al., 2010; Zhao et al., 2008) and for EE2 (Joss et al., 2004a; Li et al., 2011; Muller et al., 2008; Zeng et al., 2013). In contrast, some researchers found higher removal of TCS in full-scale AS systems due to sorption on the SS (Heidler and Halden, 2007; Nakada et al., 2010).

Table 6-6 Mass balances (\%) of the target MCs in continuous-flow AS systems

\begin{tabular}{|c|c|c|c|c|c|c|c|c|c|}
\hline \multirow[b]{2}{*}{$\mathrm{HRT}=6 \mathrm{~h}$} & \multicolumn{3}{|c|}{ BPA } & \multicolumn{3}{|c|}{ EE2 } & \multicolumn{3}{|c|}{ TCS } \\
\hline & $\begin{array}{l}M_{b} \\
(\%)\end{array}$ & $\begin{array}{l}M_{\text {sor }} \\
(\%)\end{array}$ & $\begin{array}{l}M_{\text {eff }} \\
(\%)\end{array}$ & $\begin{array}{l}M_{b} \\
(\%)\end{array}$ & $\begin{array}{l}\mathrm{M}_{\text {sor }} \\
(\%)\end{array}$ & $\begin{array}{l}M_{\text {eff }} \\
(\%)\end{array}$ & $\begin{array}{l}M_{b} \\
(\%)\end{array}$ & $\begin{array}{l}\mathrm{M}_{\text {sor }} \\
(\%)\end{array}$ & $\begin{array}{l}M_{\text {eff }} \\
(\%)\end{array}$ \\
\hline $\begin{array}{l}\text { Reactor } 1 \text { (SRT= } \\
15 \text { days) }(n=27)\end{array}$ & $\begin{array}{l}98 \pm \\
0.6\end{array}$ & $\begin{array}{c}0.1 \pm \\
0.0\end{array}$ & $\begin{array}{l}2 \pm \\
0.6\end{array}$ & $\begin{array}{c}85 \\
\pm \\
2.1\end{array}$ & $\begin{array}{c}0.8 \pm \\
0.2\end{array}$ & $\begin{array}{c}14 \pm \\
2\end{array}$ & $\begin{array}{c}98 \pm \\
0.4\end{array}$ & $\begin{array}{c}0.2 \pm \\
0.0\end{array}$ & $\begin{array}{l}2 \pm \\
0.3\end{array}$ \\
\hline $\begin{array}{l}\text { Reactor } 2 \text { (SRT= } \\
10 \text { days) }(n=27)\end{array}$ & $\begin{array}{c}97 \pm \\
1.1\end{array}$ & $\begin{array}{c}0.1 \pm \\
0.0\end{array}$ & $3 \pm 1$ & $\begin{array}{c}87 \\
\pm \\
2.9 \\
\end{array}$ & $\begin{array}{c}1 \pm \\
0.0 .3\end{array}$ & $\begin{array}{c}12 \pm \\
2.7\end{array}$ & $\begin{array}{l}98 \pm \\
30.4\end{array}$ & $\begin{array}{c}0.3 \pm \\
0.0\end{array}$ & $\begin{array}{l}2 \pm \\
0.4\end{array}$ \\
\hline $\begin{array}{l}\text { Reactor } 3 \text { (SRT= } \\
5 \text { days) }(n=27)\end{array}$ & $\begin{array}{c}95 \pm \\
1.6\end{array}$ & $\begin{array}{c}0.1 \pm \\
0.1\end{array}$ & $\begin{array}{l}5 \pm \\
1.6\end{array}$ & $\begin{array}{c}68 \\
\pm \\
5.1 \\
\end{array}$ & $\begin{array}{c}2.9 \pm \\
0.4\end{array}$ & $\begin{array}{c}29 \pm \\
4.8\end{array}$ & $\begin{array}{c}97 \pm \\
0.4\end{array}$ & $\begin{array}{c}0.4 \pm \\
0.1\end{array}$ & $\begin{array}{l}2 \pm \\
0.3\end{array}$ \\
\hline \multicolumn{10}{|l|}{$\mathrm{HRT}=10 \mathrm{~h}$} \\
\hline $\begin{array}{l}\text { Reactor } 1 \text { (SRT= } \\
15 \text { days) }(n=27)\end{array}$ & $\begin{array}{c}98 \pm \\
0.3\end{array}$ & $\begin{array}{r}0.03 \\
\pm 0.0\end{array}$ & $\begin{array}{l}2 \pm \\
0.3\end{array}$ & $\begin{array}{c}91 \\
\pm \\
1.3 \\
\end{array}$ & $\begin{array}{c}0.5 \pm \\
0.1\end{array}$ & $\begin{array}{l}9 \pm \\
1.3\end{array}$ & $\begin{array}{c}98 \pm \\
0.3\end{array}$ & $\begin{array}{c}0.2 \pm \\
0.0\end{array}$ & $\begin{array}{l}2 \pm \\
0.3\end{array}$ \\
\hline $\begin{array}{l}\text { Reactor } 2 \text { (SRT= } \\
10 \text { days) }(n=27)\end{array}$ & $\begin{array}{c}96 \pm \\
0.9\end{array}$ & $\begin{array}{c}0.1 \pm \\
0.0\end{array}$ & $\begin{array}{l}4 \pm \\
0.9\end{array}$ & $\begin{array}{c}83 \\
\pm \\
3.3 \\
\end{array}$ & $\begin{array}{c}1.5 \pm \\
0.3\end{array}$ & $\begin{array}{c}15 \pm \\
3\end{array}$ & $\begin{array}{c}97 \pm \\
0.5\end{array}$ & $\begin{array}{c}0.4 \pm \\
0.1\end{array}$ & $\begin{array}{l}2 \pm \\
0.4\end{array}$ \\
\hline $\begin{array}{l}\text { Reactor } 3 \text { (SRT= } \\
5 \text { days) }(n=27)\end{array}$ & $\begin{array}{c}98 \pm \\
0.9\end{array}$ & $\begin{array}{c}0.1 \pm \\
0.0\end{array}$ & $\begin{array}{l}2 \pm \\
0.9\end{array}$ & $\begin{array}{c}62 \\
\pm \\
4.8 \\
\end{array}$ & $\begin{array}{c}3.7 \pm \\
0.3\end{array}$ & $\begin{array}{c}34 \pm \\
5\end{array}$ & $\begin{array}{c}97 \pm \\
0.8\end{array}$ & $\begin{array}{c}0.6 \pm \\
0.2\end{array}$ & $\begin{array}{l}2 \pm \\
0.7\end{array}$ \\
\hline \multicolumn{10}{|l|}{$\mathrm{HRT}=4 \mathrm{~h}$} \\
\hline $\begin{array}{l}\text { Reactor } 1 \text { (SRT= } \\
15 \text { days) }(n=27)\end{array}$ & $\begin{array}{c}97 \pm \\
1.2\end{array}$ & $\begin{array}{c}0.1 \pm \\
0.0\end{array}$ & $\begin{array}{l}3 \pm \\
1.1\end{array}$ & $\begin{array}{c}69 \\
\pm \\
3.5 \\
\end{array}$ & $\begin{array}{c}1.6 \pm \\
0.2\end{array}$ & $\begin{array}{c}29 \pm \\
3.4\end{array}$ & $\begin{array}{c}98 \pm \\
0.4\end{array}$ & $\begin{array}{c}0.2 \pm \\
0.0\end{array}$ & $\begin{array}{l}2 \pm \\
0.4\end{array}$ \\
\hline $\begin{array}{l}\text { Reactor } 2 \text { (SRT= } \\
10 \text { days) }(n=27)\end{array}$ & $\begin{array}{c}90 \pm \\
2.2\end{array}$ & $\begin{array}{c}0.3 \pm \\
0.1\end{array}$ & $\begin{array}{l}9 \pm \\
2.1\end{array}$ & $\begin{array}{c}72 \\
\pm \\
4.6 \\
\end{array}$ & $\begin{array}{c}2.5 \pm \\
0.4\end{array}$ & $\begin{array}{c}26 \pm \\
4.3\end{array}$ & $\begin{array}{c}97 \pm \\
0.8\end{array}$ & $\begin{array}{c}0.5 \pm \\
0.1\end{array}$ & $\begin{array}{l}3 \pm \\
0.7\end{array}$ \\
\hline $\begin{array}{l}\text { Reactor } 3 \text { (SRT= } \\
5 \text { days) }(n=27)\end{array}$ & $\begin{array}{c}91 \pm \\
2.3\end{array}$ & $\begin{array}{c}0.2 \pm \\
0.1\end{array}$ & $\begin{array}{l}9 \pm \\
2.2\end{array}$ & $\begin{array}{c}58 \\
\pm \\
3.7 \\
\end{array}$ & $\begin{array}{c}3.8 \pm \\
0.6\end{array}$ & $\begin{array}{c}38 \pm \\
3.4\end{array}$ & $\begin{array}{c}97 \pm \\
0.4\end{array}$ & $\begin{array}{l}0.5 \pm \\
0.10\end{array}$ & $\begin{array}{l}2 \pm \\
0.3\end{array}$ \\
\hline
\end{tabular}




\section{P a g e $\mid \mathbf{2 2 5}$}

The mass of MCs biotransformed from bioreactors were normalized for one gram of MLVSS in the reactor (Figure 6-1) and it was found that biomass in reactors operating at different SRTs and HRTs had different performances with regards to MCs degradation and the SRT did not exhibit a straightforward trend for removal of an MC. This result is in agreement with other studies in the literature (Majewsky et al., 2011; Stasinakis et al., 2010) and could be explained by the fact that only a fraction of SS can be considered as active biomass. Moreover, not all the active biomass can degrade MCs in AS systems, so it is reasonable to assume specific microorganisms are responsible for degradation of MCs.

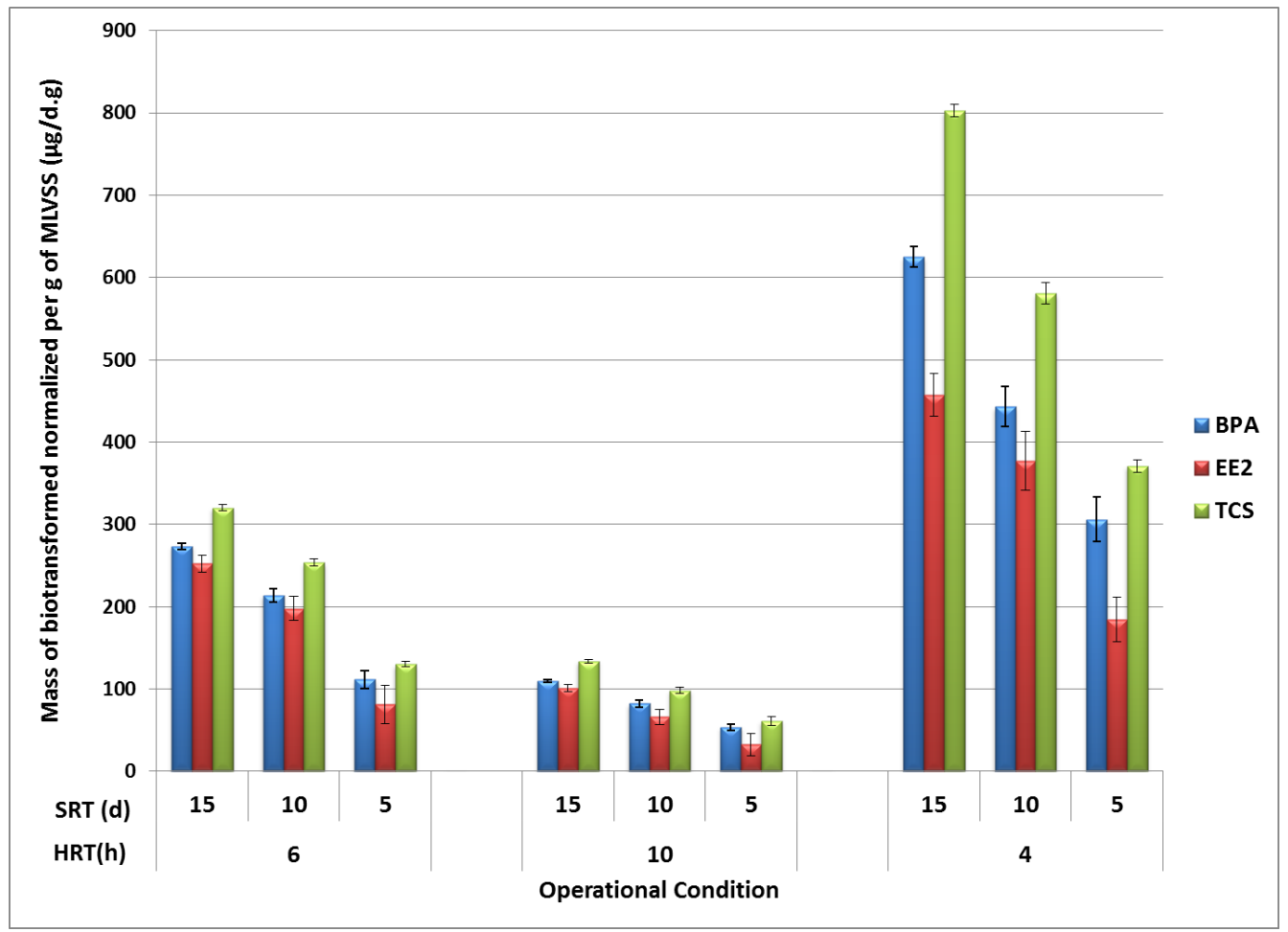

Figure 6-1. Effect of operational conditions on biomass degradation performance normalized to VSS 
P a g e $\mid \mathbf{2 2 6}$

\subsubsection{Parameter estimation results}

Table 6-7 shows the estimated parameters $\left(\mathrm{K}_{\mathrm{m}}, \mathrm{K}_{\mathrm{c}}, \mathrm{K}_{\mathrm{ms}}, \mathrm{K}_{\mathrm{mp}}\right)$ for each experimental run. The amount of Xc for reactors operating at different SRTs and HRTs were also calculated by optimizing the analytical solution to Eq. 6-6 and minimizing the sum of $\chi^{2}$ in parameter estimation procedures.

Table 6-7 Estimation of biodegradation kinetics for each model and the sum of chi squares

\begin{tabular}{|c|c|c|c|c|c|c|c|c|c|c|c|c|c|c|c|}
\hline \multirow{3}{*}{$\begin{array}{c}\text { Model } \\
\text { No. }\end{array}$} & \multicolumn{15}{|c|}{ Estimated Parameters } \\
\hline & \multicolumn{5}{|c|}{$\mathrm{BPA}$} & \multicolumn{5}{|c|}{ EE2 } & \multicolumn{5}{|c|}{ TCS } \\
\hline & $\mathrm{K}_{\mathrm{m}}$ & $\mathrm{K}_{\mathrm{ms}}$ & $\mathrm{K}_{\mathrm{mp}}$ & $\mathrm{K}_{\mathrm{c}}$ & $\Sigma \chi^{2}$ & $\mathrm{~K}_{\mathrm{m}}$ & $\mathrm{K}_{\mathrm{ms}}$ & $\mathrm{K}_{\mathrm{mp}}$ & $\mathrm{K}_{\mathrm{c}}$ & $\Sigma \chi^{2}$ & $\mathrm{~K}_{\mathrm{m}}$ & $\mathrm{K}_{\mathrm{ms}}$ & $\mathrm{K}_{\mathrm{mp}}$ & $\mathrm{K}_{\mathrm{c}}$ & $\Sigma \chi^{2}$ \\
\hline 1 & 79.6 & & & & 42.4 & 62.0 & & & & 45.7 & 97.2 & & & & 37.0 \\
\hline 2 & 72.3 & & & & 14.5 & 11.5 & & & & 18.6 & 184.6 & & & & 7.4 \\
\hline $3 a$ & 31.4 & & & & 18.6 & 2.9 & & & & 11.4 & 25.6 & & & & 3.8 \\
\hline $3 b$ & 48.0 & & & & 12.9 & 4.4 & & & & 16.4 & 46.8 & & & & 2.4 \\
\hline $3 \mathrm{c}$ & 61.1 & & & & 10.1 & 7.6 & & & & 7.8 & 57.0 & & & & 1.8 \\
\hline $4 \mathrm{a}$ & & 72.3 & 0.0 & & 14.5 & & 3.8 & 2.6 & & 11.3 & & 79.7 & 17.8 & & 2.7 \\
\hline $4 \mathrm{~b}$ & & 35.2 & 74.2 & & 12.3 & & 2.7 & 5.5 & & 16.3 & & 50.0 & 46.1 & & 2.5 \\
\hline $5 \mathrm{a}$ & 21.6 & & & & 19.2 & 3.8 & & & & 14.5 & 61.4 & & & & 4.0 \\
\hline $5 b$ & 50.4 & & & & 10.8 & 7.2 & & & & 18.5 & 126.3 & & & & 2.7 \\
\hline $5 \mathrm{c}$ & 121.7 & & & & 0.0 & 21.1 & & & & 0.0 & 172.9 & & & & 0.0 \\
\hline $6 a$ & 7.9 & & & & 28.0 & 0.7 & & & & 23.7 & 6.1 & & & & 14.0 \\
\hline $6 \mathrm{~b}$ & 22.3 & & & & 12.4 & 1.5 & & & & 21.3 & 14.5 & & & & 7.7 \\
\hline $6 \mathrm{c}$ & 51.7 & & & & 4.4 & 4.3 & & & & 6.1 & 19.3 & & & & 6.2 \\
\hline $7 \mathrm{a}$ & & 40.2 & 0.0 & & 67.1 & & 3.8 & 0.0 & & 14.5 & & 61.4 & 0.0 & & 4.0 \\
\hline $7 b$ & & 42.5 & 6.7 & & 10.5 & & 5.9 & 0.4 & & 18.2 & & 114.9 & 1.6 & & 2.6 \\
\hline $7 \mathrm{c}$ & & 121.7 & 0.0 & & 0.0 & & 21.0 & 0.0 & & 0.0 & & 172.8 & 0.0 & & 0.0 \\
\hline 8 & 32.7 & & & & 9.5 & 2.5 & & & & 22.7 & 26.9 & & & & 5.8 \\
\hline 9 & & 17.6 & 59.5 & & 9.2 & & 7.2 & 0.0 & & 18.5 & & 126.3 & 0.0 & & 2.7 \\
\hline 10 & 136.8 & & & 0.5 & 5.3 & 71.9 & & & 0.6 & 8.6 & 200.0 & & & 1147 & 72.0 \\
\hline $11 \mathrm{a}$ & 38.4 & & & 0.3 & 4.6 & 20.9 & & & 0.0 & 4.4 & 179.8 & & & 2.4 & 4.0 \\
\hline $11 \mathrm{~b}$ & 53.6 & & & 0.3 & 5.0 & 41.5 & & & 0.3 & 5.9 & 65.9 & & & 0.3 & 4.8 \\
\hline $11 \mathrm{c}$ & 130.0 & & & 0.5 & 11.6 & 71.9 & & & 0.5 & 15.5 & 179.8 & & & 0.5 & 0.4 \\
\hline
\end{tabular}




\section{P a g e | 227}

The concentrations of $X_{c}$ in reactors operating at different HRT and SRT were compared to the concentration of active biomass found experimentally in this study (Table 6-8).

The result of $\mathrm{X}_{\mathrm{C}}$ estimation showed that SRT plays an important role in formation of the biomass capable of degrading selected MCs. It is also observed that the MCs degraders are naturally present in the AS system even at low SRTs; however, the concentration of $\mathrm{X}_{\mathrm{c}}$ is much lower at SRT of $5 \mathrm{~d}$ compared to SRT of $15 \mathrm{~d}$. The simplest explanation is growth of slow growing biomass and diversified enzymes which might not be present as much in reactors operating at lower SRTs.

Similar results were reported in the literature that links higher SRTs to growth of specific MCs degraders (Lindblom et al., 2009; Majewsky et al., 2011; Melcer and Klecka, 2011). In contrast, Helbling et al. (2012) reviewed the MCs biotransformation kinetic and microbial communities in different WWTPs and indicated that neither biomass concentrations nor sludge age alone can explain the variability in biotransformation of a diverse set of MCs in WWTPs. However in those reviewed studies biomass concentrations were mostly estimated by VSS concentration and $\mathrm{X}_{\mathrm{C}}$ were not identified. 


\section{P a g e $\mid \mathbf{2 2 8}$}

Table 6-8 Estimation of active MCs degraders $\left(\mathrm{X}_{\mathrm{C}}\right)$ and comparison with active biomass $\left(\mathrm{X}_{\mathrm{H}}\right)$

\begin{tabular}{|c|c|c|c|c|c|c|c|c|c|c|}
\hline \multicolumn{2}{|c|}{ Runs } & \multicolumn{3}{|c|}{ Phase B } & \multicolumn{3}{|c|}{ Phase C } & \multicolumn{3}{|c|}{ Phase D } \\
\hline Parameter & Unit & 1 & 2 & 3 & 4 & 5 & 6 & 7 & 8 & 9 \\
\hline HRT & $\mathrm{h}$ & 6 & 6 & 6 & 10 & 10 & 10 & 4 & 4 & 4 \\
\hline SRT & $d$ & 5 & 10 & 15 & 5 & 10 & 15 & 5 & 10 & 15 \\
\hline MLVSS & $\begin{array}{c}\mathrm{mg} / \\
\mathrm{L}\end{array}$ & 1563 & 2685 & 3601 & 1112 & 1681 & 2302 & 2571 & 4085 & 5335 \\
\hline$X_{H}$ & $\begin{array}{c}\mathrm{mg} / \\
\mathrm{L}\end{array}$ & 1030 & 1502 & 1765 & 745 & 958 & 1151 & 1670 & 2290 & 2560 \\
\hline $\mathrm{X}_{\mathrm{H}} / \mathrm{MLVSS}$ & - & 0.66 & 0.56 & 0.49 & 0.67 & 0.57 & 0.5 & 0.65 & 0.56 & 0.48 \\
\hline$X_{c}, B P A$ & $\begin{array}{c}\mathrm{mg} / \\
\mathrm{L}\end{array}$ & 599 & 1039 & 1417 & 901 & 536 & 1151 & 512 & 462 & 1689 \\
\hline$X_{c} / X_{v}$, BPA & - & 0.38 & 0.39 & 0.39 & 0.81 & 0.32 & 0.50 & 0.20 & 0.11 & 0.32 \\
\hline$X_{c}, E E 2$ & $\begin{array}{c}\mathrm{mg} / \\
\mathrm{L}\end{array}$ & 417 & 1495 & 1108 & 209 & 629 & 1147 & 451 & 781 & 682 \\
\hline$X_{c} / X_{v}$, EE2 & - & 0.27 & 0.56 & 0.31 & 0.19 & 0.37 & 0.50 & 0.18 & 0.19 & 0.13 \\
\hline$x_{C}$, TCS & $\begin{array}{c}\mathrm{mg} / \\
\mathrm{L}\end{array}$ & 861 & 1162 & 1255 & 550 & 603 & 840 & 1439 & 1285 & 1582 \\
\hline$X_{c} / X_{v}$, TCS & - & 0.35 & 0.43 & 0.55 & 0.49 & 0.36 & 0.36 & 0.56 & 0.31 & 0.30 \\
\hline
\end{tabular}

The highest $X_{C}$ to $X_{V}$ ratio for TCS was found for reactors operating at SRT of $5 \mathrm{~d}$ and HRT of $4 \mathrm{~h}$ as well as SRT of $15 \mathrm{~d}$ and HRT of $6 \mathrm{~h}$. However mixed results were observed for BPA and EE2 operating at different HRTs. The higher concentration of $\mathrm{X}_{\mathrm{C}}$ as well as higher $\mathrm{X}_{\mathrm{C}}$ to $\mathrm{X}_{\mathrm{V}}$ ratio at higher $\mathrm{SRT}$ might suggest that some non MCs degraders in lower SRTs might have acquired the capability to degrade MCs due to acclimation process. This is also suggested by other authors studying the acclimation of biomass to MCs (Chong and Lin, 2007; Rezouga et al., 2009).

The variability of $\mathrm{K}_{\mathrm{m}}$ was found in this study (Table 6-7) for targeted MCs except for models that incorporate $\mathrm{X}_{\mathrm{C}}$ into their degradation kinetic calculation which would 


\section{P a g e | 229}

suggest that even though the operational conditions such as SRT and HRT can play an important role in MCs degradation in AS systems, but the use of traditional parameters such as VSS, TSS and more advanced parameter (e.g., $\mathrm{X}_{\mathrm{H}}$ ) could not explain how different AS communities can have very different MCs biotransformation capabilities even in terms of specific biotransformation reaction at the individual MC level. These variations in $\mathrm{K}_{\mathrm{m}}$ values were also found by other studies in the literature and authors were mostly unable to explain the reason behind their findings except linking it to the type and characteristic of the biomass in different AS systems (Helbling et al., 2012; Majewsky et al., 2011; Stasinakis et al., 2010; Ziels et al., 2014). However, by evaluating their models it was found that they have mostly used first-order and pseudo second-order kinetic models with respect to VSS in their models and did not incorporate $\mathrm{X}_{\mathrm{C}}$ which in this study has been found to be an important parameter to estimate the fate of MCs in AS systems. It should be noted that the concentration of $\mathrm{X}_{\mathrm{C}}$ was estimated mathematically in this study and further experimental studies are needed to better understand the role of specific microorganism in degradation of MCs in AS systems by using fluorescent in situ hybridization (FISH) with group-specific rRNA-targeted probes as described in the literature (Thayanukul et al., 2010; Zang et al., 2008). 


\subsubsection{Evaluation of biodegradation kinetic models}

Once the $K_{m}$ was estimated the least squares linear model was used to find the goodness of fit of the estimated $\mathrm{M}_{\mathrm{b}}$ from each model to the measured data observed in this study. The results of coefficient of determination $\mathrm{r}^{2}$ are presented in Table 6-9.

Table 6-9 Evaluation of biodegradation kinetics models based on linear least squares method

\begin{tabular}{|c|c|c|c|}
\hline \multirow{2}{*}{$\begin{array}{c}\text { Model } \\
\text { No. }\end{array}$} & \multicolumn{3}{|c|}{ Coefficient of Determination, $\mathrm{r}^{2}$} \\
\cline { 2 - 4 } & BPA & EE2 & TCS \\
\hline 1 & 0.0 & 0 & 0 \\
\hline 2 & 0.4 & 0 & 0 \\
\hline $3 \mathrm{a}$ & 0.4 & 0.49 & 0.72 \\
\hline $3 \mathrm{~b}$ & 0.5 & 0.1 & 0.52 \\
\hline 3c & 0.51 & 0.1 & 0.75 \\
\hline 4a & 0.42 & 0.46 & 0.64 \\
\hline $4 \mathrm{~b}$ & 0.53 & 0.14 & 0.49 \\
\hline $5 \mathrm{a}$ & 0.48 & 0.51 & 0.73 \\
\hline $5 \mathrm{~b}$ & 0.61 & 0.24 & 0.67 \\
\hline $5 \mathrm{c}$ & 0.99 & 0.99 & 0.99 \\
\hline $6 \mathrm{a}$ & 0.38 & 0.46 & 0.55 \\
\hline $6 \mathrm{~b}$ & 0.62 & 0.42 & 0.67 \\
\hline $6 \mathrm{c}$ & 0.77 & 0.76 & 0.74 \\
\hline $7 \mathrm{a}$ & 0.48 & 0.51 & 0.73 \\
\hline $7 \mathrm{~b}$ & 0.64 & 0.31 & 0.72 \\
\hline $7 \mathrm{c}$ & 0.99 & 0.99 & 0.99 \\
\hline 8 & 0.67 & 0.3 & 0.67 \\
\hline 9 & 0.69 & 0.24 & 0.67 \\
\hline 10 & 0 & 0 & 0 \\
\hline $11 \mathrm{a}$ & 0.73 & 0.73 & 0.73 \\
\hline $11 \mathrm{~b}$ & 0.39 & 0.34 & 0.31 \\
\hline $11 \mathrm{c}$ & 0 & 0.11 & 0.95 \\
\hline
\end{tabular}




\section{P a g e $\mid \mathbf{2 3 1}$}

The evaluation of biodegradation kinetic models showed that pseudo second-order model with degradation by active MCs degraders only in the soluble phase (model 5c) and soluble and solid phases (7c) fit the experimental data efficiently. However, the estimated value of $\mathrm{K}_{\mathrm{mp}}$ in model $7 \mathrm{c}$ (close to zero) results in the same model as in 5c (Table 6-9). To investigate the possible degradation of sorbed MCs by model 7c, more constraints were applied into the estimation process and it was found that a value of $\mathrm{K}_{\mathrm{mp}}$ less than 10 would still result in a very good coefficients of determination for BPA but not for TCS and EE2 (data not shown). Model 11a also showed a good agreement with the experimental results $\left(r^{2}=73 \%\right)$, however the $K_{c}$ values found in this model for selected MCs were very small (0-2.4 $\mu \mathrm{g} / \mathrm{L})$. Other model that showed promising application was model 6c, which assumes degradation in both solid and liquid phases with the same kinetic rate. By comparing models 5a, b with $6 a$, b, it was found that assuming possible degradation in both solid and liquid phases would not necessarily increase the goodness of fit in those models.

\subsection{Conclusions}

The operation of continuous-flow AS systems in the presence of $20 \mu \mathrm{g} / \mathrm{L}$ of MCs indicated that 90-98, 63-91 and 97-98\% of BPA, EE2 and TCS, respectively, can be removed during the AS process in systems operating at SRT of 5-15 d and HRT of 4-10 h. Determination of MCs in the dissolved and particulate phase and calculation of their mass flux showed that biotransformation was the principal removal mechanism of 
P a g e $\mid \mathbf{2 3 2}$

selected MCs. Evaluation of various biodegradation kinetic models showed poor agreement between measured data and modeled values except for the pseudo-secondorder model with degradation by active MCs degraders only in soluble phase. The result of this study could be seen in the context, where the active MCs degraders are proposed to reduce the variability of $\mathrm{K}_{\mathrm{m}}$ in $\mathrm{AS}$ systems operating at different operational conditions. This study also explains why other researchers using $X_{v}, X_{T}$, and $X_{H}$ in their models (Majewsky et al., 2011; Stasinakis et al., 2010; Ziels et al., 2014) found different biodegradation kinetics for the same compound in various AS systems.

\subsection{References}

Abegglen C, Joss A, McArdell CS, Fink G, Schlusener MP, Ternes TA, et al. The fate of selected micropollutants in a single-house MBR. Water Res 2009; 43: 2036-46.

Atkinson SK, Marlatt VL, Kimpe LE, Lean DR, Trudeau VL, Blais JM. The occurrence of steroidal estrogens in south-eastern Ontario wastewater treatment plants. Sci Total Environ 2012; 430: 119-25.

Banihashemi B, Droste RL. Evaluation of Biodegradation Kinetics Models for Microconstituents Under Typical Sewage Treatment Conditions. Water Environment Federation 2011: 5049-5061.

Banihashemi B, Droste RL. Trace level determination of bisphenol-A in wastewater and sewage sludge by high-performance liquid chromatography and UV detection. Water Quality Research Journal of Canada 2013; 48: 133-144.

Banihashemi B, Droste RL. Sorption-desorption and biosorption of bisphenol A, triclosan, and 17alpha-ethinylestradiol to sewage sludge. Sci Total Environ 2014; 487: 813-21.

Barret M, Patureau D, Latrille E, Carrere H. A three-compartment model for micropollutants sorption in sludge: methodological approach and insights. Water Res 2010; 44: 616-24.

Bennie DT, Struger, J.S. Pharmaceuticals and personal care products (PPCP) in Canadian urban waters: Research and policy directions. Environment Canada, 2008. 
Borrirukwisitsak S, Keenan HE, Gauchotte-Lindsay C. Effects of salinity, pH and temperature on the octanol-water partition coefficient of bisphenol A. International Journal of Environmental Science and Development 2012; 3(5): 460-464.

Byrns G. The fate of xenobiotic organic compounds in wastewater treatment plants. Water Res 2001; 35: 2523-33.

Carballa M, Omil F, Lema JM. Calculation methods to perform mass balances of micropollutants in sewage treatment plants. application to pharmaceutical and personal care products (PPCPs). Environ Sci Technol 2007; 41: 884-90.

Chong NM, Lin TY. Measurement of the degradation capacity of activated sludge for a xenobiotic organic. Bioresour Technol 2007; 98: 1124-7.

Clara M, Kreuzinger N, Strenn B, Gans O, Kroiss H. The solids retention time-a suitable design parameter to evaluate the capacity of wastewater treatment plants to remove micropollutants. Water Res 2005; 39: 97-106.

Cowan CE, Larson RJ, Feijtel TCJ, Rapaport RA. An improved model for predicting the fate of consumer product chemicals in wastewater treatment plants. Water Research 1993; 27: 561-573.

Deblonde T, Cossu-Leguille C, Hartemann P. Emerging pollutants in wastewater: a review of the literature. Int J Hyg Environ Health 2011; 214: 442-8.

Feng Y, Zhang Z, Gao P, Su H, Yu Y, Ren N. Adsorption behavior of EE2 (17 alphaethinylestradiol) onto the inactivated sewage sludge: kinetics, thermodynamics and influence factors. J Hazard Mater 2010; 175: 970-6.

Fernandez-Fontaina E, Pinho I, Carballa M, Omil F, Lema JM. Biodegradation kinetic constants and sorption coefficients of micropollutants in membrane bioreactors. Biodegradation 2013; 24: 165-77.

Fernandez MP, Ikonomou MG, Buchanan I. An assessment of estrogenic organic contaminants in Canadian wastewaters. Sci Total Environ 2007; 373: 250-69.

Govind R, Lai L, Dobbs R. Integrated model for predicting the fate of organics in wastewater treatment plants. Environmental Progress 1991; 10: 13-23.

Heberer T. Tracking persistent pharmaceutical residues from municipal sewage to drinking water. Journal of Hydrology 2002; 266: 175-189.

Heidler J, Halden RU. Mass balance assessment of triclosan removal during conventional sewage treatment. Chemosphere 2007; 66: 362-9.

Helbling DE, Johnson DR, Honti M, Fenner K. Micropollutant biotransformation kinetics associate with WWTP process parameters and microbial community characteristics. Environ Sci Technol 2012; 46: 10579-88.

Jacobsen BN, Arvin E. Biodegradation kinetics and fate modelling of pentachlorophenol in bioaugmented activated sludge reactors. Water Research 1996; 30: 1184-1194.

Joss A, Andersen H, Ternes T, Richle PR, Siegrist H. Removal of Estrogens in Municipal Wastewater Treatment under Aerobic and Anaerobic Conditions: Consequences 
for Plant Optimization. Environmental Science \& Technology 2004; 38: 30473055 .

Joss A, Zabczynski S, Gobel A, Hoffmann B, Loffler D, McArdell CS, et al. Biological degradation of pharmaceuticals in municipal wastewater treatment: proposing a classification scheme. Water Res 2006; 40: 1686-96.

Klecka GM, Staples CA, Clark KE, Van der Hoeven N, Thomas DE, Hentges SG. Exposure analysis of bisphenol A in surface water systems in North America and Europe. Environ Sci Technol 2009; 43: 6145-50.

Kumar AK, Mohan SV, Sarma PN. Sorptive removal of endocrine-disruptive compound (estriol, E3) from aqueous phase by batch and column studies: kinetic and mechanistic evaluation. J Hazard Mater 2009; 164: 820-8.

Lai KM, Johnson KL, Scrimshaw MD, Lester JN. Binding of waterborne steroid estrogens to solid phases in river and estuarine systems. Environmental Science \& Technology 2000; 34: 3890-3894.

Lapworth DJ, Baran N, Stuart ME, Ward RS. Emerging organic contaminants in groundwater: A review of sources, fate and occurrence. Environ Pollut 2012; 163: 287-303.

Larcher S, Yargeau V. Biodegradation of 17alpha-ethinylestradiol by heterotrophic bacteria. Environ Pollut 2013; 173: 17-22.

Latorre A, Lacorte S, Barcelo D. Presence of nonylphenol, octyphenol and bisphenol a in two aquifers close to agricultural, industrial and urban areas. Chromatographia 2003; 57: 111-116.

Lee do G, Zhao F, Rezenom YH, Russell DH, Chu KH. Biodegradation of triclosan by a wastewater microorganism. Water Res 2012; 46: 4226-34.

Lee HB, Peart TE, Chan J, Gris G. Occurrence of endocrine-disrupting chemicals in sewage and sludge samples in Toronto, Canada. Water Quality Research Journal of Canada 2004; 39: 57-63.

Lee KC, Rittmann BE, Shi JC, McAvoy D. Advanced steady-state model for the fate of hydrophobic and volatile compounds in activated sludge. Water Environment Research 1998; 70: 1118-1131.

Li F, Yuasa A, Obara A, Mathews AP. Aerobic batch degradation of 17-beta estradiol (E2) by activated sludge: effects of spiking E2 concentrations, MLVSS and temperatures. Water Res 2005; 39: 2065-75.

Li YM, Zeng QL, Yang SJ. Removal and fate of estrogens in an anaerobic-anoxic-oxic activated sludge system. Water Sci Technol 2011; 63: 51-6.

Lindblom E, Press-Kristensen K, Vanrolleghem PA, Mikkelsen PS, Henze M. Dynamic experiments with high bisphenol-A concentrations modelled with an ASM model extended to include a separate XOC degrading microorganism. Water Res 2009; 43: 3169-76. 
Lopez-Avila V, Hites RA. Organic compounds in an industrial wastewater. Their transport into sediments. Environmental Science \& Technology 1980; 14: 13821390.

Majewsky M, Galle T, Yargeau V, Fischer K. Active heterotrophic biomass and sludge retention time (SRT) as determining factors for biodegradation kinetics of pharmaceuticals in activated sludge. Bioresour Technol 2011; 102: 7415-21.

Marfil-Vega R, Suidan MT, Mills MA. Abiotic transformation of estrogens in synthetic municipal wastewater: an alternative for treatment? Environ Pollut 2010; 158: 3372-7.

Martin J, Camacho-Munoz D, Santos JL, Aparicio I, Alonso E. Occurrence of pharmaceutical compounds in wastewater and sludge from wastewater treatment plants: removal and ecotoxicological impact of wastewater discharges and sludge disposal. J Hazard Mater 2012; 239-240: 40-7.

Maurer M, Escher BI, Richle P, Schaffner C, Alder AC. Elimination of beta-blockers in sewage treatment plants. Water Res 2007; 41: 1614-22.

Melcer H, Klecka G. Treatment of wastewaters containing bisphenol A: state of the science review. Water Environ Res 2011; 83: 650-66.

Mohapatra DP, Brar SK, Tyagi RD, Surampalli RY. Occurrence of bisphenol A in wastewater and wastewater sludge of CUQ treatment plant. Journal of Xenobiotics 2011; 1.

Muller M, Rabenoelina F, Balaguer P, Patureau D, Lemenach K, Budzinski H, et al. Chemical and biological analysis of endocrine-disrupting hormones and estrogenic activity in an advanced sewage treatment plant. Environ Toxicol Chem 2008; 27: 1649-58.

Nakada N, Yasojima M, Okayasu Y, Komori K, Suzuki Y. Mass balance analysis of triclosan, diethyltoluamide, crotamiton and carbamazepine in sewage treatment plants. Water Sci Technol 2010; 61: 1739-47.

Nie Y, Qiang Z, Zhang H, Adams C. Determination of endocrine-disrupting chemicals in the liquid and solid phases of activated sludge by solid phase extraction and gas chromatography-mass spectrometry. J Chromatogr A 2009; 1216: 7071-80.

Plósz BG, Langford KH, Thomas KV. An activated sludge modeling framework for xenobiotic trace chemicals (ASM-X): Assessment of diclofenac and carbamazepine. Biotechnology and Bioengineering 2012; 109: 2757-2769.

Plosz BG, Leknes H, Thomas KV. Impacts of competitive inhibition, parent compound formation and partitioning behavior on the removal of antibiotics in municipal wastewater treatment. Environ Sci Technol 2010; 44: 734-42.

Pomiès M, Choubert JM, Wisniewski C, Coquery M. Modelling of micropollutant removal in biological wastewater treatments: a review. Sci Total Environ 2013; 443: 733-48. 
Press-Kristensen K, Lindblom E, Henze M. Modelling as a tool when interpreting biodegradation of micro pollutants in activated sludge systems. Water Science and Technology 2007; 56: 11-16.

Radjenovic J, Petrovic M, Barcelo D. Fate and distribution of pharmaceuticals in wastewater and sewage sludge of the conventional activated sludge (CAS) and advanced membrane bioreactor (MBR) treatment. Water Res 2009; 43: 831-41.

Ramdani A, Dold P, Deleris S, Lamarre D, Gadbois A, Comeau Y. Biodegradation of the endogenous residue of activated sludge. Water Res 2010; 44: 2179-88.

Ramdani A, Dold P, Gadbois A, Deleris S, Houweling D, Comeau Y. Characterization of the heterotrophic biomass and the endogenous residue of activated sludge. Water Res 2012; 46: 653-68.

Rezouga F, Hamdi M, Sperandio M. Variability of kinetic parameters due to biomass acclimation: case of para-nitrophenol biodegradation. Bioresour Technol 2009; 100: 5021-9.

Robinson BJ, Hui JP, Soo EC, Hellou J. Estrogenic compounds in seawater and sediment from Halifax Harbour, Nova Scotia, Canada. Environ Toxicol Chem 2009; 28: $18-25$.

Seyhi B, Drogui P, Buelna G, Blais JF. Modeling of sorption of bisphenol A in sludge obtained from a membrane bioreactor process. Chemical Engineering Journal 2011; 172: 61-67.

Shen G, Huang J, Yu G. Measurement of the free concentrations of alkyl phenols and bisphenol A to determine their biodegradation kinetics by activated sludge. Chinese Science Bulletin 2007; 52: 2766-2770.

Shi J, Fujisawa S, Nakai S, Hosomi M. Biodegradation of natural and synthetic estrogens by nitrifying activated sludge and ammonia-oxidizing bacterium Nitrosomonas europaea. Water Res 2004; 38: 2322-9.

Stasinakis AS, Gatidou G, Mamais D, Thomaidis NS, Lekkas TD. Occurrence and fate of endocrine disrupters in Greek sewage treatment plants. Water Res 2008; 42: 1796-804.

Stasinakis AS, Kordoutis CI, Tsiouma VC, Gatidou G, Thomaidis NS. Removal of selected endocrine disrupters in activated sludge systems: effect of sludge retention time on their sorption and biodegradation. Bioresour Technol 2010; 101: 2090-5.

Stasinakis AS, Mermigka S, Samaras VG, Farmaki E, Thomaidis NS. Occurrence of endocrine disrupters and selected pharmaceuticals in Aisonas River (Greece) and environmental risk assessment using hazard indexes. Environ Sci Pollut Res Int 2012; 19: 1574-83.

Stevens-Garmon J, Drewes JE, Khan SJ, McDonald JA, Dickenson ER. Sorption of emerging trace organic compounds onto wastewater sludge solids. Water Res 2011; 45: 3417-26. 
Suarez S, Reif R, Lema JM, Omil F. Mass balance of pharmaceutical and personal care products in a pilot-scale single-sludge system: influence of $\mathrm{T}$, SRT and recirculation ratio. Chemosphere 2012; 89: 164-71.

Tan BL, Hawker DW, Muller JF, Leusch FD, Tremblay LA, Chapman HF. Modelling of the fate of selected endocrine disruptors in a municipal wastewater treatment plant in South East Queensland, Australia. Chemosphere 2007; 69: 644-54.

Tchobanoglous G, Burton, F. L., Stensel, D. H. Wastewater engineering: treatment and reuse. New York: McGraw-Hill, 2003.

Thayanukul P, Zang K, Janhom T, Kurisu F, Kasuga I, Furumai H. Concentrationdependent response of estrone-degrading bacterial community in activated sludge analyzed by microautoradiography-fluorescence in situ hybridization. Water Res 2010; 44: 4878-87.

Tomei MC, Annesini MC, Rita S, Daugulis AJ. Biodegradation of 4-nitrophenol in a two-phase sequencing batch reactor: concept demonstration, kinetics and modelling. Applied Microbiology and Biotechnology 2008; 80: 1105-12.

Urase T, Kikuta T. Separate estimation of adsorption and degradation of pharmaceutical substances and estrogens in the activated sludge process. Water Res 2005; 39: 1289-300.

Vulliet E, Cren-Olive C, Grenier-Loustalot MF. Occurrence of pharmaceuticals and hormones in drinking water treated from surface waters. Environmental Chemistry Letters 2011; 9: 103-114.

Wick A, Fink G, Joss A, Siegrist H, Ternes TA. Fate of beta blockers and psycho-active drugs in conventional wastewater treatment. Water Res 2009; 43: 1060-74.

Xue W, Wu C, Xiao K, Huang X, Zhou H, Tsuno H, et al. Elimination and fate of selected micro-organic pollutants in a full-scale anaerobic/anoxic/aerobic process combined with membrane bioreactor for municipal wastewater reclamation. Water Res 2010; 44: 5999-6010.

Yi T, Mackintosh S, Aga DS, Harper WF, Jr. Exploring 17alpha-ethinylestradiol removal, mineralization, and bioincorporation in engineered bioreactors. Water Res 2011; 45: 1369-77.

Ying GG, Yu XY, Kookana RS. Biological degradation of triclocarban and triclosan in a soil under aerobic and anaerobic conditions and comparison with environmental fate modelling. Environ Pollut 2007; 150: 300-5.

Zang K, Kurisu F, Kasuga I, Furumai H, Yagi O. Analysis of the phylogenetic diversity of estrone-degrading bacteria in activated sewage sludge using microautoradiography-fluorescence in situ hybridization. Syst Appl Microbiol 2008; 31: 206-14.

Zeng QL, Li YM, Yang SJ. Sludge Retention Time as a Suitable Operational Parameter to Remove Both Estrogen and Nutrients in an Anaerobic-Anoxic-Aerobic Activated Sludge System. Environmental engineering science 2013; 30: 161-169. 


\section{P a g e $\mid \mathbf{2 3 8}$}

Zhao J, Li Y, Zhang C, Zeng Q, Zhou Q. Sorption and degradation of bisphenol A by aerobic activated sludge. J Hazard Mater 2008; 155: 305-11.

Zhou JL, Liu R, Wilding A, Hibberd A. Sorption of selected endocrine disrupting chemicals to different aquatic colloids. Environ Sci Technol 2007; 41: 206-13.

Zhou X, Oleszkiewicz JA. Biodegradation of oestrogens in nitrifying activated sludge. Environ Technol 2010; 31: 1263-9.

Ziels RM, Lust MJ, Gough HL, Strand SE, Stensel HD. Influence of Bioselector Processes on 17alpha-Ethinylestradiol Biodegradation in Activated Sludge Wastewater Treatment Systems. Environ Sci Technol 2014. 


\section{Chapter 7: Discussions and Conclusions}

The operation of simulated continuous-flow AS systems in the presence of $20 \mu \mathrm{g} / \mathrm{L}$ of selected MCs showed that these compounds were mostly eliminated during the AS process. $90-98,63-91$ and $97-98 \%$ of BPA, EE2 and TCS, respectively were removed in systems operating at SRT of 5-15 d and HRT of 4-10 h. The results of sorption equilibrium study, showed that equilibrium was reached within a few hours between sorbed and dissolved MCs. Sorption and biosorption studies with inactivated and active biomass were compared and two stages were distinguished for MCs sorption to AS: a rapid physico-chemical sorption stage followed by biosorption (possibly by biodegradation in both solid and liquid phases). However, more studies need to be done to closely investigate the possible biodegradation or biotransformation of sorbed MCs

into AS by carefully monitoring the ${ }^{14} \mathrm{C}$-radiolabeled $\mathrm{MCs}$ and their radioactivity within the biomass, ${ }^{14} \mathrm{C}-\mathrm{CO} 2$, and the substrate.

Freundlich sorption isotherms with values of $1 / \mathrm{n}$ close to 1 were found to best fit the results of sorption batch studies, demonstrating that all tested concentrations result on the linear part of the Freundlich isotherm. The results of distribution coefficient, $\mathrm{K}_{\mathrm{d}}$ of selected MCs showed the greater tendency of EE2 and TCS for sorption, compared to 


\section{P a g e $\mid \mathbf{2 4 0}$}

BPA. The higher desorption kinetic coefficients compared to sorption kinetic coefficients were found for all three selected MCs. However, rapid sorption and desorption kinetics of selected MCs suggested that sorption-desorption kinetics cannot limit BPA, EE2, and TCS biodegradation in biological treatment systems and the equilibrium state assumption is valid to represent sorption phenomena.

Calculation of mass fluxes and determination of MCs in the dissolved and particulate phases illustrated that biotransformation was the principal removal mechanism of selected MCs. Statistical analysis revealed that both SRT and HRT had a significant effect on the fate of MCs where the highest sorption constant was achieved for a SRT of $10 \mathrm{~d}$ for targeted MCs which might be explained by the change of the morphology of the biomass from reactors operating at different SRTs. Nevertheless, further research needs to be carried to investigate the microbial morphology of MCs acclimated biomass originated from reactors operating at various SRTs. Higher biotransformation removal rate was also found for TCS and BPA in reactors operating at higher SRTs and HRTs, whereas the lowest rate was found for EE2 in the reactor operating at SRT of $5 \mathrm{~d}$ and HRT of $4 \mathrm{~h}$. In addition, the removal of selected MCs in nitrification-inhibited and uninhibited AS systems, suggested that AOB might play a role in the fate of the targeted MCs; however, heterotrophs were most likely responsible for the degradation of selected MCs. 


\section{P a g e $\mid \mathbf{2 4 1}$}

To evaluate the fate models for selected MCs in AS system, various biodegradation kinetic models were applied to the data collected in biodegradation and sorption studies and it was found that only pseudo second-order model with degradation by active MCs degraders could present the data efficiently. This study illustrated why other researchers using $X_{v}, X_{T}$, and $X_{H}$ in their models found different biodegradation kinetics for the same compound in various AS systems. Therefore, the contribution of this thesis could be seen in the context, where the active MCs degraders are proposed to reduce the variability of $\mathrm{K}_{\mathrm{m}}$ in AS systems operating at different operational conditions.

It should be noted that the concentration of $\mathrm{X}_{\mathrm{C}}$ was estimated mathematically in this study and further experimental studies are needed to better understand the role of specific microorganism in degradation of MCs in AS systems by using fluorescent in situ hybridization (FISH) with group-specific rRNA-targeted probes or any other appropriate methods.

Furthermore, studies with broader selection of MCs in full-scale AS systems operating at various SRTs and HRTs are needed to evaluate the applicability of proposed model, where dynamic variations are incorporated into the analysis. 
P a g e | 242

Appendices 


\section{Appendix A: Extraction systems used for selected MCs}

\section{1- Accelerated solvent}

Dionex ACE 200 (Figure 1) was used for sludge extraction of BPA. The extraction process consists of five steps: (1) filling and pressurising cell with solvent at selected pressure; (2) heating cell at selected temperature for temperature equilibration at constant pressure (heat); (3) static extraction at constant pressure and temperature of extraction solvent (static); (4) washing of cell with fresh solvent for total recovery of products, after transfer of extract to sealed vials; the volume of fresh solvent is indicated in \% of volume cell (flush); (5) final solvent purging with nitrogen gas (purge).

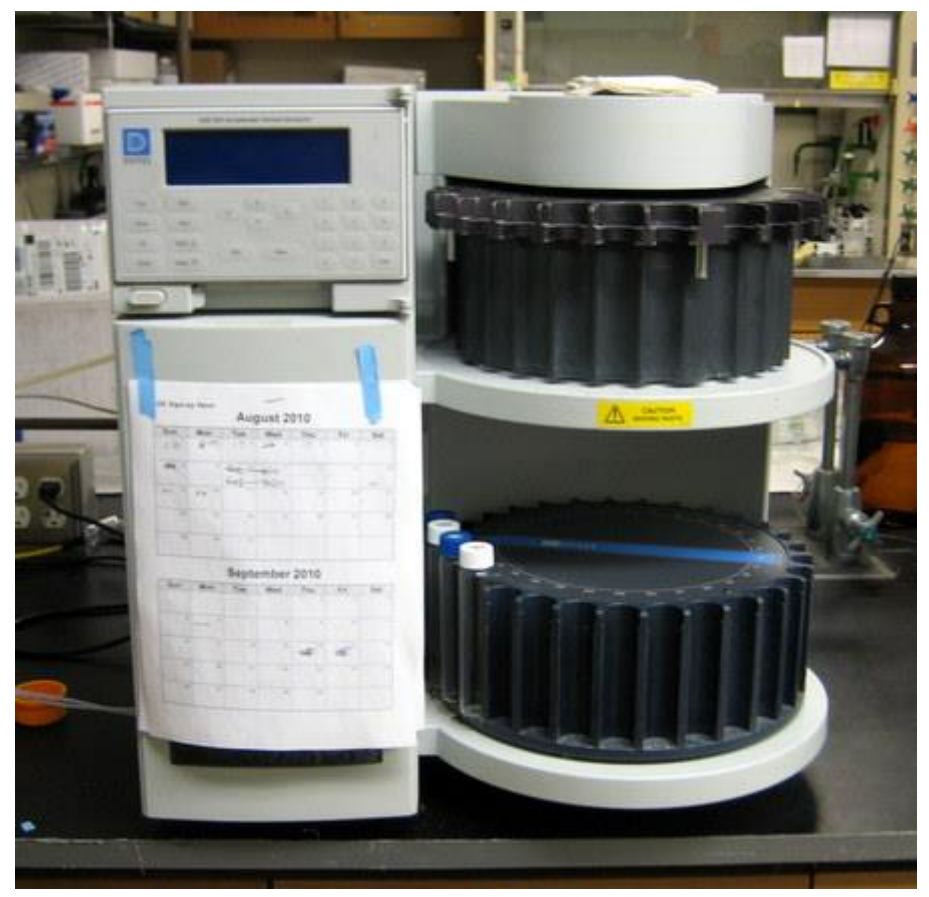

Figure 1: ACE Equipment 


\section{2- Ultrasound extraction system}

For extraction of BPA from sludge, a sonifier system (Branson model S-450D) was used (Figure 2). This device consists of a power supply, a converter, a mechanical probe or horn and a tip. The converter changes standard electrical power to high frequency mechanical energy, which is then applied to the horn, where it is further amplified by the tip and penetrated to the waste sample. Frequency of the sonifier is $20 \mathrm{KHz}$.
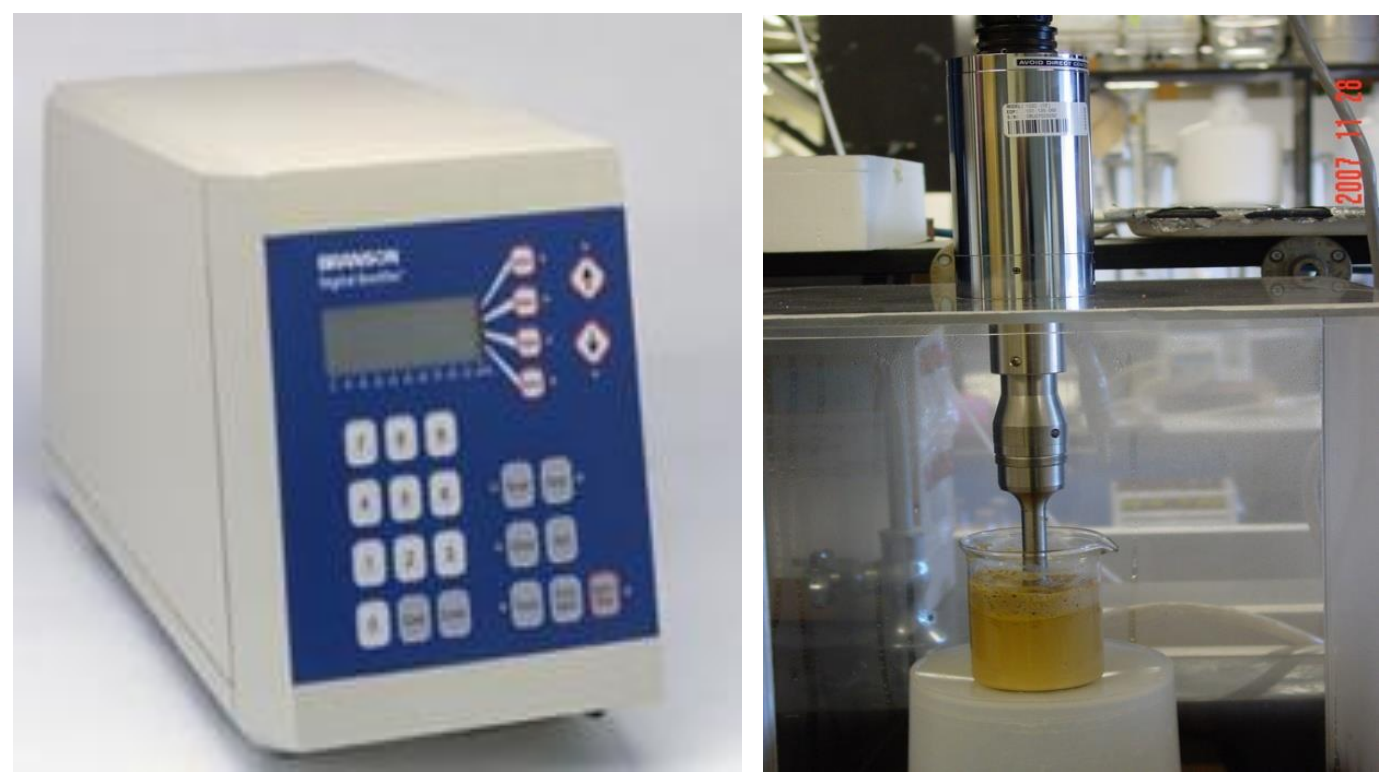

Figure 2: US Equipment

\section{3- Microwave-assisted extraction procedure}

MW extraction were carried out with a Mars $5^{\circledR}$ (MW Accelerated Reaction System; CEM Corporation) MW oven (Figure 3). Mars $5^{\circledR}$ has a frequency of $2450 \mathrm{MHz}$ and can deliver $1200 \mathrm{~W} \pm 15 \%$ of MW energy at full power with complete MW penetration of the sample vessels. With its temperature and pressure sensors it is possible to monitor and 
control operating conditions up to $250^{\circ} \mathrm{C}$ and $3.5 \mathrm{MPa}$. This system allowed up to 14 extraction vessels to be irradiated simultaneously. This extraction method uses MW energy to produce elevated temperature and pressure conditions (i.e., $100-115^{\circ} \mathrm{C}$ and 50 - 175 psi) in a closed vessel.

The main components of the Mars $5^{\circledR}$ MW oven as shown in Figure 4 are:

- Magnetron: Generates the MWs.

- Wave guide: Directs the waves to MW cavity

- Mode stirrer: Distributes the incoming energy

- Cavity: Where the mode stirrer distributes the incoming energy

- Heat dissipater: Safely dissipates the reflected energy to protect the magnetron

- Isolator: Directs the lost energy to heat dissipater

- Vessel: holds sample

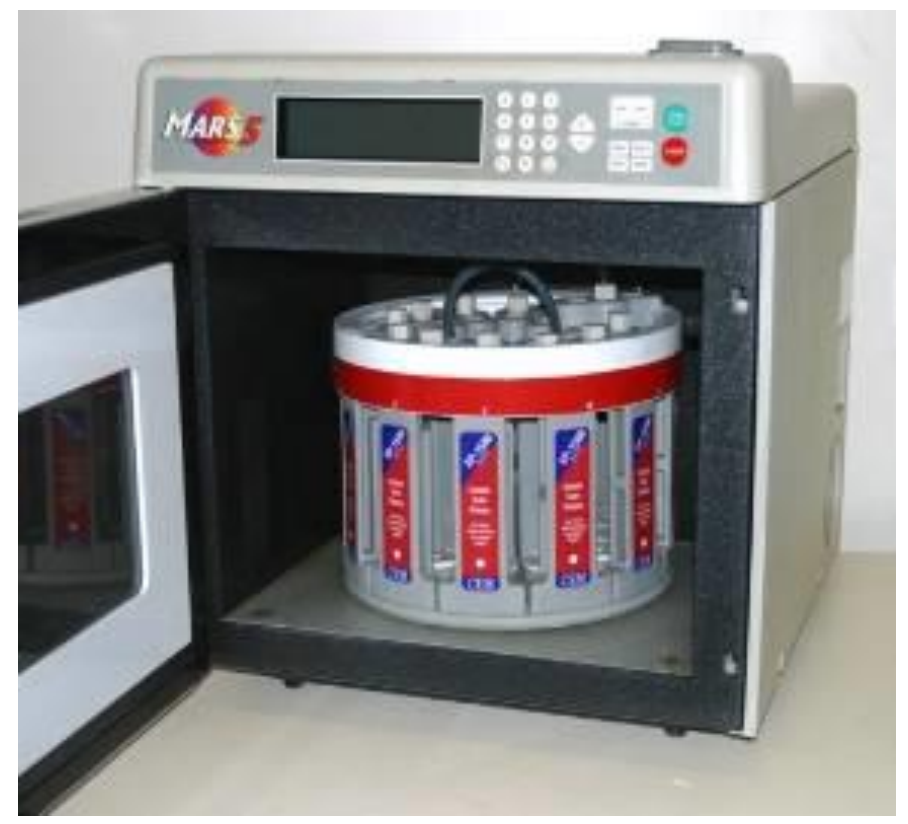

Figure 3: Mars $5^{\circledR}$ Microwave apparatus 
P a g e $\mid \mathbf{2 4 6}$

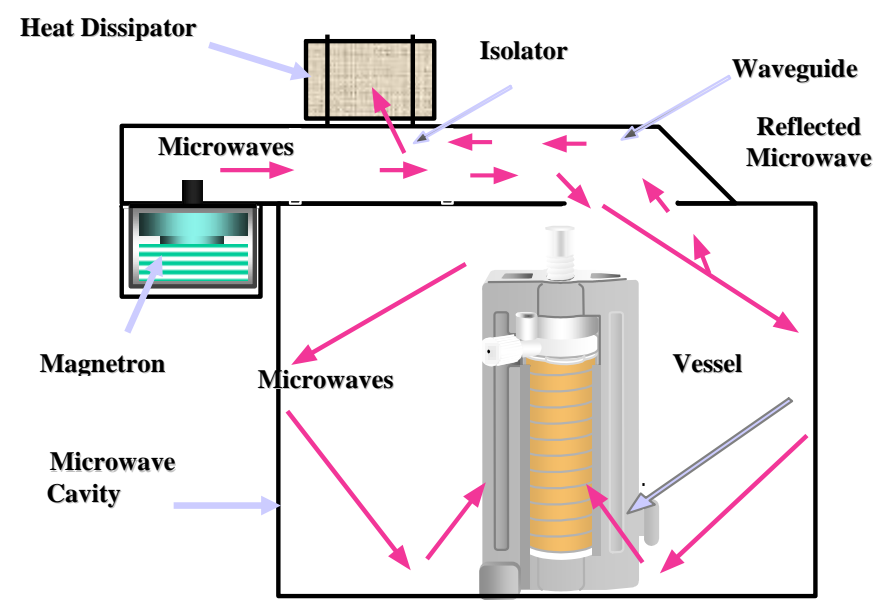

Figure 4: Mars $5^{\circledR}$ Vessel (HP-500)

\section{4- High Pressure Homogenizer extraction}

High pressure homogenizing extraction were carried out with the EmulsiFlex-C3 homogenizer which is powered by an electric motor, homogenizing valve, pressurize tank (adjustable between 500 and 30000 psi or 35 and 2000 bar) and temperature control system by heat exchanger (Figure 5).

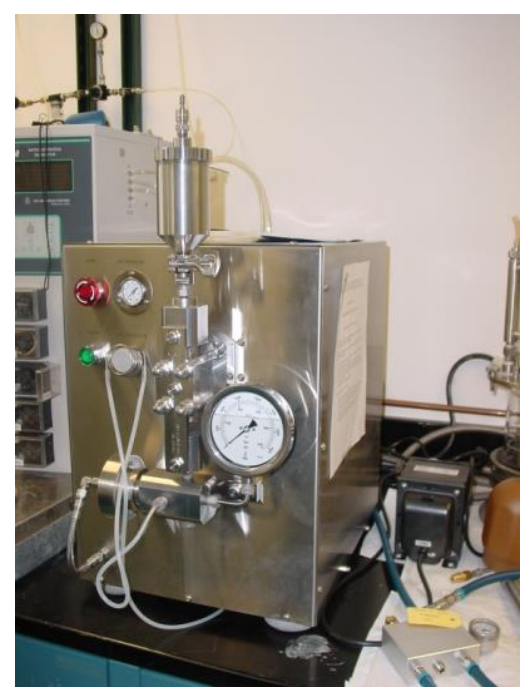

Figure 5: EmulsiFlex-C3 homogenizer 


\section{P a g e $\mid \mathbf{2 4 7}$}

\section{Appendix B: Reactors performance in phases A and B}

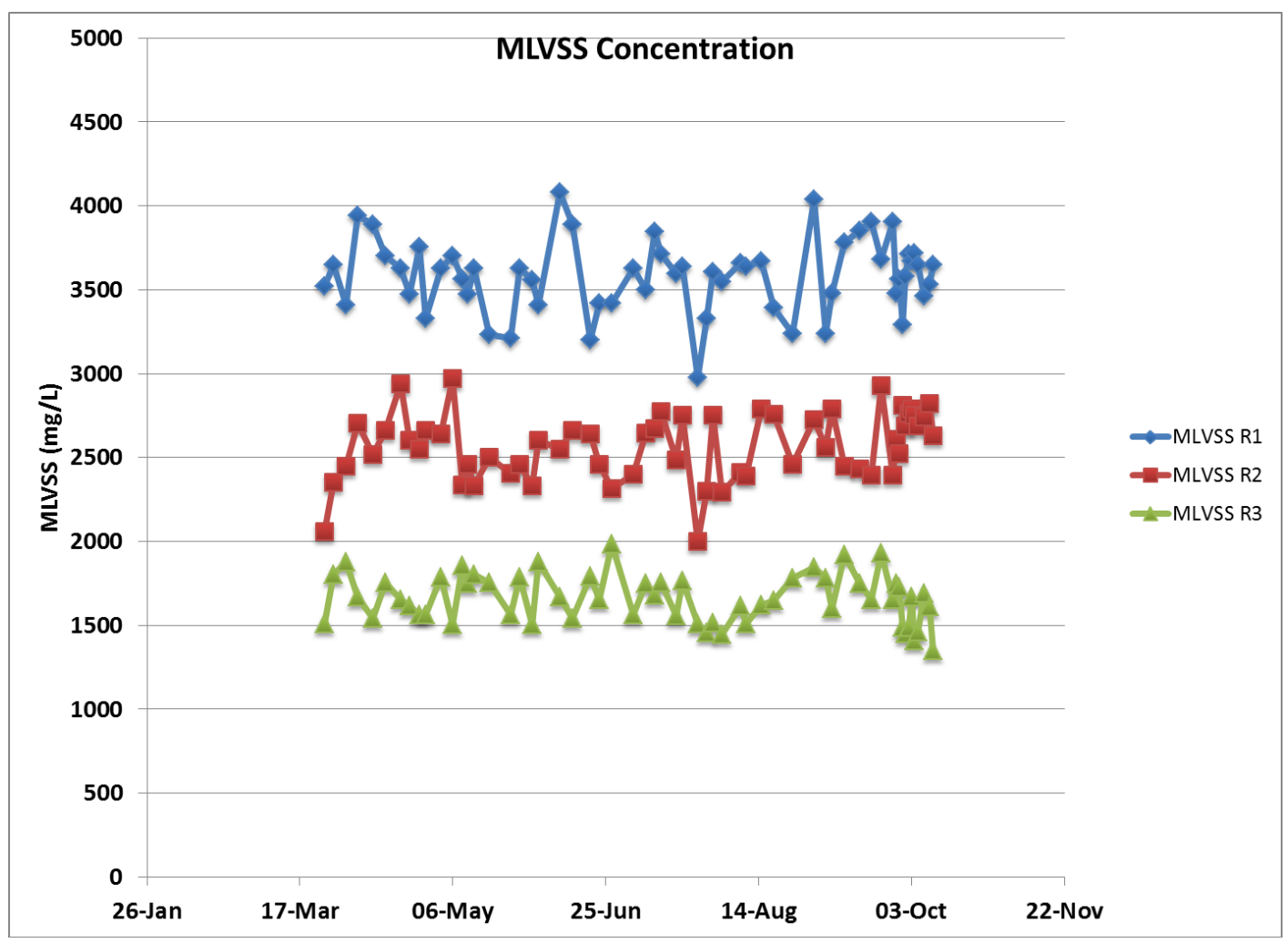

Figure 6: MLVSS concentrations (Phase A and B) 
P a g e | 248

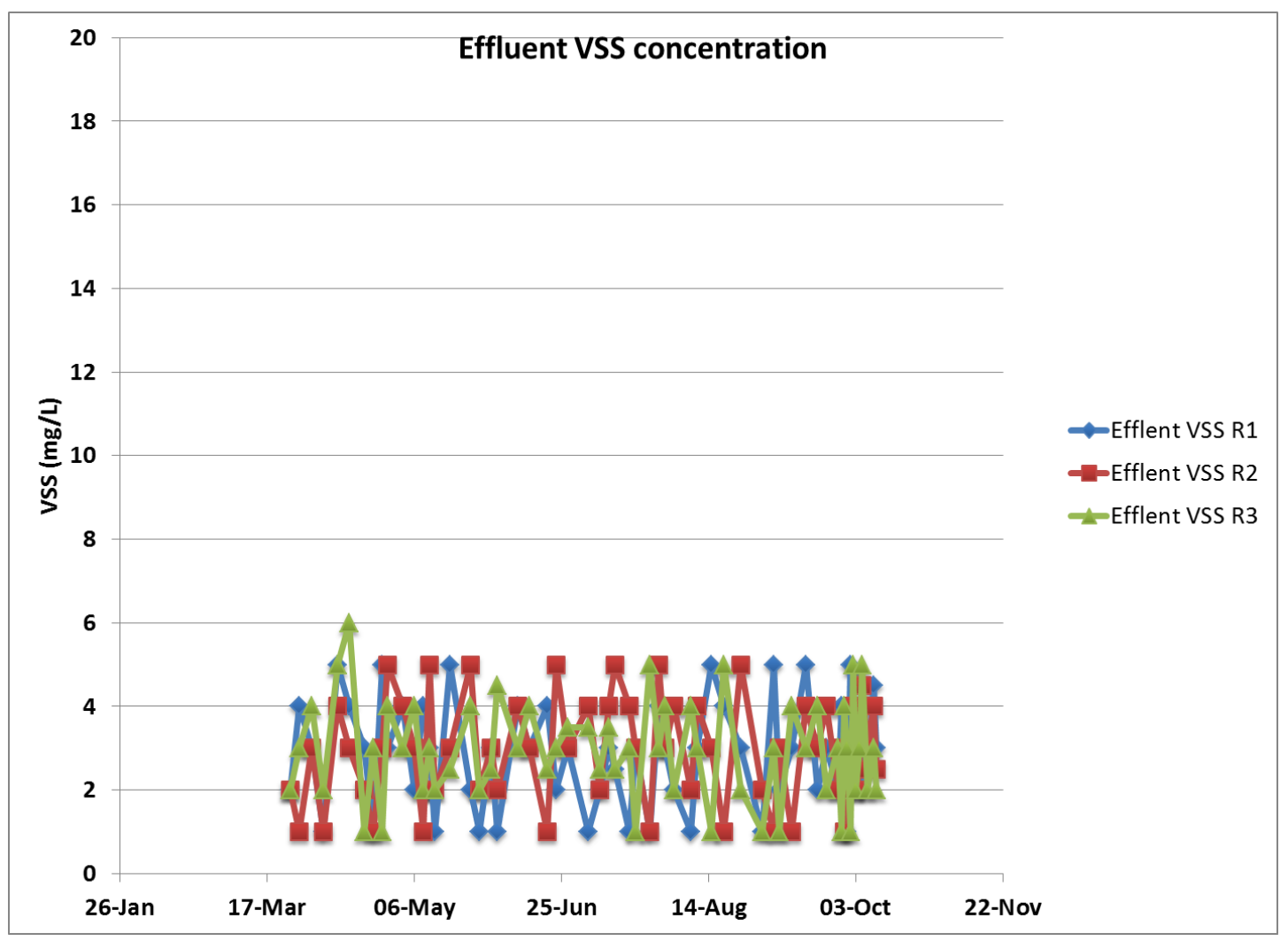

Figure 7: Effluent VSS concentrations (Phase A and B) 
P a g e | 249

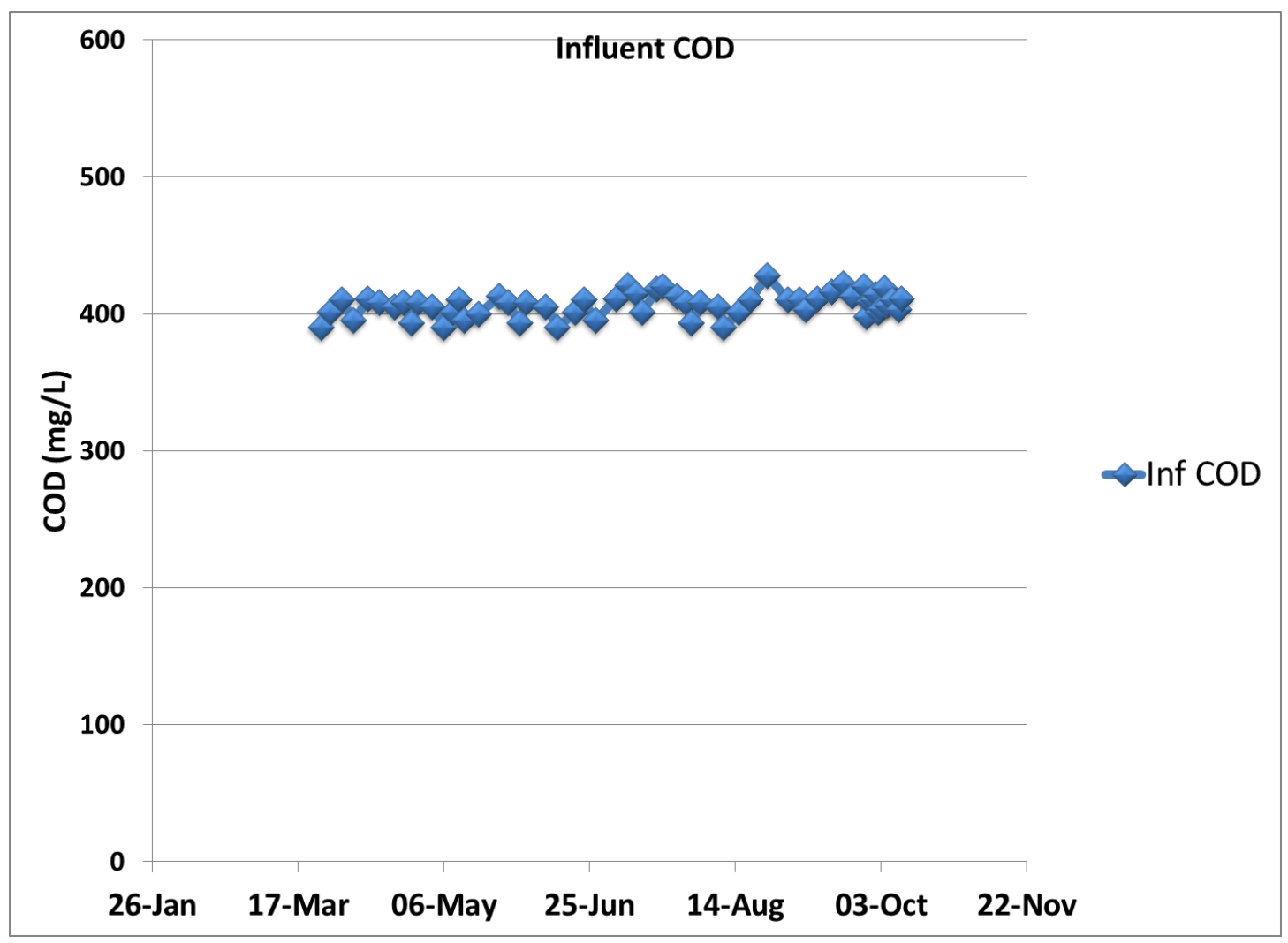

Figure 8: Influent COD concentrations (Phase A and B) 